\title{
ESTEBAN TORRE
}

\section{ZEUXIS Y AZEUXIS \\ Y OTRAS CUESTIONES MÉTRICAS}

RHYTHMICA, REVISTA ESPAÑOLA

DE MÉTRICA COMPARADA

ANEJO V, 2017 


ZEUXIS Y AZEUXIS

Y OTRAS CUESTIONES MÉTRICAS 

ESTEBAN TORRE

\section{ZEUXIS Y AZEUXIS Y OTRAS CUESTIONES MÉTRICAS}

\section{$\operatorname{ses}$}

RHYTHMICA, REVISTA ESPAÑOLA

DE MÉTRICA COMPARADA

ANEJO V, 2017 
(C) Esteban TORRE

(C) De esta edición: Padilla Libros

D. LEGAL: SE 1-2017

ISBN 978-84-8434-621-0

PAdilla Libros Editores \& Libreros

C/ Trajano n. ${ }^{\circ} 18$

41002 SeVIlla (EsPaÑa) 
A Isabel Paraíso Almansa y José Domínguez Caparrós, grandes amigos y maestros indiscutibles de la Ciencia del Verso. 



\section{PRÓLOGO}

ON los nombres de poética, arte poética, versificación, preceptiva literaria, ciencia del verso, métrica, se han venido desarrollando distintos estudios y diversas teorías a lo largo de los siglos, tanto en lo que concierne a las lenguas clásicas como en lo relativo a las lenguas modernas. Establecían los latinos una neta separación entre el verso (uersus o uorsus, línea que vuelve) y prosa (prorsus, línea que prosigue). La base esencial del verso, en la lengua griega y en la latina, era la cantidad silábica: las sílabas largas y las breves se organizaban en conjuntos rítmicos o pies métricos.

La poesía épica alcanzó las máximas alturas, en las manos de un Homero o de un Virgilio, con el hexámetro, verso de seis pies métricos constituidos por espondeos (dos sílabas largas) y dáctilos (una sílaba larga y dos breves), indistintamente, excepto al final del verso, donde necesariamente había de figurar un dáctilo seguido de un espondeo, o de un troqueo (una sílaba larga y otra breve). Una sílaba larga equivalía a dos breves. La llamada «cantidad» consistía realmente en una «cualidad» de la sílaba, no traducible en términos de duración cronológica, que le confería el valor de larga o breve en la percepción directa del oyente.

En las modernas lenguas de origen indoeuropeo, y también en otras, como el árabe actual, se ha perdido esa antigua distinción cuantitativa, o cualitativa si se quiere. Todas las sílabas son ahora 
equivalentes. El verso está determinado por el número de sílabas: hexasílabos, heptasílabos, octosílabos, etc. El cómputo silábico, junto con la distribución de los acentos, viene a definir la entidad denominada verso.

Hace ya algunos años (El ritmo del verso. Murcia: Universidad, 1999), hice algunas propuestas para el análisis y la interpretación de los elementos estructurales del verso español. Ante todo, hemos de considerar el verso como la unidad rítmica fundamental del conjunto poemático. El armazón rítmico del verso está constituido por sílabas y acentos. El acento no representa en el verso una entidad absoluta, sino relativa, ya que la relevancia de la sílaba acentuada se refiere siempre a un entorno de sílabas relativamente menos acentuadas. Los factores constitutivos del acento son la intensidad acústica y el tono, existiendo algunos casos en los que el correlato físico del acento es precisamente el tono que recae en una sílaba en relación con su entorno, y no la intensidad. La pausa es un elemento demarcador esencial, que distingue y separa los versos en la serie poemática; en virtud de la pausa, la última sílaba acentuada del verso adquiere un carácter culminante.

El verso termina realmente en la última sílaba acentuada, y carece de sentido la distinción entre un supuesto periodo rítmico y un pretendido periodo de enlace. Las sílabas marcadas por el acento se agrupan con las no marcadas en secuencias fónicas, intermedias entre la sílaba aislada y la línea del verso; son los llamados pies métricos, o cláusulas, de utilidad en el análisis de la estructura rítmica, siempre que con su empleo no se trate de suplantar la genuina unidad del verso. En el número de sílabas, especialmente cuando éste no excede de nueve, reside el carácter memorizable de la estructura rítmica. En los versos de mayor medida, como es el caso del endecasílabo, el número de sílabas es condición necesaria, pero no suficiente, para la realización y percepción del verso, por lo que habrá que tener también en cuenta en estos versos sus distintos patrones acentuales.

En los estudios métricos tradicionales del verso español, podemos apreciar en ocasiones ciertos prejuicios, entre los que figura el 
empeño en medir la duración cronológica de cada una de las sílabas, sucumbiendo así al espejismo de los criterios cuantitativos de las lenguas clásicas. Esto es especialmente ostensible en algunas interpretaciones del fenómeno de la equivalencia de los versos con finales agudos, llanos y esdrújulos.

Por otra parte, el contacto entre vocales, en la secuencia del verso, ha dado lugar a múltiples y contradictorias clasificaciones, considerándose las circunstancias de unión silábica o zeuxis (sinéresis, sinalefa, sinafía) y desunión silábica o azeuxis (diéresis, dialefa) como «licencias» poéticas, esto es, como transgresiones de las leyes gramaticales, que se permitirían sólo en nombre de las necesidades métricas. La consideración dicotómica de las sílabas como «gramaticales»y «métricas», la insuficiente comprensión del papel de los acentos rítmicos y la visión de la lengua poética como un artefacto sui generis, desvinculado por completo del lenguaje ordinario, son otras tantas formas erróneas de acercamiento al estudio del verso.

Desde la primera edición de Métrica española comparada (Sevi1la: Universidad, 1999) hasta la fecha, he tratado de elucidar algunos de los puntos conflictivos de la ciencia del verso, a través de varios trabajos, que estos últimos años han ido apareciendo en distintas publicaciones, especialmente en Rhythmica: Revista española de métrica comparada. Oportunamente revisados, los ofrezco ahora al público lector. Ojalá puedan estas páginas contribuir a un adecuado conocimiento de la exacta medida del verso, que, en fin de cuentas, es la imprescindible puerta de entrada al maravilloso palacio de la poesía. 



\section{ESTUDIOS PRECEDENTES}

El ritmo del verso: Estudios sobre el cómputo silábico y la distribución acentual, a la luz de la Métrica Comparada, en el verso español moderno. Murcia: Universidad, 1999.

Métrica española comparada. Sevilla: Universidad, 1999.

«Prólogo» a BENOT, Eduardo: Prosodia castellana y versificación, ed. facsímil al cuidado de Esteban Torre. Anejo I de Rhythmica: Revista española de métrica comparada, 2003, pp. VI-XXXI.

«Sílabas y acentos: fundamentos fonéticos y fonológicos del ritmo», Rhythmica cit., 1, 2003, pp. 273-301.

«Los sonetos de Juan Ramón Jiménez», en Estudios de Teoría Literaria como experiencia vital. Cádiz: Universidad, 2008, pp. 427-438. «La métrica de Minturno», Rhythmica cit., 8, 2010, pp. 191-217. «Zeuxis y azeuxis en la configuración silábica», Rhythmica cit., 9, 2011, pp. 183-199.

«La perfección de algunos endecasílabos "imperfectos" de Garcilaso de la Vega», Rhythmica cit., 10, 2012, pp. 187-204.

«Zeuxis y azeuxis: más sobre vocales en contacto», Rhythmica cit., 11, 2013, pp. 187-205.

«iAcentos contiguos en el verso español?», Rhythmica cit., 12. 2014, pp. 171-192. 
«La métrica de Andrés Bello», Rhythmica cit., 13, 2015, pp. 211-232. «El soneto "Basta" de Blas de Otero: ritmo y gramática», Rhythmica cit., 14, 2016, pp. 145-158.

«Métrica, tropos y figuras en las Anotaciones de Fernando de Herrera», Revista de Literatura, vol. LXXVIII, n. ${ }^{\circ} 155,2016$, pp. 37-59. 
TEORÍA 



\section{ZEUXISYAZEUXIS}

T $\mathrm{N}$ la configuración de la sílaba, como elemento básico del metro, juega un papel de excepcional importancia el contacto entre vocales. En las lenguas románicas, se considera que existe un núcleo, o parte central de la sílaba, que ha de estar siempre representado por una vocal, pudiendo aparecer como partes marginales tanto las vocales como las consonantes. No presenta grandes dificultades la delimitación silábica entre consonantes o entre vocal y consonante, si bien la adscripción de una determinada parte marginal a una u otra sílaba varía según las lenguas y sus distintas convenciones gramaticales. Los problemas surgen cuando la frontera silábica se establece entre vocales. La agrupación o la separación silábica de dos vocales contiguas -entre palabras o en cuerpo de una palabra aislada- da origen a una serie muy compleja de fenómenos fonéticos, que han sido objeto de numerosos estudios, contradictorios en ocasiones.

Se ha venido elaborando una extensa terminología con el objeto de distinguir y analizar las distintas circunstancias del encuentro entre vocales. La diversidad de los criterios seguidos y la evolución histórica de los mismos han dado lugar a que algunos términos -diptongo, hiato, sinéresis, diéresis, sinalefa, dialefa, sinafía - no sean utilizados en la actualidad de una manera unívoca por la generalidad de los tratadistas. Como muchas veces ocurre en el dominio de las 
ciencias humanas, las palabras ahogan las ideas y los términos falsean la realidad. Pero, a decir verdad, la realidad que nos ocupa es bien sencilla. El contacto entre dos o más vocales, en la línea secuencial del discurso, y concretamente en la línea del verso, trae consigo dos posibles realizaciones prosódicas: o bien se produce la unión de las vocales en un solo elemento silábico, y por tanto la unión en una sola entidad silábica de las sílabas en las que se insertan dichas vocales, o por el contrario no se unen las vocales, y en consecuencia quedan separadas y distintas las sílabas a las que estas vocales pertenecen. Esto ocurre tanto en el interior de la palabra aislada como entre palabras contiguas, y tanto en la línea del verso como en el lenguaje ordinario. En anteriores trabajos, he llamado zeuxis a la unión, y azeuxis a la desunión.

Existían ya los términos diptongo y hiato, que implican también unión y desunión respectivamente. Pero el uso que se ha venido haciendo de ellos es más restrictivo, y en ocasiones dispar y contradictorio. Otros términos, como sinéresis y diéresis, suponen asimismo unión y desunión, pero su empleo por los tratadistas es de lo más abigarrado, ya que se parte del prejuicio de lo que debe considerarse como natural o como artificioso en la pronunciación de las palabras. Lo mismo ocurre con la sinalefa y la dialefa. La sinalefa alude a la unión silábica que resulta del contacto entre vocales de palabras contiguas, como si esta circunstancia implicara algo sustancialmente distinto al encuentro de las vocales en el interior de la palabra. La dialefa, término menos empleado, vendría a ser el fenómeno opuesto a la sinalefa, esto es, la desunión de las vocales.

Quisiera poner de manifiesto que la distinción conceptual entre zeuxis y azeuxis está justificada por razones que no obedecen meramente a criterios de simplificación terminológica, lo cual sería ya de por sí suficiente motivo para su utilización, sino que dimanan directamente de las exigencias de objetividad y rigor científico de la prosodia y de la métrica como disciplinas académicas. Los términos diptongo, hiato, sinéresis, diéresis, sinalefa y dialefa pueden seguir siendo utilizados, obviamente, siempre que su empleo no implique 
confusión o arbitrariedad. Lo que a todo trance debe ser evitado y superado es el incurrir o recaer en algunos errores y prejuicios que, si bien han sido ineludibles hasta ahora en la evolución histórica de los estudios prosódicos, son totalmente inadmisibles en el estado actual de la ciencia del verso.

\section{Errores y prejuicios}

1. Un antiguo prejuicio, que lamentablemente reaparece aquí y allá, es el de considerar el verso como un artefacto sui generis, desvinculado del lenguaje ordinario, cuyas reglas conculca sistemáticamente en aras del metro y de la estética. En lo que concierne al cómputo silábico, algunas situaciones vocálicas de zeuxis o de azeuxis, que puedan diferir de las consideradas arbitrariamente como normales y preceptivas en el lenguaje ordinario, son conceptuadas como licencias poéticas, es decir, como transgresiones de las leyes gramaticales, que se permitirían sólo en nombre de las necesidades métricas. Desde este punto de vista, habría que distinguir entre sílabas gramaticales y sílabas métricas, tal como se hace en el Esbozo de una nueva gramática de la lengua española, de 1973, o entre sílabas fonológicas y sílabas fonéticas, como indica más recientemente la Nueva gramática de la lengua española, de 2010. Así, por ejemplo, la palabra «piano» (pia.no) constaría de dos sílabas gramaticales o fonológicas, que sería lo normal y preceptivo, o bien de tres sílabas métricas o fonéticas (pi.a.no), lo que supondría una «licencia» poética.

Conviene reparar en el hecho de que tanto la forma bisilábica como la trisilábica de la palabra «piano» son igualmente normales y gramaticales. En el lenguaje ordinario, especialmente en el español peninsular, y sobre todo en el español de Andalucía, están plenamente vigentes y vivas ambas realizaciones, siendo más frecuente la forma trisilábica. El poeta, cuando introduce en su verso la forma trisilábica, no hace más que utilizar de una manera intuitiva y espontánea lo que está ya en el lenguaje ordinario, sin que conculque, viole o transgreda ninguna regla gramatical. 
Por otra parte, no tiene sentido alguno distinguir entre sílabas fonológicas y fonéticas. La sílaba no es una unidad fonológica, ya que carece de cualquier clase de capacidad distintiva de significados. Se trata simplemente de una unidad métrica, que, junto con el acento, constituye el armazón rítmico del verso.

Cierto es que a la sílaba, en cuanto unidad mínima portadora de un acento, se le podría atribuir un valor fonológico - «cántara, frente a «cantara»o 0 <cantará $\gg-$, pero en todo caso es el acento, y no la sílaba, el depositario del valor fonológico suprasegmental. Por lo demás, el rendimiento del acento, como unidad suprasegmental, fonológica-y, por lo tanto, distintiva de significados-, es en verdad irrelevante en la lengua española, y nulo en otras lenguas. Lo que interesa destacar en el acento es su carácter melódico, que se inserta en la línea discursiva (sea prosa, sea verso, sea simplemente lenguaje ordinario) con alternancia de sílabas tónicas, o más acentuadas, y átonas, o menos acentuadas, lo cual origina esa especie de pulso o latido rítmico de donde dimana la eufonía y por donde transcurre la cadencia del verso.

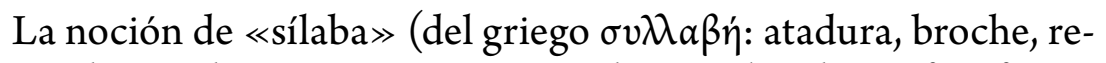
unión de sonidos; sustantivo conectado con el verbo $\sigma v \lambda \lambda \alpha \mu \beta a ́ v \omega$ : reunir, recoger; en latín, syllaba) es, desde luego, tan poco clara desde un punto de vista gramatical como intuitiva en la conciencia lingüística de todo hablante. Consiste, en realidad, en una unidad rítmica de base fisiológica y acústica, constituida por una vocal, o por el conjunto de vocales y consonantes, que se pronuncia en una sola emisión de voz. Aparece el silabeo, de una manera espontánea, en los juegos infantiles para contar y echar a suertes. Así ocurre, por ejemplo, en la lengua española, o en la inglesa, o en la francesa:

Pito, pito, gorgorito, / ¿dónde vas tú tan bonito?...

Eeny, meeny, miny, moe, / catch a tiger by the toe...

Un, deux, trois, / nous irons au bois...

La escansión de estas canciones infantiles es sencilla y clara, con ritmo binario tanto en español (pí.to.pí.to.gór.go.rí.to / dón.de.vás. 
tu.tán.bó.ní.to) como en inglés (ée.ny.mée.ny.mí.ny.móe.ø / cátch.a.tí. ger.bý.the.tóe.ø). En francés, se da una sucesión monocorde de sílabas (un.deux.trois / nous.i.rons.au.bois). El silabeo de estas canciones nos retrotrae al origen acústico y memorizable del ritmo y de la métrica, $y$-ipor qué no?- de la poesía.

La sílaba es en fin de cuentas el andamiaje del verso, o por mejor decir, su fundamento arquitectónico. Marco Aurelio Marcial, poeta bilbilitano del siglo I, considera que las syllabae vienen a ser lo mismo que el verso y el poema, cuando escribe: Verona docti syllabas amat vatis (MART. 1, 61, 1), «Verona ama los versos del hábil poeta».

2. Otro notable error o prejuicio de la gramática y la métrica tradicionales es la de considerar sólo como unión vocálica natural y gramaticalmente correcta, en el llamado diptongo, la agrupación de una vocal de la serie /i, u/ con otra de la serie /a, e, o/: ai, ei, oi, au, eu, ou, ia, ie, io, ua, ue, uo; o bien la agrupación de las dos vocales de la serie /i, u/ entre sí: iu, ui. El encuentro de las vocales de la serie /a, e, o/ entre sí daría lugar al hiato.

Hay que esperar hasta el año 1973 para que, en el Esbozo de una nueva gramática de la lengua española, se admita la posibilidad de que existan también diptongos con vocales de la serie /a, e, o/ combinadas entre sí, lo cual había sido siendo antes considerado como anómalo o impropio. En palabras tales como «línea», «coágulo», «óleo», «coexistir», se reconoce que, junto a las divisiones silábicas lí.ne.a, co.á.gu.lo, ó.le.o, co.e.xis.tir, consideradas como normales, podrían asimismo darse las escansiones lí-nea, coá-gu.lo, óleo, coe.xis.tir.

Así, por ejemplo, en la palabra «óleo», académicamente conceptuada como esdrújula y trisilábica (ó.le.o), podría producirse un diptongo entre las dos últimas sílabas (óleo). En este caso, la palabra sería bisilábica, y por lo tanto llana o paroxítona, al igual que «olio», por lo que debería carecer de tilde. Pero no: se mantiene la tilde. La razón es clara: según los criterios académicos, la intervención de una vocal de la serie /i, u/ seguiría siendo imprescindible para la formación «normal»y $\mathrm{y} \ll$ natural» del diptongo. De 
este modo, para justificar la unión silábica de las vocales de la serie /a, e, o/, se recurre al término sinéresis, que vendría a ser la pronunciación en una sola sílaba de dos vocales que normativamente deberían formar hiato.

Tan natural y normal sería, según algunos criterios tradicionales, la formación de diptongos en el contacto de vocales abiertas de la serie /a, e, o/ con vocales cerradas de la serie /i, u/, o de vocales de esta última serie entre sí, que, en vocablos como «viaje», «cliente», «brioso», «gradual», «cruel», «sinuoso», «diurno», «ruido», lo normativo habría de ser la agrupación silábica: via.je, clien. te, brio.so, gra.dual, cruel, si.nuo.so, diur.no, rui.do. Pero lo cierto es que, en el lenguaje ordinario -y en el verso, que de él proviene-, encontramos frecuentemente no la agrupación, sino la separación silábica, no la zeuxis, sino la azeuxis: vi.a.je, cli.en.te, bri.o.so, gra. du.al, cru.el, si.nu.o.so, di.ur.no, ru.i.do.

Si en algunas palabras, como en «ruido», el uso fluctúa entre la agrupación (rui.do) y la separación (ru.i.do), en otras, como en «cruel», lo más habitual es precisamente la separación silábica (cru.el); al menos en lo que concierne al español peninsular, ya que en la mayor parte de las hablas hispanoamericanas se prefiere el diptongo (cruel).

La preceptiva tradicional consideraba la separación silábica, en todos estos casos, como una licencia poética o métrica, a la que se vino en llamar diéresis, esto es, pronunciación en sílabas separadas de las vocales que normativamente deberían formar diptongo.

El problema surge a la hora de dilucidar qué es lo natural, lo normal y lo preceptivo. Para algunos preceptistas, habría que hablar de sinéresis únicamente en el caso de una pronunciación o escansión del verso, forzada y artificiosa, en una sola sílaba, de lo que «normalmente» se pronuncia en sílabas separadas. Y, a su vez, se daría el fenómeno de la diéresis cuando se hacen artificialmente dos sílabas de lo que debería constituir una sola. Incluso se ha llegado a proponer lecturas aberrantes, con el nombre de diéresis, tales como la separación silábica en vocablos como «bien» (*bi.en) o «bueno» (*bu.e.no). 
Huelga decir que la conciencia lingüística impide de todo punto la opción alternativa entre zeuxis y azeuxis en las agrupaciones vocálicas ie y ue provenientes de $\breve{e}$ (bene) y $\breve{o}$ (bonum) tónicas latinas. Aquí se produce siempre la zeuxis (bien, bue.no). A la conciencia lingüística, habría que añadir la intuición, la estética y el sentido común para marcar el límite entre la adecuada percepción acústica y la lucubración disparatada.

3. Prejuicio, que conviene superar, es también el recurso a una supuesta dislocación acentual para explicar la unión silábica, o zeuxis, entre una vocal acentuada de la serie $/ \mathrm{i}, \mathrm{u} / \mathrm{y}$ una vocal no acentuada de la serie /a, e, o/. Consideremos los siguientes versos:

Ver cómo se mece el árbol, oír el hilo de la fuente...

JuAN RAMÓN JimÉneZ

Aún no nos damos por vencidos. Dicen que se perdió una guerra. No sé nada...

Blas de Otero

Los citados versos de Juan Ramón Jiménez son octosílabos, y los de Blas de Otero endecasílabos. En el primer fragmento, la palabra «oír» es monosilábica; en el segundo, también lo es «aún». Ambos vocablos, que en otros contextos funcionan como bisilábicos, no lo son aquí. Tiene lugar la zeuxis, o la sinéresis si se quiere, en ambos casos. La preceptiva tradicional diría que esta «licencia» viene impuesta por las «necesidades métricas». El poeta habría forzado, violentado, atornillado el lenguaje para conseguir las sílabas requeridas.

Una vez reconocida la unión silábica, queda por dilucidar en qué vocal recae el acento. Para la gramática tradicional, sería difícil admitir que la vocal nuclear fuera la más cerrada, cumpliendo la más abierta el papel de elemento marginal: «oír», «aún». La explicación que se ha venido dando es que entra en juego un mecanismo 
de dislocación acentual, desplazándose el acento de la vocal más cerrada a la más abierta: «óir», «áun».

Pero, a decir verdad, nunca me ha convencido esa interpretación de los hechos fonéticos, que falsea la realidad acústica del verso. En el «aún» de Blas de Otero, la tilde sobre la $u$ nos señala que la palabra ha de tomarse en la acepción de todavía, y no en la de incluso o inclusive, que no requeriría el uso de dicha tilde, indicativa de la carga acentual. No dice Blas de Otero «incluso no nos damos por vencidos», sino «todavía no nos damos por vencidos». La rotunda fuerza del «aún» vibra en esa $u$ profunda y tenebrosa, que es acústicamente el centro nuclear del grupo silábico. Pienso que lo que ocurre es que la $a$ del «aún» ha quedado oscurecida y se hace menos perceptible, hasta el punto de asumir el papel de mero elemento marginal. Algo análogo sucedería en el «oír» de Juan Ramón Jiménez. Un buen lector de poesía tal vez perciba el tintineo del hilo de la fuente en el agudo timbre de la $i$ acentuada.

En los endecasílabos de Garcilaso de la Vega, como ya hice notar en un artículo publicado en el número $\mathrm{x}$ de Rhythmica, es por lo demás frecuentísima la zeuxis, o unión silábica, o sinéresis, de la vocal cerrada tónica $i$ con las vocales abiertas átonas $a$ y $o$. Es bien conocido el siguiente verso:

\section{Hermosas nymphas que en el rîo metidas...}

Fernando de Herrera, en sus Obras de Garcilaso de la Vega con anotaciones, escribía «rîo», y en otros lugares «mîos», «perdîa», queriendo indicar con el acento circunflejo la presencia de un especial fenómeno fonético, que afectaba directamente al grupo silábico. La vocal resaltada por la tilde era precisamente la $i$, la más cerrada, que pasaba a ser así el centro del grupo silábico.

De Garcilaso es también un endecasílabo en el que tiene lugar el contacto entre una vocal abierta y átona con una vocal cerrada y tónica, produciéndose la zeuxis. En esta ocasión, la unión silábica se da entre palabras contiguas, y el hecho aparece precisamente citado 
como «curiosa» licencia poética en el Esbozo de una nueva gramática de la lengua española (párrafo 1.6.8.c):

Otra curiosa «licencia» poética, que en este caso afecta también a la rima, aparece en el endecasílabo de Garcilaso (Égloga I, v. 122): Y por nuevo camino el agua SE Iba, donde se computa como una sílaba el grupo final /éi/, con dislocación del acento, lo que no impide que iba sea consonante de estiva. Lo mismo ocurre en Góngora (Sonetos completos, ed. 1969, pág. 27): Que a Júpiter ministra el garzón DE Ida, verso aconsonantado en -ida a pesar de la sinalefa /éi/, o en Ponga, pues, fin a las querellas QUE Usa (ibíd., 127), con sinalefa /éu/, pero con rima-usa.

El texto citado merece, sin duda, una detenida atención. En primer lugar, es de advertir que los grupos vocálicos que se aducen -/éi/, /éu/- se computan «como una sílaba». No es que se admita que constituyan auténticas sílabas, sino que se les concede ese valor en virtud de la «sinalefa», conceptuada aquí como «curiosa» licencia poética. En segundo lugar, se afirma algo que es obvio: que esa licencia afecta a la rima. Ahora bien, se asume que el acento no puede recaer en modo alguno sobre una vocal de la serie cerrada /i, u/, sino sobre la vocal más abierta /e/, produciéndose así una «dislocación $\gg$ del acento.

Viene ahora la afirmación más sorprendente. Se nos dice que la dislocación del acento no impide que, en el endecasílabo de Garcilaso de la Vega, iba sea consonante de estiva, con rima -ib [v]a. Y, del mismo modo, en los restantes ejemplos, las rimas serían -ida y -usa, «a pesar de la sinalefa» y a pesar de la «dislocación del acento».

Se incurre en una clara contradicción. En efecto: si hay dislocación del acento, no puede haber rima consonante, ya que esta rima, por definición, no es otra cosa sino la completa igualdad de sonidos con que terminan dos o más palabras a partir de la última vocal acentuada; y si hay rima, no puede haber dislocación del acento. Por lo tanto, y en pura lógica, si existe rima -que sí que existe-, el acento ha de recaer necesariamente en la vocal inicial de dicha rima: 
y.por.nué.vo.ca.mí.noel.á.gua.seí.ba

quea.jú.pi.ter.mi.nís.trael.gar.zon.deí.da

pón.ga.pues.fín.a.las.que.ré.llas.queú.sa

Habría, en consecuencia, que revisar algunos criterios tradicionales y afirmar que, en casos como éstos, no tiene sentido desplazar el acento a la vocal más abierta. Si no queremos caer en la contradicción de admitir simultáneamente la existencia de rima y de dislocación acentual, hemos de rechazar decididamente esta última. Así lo percibían Garcilaso y Góngora. Y así lo percibe el oído del atento lector de poesía. Como más arriba se indicó, al recaer el acento en la vocal más cerrada del grupo silábico, es la vocal más abierta la que precisamente se oscurece y se hace menos perceptible, convirtiéndose en vocal neutra [ə], y asumiendo el papel de elemento marginal:

y.por.nué.vo.ca.mí.noel.á.gua.səí.ba

quea.jú.pi.ter.mi.nís.trael.gar.zon.dəí.da

pón.ga.pues.fín.a.las.que.ré.llas.quəú.sa

4. Por último, quisiera hacer mención de un frecuente error en los estudios métricos, que consiste en considerar los límites entre palabras contiguas como fronteras infranqueables para la realización de una auténtica zeuxis o unión silábica, como si el blanco de la escritura constituyera una entidad fonética. Veamos un ejemplo muy ilustrativo:

$$
\begin{aligned}
& \text { Abril, sin tu asistencia clara, fuera... } \\
& \text { (a.bríl.sin.tua.sis.tén.cia.clá.ra.fué.ra) } \\
& \text { JUAN RAMÓN JIMÉNEZ }
\end{aligned}
$$

La sílaba tua contiene un grupo vocálico que debería ser considerado, con toda propiedad, como diptongo, al igual que sucede en el caso de las sílabas cia y fue. Pero no es así. Los grupos vocálicos de estas últimas sílabas siempre han tenido la consideración de diptongos. En cambio, para denominar el grupo vocálico de la sílaba tua, se recurre al término sinalefa, al que se le otorga la condición de 
licencia poética. Y esto, ¿̇por qué? Porque, sin duda, se piensa que la arquitectura fonológica de las palabras aisladas quedaría comprometida si se admite que pueda existir entre ellas el engarce silábico que implica el diptongo. De ahí que se considere necesario hacer una neta distinción entre sílabas gramaticales y métricas, o entre sílabas fonológicas y fonéticas.

Según estos criterios, el citado verso constaría realmente de doce sílabas gramaticales o fonológicas, y sólo tendría once sílabas -métricas o fonéticas- en virtud de la licencia llamada sinalefa. Se incide así en un palmario error de enfoque y de perspectiva. Obsérvese que lo que en realidad ocurre es que dicho verso consta originariamente de once sílabas o entidades articulatorias -acústicas, fonéticas, métricas o como se la quiera denominar-, tanto en el discurso ordinario como en la línea poética, y que sólo una consideración mecanicista de las palabras aisladas trataría de ofrecernos una segmentación del verso en doce sílabas, desuniendo lo que estaba naturalmente unido, para luego volverlo a unir mediante una supuesta licencia métrica o poética.

Veamos lo que nos dice a este respecto la Nueva gramática de la lengua española (párrafo 1.4ñ):

Las sílabas fonológicas no se corresponden necesariamente con las sílabas fonéticas. En el verso entre el vivir y el soñar (Machado, Nuevas canciones), se observa la diferencia entre estos dos aspectos. Las sílabas fonológicas en.tre.el.vi.vir.y.el.so.ñar se convierten desde el punto de vista fonético en en.trel.vi.vir.yel.so.ñar.

Se admite, al menos, que las sílabas «fonéticas» que se producen por el contacto de vocales entre palabras son auténticas sílabas, sin tener que recurrir al término sinalefa para justificar la anomalía originada por la «licencia» poética. Pero se nos dice que, en el citado verso, las sílabas fonológicas «se convierten» en fonéticas, cuando lo que sucede es justamente lo contrario: es la realidad fonética la que se abstrae y se convierte en sistema fonológico. El fonema presupone el sonido, que es lo que el oído directamente capta. Oímos 
y hablamos con sonidos, articulados en sílabas, cuyos elementos fónicos no se detienen ante las fronteras ficticias que marcan en la escritura los espacios blancos existentes entre las palabras.

La sílaba no tiene en sí misma valor fonológico alguno, a no ser como unidad mínima portadora de un acento. Aunque, a decir verdad, el acento viene a su vez definido, tautológicamente, por un mayor relieve de la sílaba acentuada. La sílaba remite al acento, y el acento a la sílaba. En lo que concierne al contacto entre vocales y su incidencia sobre las posibles divisiones silábicas, carecería de sentido el tratar de atribuir un papel fonológico - distintivo de significados-al hecho de que tenga lugar la zeuxis o la azeuxis. Es obvio que un piano no es más o menos piano, ni mejor ni peor, porque tenga dos sílabas (pia.no) o tres (pi.a.no). Y es que sucede que la sílaba no es un elemento gramatical, sino rítmico.

Sílabas y acentos vienen a configurar el armazón rítmico del verso y su análisis pertenece al dominio de la métrica, la poética y la estética, y no a los estudios gramaticales o lingüísticos. La Real Academia Española, que todavía en el Esbozo prestaba alguna atención a las sílabas, el acento y la fonología sintáctica, en la Nueva gramática pasa ya por estas cuestiones como sobre ascuas. Significativamente, el Manual de la Nueva gramática dedica a las unidades fónicas sólo dos brevísimos párrafos, que vienen a ocupar no más de media página de un total de novecientas noventa y tres.

De la sílaba, se nos dice escuetamente que es «el grupo mínimo de sonidos dotado normalmente de estructura interna en la cadena hablada» (Manual, 1.2.1). Conviene que nos detengamos en la calificación adverbial normalmente. Cabría deducir de esa definición que puede haber sílabas anormales o desprovistas de estructura interna. ¿Serán estas sílabas anormales y desestructuradas las que tradicionalmente se consideraban como «métricas», frente a las «gramaticales», y más recientemente «fonéticas», frente a las «fonológicas»?

Si escasa o nula es la atención que el Manual concede a la sílaba, no es mayor la que otorga al acento. En este caso, a la parquedad hay 
que unir una cierta confusión o una franca incongruencia. Tras hacer alusión a la prosodia como «disciplina que estudia el conjunto de los elementos fónicos SUPRASEGMENTALES $\gg$, define el acento como «grado de fuerza con el que se pronuncia una sílaba y el que la dota de prominencia con respecto a otras limítrofes» (Manual, 1.2.2).

Conviene recordar que tanto el acento como la prosodia son palabras latinas con idéntico significado: la primera (accentus), como calco del griego $(\pi \rho \sigma \omega \delta \mathrm{\delta} \alpha)$; la segunda, como directo préstamo del mismo. En la lengua originaria griega, la prosodia es el canto con acompañamiento de un instrumento musical, el acorde, la armonía, la buena pronunciación. La prosodia, como parte de la gramática, no ha venido significando en efecto otra cosa que pronunciación: pronunciación correcta, pronunciación exquisita; del mismo modo que la ortografía se ha venido siempre considerando como correcta escritura, recta grafía. Morfología, sintaxis, prosodia y ortografía eran las partes tradicionales de la gramática. Carece, por tanto, de sentido limitar la prosodia a los elementos fónicos suprasegmentales, esto es, al acento y a la entonación.

Por otra parte, no es oportuno atribuir el acento a la «fuerza» con la que se pronuncia una sílaba. En la constitución del acento tanto en la palabra aislada, como en la línea discursiva del lenguaje ordinario o en la línea del verso- intervienen fundamentalmente dos cualidades del sonido: la intensidad y el tono. Si atendemos a la intensidad acústica, el acento no es una fuerza, sino una energía, esto es, una magnitud física de mayor complejidad que la fuerza, y proporcional a la amplitud de la onda sonora. Si atendemos al tono musical, lo que entra en juego es la frecuencia, es decir, el número de ciclos por segundo de los sonidos emitidos.

Hechas estas salvedades, una relación sumaria de los términos al uso -diptongo, hiato, sinéresis, diéresis, sinalefa, dialefa- pondrá de manifiesto la oportunidad de introducir los nombres de zeuxis y azeuxis, como propuesta conceptual y terminológica para distinguir la unión silábica de vocales de su desunión en sílabas distintas. 


\section{Diptongo}

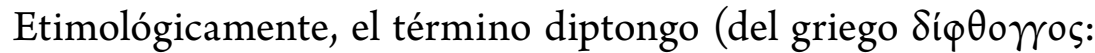
de doble sonido; en latín, diphthongos o diphthongus) es algo impreciso: no señala si los dos sonidos o vocales están unidos en una sola sílaba o separados en sílabas diferentes. Su empleo en las lenguas románicas viene de muy antiguo. En la lengua francesa, el diccionario Robert documenta ya el término diphtongue en el siglo XIII.

Se ha venido aplicando habitual y restrictivamente a la unión silábica de una vocal abierta de la serie /a, e o/ y una cerrada de la serie /i, u/, o de dos vocales de esta serie entre sí, siempre con acento en la más abierta y en el interior de la palabra aislada. Su empleo en otras circunstancias podría inducir a error. Son útiles, en todo caso, tanto el sustantivo «diptongación» como el verbo «diptongar» para hacer referencia al fenómeno de convertirse en diptongo una vocal, como es el caso de las agrupaciones vocálicas ie y ue provenientes de $\breve{e}$ (bene) y $\breve{o}$ (bonum) tónicas latinas. Estos diptongos son percibidos, en el devenir histórico de la lengua, como entidades vocálicas inseparables.

En algunas lenguas, como la rusa, las vocales $e$ y $o$, pronunciadas como ie y uo, se realizan indistintamente en el uso del lenguaje ordinario como vocal o como diptongo. En italiano, incluso en su modalidad toscana, hay vacilación entre el diptongo y la vocal en expresiones tan cotidianas como buona sera, pronunciado a veces como bona sera.

Es de advertir que, en otros casos, el origen etimológico no es vía segura para determinar la realización del diptongo. En la palabra «fiel» (del latín fidelem), por ejemplo, se da el diptongo, mientras que en la palabra «cruel» (del latín crudelem) no se realiza habitualmente.

\section{Hiato}

Su etimología (del latín hiatus: hendidura, grieta, abertura, bostezo) confiere al término un matiz peyorativo, ya que implica una 
carga afectiva de cacofonía no deseada. Como encuentro de dos vocales que se pronuncian en sílabas distintas, se aplica generalmente al contacto, en el interior de la palabra, de vocales de la serie /a, e, o/ entre sí, o con vocal tónica de la serie /i, u/.

Entre palabras, equivaldría a la dialefa, como fenómeno opuesto a la sinalefa. Para el Diccionario de la Lengua Española, de la Real Academia, sería en concreto la «disolución de una sinalefa, por licencia poética, para alargar un verso», definición en la que, al concepto de «licencia», se añade el recurso artificioso de «alargar» el verso.

Por otra parte, la acumulación de vocales en hiato -a lo largo de la línea versal o discursiva- ha venido siendo conceptuada, desde el punto de vista retórico, como algo reprobable por su efecto supuestamente desabrido y cacofónico. Habría, por lo tanto, que evitar el hiato. Pero, como ocurre siempre que entran en juego valores estéticos, las cosas no se atienen siempre a los estrictos patrones de la normativa. En el verso de Blas de Otero un verso en pie -ahí está el detalle-(un.ver.soen.pié.a.hí.es.tael.de.ta.lle), la cadena de vocales en hiato -/e.a.i.e/- lejos de producir un efecto acústico indeseable, restalla como un látigo en la conciencia del lector.

\section{Sinéresis y diéresis}

Del verbo griego aipźc (coger, capturar), proceden -con las partículas prepositivas $\sigma v v$ y $\delta$ ı́á, de unión y separación respecti-

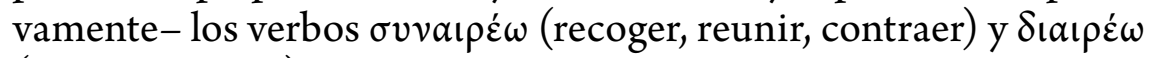

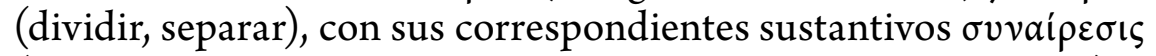
(en latín synaeresis: reunión, contracción; en español, sinéresis) y

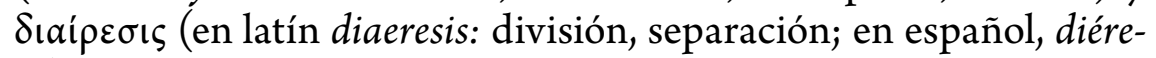
sis). Hay que señalar que, tanto en la lengua griega como en latina, se llamaba diéresis la cesura de un verso, si coincidía con el final de un pie, entendiendo por cesura la sílaba con que termina una palabra después de haber formado el pie. No es éste el sentido actual de la palabra diéresis. 
Según reza en el Diccionario de la Lengua Española, diéresis sería la «pronunciación en sílabas distintas de dos vocales que normalmente forman diptongo», y sinéresis la «reducción a una sola sílaba, en una misma palabra, de vocales que normalmente se pronuncian en sílabas distintas».

Habría que precisar qué es lo que se entiende por «normalmente». Si se considera que «piano» 0 «suave» son normalmente palabras bisilábicas, con los correspondientes diptongos ia y ua, entonces la pronunciación en sílabas distintas de estas vocales habría de ser conceptuada como diéresis. Pero si se admite que dichas palabras son trisilábicas y que las vocales de los grupos $i$ y y ua se pronuncian normalmente en sílabas distintas, entonces la reducción a una sola sílaba de estos grupos vocálicos habría de ser conceptuada como sinéresis.

Recientemente, la Academia Española admite, en algún caso, como en la palabra «guión», recogida también como «guion», que la pronunciación pueda realizarse de dos formas naturales y diferentes: como bisílabo, «guión», con azeuxis y por tanto con la correspondiente tilde, o como monosílabo, «guion», con zeuxis y sin tilde.

En la lengua francesa, el Robert nos dice que en la palabra violon se pronuncian en sílabas distintas las vocales del grupo io, cuando se trata del lenguaje poético; pero que, en el lenguaje ordinario, se pronuncian en una sola sílaba, y es a esto lo que habría que llamar sinéresis. Lo «natural» sería aquí la azeuxis del lenguaje poético, frente a la zeuxis del lenguaje coloquial.

En los tratados de métrica italiana, algunos autores dan una definición correlativa de ambos términos: si dos vocales contiguas, en el interior de una palabra, forman una sola sílaba, existiría sinéresis; el fenómeno contrario sería la diéresis. Otros autores, en cambio, conceptúan la sinéresis y la diéresis como transgresiones de la norma. Supondrían una escansión «artificiosa y y distinta de la «normal». Me he ocupado ampliamente de esto en mi libro El ritmo del verso. 


\section{Sinalefa y dialefa}

Del verbo griego $a \lambda \lambda^{\prime} \varphi \omega$ (frotar, untar), provienen $\sigma v v a \lambda \varepsilon i ́ \varphi \omega$ (contraer) y $\delta\llcorner\alpha \lambda \varepsilon i ́ \omega \omega$ (borrar con una sustancia grasa). El sustanti-

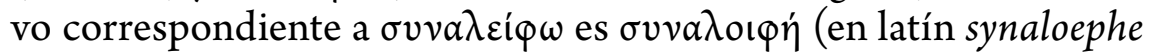
o synaloepha: fusión, unión, mezcla; en español, sinalefa). Sobre $\delta ı \alpha \lambda \varepsilon i \varphi \omega$, cuya partícula prepositiva $\delta ı \alpha ́$ indica separación, se formó la palabra dialefa.

Se entiende por sinalefa la unión silábica que resulta del contacto entre dos o más vocales pertenecientes a palabras distintas. Lejos de ser una licencia métrica o poética, tal como vino siendo considerada, es un fenómeno fonético que se da habitualmente en el verso y en el lenguaje ordinario.

Ni los signos de puntuación, ni las pausas que éstos señalan, se oponen a la unión vocálica y silábica que la sinalefa implica. A este respecto, vale la pena considerar la opinión que les merecía a los redactores del Esbozo de una nueva gramática de la lengua española (párrafo 1.6.8.b) la realización de la sinalefa tras una pausa sintáctica:

El verso de metro regular emplea algunas libertades en la formación de la sinalefa. En el endecasílabo de Gerardo Diego (Primera antología, ed. 1947, pág. 62): Mi nombre esperA. un día y otro día, la pausa destruye silábicamente el grupo /áu/, pero métricamente se computa como una sílaba, es decir, como una sinalefa. Lo mismo en Bécquer (Rimas, ed. 1911, LXV): ¡Estaba en un desierto! Aunque a mi oído. Esta organización del verso es muy frecuente.

Se termina reconociendo que estamos en presencia de una organización «muy frecuente»; pero, al comienzo del párrafo, se indica que se trata de «algunas libertades», rarezas o licencias del verso, y concretamente del «verso de metro regular». Se sobrentiende que el verso de metro irregular no presentaría problema alguno, puesto que no estaría sujeto a la tiranía de las convenciones métricas que obligan al poeta a cosas tan raras -al parecer-como realizar una sinalefa allí donde el oído le dice que tiene que haber sinalefa. Es 
llamativo el empecinamiento de algunos tratadistas en considerar como excepción, anomalía y rareza aquello que es sencillo y natural para el poeta y para el competente lector de poesía.

Se afirma que la pausa destruye «silábicamente» el grupo /áu/. Es evidente que se confunde la pausa motivada por la sintaxis, por el deseo de destacar el sentido o simplemente por la necesidad de respirar, con la pausa versal, esto es, la pausa final del verso o final de hemistiquio. Se olvida que ni siquiera la alternancia de hablantes, en la obra de teatro en verso, rompe la continuidad de la línea poética.

El citado párrafo del Esbozo admite que el grupo /áu/, destruido «silábicamente», puede «métricamente» computarse «como una sílaba». No es ya que no exista realmente una sílaba, ni siquiera una sílaba métrica o fonética, en oposición a las auténticas sílabas gramaticales o fonológicas; no. Lo que ocurre, según el sentir del Esbozo, es que tampoco existiría una verdadera sinalefa. Sólo se concede que dicho grupo silábico se computa «como una sílaba, es decir, como una sinalefa».

Serían innumerables los casos y las circunstancias que una minuciosa casuística podría establecer en relación con la sinalefa, como unión de vocales, y la dialefa, como ausencia de dicha unión. Y siempre sobre la base de suponer que la fonética de la línea sintagmática del discurso, del poema, sea algo distinto de la fonética de las palabras aisladas.

\section{Zeuxis y azeuxis}

En todos los casos de vocales en contacto, tanto en el interior de la palabra aislada como entre palabras contiguas, sería más conveniente hablar sencilla y llanamente de «unión»o «desunión» silábica. Y, para ello, la lengua griega nos proporciona dos términos claramente delimitados: zeuxis ( $\zeta \varepsilon v ́ \xi ı$ : enganche, unión) y azeuxis

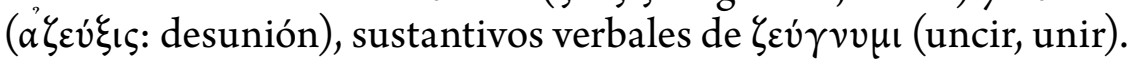

El término azeuxis ha venido ya siendo utilizado en la lengua española, justamente como sinónimo de hiato o encuentro de vocales 
que se pronuncian en sílabas diferentes. No ocurre lo mismo con el término zeuxis, como indicativo de la unión de vocales que se pronuncian en una sola sílaba, pues hasta ahora no había formado parte de la nomenclatura métrica. Existía, sin embargo, el término

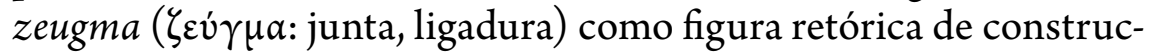
ción, que también es sustantivo verbal de $\varepsilon_{\varepsilon} \gamma \nu v \mu$ y que consiste en sobrentender una palabra o sintagma en varias oraciones o cláusulas, aunque sólo está presente en una de ellas.

El término zeugma aparece ya en el Diccionario de Autoridades de 1737 , donde se le define como «figura rhetórica, que vale lo mismo que conexión o junta; y es aquella, en virtud de la cual un mismo verbo forma diversas oraciones, y sirve para varias sentencias, conservando siempre el mismo significado». Como autoridad, se cita el comentario de Fernando de Herrera a los dos primeros versos del Soneto I:

Cuando me paro a contemplar mi estado, i a ver los passos por do m’à traido...

Dice, en efecto, Fernando de Herrera, a propósito de la voz «paro»: «es figura zeuma, que sinificar à en Español ligadura, o ayuntamiento; cuando un verbo se llega comúnmente a muchas sentencias, i conviene a todas con igual sinificado, como este, que se refiere a contemplar y ver». Es precisamente la idea de conexión, junta, ligadura o ayuntamiento la que adquiere también la zeuxis frente a la azeuxis.

Tanto zeuxis como zeugma son sustantivos verbales, si bien el primero expresa la acción del verbo, y el segundo, el resultado. Es lo mismo que ocurre con los términos sintaxis ( $\sigma \dot{v} v \tau \alpha \xi ı \zeta$ : orden, disposición, orden de combate) y sintagma ( $\sigma \dot{v} v \tau \alpha \gamma \mu \alpha$ : ordenamiento, constitución, fila de combate), sustantivos verbales que expresan respectivamente la acción y el resultado de $\sigma v v \tau \alpha ́ \sigma \sigma \omega$ (ordenar, organizar). La introducción del término zeuxis en la nomenclatura métrica viene así de la mano de la utilización del término zeugma en la nomenclatura retórica. 
El término zeuxis es, por otra parte, más exacto que el término diptongo, ya que su significado no se limita a sólo dos elementos fónicos y a unas determinadas circunstancias del contacto entre vocales en el interior de la palabra aislada. Pueden ser tres (el llamado triptongo) o más las vocales que se agrupan en una unidad silábica, tanto en la palabra aislada como entre palabras contiguas. Por su parte, azeuxis carece de las connotaciones peyorativas del hiato, e indica además con toda claridad que existe desunión entre las vocales en contacto, esto es, neta separación de las sílabas que se constituyen en torno a ellas.

Como ya propuse en anteriores trabajos, y concretamente en el artículo «Zeuxis y azeuxis en la configuración silábica», publicado en el número Ix de Rhythmica, el empleo del término zeuxis para todos los casos de presencia de unión vocálica, y del término azeuxis para la ausencia de dicha unión, vendría a simplificar y aclarar, terminológica y conceptualmente, la cuestión de las vocales en contacto, excesivamente enmarañada por una casuística nimia, que no atiende a la directa audición del verso.

La cosa es muy sencilla: dos o más vocales contiguas, indistintamente en la palabra aislada o entre palabras adyacentes, pueden unirse en una sola entidad silábica (zeuxis), o no unirse (azeuxis). Bien entendido que la unión o la desunión no se producen en virtud de la zeuxis (diptongo, sinéresis, sinalefa) o la azeuxis (hiato, diéresis, dialefa), sino que tienen lugar por obra y gracia de la eufonía, que el poeta sabe medir y administrar. La eufonía, el buen sonido de la palabra poética, es el hecho del que se parte. Lo demás sólo son términos, que designan e interpretan en la medida de lo posible esa realidad. 


\section{MÉTRICA Y FONÉTICA}

L

OS estudios fonéticos y fonológicos guardan, sin lugar a duda, una estrecha relación con la ciencia del verso. Especialmente en el terreno de la Fonética Acústica, los conceptos que han tenido una mayor incidencia en lo que concierne al cómputo silábico son los de isocronía e isosilabia. Conviene precisar el valor de estos términos, porque, en distintos contextos, y según los diversos autores, pueden aparecer investidos de muy dispares significados.

Por isocronía se entiende específicamente la isocronía acentual, esto es, la hipotética igualdad de las distancias temporales entre los acentos, independientemente del número de sílabas inacentuadas que existan entre ellos. La isosilabia designa, en cambio, la igualdad en la duración de cada una de las sílabas. A este respecto, las lenguas naturales se han venido tradicionalmente clasificando de acuerdo con dos patrones rítmicos: la tendencia a la isocronía acentual, o isocronía entre los pies acentuales, y la tendencia a la isosilabia, o isocronía silábica con anisocronía acentual. Dado el indiscutible dominio que la lengua inglesa ha venido ejerciendo en gran parte de la historia de los estudios sobre el ritmo, no es extraño que las lenguas del primer grupo sean muchas veces denominadas stress-timed, y las del segundo grupo syllable-timed, siguiendo las pautas de Abercrombie ${ }^{1}$.

\footnotetext{
${ }^{1}$ ABERCROMBIE, D.: Elements of General Phhonetics. Edimburgo: Edinburgh University Press, 1967.
} 
En la bibliografía especializada española, pueden encontrarse varias denominaciones para los términos ingleses stress-timed language y syllable-timed language. Se habla, así, de «lenguas de isocronía acentual»y $\ll$ lenguas de anisocronía acentual $»^{2}$, «lenguas de compás acentual»y «lenguas de compás silábico ${ }^{3}$, o lenguas de «ritmo acentual»y lenguas de «ritmo silábico». Al primer grupo se adscribieron lenguas tan dispares como el inglés, el ruso y el árabe; y al segundo grupo, el español, el francés, el italiano y el catalán. No obstante, en estudios posteriores sobre el español, se rechazó esa tendencia a la isocronía silábica, ya que no existiría similitud temporal ni entre las sílabas ni entre los intervalos acentuales.

A decir verdad, la clasificación de las lenguas en dos grandes grupos, con características métricas bien definidas, dista mucho de constituir un cuerpo de doctrina sólidamente fundado. Y, desde luego, no puede basarse en esta división dicotómica de las lenguas una separación tajante entre la métrica silábica y la métrica acentual. En ocasiones, asistimos a ciertas formulaciones que destruyen en la práctica toda posibilidad de alcanzar la exactitud en el cómputo silábico, colocando acá y allá, cada dos, tres o más sílabas, acentos arbitrarios.

De especial interés para la medida del verso es la disyuntiva entre versificación regular y versificación irregular. Y, desde luego, hay que tener en cuenta el papel desempeñado a lo largo del pasado siglo $\mathrm{xx}$ por el verso libre, que en principio supone la negación de toda posibilidad de cómputo silábico. A decir verdad, ya en las últimas décadas del siglo $\mathrm{xx}$ aparecía superado el dominio absoluto del versolibrismo. El verso regular, tradicional si se quiere, canónico, pautado - que ciertamente no había caído en olvido en la poesía de Juan Ramón Jiménez, Manuel Machado, Antonio

2 TOLEDO, G. A.: El ritmo en el español. Estudio fonético con base computacional. Madrid: Gredos: 1988.

${ }^{3}$ CANTÍN I MAS, M., y RÍOS MESTRE, A.: «Análisis experimental del ritmo de la lengua catalana», Anuario del Seminario de Filología Vasca «Julio de Urquijo». XXV, 2, 1991, pp. 487-513. 
Machado, Federico García Lorca, Blas de Otero, Carlos Álvarez, Ángel García López, Luis Alberto de Cuenca- se va consolidando cada vez con mayor firmeza.

Cierto es que el versolibrismo, cuyos orígenes se remontan a los años finales del siglo XIX, supuso en su día un notable esfuerzo de expansión, depuración y movilidad de los cauces métricos tradicionales. Pero, en la actualidad, aparece más bien como una noble experiencia, ya superada. Distintos autores del mundo anglosajón ${ }^{4}$ han puesto de manifiesto el declive del verso libre ya hacia 1970. Entre nosotros, han estudiado con profundidad el verso libre Isabel Paraíso Almansa y María Victoria Utrera Torremocha. Isabel Paraíso considera la versificación libre como la forma métrica característica del siglo $\mathrm{xx}$, en todas las literaturas occidentales, y ofrece una detallada tipología del verso libre en la literatura española ${ }^{5}$. Por su parte, María Victoria Utrera se remonta en su estudio al versículo de Walt Whitman, a las corrientes simbolistas y modernistas, y al verso libre de las vanguardias. En lo que concierne a la presencia del verso libre en la poesía española de las últimas tres décadas del siglo $\mathrm{xx}$, termina reconociendo el claro descenso del verso libre y el generalizado retorno a los moldes tradicionales ${ }^{6}$.

En lo que concierne al verso español irregular y fluctuante, los mayores esfuerzos por resaltar su importancia fueron los realizados por Pedro Henríquez de Ureña ${ }^{7}$. Dorothy Clotelle Clarke lo considera como el autor cuya obra «ha destruido la superstición

${ }^{4}$ Vid. SILKIN, J.: The Life of Metrical and Free Verse in Twentieth-Century Poetry. Londres: MacMillan Press, 1997.

${ }^{5}$ PARAÍSO ALMANSA, I.: El verso libre hispánico. Orígenes y corrientes. Madrid: Gredos, 1985.

${ }^{6}$ UTRERA TORREMOCHA, M. V.: Estructura y teoría del verso libre. Madrid: CSIC, 2010.

${ }^{7}$ Vid. HENRÍQUEZ UREÑA, P.: La versificación irregular en la poesía castellana. Madrid: Revista de Filología Española, 1920; Obra crítica. México: F.C.E., 1960; Estudios de versificación española. Buenos Aires: Universidad de Buenos Aires, 1961. 
del isosilabismo $\gg^{8}$. Se entiende aquí el isosilabismo, o la isosilabia, como la igualdad en el número de sílabas de los versos, y no en el sentido habitual de la Fonética Acústica. Los puntos básicos de la historia del verso irregular serían los siguientes:

El fenómeno de la fluctuación existe en toda la versificación española, salvo contadas excepciones, desde el siglo XII hasta fines del XIV. Durante los siglos XIV y XV, se desarrolla también una forma de versificación irregular de tipo acentual, que aflora especialmente a fines del XV, primero entre el pueblo, y, después, entre los poetas cortesanos y ciudadanos. Al terminar el siglo XVI, los elementos populares acaban por penetrar en el drama, en la poesía lírica y en la novela. La versificación irregular mantiene el contacto con la poesía del pueblo, sobre todo antes de 1650 .

A partir de 1650, toda esta variedad de formas se irá regularizando y reduciendo. Hacia el final del siglo XviII, la antigua versificación irregular acaba por desaparecer. El imperio de la uniformidad isosilábica durará aproximadamente hasta 1895.

En 1896, el libro Prosas profanas, de Rubén Darío, señala el resurgimiento de la versificación irregular. Juan Ramón Jiménez, en fin, se convertirá en el principal cultivador de los metros libres. Es por esto por lo que, como conclusión final, escribe Henríquez Ureña:

Como se ve, el movimiento iniciado en América entre 1890 y 1895, y extendido a España desde 1900, ha restaurado en la poesía culta los dos tipos de versificación irregular que habían existido en castellano: el amétrico, que domina desde el siglo XII al XIV, y el acentual, que florece del XIV al XVII'.

Según esto, la versificación regular, «el imperio de la uniformidad isosilábica», habría tenido la escasa duración de poco más de un siglo: desde mediados del siglo XVIII hasta finales del siglo XIX.

\footnotetext{
${ }^{8}$ CLARKE, D. C.: «Resumen antológico de la obra métrica de Pedro Henríquez Ureña», Revista Iberoamericana. Iowa, 21, 1956, pp. 149-158.

${ }^{9}$ HENRÍQUEZ UREÑA, P.: Estudios de versificación española, cit., p. 249.
} 
Para ello, tendríamos que considerar como irregular la versificación de poetas como Juan Ramón Jiménez, principal cultivador de los metros libres según Henríquez Ureña. Y, en efecto, como de versos irregulares consideran algunos autore ${ }^{10}$ la siguiente composición de Juan Ramón Jiménez:

Siento que el barco mío

ha tropezado, allá en el fondo,

con algo grande.

¡Y nada

sucede! Nada... Quietud... Olas...

¿Nada sucede; o es que ha sucedido todo,

y estamos ya, tranquilos, en lo nuevo?

Sorprende que se cataloguen estos versos como irregulares, sin igualdad de sílabas ni de cláusulas, esto es, fuera de toda norma en lo relativo al cómputo silábico. Porque lo cierto es que se trata de versos que se encuentran perfectamente dentro de los cauces del más exacto ritmo endecasilábico. El primer verso es un heptasílabo, y el segundo es un eneasílabo. El tercero (con-al-go-grandey-na-da) aparece escalonado, siendo también un heptasílabo. El cuarto es nuevamente un eneasílabo. El quinto es un alejandrino, compuesto por dos hemistiquios heptasilábicos (na-da-su-ce-deoés-[0] / queha-su-ce-di-do-to-do). Por último, el verso sexto es un endecasílabo italiano.

Pero los referidos autores, María Josefa Canellada y John Kuhlmann Madsen, ignoran la existencia del escalonamiento en el verso tercero, y consideran el quinto como un verso compuesto por dos hemistiquios de cinco y ocho sílabas respectivamente (nada sucede / oes que ha sucedido todo). Por otra parte, el uso distributivo que hacen de los acentos, principales y secundarios, es totalmente caprichoso.

Es evidente que el acento no constituye una entidad absoluta, sino relativa. La sílaba acentuada lo es siempre en relación a un entorno. Una sílaba, con relieve acentual en la palabra aislada, puede

${ }^{10}$ CANELLADA, M. J., y MADSEN, J. K.: Pronunciación del español. Lengua hablada y literaria. Madrid: Castalia, 1987, pp. 154-156. 
perderlo en la línea del verso. Y, a la inversa, una sílaba menos relevante puede experimentar un incremento acentual por su posición en el verso, la entonación o el énfasis que se ponga en la lectura para destacar el sentido o el ritmo.

En el verso inglés, dadas dos sílabas consecutivas, una deberá ser relativamente más acentuada que la otra: one will be relatively more accented tan the other ${ }^{11}$. Y lo mismo ocurre en el verso italiano, donde se hace notar la imposibilidad de que existan dos acentos rítmicos consecutivos $^{12}$. Con todo, algún autor defiende la tesis contraria: podría haber dos sílabas adyacentes provistas ambas de acento rítmico, esto es, los versos podrían presentar dos ictus consecutivos.

El concepto de alternancia ha sido desarrollado por investigadores de signo muy diverso, tanto en el aspecto teórico de la Fonología Métrica como en el práctico y experimental de la Fonética Acústica. En Fonología Métrica, el acento se entiende como una relación sintagmática entre dos componentes, uno fuerte y otro débil, que, como ya se indicó, no constituyen entidades absolutas, sino relativas. Las representaciones mentales de los patrones de acento estarían, en todo caso, organizadas jerárquicamente. Una grilla métrica abstracta (metrical grid) representaría las relaciones acentuales en la palabra o en la frase. Cada sílaba recibiría una marca de grilla en el nivel más bajo. Las sílabas que sólo llevaran una marca se percibirían como inacentuadas, y las que tuvieran dos o más marcas se percibirían como acentuadas.

Puede tener lugar un desplazamiento acentual (stress shift) ${ }^{13}$, debido a la proximidad de un elemento más prominente. Así, en inglés, mediante la regla de «inversión yámbica», se impide la sucesión de dos sílabas tónicas. Es lo que ocurre en la pronunciación de la palabra Heathrow como localidad o como aeropuerto.

11 BAKER, D., ed.: Meter in English: A critical Engagement. Fayetteville: University of Arkansas Press, 1996, p. 286.

12 PAZZAGLIA, M.: Manuale di métrica italiana. Florencia: Sansoni, 1990, p. 82.

13 HAYES, B.: Metrical Stress Theory. Principles and Case Syudies. Chicago: The University of Chicago Press, 1995. 
El nombre de la localidad es Heathrów, con acentuación de la última sílaba. Pero si nos referimos al aeropuerto, la pronunciación es Héathrow Áirport, con acento en la primera sílaba para evitar el choque acentual con la sílaba inicial tónica de Áirport. Del mismo modo, la palabra thirteen, pronunciada habitualmente como thirtéen, cuando pasa a formar parte de la frase thirteen men, experimenta una inversión del acento: thírteen mén.

En cualquier caso, los meros criterios fonéticos y fonológicos no nos proporcionan un instrumento de análisis que pueda ser aplicable, sin más, al estudio de la métrica. Los mismos conceptos de sílaba y acento son problemáticos. La noción de sílaba, directa e intuitiva en la conciencia del hablante, es poco clara desde el punto de vista científico ${ }^{14}$. Si para la Real Academia Española, se trataría efectivamente de una noción más intuitiva que científica ${ }^{15}$, para la Academia Húngara la sílaba carecería prácticamente de «función lingüística» y consistiría en realidad en una «unidad rítmica» de base fisiológica y acústica ${ }^{16}$.

Para el metrista italiano Pietro Beltrami, que considera asimismo la sílaba como fundamento básico del ritmo, sería preferible llamarla «elemento rítmico», reservando para el verso la denominación de «unidad rítmica», y es desde luego una noción difícil de definir científicamente ${ }^{17}$. Con todo, a pesar de la oscuridad de la noción de «sílaba», no hay duda de que en el habla alienta una especie de «pulso»o «latido» (pulse phenomenon) que se percibe antes y mejor que los fonemas mismos ${ }^{18}$.

14 ROSA, F. de, y SANGIRARDI, G.: Introduzione alla metrica italiana. Milán: Sansoni, 1996, p. 20.

15 REAL ACADEMIA ESPAÑOLA: Esbozo de una nueva Gramática de la Lengua Española. Madrid: Espasa-Calpe, 1973, p. 12.

16 NYÉKI, L.: «Le rythme linguistique en français et en hongrois (Essai de prosodie contrastive) $\gg$, Langue Française. 19, 1973, pp. 120-142.

17 BELTRAMI, P. G.: Gli strumenti della poesia. Guida alla metrica italiana. Bolonia: Il Mulino, 1996, p. 31.

18 LOTZ, J.: «Metrics», en SEBEOK, Th. A., ed.: Current Trends in Linguistics, XII. La 
A la imprecisión del concepto de sílaba viene a añadirse el problema del contacto entre vocales, que puede dar origen a la unión o a la desunión silábica, esto es, a la zeuxis o la azeuxis. En el caso particular del verso francés, habrá que tener también en cuenta la cuestión de la $e$ muda. Diptongos y $e$ muda constituirían, para los exégetas del relativismo en la medida del verso, les points vulnérables du syllabisme $e^{19}$. El carácter inestable de la $e$ muda francesa amenazaría el silabismo en sus mismos fundamentos ${ }^{20}$. Algo similar ocurre en el estado actual de la lengua portuguesa, donde es habitual la elisión de las vocales átonas. En alemán, las frecuentes contracciones que se producen en el lenguaje ordinario plantean un análogo problema.

La preceptiva española tradicional consideraba los fenómenos de zeuxis (diptongo, sinéresis, sinalefa, sinafía) y azeuxis (hiato, diéresis, dialefa) como «licencias poéticas», es decir, como transgresiones de las leyes gramaticales, que se permitirían sólo en nombre de las «necesidades métricas». Desde luego no es así. Se trata simplemente de un hecho de habla, que el poeta utiliza de una manera intuitiva y espontánea.

También en los tratados de métrica italiana, se conceptúan frecuentemente estos fenómenos como transgresiones de la norma. Así, diéresis y sinéresis, por ejemplo, indicarían una escansión distinta de la «normal» ${ }^{21}$, y consistirían en pronunciar dos vocales contiguas en el interior de la palabra de forma diferente a la de la «norma italiana $»^{22}$. Se daría, en concreto, el fenómeno de la diéresis cuando se hacen «artificialmente» dos sílabas de lo que, en la lengua, constituye una sola ${ }^{23}$.

Haya: Mouton, 1974, pp. 963-978.

19 KIBÉDI VARGA, A.: Les constantes du poème. Analyse du langage poétique. París: Picard, 1977, p. 76.

20 Ibíd., p. 80.

21 BELTRAMI, P. G.: ob. cit., p. 34.

22 ORLANDO, S.: Manuale di metrica italiana. Bolonia: Bompiani, 1993, p. 26.

23 MENICHETTI, A.: «Per un nuovo manuale di metrica italiana», Metrica. IV, 
En alguna ocasión, la interpretación que reciben estos fenómenos son, en verdad, sorprendentes. Es lo que ocurre, por ejemplo, con el siguiente endecasílabo de Dante Alighieri (Par., XXXI, 37):

io, che al divino dall'umano

La lectura correcta es, sin duda alguna, la que introduce una diéresis en io (i-o) y una dialefa entre che y al (che-al). Pues bien, algún autor afirma que lo que existe no es una diéresis, sino una «sílaba silenciosa» (non una dieresi ma una sillaba silenziosa) ${ }^{24}$. Cuando el número de sílabas de un endecasílabo no fuera el de «once», se pasaría por alto la sílaba excesiva, o se pondría un silencio en lugar de la que faltara: la voce tende o a eliminare o a passare in sordina le sillabe eccesive, o a porre delle pause dove le sillabe sono mancat $i^{25}$.

La presencia de una pretendida «sílaba silenciosa» para completar el verso, interpretada como una «pausa», así como el pasar por alto o eliminar una sílaba cuando hay una de más, fueron ideas oportunamente tildadas de extravagantes por parte de la misma crítica italiana ${ }^{26}$.

A decir verdad, la escansión del verso puede entrañar algunas dificultades, aun en circunstancias aparentemente sencillas. Consideremos, por ejemplo, estos versos de Juan Ramón Jiménez:

Ya están las rosas primeras

dispuestas a embriagarnos.

La lectura del primer verso como octosílabo no ofrece la menor dificultad. Nadie dudaría en realizar la sinalefa o zeuxis (yaes) entre ya y es- (de están). En cambio, en el segundo verso, que también es un octosílabo de la serie arromanzada, podrían surgir discrepancias a la hora de su escansión. Habría dos posibles lecturas:

1986, p. 17.

${ }^{24}$ FUBINI, M.: Metrica e poesia. Lezioni sulle forme metriche italiane. Milán: Feltrinelli, 1975, p. 37.

${ }^{25}$ Ibid., p. 39.

${ }^{26}$ MENICHETTI, A.: Ob. cit., p. 7. 
1. Diéresis o azeuxis (bri-a) en embriagarnos y sinalefa o zeuxis (aem) entre a y em- (de embriagarnos):

dis-pues-tas-aem-bri-a-gar-nos

2. Dialefa o azeuxis (a-em) entre a y em- (de embriagarnos, sin diéresis o azeuxis):

dis-pues-tas-a-em-bria-gar-nos

La primera lectura es, sin duda, la correcta. Pero no disponemos de un procedimiento objetivo que nos permita demostrarlo científicamente.

Con el fin de obtener un correlato físico, objetivo, de los fenómenos fonéticos implicados en la escansión del verso, llevé a cabo, entre 1997 y 1998, diversas experiencias en el Laboratorio de Fonética de la Facultad de Filología, en la Universidad de Sevilla ${ }^{27}$. Como más representativas, se reproducen aquí las gráficas que recogen el oscilograma de intensidades y el espectrograma de la curva melódica, realizadas por ordenador con el sistema xwaves+ de Entropic para entorno UNIX, a partir de los siguientes versos de Federico García Lorca:

¿Qué es aquello que reluce por los altos corredores?

Cierra la puerta, hijo mío; acaban de dar las once.

El oscilograma recoge las intensidades de los sonidos emitidos en el decurso de la lectura de cada uno de los versos. Como es sabido, la intensidad acústica es la cantidad de energía que, en la unidad de tiempo, atraviesa una unidad de superficie situada perpendicularmente a la dirección de propagación de las ondas sonoras. Se mide en Watios $/ \mathrm{m}^{2}$, y es proporcional a la amplitud de la onda. Se observa, en las gráficas en el eje vertical de las ordenadas. La du-

27 TORRE, E.: El ritmo del verso. Estudios sobre el cómputo silábico y la distribución acentual, a la luz de la Métrica Comparada. Murcia: Universidad, 1999, pp. 42-50. 
ración se mide, en fracciones de segundo, sobre el eje horizontal de las abscisas.

El espectograma de la curva melódica aparece bajo el oscilograma, y nos da el tono musical, esto es, la frecuencia o número de ciclos por segundo de los sonidos emitidos. Se mide en Hercios sobre el eje vertical de las ordenadas. La duración va, al igual que en el caso del oscilograma, en fracciones de segundo sobre el eje horizontal de las abscisas. Es de advertir que la frecuencia que se recoge en esta curva melódica es la frecuencia fundamental, si bien existe un cierto número de armónicos, que determinan el timbre y que no se tienen en cuenta en el presente estudio. Intensidad, tono y timbre son las cualidades esenciales del sonido. La duración, en el terreno de la métrica, tiene un interés secundario.

Las gráficas más ilustrativas son las que corresponden a los tres últimos versos. El oscilograma del verso segundo (figura 1) refleja claramente la mayor intensidad de las sílabas impares, siendo ostensible la materialización del ritmo binario, trocaico:
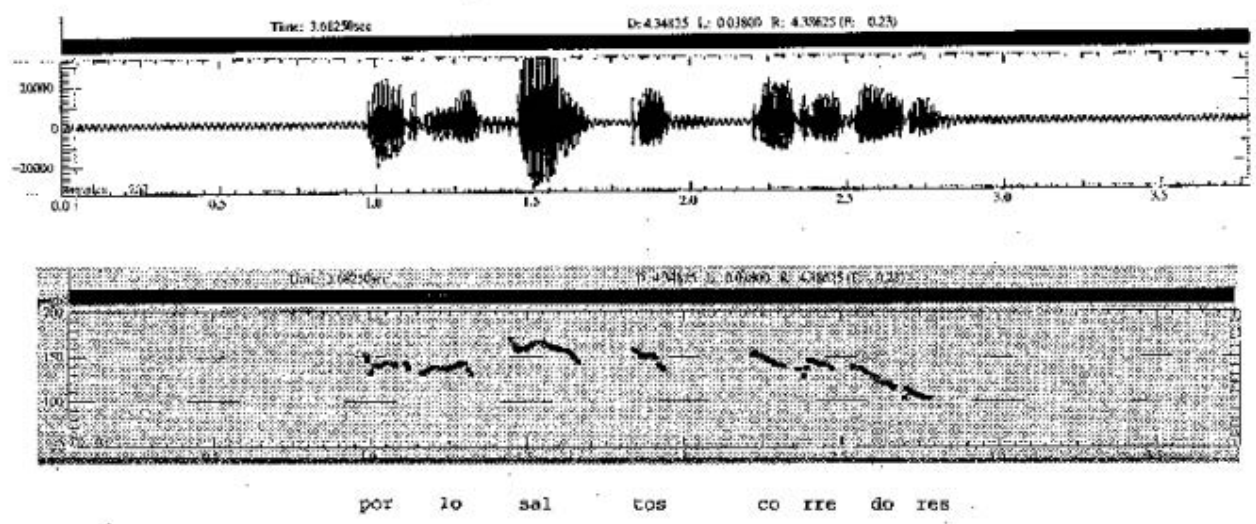

... por los altos corredores?

FiguRA I 
El oscilograma del verso tercero (figura II) nos muestra la existencia de un ritmo ternario, dactílico, siendo el segundo pie el más marcado. Obsérvese que hay zeuxis o sinalefa entre -ta (de puerta) e hi- (de hijo), por lo que el segmento «puerta, hijo» es una secuencia trisilábica (puér-tahi-jo), tal como se recoge en la fráfica del oscilograma.
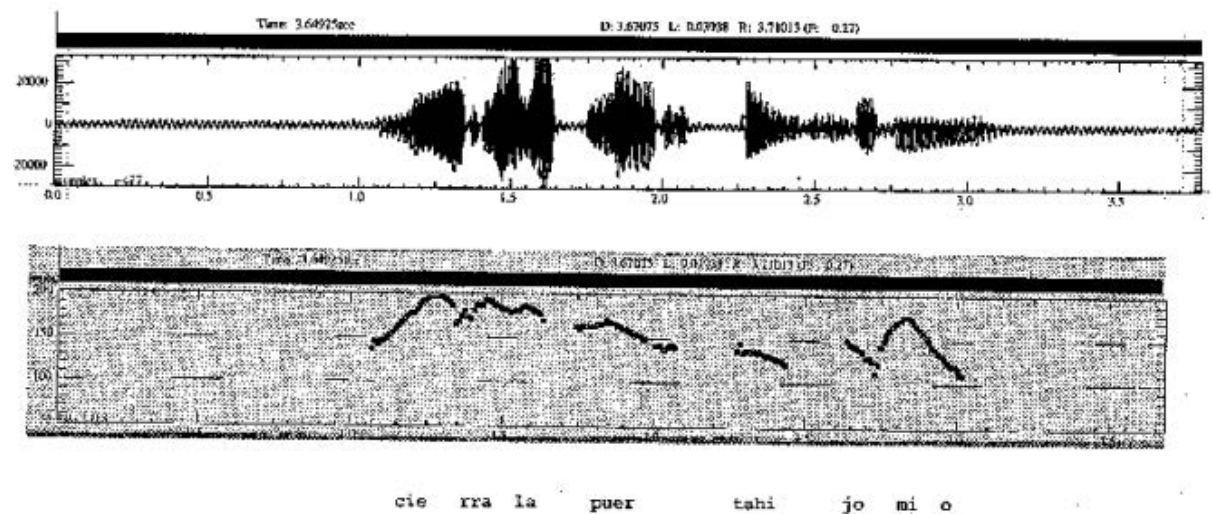

Cierra la puerta, hijo mío...

Figura II

El acento de la palabra aislada «hijo» queda anulado en la línea del verso. Pero, además, de la intensidad acústica, hay que tener en cuenta las diferencias tonales, que aparecen en el espectrograma. La palabra «hijo» conserva una cierta independencia con respecto a la palabra «puerta» en virtud de la frecuencia acústica, esto es, del tono, y no de la intensidad. Se da un cambio de tono entre puer-y-tahi-, lo cual confiere una matización acústica a esta última sílaba, átona según las intensidades acústicas, pero marcada por el cambio tonal.

El análisis acústico de la sílabas finales, mí-o, presenta asimismo un alto interés. El oscilograma no acusa diferencia alguna entre las 
intensidades de las dos sílabas. Al no existir entre amabas sílabas ningún tipo de cerrazón consonántica, no se interrumpe el fluir sonoro, como se aprecia en la gráfica. Es decir, el oscilograma no contiene señal alguna que nos permita establecer unos límites silábicos. En otras palabras: el oscilograma no distingue entre la zeuxis (mio) y la azeuxis $(m i-o)$. Ahora bien, el espectrograma muestra con toda claridad la gran diferencia tonal que existe entre mí- y-o. Aquí, el correlato físico del acento es, por lo tanto, el tono y no la intensidad.

Un desdoble del tono, como el que acabamos de ver, no implica necesariamente una duplicidad silábica. En la línea melódica correspondiente al cuarto verso (figura III), puede apreciarse cómo la sílaba final tónica, on- (de once), experimenta un desdoblamiento tonal muy marcado. Pero, en este caso, el segundo tono no corresponde a una unidad silábica independiente, sino a la sonoridad de la coda nasal:
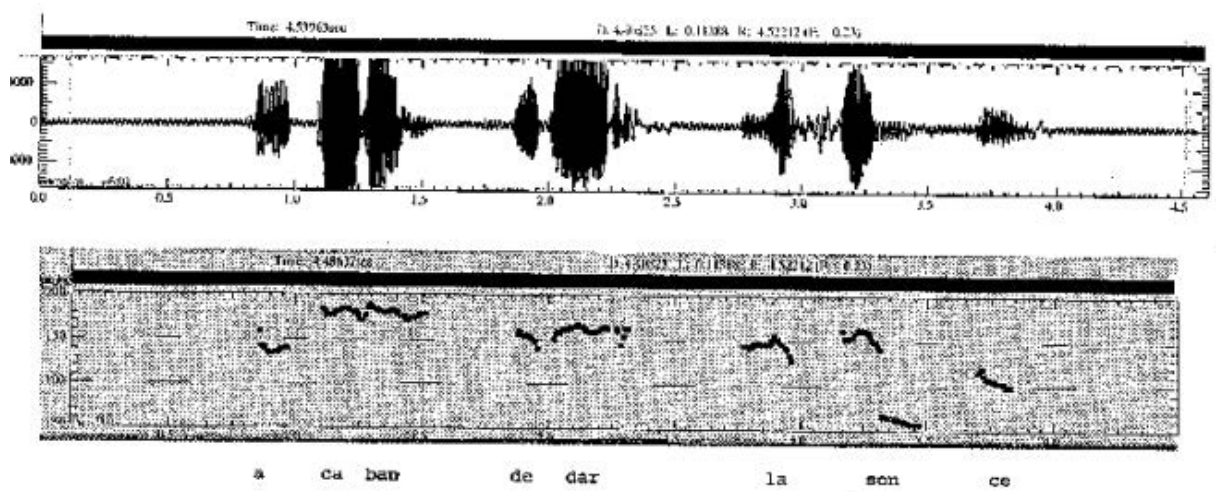

...acaban de dar las once.

Figura III 
Las aportaciones de la Fonética Acústica, las gráficas experimentales, no nos permiten distinguir, en consecuencia, las situaciones de zeuxis y azeuxis, que siguen perteneciendo, como la sílaba misma, al terreno de la intuición. En todo caso, constituyen un valioso punto de apoyo para los estudios métricos.

En el oscilograma de este mismo verso, aparece una clarísima distribución de las intensidades acústicas en tres grupos fónicos bien definidos: acában - dedár - lasónce. Utilizando, mutatis mutandis, la terminología de la métrica grecolatina, podríamos decir que el verso consta de los siguientes pies: anfíbraco, yambo y anfíbraco. Cualquier otro tipo de segmentación, que considerara como anacrusis la sílaba átona inicial de acaban, y tratara de adscribir el verso a un supuesto ritmo dactílico-trocaico, supondría no sólo el olvido del componente sintáctico-semántico del verso, sino también un total desconocimiento del mismo sustrato fónico que la gráfica del oscilograma pone de manifiesto.

En ocasiones, advertimos unas pautas muy sencillas en la disposición del acento: las sílabas se ordenan cíclicamente, en función de una relevancia acentual mayor (sílabas tónicas) o menor (sílabas átonas), de acuerdo con un patrón binario o ternario. Entraríamos, así, en el terreno de los llamados pies métricos o cláusulas. El concepto de pie métrico, como elemento intermedio entre la sílaba y la línea del verso, puede ser de utilidad en el análisis de la estructura rítmica. Pero también puede conducir a un abierto relativismo en lo que concierne al cómputo silábico, de tal manera que, considerándose superfluo el número exacto de sílabas, se llegue a negar toda entidad al verso como unidad rítmica.

Bien es verdad que, en un sentido diametralmente opuesto, existen también actitudes ciertamente fetichistas en relación con la medida del verso. No faltan en la bibliografía interpretaciones mágicas en torno al valor simbólico del número de sílabas. Así, por ejemplo, se ha querido ver en la proporción $5 / 7$ del haiku japonés una especie de prefiguración de la sección áurea, que representaría en el arte el ideal de una perfecta proporcionalidad estética: 
This proportion [...] is almost like the proportion of the golden section, which represents in art the desire for aesthetic balance ${ }^{28}$.

Sin caer en formulaciones mágicas, o relativistas, hay que hacer constar que la determinación del número de sílabas es esencial para la definición del verso español moderno, independientemente del factor rítmico que introduce la alternancia acentual. En la percepción del verso, como tal verso, el fundamental el carácter iterativo que representa la igualdad exacta en el número de sílabas. Cierto es que existe un límite en lo que podríamos llamar capacidad métrica para el reconocimiento de la igualdad silábica en un conjunto de versos.

Para la lengua francesa, este límite ha sido, de hecho, fijado en ocho sílabas, o en menos ${ }^{29}$. En la lengua italiana, la capacidad métrica o competenza metrica es pertinente en secuencias que no excedan las ocho o nueve sílabas ${ }^{30}$. En secuencias algo mayores, como el endecasílabo, una pausa sintáctica o semántica descompondría el verso en miembros menores.

Para Benoît de Cornulier, todas las métricas son en realidad silábicas y numéricas. El que las diversas clases de sílabas (tónicas y átonas, largas y breves) puedan disponerse en un cierto orden, según las diferentes formas de la alternancia, no quita nada al hecho de la numeración. El cómputo de las sílabas sería lo decisivo, tanto en las lenguas modernas europeas como en las clásicas: compter différemment selon qu'elles sont longues ou breves n'est pas cesser de compter ${ }^{31}$. En el caso concreto del verso francés, dicho autor llega a prescindir por completo del factor acentual: la mesure $d u$ vers français se définit simplement en termes de nombre syllabique ${ }^{32}$.

28 YASUDA, K.: The Japanese Haiku: Its Essential Nature, History, and Possibilities in English, with Selected Examples. Tokyo: Charles E. Tuttle, 1963, p. 61.

29 CORNULIER, B. de: Théorie du vers. Rimbaud, Verlaine, Mallarmé. París: Seuil, 1982, p. 90.

30 MORONI, G.: Appunti di ritmica e metrica. In margine a una trascurata teoria musicale del ritmo poetico. Bolonia: Cooperativa Libraria Universitaria, 1995, p. 79.

${ }^{31}$ CORNULIER, B. de: Ob. cit., p. 65.

${ }^{32}$ Ibid., p. 288. 
Es obvio que tales criterios métricos no pueden ser aplicados indiscriminadamente al verso español. En los llamados versos de arte menor, como el octosílabo de los romanes, o el hexasílabo y el heptasílabo de los romancillos y las endechas, la métrica se basa ciertamente en el número de sílabas, mientras que los distintos patrones de distribución acentual son prácticamente marginales. En cambio, en los versos de grupos fónicos o cláusulas, es fundamental la posición del acento, que se distribuye de una manera totalmente regular. Es el caso del decasílabo simple o del tridecasílabo, que están constituidos por series de grupos trisilábicos anapésticos:

...me he quedado mirando a la luna a través de las finas acacias.

JUAN RAMÓN JiMÉnEZ

Yo palpito, tu gloria mirando sublime, noble autor de los vivos y varios colores.

Gertrudis Gómez de Avellaneda

En lo que concierne al endecasílabo, el número de sílabas es condición necesaria, pero no suficiente, para la constitución del verso. La distribución acentual, siguiendo alguno de los patrones rítmicos canónicos, es aquí absolutamente precisa. En cualquier caso, hay que reconocer que contar las sílabas -en el marco de la moderna teoría literaria y sobre la base de los más recientes avances tecnológicos de la Fonética Acústica- es una tarea inicial, ineludible, para los estudios métricos. 


\section{ACENTOS RÍTMICOS, METARRÍTMICOSY PARARRÍTMICOS}

U

$\mathrm{N}$ exhaustivo análisis de los versos endecasílabos del libro de poemas Ancia de Blas de Otero, así como el estudio métrico de algunos otros textos poéticos, pone de manifiesto el papel de los acentos principales o rítmicos, y los secundarios o metarrítmicos. En un eventual choque de sílabas tónicas, pertenecientes a palabras adyacentes, la prominencia del acento rítmico o metarrítmico anula o debilita el acento de la sílaba contigua. Podemos llamar pararrítmico este acento.

En la línea sintagmática del lenguaje poético, al igual que en el decurso del lenguaje ordinario, se aprecia la existencia de un cierto patrón rítmico, consistente en la alternancia de sílabas acentuadas e inacentuadas. El principio de alternancia, o lo que es lo mismo, de eufonía o eurritmia (prefiero esta grafía, eurritmia, a la académica euritmia, que puede llevar y lleva a una errónea prosodia), parte de la observación de que las lenguas evitan la sucesión de sílabas con el mismo grado de tensión, haciendo que alternen con mayor o menor regularidad las sílabas fuertes con la sílabas débiles.

En algunas lenguas, puede llegarse al desplazamiento acentual con el objeto de asegurar el principio de eufonía. Así, en inglés, mediante la regla de «inversión yámbica», se impide la sucesión de dos sílabas tónicas. Es bien conocido el ejemplo del sintagma 
thirteen men. Como palabra aislada, el acento de thirteen recae en la segunda sílaba (thirtéen); pero, en la frase, la mayor prominencia de men (mén) impide la pronunciación thirtéen mén y determina la inversión del acento de la primera palabra: thírteen mén. Tiene lugar, así pues, un desplazamiento acentual (stress shift). En otros casos, el choque acentual que produciría la presencia de dos acentos consecutivos se resuelve mediante la anulación de uno de los dos acentos. Así, en italiano ${ }^{33}$, la cittá vécchia pasa a ser la cittavécchia. Del mismo modo, en catalán ${ }^{34}$, secuencias como molí nét (molino limpio) y molinét (molinillo) se perciben como homófonas. En español, nombres de pila como Miguel Ángel o José Luis se pronuncian respectivamente Miguelángel y Joseluís. La pérdida del acento en una de las dos palabras se puede dar también en ausencia del choque acentual: José Antonio > Joseantonio, José María > Josemaría.

Algunos estudios han puesto de manifiesto la existencia de formas de rechazo al choque acentual, que tendría lugar sólo en determinadas circunstancias ${ }^{35}$. El sintagma primer niño (primér níno) pasaría a ser primerníno. Sin embargo, en la expresión azul claro (azúl cláro) conservarían el acento tanto la palabra azul como la palabra claro. Habría entre ellas un cierto intervalo de silencio o pausa. Parece esto aceptable en el lenguaje ordinario. Pero, en el verso, con sus hábitos y modelos rítmicos peculiares, las cosas podrían ser diferentes. Veamos las siguientes secuencias versales:

un cielo de azul claro entre las nubes este cielo de azul claro entre nubes

33 NESPOR, Marina y VOGEL, Irene: «On clashes and lapses». Phonology, 1989, 6, pp. 69-116.

34 PRIETO, Pilar: «Efectos de coarticulación tonal en choques acentuales», en HERRERA, Esther y BUTRAGUEÑO, Pedro (eds.), La tonía: dimensiones fonéticas y fonológicas. México: Colegio de México, 2003, pp. 187-218.

35 ALMEIDA, Manuel: «Alternancia temporal y ritmo en español». Verba, 1993, 20, pp. 433-443. 
Ningún lector avezado en la escansión del verso pondría reparos a la siguiente medida:

un.cie.lo.dea.zul.clá.roen.tre.las.nú.bes

es.te.cie.lo.dea.zúl.cla.roen.tre.nú.bes

La neutralización del acento en la primera o en la segunda de las dos sílabas tónicas depende del contexto rítmico. No constituye el acento en la línea del verso una entidad absoluta, sino relativa. La sílaba acentuada lo es siempre en relación a un entorno. Una sílaba, con relieve acentual en la palabra aislada, puede perderlo en la línea del verso. Y, a su vez, una sílaba menos relevante puede experimentar un incremento acentual por su posición en el verso, la entonación o el énfasis que se ponga en la lectura para destacar el sentido.

La posición de los acentos en el verso coincide, generalmente, con la de las sílabas tónicas de cada una de las palabras que lo integran. Pero no siempre es así. Puede ocurrir, como es el caso que nos ocupa, que entren en contacto dos sílabas tónicas, pertenecientes a palabras consecutivas. En estas circunstancias, como quiera que la sílaba tónica o más acentuada lo es siempre en relación a un entorno de sílabas átonas o menos acentuadas, una de las dos sílabas en contacto deberá ser relativamente más acentuada, asumiendo así el papel de sílaba tónica. La imposibilidad de que existan dos acentos rítmicos contiguos ${ }^{36}$ viene a confirmar el principio de eufonía o eurritmia.

Podemos denominar acento pararrítmico al de la palabra aislada que ocupa una posición menos relevante en la línea del verso, quedando neutralizado ante la presencia del acento rítmico. En el primero de los ejemplos más arriba propuestos, la palabra azul pierde el acento de su sílaba final ante la prominencia de la sílaba inicial de la palabra claro. En el segundo ejemplo, es la sílaba final de la palabra azul la más prominente en relación con la sílaba inicial de la palabra claro, que queda neutralizada. En ambos casos, la sílaba $6^{a}$

36 Vid. PAMIES BERTRÁN, Antonio: «Los acentos contiguos en español». Estudios de fonética experimental, 1994, 6, pp. 91-111. 
es la más prominente, y sobre ella recae el acento rítmico: clá- (de claro), en el primer ejemplo, y zúl- (de azul), en el segundo.

Con el fin de obtener un correlato físico, objetivo, de los fenómenos fonéticos implicados en la escansión del verso, se llevaron a cabo en 1998 diversas experiencias ${ }^{37}$ en el Laboratorio de Fonética de la Universidad de Sevilla. Fueron oportunamente publicadas las gráficas que recogen tanto el oscilograma de las intensidades acústicas como el espectrograma de la curva melódica, realizadas por ordenador. Se puso en estas experiencias de manifiesto que el acento rítmico está en función no sólo de la intensidad acústica, sino también de la frecuencia fundamental o tono de cada una de las sílabas. En cambio, la duración o cuantificación temporal, en fracciones de segundo, carece de relevancia.

En cualquier caso, conviene no perder de vista que las nociones de sílaba y acento, que constituyen en definitiva el armazón rítmico del verso, tienen una base fundamentalmente intuitiva, y su análisis corresponde al dominio de la métrica, la poética y la estética. La Fonética acústica, por una parte, y la Fonología métrica, por otra, proporcionan al metrista una ayuda sin duda valiosa; pero en la ciencia del verso intervienen factores que van más allá de lo estrictamente gramatical o lingüístico. Se trata de elementos fónicos peculiares, de cuya combinación oportuna surge el efecto acústico agradable que llamamos eufonía, debiendo tenerse en cuenta que esta combinación de elementos puede también conducir al fenómeno contrario a la eufonía, esto es, a la cacofonía. La diferencia es de orden estético. Es evidente que los meros criterios fonéticos y fonológicos no nos proporcionan un instrumento de análisis que pueda ser aplicado, sin más, al estudio de la métrica.

Los mismos conceptos de sílaba y acento son problemáticos. La noción de sílaba es tan poco clara, desde un punto de vista científico, como intuitiva en la conciencia de todo hablante. Si para la Real Academia Española se trata efectivamente de una noción más intuitiva que científica, para la Academia Húngara la sílaba carece

${ }^{37}$ Vid. TORRE, Esteban: El ritmo del verso. Murcia: Universidad de Murcia, 1999. 
prácticamente de función lingüística y consiste tan sólo en una unidad rítmica, de base fisiológica y acústica, cuya existencia depende de la convención y el uso de una determinada comunidad lingüísti$\mathrm{ca}^{38}$. En realidad, la sílaba no tiene en sí misma valor fonológico alguno, a no ser como unidad portadora de un acento. Pero el acento viene a su vez definido, tautológicamente, por un mayor relieve de la sílaba acentuada. La sílaba remite al acento, y el acento a la sílaba.

El rendimiento del acento, como unidad suprasegmental, fonológica, distintiva de significados, es realmente insignificante en español, y nulo en otras lenguas. Lo que de verdad interesa en el acento es su carácter melódico, que se inserta en la línea discursiva o versal con una alternancia de sílabas tónicas, o más acentuadas, y átonas, o menos acentuadas, lo que origina una especie de pulso o latido rítmico.

Generalmente se adscribe el acento, considerado como el alma indiscutida del ritmo, a la intensidad del sonido, esto es, a la cantidad de energía acústica. Pero, además de la intensidad, hemos de tener en cuenta el tono, esto es, la frecuencia o número de ciclos vibratorios por segundo. Habría que considerar también otra cualidad del sonido, el timbre, determinado por los armónicos que acompañan a la frecuencia fundamental del tono. Como es sabido, el timbre no depende de la fuente del sonido, sino de la caja de resonancia, que en el caso que nos ocupa es la cavidad bucal. Podríamos así hablar de un cierto timbre vocálico. Combinado este timbre con el juego aliterativo de los sonidos consonánticos, puede reforzarse y afinarse el ritmo básico que produce la mera distribución acentual. Veámoslo en el siguiente poema de Blas de Otero:

Es a la inmensa mayoría, fronda de turbias frentes y sufrientes pechos, a los que luchan contra Dios, deshechos de un solo golpe en su tiniebla honda.

38 Vid. TORRE, Esteban: Métrica española comparada. Sevilla: Universidad de Sevi1la, 2000. 
A ti, y a ti, y a ti, tapia redonda

de un sol con sed, famélicos barbechos,

a todos, oh sí, a todos van, derechos,

estos poemas hechos carne $y$ ronda.

Oídlos cual al mar. Muerden la mano

de quien la pasa por su hirviente lomo.

Restalla al margen su bramar cercano

y se derrumban como un mar de plomo.

$¡ A y$, ese ángel fieramente humano

corre a salvarnos, y no sabe cómo!

Se trata del soneto inaugural del libro Ancia. La solemnidad y el dramatismo del poema encuentran un adecuado punto de apoyo en la fuerza expresiva del endecasílabo sáfico. Diez de los catorce versos llevan el acento en las sílabas $4^{\mathrm{a}}$ y $8^{\mathrm{a}}$. Como más adelante tendremos ocasión de ver, esta clase de versos es generalmente muy inferior en número a la de los endecasílabos comunes, acentuados en la sílaba $6^{a}$. En el presente soneto, en cambio, sólo son endecasílabos comunes los versos 5, 6, 7 y 9. De estos cuatro versos, tres $(5,6$ y 9) llevan el acento de la sílaba $6^{\mathrm{a}}$ sobre monosílabo tónico, existiendo acento pararrítmico en la sílaba $7^{\text {a }}$ en los versos 5 y 9.

Prestemos atención al choque de los acentos de las sílabas $6^{\mathrm{a}}$ y $7^{\mathrm{a}}$, acentos «rebotados», o ribattuti, en el sentir de algunos metristas italianos. En el primero de estos dos versos, la insistencia aliterativa de la dental sorda culmina en el encuentro ti-ta, con contraste en el timbre de $i$ y $a$. En el segundo verso, el encuentro mar-muer, con contraste en el timbre de $a$ y $e$, se prolonga en una aliteración de nasales. El choque de las sílabas tónicas de las palabras aisladas ( $t i$ y tapia, mar y muerden) es un elemento más que se añade a las similitudes y a los contrastes de la expresividad fónica. Obsérvense ahora los versos 6 y 7 . El lector avezado en la audición del verso endecasílabo percibirá fácilmente cómo el modelo básico de los cuatro versos citados es idéntico: acento rítmico en la sílaba $6^{a}$. Pero, evidentemente, hay 
otras facetas rítmicas, entre las que cabe destacar el contraste aliterativo entre sol y sed. En el último de estos versos, existe unión silábica o zeuxis entre sí $y$ a, unión que conforma la sílaba $5^{\circ}$, contigua a la $6^{a}$ tónica. En este caso, es clara la neutralización del acento pararrítmico de la sílaba $5^{\circ}$, sia, frente a la $6^{\text {a }}$, tó-, de mayor prominencia.

En cuanto a los endecasílabos sáficos del citado soneto, son de destacar las aliteraciones y el simbolismo fónico de los versos de los versos 2 y 12 . El armazón rítmico del verso consiste ahora en acentuación de las sílabas $4^{\mathrm{a}}$ y $8^{\mathrm{a}}$, además (obviamente) de la $10^{\mathrm{a}}$. En lo que concierne al endecasílabo, que es el verso más estrictamente pautado de la versificación española, tales son los esquemas acentuales básicos: acentos rítmicos en la sílaba $6^{\mathrm{a}}$ y $10^{\mathrm{a}}$, en el llamando endecasílabo común, o bien en las sílabas $4^{\circ}, 8^{a}$ y $10^{\mathrm{a}}$, en el denominado endecasílabo sáfico.

Pero, naturalmente, además de estos acentos principales o predominantes, que pueden ser considerados fundamentales o constituyentes del verso y que venimos llamando rítmicos, existen otros acentos secundarios, que podemos llamar metarrítmicos, que contribuyen a mantener y flexibilizar el ritmo, evitando el riesgo de la monotonía. En el endecasílabo común, el acento metarrítmico puede incidir sobre alguna o algunas de las sílabas $1^{\mathrm{a}}, 2^{\mathrm{a}}, 3^{\mathrm{a}}, 4^{\mathrm{a}}$ y $8^{\mathrm{a}}$. Los acentuados en $1^{\mathrm{a}}, 2^{\circ} \mathrm{o} 3^{\mathrm{a}}$ suelen denominarse enfáticos, heroicos y melódicos respectivamente. En lo que respecta al endecasílabo sáfico, el acento metarrítmico puede corresponder a las sílabas $1^{\text {a }}$, $2^{\mathrm{a}}$ o $6^{\mathrm{a}}$.

Son acentos pararrítmicos los situados en sílabas contiguas a los acentos rítmicos. Ocurre esto antes o después de la sílaba $6^{a}$, y antes de $10^{a}$, en el endecasílabo común, es decir, en las sílabas $5^{\mathrm{a}}$, $7^{\mathrm{a}} \mathrm{y}$ $9^{a}$. En el endecasílabo sáfico, son pararrítmicos los situados antes o después de las sílabas $4^{a}$ y $8^{a}$, es decir, en las sílabas $3^{a}, 5^{a}, 7^{a}$ y $9^{a}$. También son pararrítmicos los situados en sílabas contiguas a cualquiera de las portadoras del acento metarrítmico.

Conviene distinguir claramente entre los acentos rítmicos y metarrítmicos, por una parte, y los acentos pararrítmicos, por otra. 
Los primeros son realmente acentos del verso, mientras que los pararrítmicos son acentos de la palabra aislada, que se encuentran neutralizados en la línea del verso, pero que juegan también un papel importante en la matización del ritmo con el breve silencio que se inserta entre las sílabas afectadas y con la inflexión tonal que se da entre ellas. Esto viene a sumarse al juego aliterativo de las consonantes y el fluctuante timbre de las vocales.

Con el fin de precisar el valor de estos términos, atendamos al silabeo o escansión de los versos del citado soneto. Se marca con una tilde los acentos rítmicos y metarrítmicos:

és.a.lain.mén.sa.ma.yo.rí.a.frón.da

Acentos rítmicos en las sílabas $4^{\mathrm{a}}, 8^{\mathrm{a}}$ y $10^{\mathrm{a}}$, y metarrítmico en $1^{\mathrm{a}}$.

de.túr.bias.frén.tes.y.su.frién.tes.pé.chos

Acentos rítmicos en las sílabas $4^{\mathrm{a}}, 8^{\mathrm{a}}$ y $10^{\mathrm{a}}$, y metarrítmico en $2^{\mathrm{a}}$.

a.los.que.lú.chan.contra.diós.des.hé.chos

Acentos rítmicos en las sílabas $4^{\mathrm{a}}, 8^{\mathrm{o}}$ y $10^{\mathrm{a}}$.

deun.só.lo.gól.peen.su.ti.nié.bla.hón.da

Acentos rítmicos en las sílabas $4^{\mathrm{a}}, 8^{\mathrm{a}}$ y $10^{\mathrm{a}}$, metarrítmico en $2^{\mathrm{a}}$ y pararrítmico en $1^{\text {a }}$.

a.tí.ya.tí.ya.tí.ta.pia.re.dón.da

Acentos rítmicos en las sílabas $6^{\mathrm{a}}$ y $10^{\mathrm{a}}$, metarrítmicos en $2^{\mathrm{a}}$ y $4^{\mathrm{a}}$, y pararrítmico en $7^{\mathrm{a}}$.

deun.sól.con.séd.fa.mé.li.cos.bar.bé.chos

Acentos rítmicos en las sílabas $6^{\mathrm{a}}$ y $10^{\mathrm{a}}$, metarrítmicos en $2^{\mathrm{a}}$ y $4^{\mathrm{a}}$, y pararrítmico en $1^{\mathrm{a}}$.

a.tó.dos.óh.sía.tó.dos.ván.de.ré.chos

Acentos rítmicos en las sílabas $6^{a}$ y $10^{a}$, metarrítmicos en $2^{\mathrm{a}}$ y $4^{\mathrm{a}}$, y pararrítmico en $5^{\mathrm{a}}$. 
és.tos.po.é.mas.hé.chos.cár.ney.rón.da

Acentos rítmicos en las sílabas $4^{\mathrm{a}}, 8^{\mathrm{a}}$ y $10^{\mathrm{a}}$, y metarrítmicos en $1^{\mathrm{a}}$ y $6^{\mathrm{a}}$.

o.íd.los.cual.al.már.muer.den.la.má.no

Acentos rítmicos en las sílabas $6^{\mathrm{a}}$ y $10^{\mathrm{a}}$, metarrítmico en $2^{\mathrm{a}}$ y pararrítmico en $7^{\mathrm{a}}$.

de.quien.la.pá.sa.por.suhir.vién.te.ló.mo

Acentos rítmicos en las sílabas $4^{\mathrm{a}}, 8^{\mathrm{a}}$ y $10^{\mathrm{a}}$.

res.tá.llaal.már.gen.su.bra.már.cer.cá.no

Acentos rítmicos en las sílabas $4^{\mathrm{a}}, 8^{\mathrm{a}}$ y $10^{\mathrm{a}}$, y metarrítmico en $2^{\mathrm{a}}$.

y.se.de.rrúm.ban.co.moun.már.de.pló.mo

Acentos rítmicos en las sílabas $4^{\mathrm{a}}, 8^{\mathrm{a}}$ y $10^{\mathrm{a}}$, y pararrítmico en $7^{\mathrm{a}}$.

ay.é.se.án.gel.fié.ra.mén.tehu.má.no

Acentos rítmicos en las sílabas $4^{\mathrm{a}}, 8^{\mathrm{a}}$ y $10^{\mathrm{a}}$, metarrítmicos en $2^{\mathrm{a}} \mathrm{y}$ $6^{\mathrm{a}}$, y pararrítmico en $1^{\mathrm{a}}$.

có.rrea.sal.vár.nos.y.no.sá.be.có.mo

Acentos rítmicos en las sílabas $4^{\mathrm{a}}, 8^{\mathrm{a}}$ y $10^{\mathrm{a}}$, metarrítmico en $1^{\mathrm{a}} \mathrm{y}$ pararrítmico en $7^{\mathrm{a}}$.

No cabe duda de que el choque acentual más llamativo es el que tiene lugar entre las sílabas $6^{\mathrm{a}}$ y $7^{\mathrm{a}}$ del endecasílabo común. Para mejor precisar el alcance de este fenómeno acústico, en el presente trabajo se ha llevado a cabo un análisis rítmico de la totalidad de los versos endecasílabos del libro Ancia de Blas de Otero. Hacen un total de 1026 endecasílabos, de los que 560 corresponden a 40 sonetos y 466 a otras composiciones. De estos 1026 endecasílabos, 824 llevan acento en las sílabas $6^{\circ}$ y $10^{a}$, y 202 en $4^{a}$ y $8^{a}$. Como podemos ver, la cifra de endecasílabos comunes cuadriplica la de los sáficos. 
De los 824 endecasílabos comunes, se da el choque acentual entre las sílabas $6^{\mathrm{a}}$ y $7^{\mathrm{a}}$ en 112 ocasiones. Casi siempre ocurre que el acento de la sílaba $6^{\mathrm{a}}$ corresponde a un monosílabo tónico o una palabra aguda. Sólo en 9 casos el acento rítmico de la sílaba $6^{a}$ incide sobre palabra llana. En estas circunstancias, tiene lugar la unión silábica o zeuxis entre la sílaba postónica de la palabra llana y la inicial tónica de la palabra siguiente:
desesperadamente, esa es la cosa
ser hombre, y estar solo es estar solo
humanamente hablando, es un suplicio
ser hombre y soportarlo hasta las heces
el abismo adelante abre sus hélices
humanamente hablando, es lo que digo
la sombra es brava y vivo es el cuchillo
humanamente en tierra, es lo que digo
tu sed de Dios. Mi reino es de este mundo

Lo más frecuente es que el choque acentual de las sílabas $6^{a}$ y $7^{\text {a }}$ se produzca cuando el acento de la sílaba $6^{\mathrm{a}}$ corresponda a un monosílabo tónico o a una palabra aguda. Ocurre esto 103 veces. He aquí la lista completa de los casos, que nos ilustra sobre la gran frecuencia con que se da esta circunstancia métrica:
a ti, y a ti, y a ti, tapia redonda
oídlos cual al mar. Muerden la mano
por las manos de Dios, ¡cómo procura
la tierra: girasol, poma madura
del ansia, ciega luz. Quiero tenerte
oh Dios. Si he de morir, quiero tenerte
y sigo, muerto, en pie. Pero te llamo
y sigo, muerto, en pie. Pero te amo
dentro del corazón, cargas de nieve
oh témpano mortal, río que vuela
ancléame en tu mar, no me desames
y todo lo demás? Basta la muerte 
pero mortal, mortal, rayo partido tu silencio inmortal; quiere que grite mas no todo ha de ser ruina y vacío $y$, entre raíz mortal, fronda de anhelo mi corazón en pie, rayo sombrío oh, cállate, Señor, calla tu boca se oye del corazón casi parado dentro del corazón cava su nido como atándome a Él... Solo y desnudo clamoreando amor, tiendo, sacudo los brazos bajo el sol: signos lejanos al cielo! Mudo soy. Pero mis brazos me haces daño, Señor. Quita tu mano tengo bastante. Oh Dios, si eres humano compadécete ya, quita esa mano y miedo. Si eres Dios, yo soy tan mío no se sabe por qué. Quiero cortarte arriado de raíz, sobre la tumba dirán: Esto que veis, fue Blas de Otero vivir. Saber que soy piedra encendida y yo de pie, tenaz, brazos abiertos gritando no morir. Porque los muertos se mueren, se acabó, ya no hay remedio en cal hirviente, en pie, patas arriba pero vivir, seguir, aunque se hundiesen aquí me tienes, Dios. Soy Blas de Otero escucha cómo estoy, Dios de las ruinas no sé quién eres tú, siendo Dios mío hincando en Dios el pie, parto de vuelo Le da miedo mirar. Cierra los ojos un algo, qué sé yo qué, misterioso capaz de comprender esta agonía y el viento, vengador, viene y va, estira nadie, nadie; caer, no llegar nunca y el abrazo final es esa franja entonces, y además cuando da miedo 
hemos sufrido ya tanto silencio

del hombre; hambre inmortal; sed siempre en vilo somos pasto de luz. Llama que va cuerpo de la mujer, alma de oro al Inasible. ¡Ah, sí! Pero el suplicio y fui llama en furor. Pasto de luz en finísima luz y aguas de oro qué hacer, hombre de Dios, sino caerte de púrpura hasta el pie. Tañen mis dedos mademoiselle Isabel, rubia y francesa Isabel..., tu jardín tiembla en la mesa al ras del mirabel, tiros donceles esa tierra con luz es cielo mío música celestial, dame tu vida y yo quiero escuchar sólo esa herida de unas alas de Dios, de una luz rosa cuerpo de la mujer, río de oro un relámpago azul, unos racimos cuerpo de la mujer, fuente de llanto la soledad de dos. Y una cadena que no suena, ancla en Dios almas y limos tiras de mi raíz, subes mi muerte porque busco ese horror, esa cadena sintiendo, ipor qué, oh Dios!, que eso no basta de Dios, hambre de Dios, sed abrasada trago trozos de mar y agua rosada senos las olas son, suave el bandazo labio con labio, ¿ves?, esto es un beso y encizañó la luz ante los ojos con los puños... Mujer, dame tu hombro dije: Mi soledad es como un árbol dije: Mujer, mi mal no tiene origen sufro, no sé por qué. De esto hace mucho abre tu soledad. Deja que el llanto un perpendicular pie sobre el suelo caiga quien caiga, ¡ahé!, pese a quien pese 
poetas tentempié, gente ridícula

y cuerpo. Y por mi voz toman el aire

que os unja de agua y luz, bajo la carne

de cuerpos. Sobre Dios saltan de golpe

¿os da miedo, verdad? Sé que es más cómodo

os ayude a ser. Soy. Luego es bastante

de ansia de Dios. Con ser hombres os basta

que ya no puede más. Pero nosotros

limosna: manos no, garras insomnes

no son ángeles ya, no voladores

no son ángeles ya, sino quemadas

y un golpe, no de mar, sino de guerra

besas y lloras. ¿Ves? Yo beso, lloro

al principio creó Dios cielo y tierra

¿qué podemos hacer, qué luz alzarles?

tiempo de soledad es éste. Suena

ellos, en son de sol; ellas, de blanco

siempre la sangre, oh Dios, fue colorada

ahora vuelvo a mi ser, torno a mi obra

Tras una sílaba $6^{\mathrm{a}}$ acentuada, correspondiente a monosílabo tónico o palabra aguda, puede ocurrir que todas las sílabas siguientes sean átonas hasta la $10^{\text {a }}$. Sucede esto en 79 casos. Veamos algunos ejemplos:

sostenernos en pie y en hermosura

archivando la luz en la garganta

imagine mi horror por un momento

cadáver interior apuntalado

Puede existir también acento metarrítmico en $8^{a}$. Sucede esto en 102 ocasiones. He aquí algunos ejemplos:

nadie quiso nacer. Ni nadie quiere

silencio. Yerto mar. Soneto mío

nuestros cuerpos a Dios, desnudos, bellos

grima me da vivir, pasar el rato 
También podemos encontrar un acento pararrítmico en $9^{a}$. Se dan 10 casos. He aquí algunos:

que tiene corazón y que está vivo no sé en qué sangre o red, como un pez rojo

saber que somos luz, y sufrir frío

del vivir y el morir. Lo demás sobra

En 5 ocasiones existe acento metarrítmico en $8^{\mathrm{a}}$ y pararrítmico en $9^{a}$ :
verte un momento, oh Dios, después no verte
entonces ¿para qué vivir, oh hijos
trabas al sueño. Oh Dios, si aun no estoy muerto
Isabel, canta en él o si él es ésa
a ver si vuelve Dios. A ver qué pasa

En total, encontramos 399 endecasílabos con acento rítmico en la sílaba $6^{a}$, correspondiente a monosílabo tónico o palabra aguda. Si tenemos en cuenta que la cifra de endecasílabos comunes es 824 , vemos que la proporción aquí entre monosílabos tónicos o palabras agudas y la totalidad de las palabras, incluidas las llanas y esdrújulas, es aproximadamente de 1:2, es decir, muy superior a la del uso habitual de los vocablos en la lengua española, donde, como es sabido, predomina la palabra llana. Se trata, sin duda, de un rasgo estilístico del dramático clamar de la poesía de Blas de Otero39. El carácter incisivo del monosílabo tónico o de la sílaba tónica de

\footnotetext{
39 Un análisis rítmico, por ejemplo, de los 770 endecasílabos contenidos en los 55 sonetos del libro Sonetos espirituales, de Juan Ramón Jiménez, nos muestra la existencia de 575 endecasílabos comunes, de los cuales 179 llevan el acento de la sílaba $6^{\mathrm{a}}$ sobre monosílabo tónico o palabra aguda ( 35 de ellos con choque acentual). Como puede verse, la proporción entre monosílabos tónicos o palabras agudas y la totalidad de las palabras es ahora aproximadamente 1:3, sensiblemente inferior a la proporción 1:2 de los endecasílabos de Ancia. En ambos casos, es llamativa la frecuencia del acento de la sílaba $6^{\mathrm{a}}$ sobre monosílabo tónico o palabra aguda, con o sin choque acentual, lo que nos debe llevar a considerar este tipo de acentuación como algo habitual en la métrica española..
} 
la palabra aguda en posición $6^{a}$ cumple, sin duda, un importante papel de expresividad fónica.

En 408 casos el acento de la sílaba $6^{a}$ incide sobre palabra llana. Por ejemplo:

esta rosa redonda, reclinada

mientras la Tierra sigue a la deriva

montañas que se yerguen como altares

plumas de luz al aire en desvarío

En 17 casos, incide sobre palabra esdrújula. He aquí algunos de estos endecasílabos:

de un sol con sed, famélicos barbechos

desolación y vértigo se agolpan

y yo sabré la música ardorosa

del clavel, con la rúbrica del labio

Que el acento de la sílaba 6a incida sobre palabra aguda, llana o esdrújula, y que tras esa sílaba no haya más acentos hasta la 10a o que por el contrario exista acento metarrítmico en $8^{a}$, o pararrítmico en $7^{\mathrm{a}}$ o $9^{\mathrm{a}}$, no son más que matices o variedades del ritmo fundamental del endecasílabo común. Y, a todo esto, hay que añadir la posible existencia de acentos metarrítmicos o pararrítmicos antes de la sílaba $6^{a}$. Pero extremar las distinciones y los criterios taxonómicos a nada conduciría.

Quizá el choque acentual de las sílabas 6a y $7^{\mathrm{a}}$ sea el que ha suscitado un mayor interés. Para el profesor Márquez Guerrero, «la secuencia de los dos acentos facilita que el verso se realice y se oiga como un verso con dos hemistiquios», por lo que esta variedad de endecasílabo tendría «cierto aire de seguidilla» ${ }^{40}$. Se trata de una atinada observación, que no obstante convendría matizar. ¿Es el choque acentual el que posibilitaría la lectura del verso como un dodecasílabo del tipo $7+5$ ? ¿No sería más bien el acento de la sílaba

${ }^{40}$ MÁRQUEZ GUERRERO, Miguel Ángel: «Endecasílabos con acentos en 6a y $7^{\mathrm{a}}$ sílabas». Rhythmica. Revista Española de Métrica Comparada, 2012, X, pp. 115-132. 
$6^{a}$ sobre palabra aguda, por sí solo, sin necesidad de un acento pararrítmico en 7a, el que podría incitar a la audición del endecasílabo como verso compuesto? Cualquiera de las formas ya analizadas serviría para tal efecto:

\author{
*a ti, y a ti, y a ti, / tapia redonda \\ *sostenernos en pie / y en hermosura \\ *nadie quiso nacer. / Ni nadie quiere \\ *que tiene corazón / y que está vivo \\ *verte un momento, oh Dios, / después no verte
}

Todas estas formas podrían funcionar, desde luego como dodecasílabos $7+5$ en un contexto dodecasilábico. Y también, en lo que respecta al endecasílabo sáfico, podemos encontrar choques acentuales entre las sílabas $4^{\mathrm{a}}$ y $5^{\mathrm{a}}$ :

no sin temblor, sí con vaivén de vela muro de luz. Leve, sellado, ileso

$\mathrm{Y}$, sin choque acentual, hallamos endecasílabos sáficos cuyo acento de sílaba $4^{\mathrm{a}}$ incide sobre monosílabo tónico o palabra aguda:

ahoga mi voz en el vacío inerte mástil, bauprés, arboladura mía

En todos estos casos, sería posible efectuar una lectura de los versos como dodecasílabos 5+7:

*no sin temblor, / sí con vaivén de vela

*muro de luz. / Leve, sellado, ileso

*ahoga mi voz / en el vacío inerte

*mástil, bauprés, / arboladura mía

También ahora es el acento de la sílaba $4^{a}$ sobre monosílabo o palabra aguda, por sí solo, y no el choque acentual de $4^{\text {a }}$ y $5^{\text {a }}$, la causa de una posible lectura como verso compuesto. 
A propósito de los endecasílabos con acento en la sílaba $4^{\mathrm{a}}$, correspondiente a monosílabo tónico o sílaba tónica de palabra aguda, hemos de recordar lo que sucede en el llamado «endecasílabo a la francesa», que aparece en alguno de los poemas del libro Baladas de primavera de Juan Ramón Jiménez:

Dios está azul. La flauta y el tambor anuncian ya la $\mathrm{cruz}^{41}$ de primavera. ¡Vivan las rosas, las rosas del amor entre el verdor con sol de la pradera! («Balada de la mañana de la cruz»)

Quédate en mí, soy pobre y soy poeta, huyó en blanco pegaso la fortuna, y quiero oír tu alegre pandereta cuando florezca la nieve de la luna...

(«Balada de la mujer morena y alegre»)

Los versos que llevan el acento de la sílaba $4^{\mathrm{a}}$ sobre monosílabo tónico o palabra aguda serían aquí, como versos simples, endecasílabos comunes, ya que tienen acento en la sílaba $6^{\mathrm{a}}$ y no en la $8^{\mathrm{a}}$. Pero los versos restantes, cuyo acento de sílaba $4^{\mathrm{a}}$ incide sobre palabra llana, constan indudablemente de doce sílabas. ¿Cómo podrían ser llamados endecasílabos? ¿Considerándolos como versos compuestos, con cesura tras la sílaba $4^{\text {a }}$ de palabra aguda o monosílabo tónico, o tras la sílaba $5^{\text {a }}$ de palabra llana? Si así fuera, nos encontraríamos ante una serie de versos dodecasílabos del tipo 5+7:

Dios está azul. / La flauta y el tambor anuncian ya / la cruz de primavera. ¡Vivan las rosas, / las rosas del amor entre el verdor / con sol de la pradera!

Quédate en mí, / soy pobre y soy poeta, huyó en mi blanco / pegaso la fortuna,

${ }^{41}$ En una variante, aparece $l u z$ en lugar de cruz. Es irrelevante a los efectos métricos. 
y quiero oír / tu alegre pandereta

cuando florezca / la nieve de la luna...

Si recurrimos a los criterios de la métrica francesa, que no computa como sílabas métricas las postónicas de palabra final de verso o hemistiquio (que, en la lengua francesa, tienen que construirse necesariamente sobre la llamada e muda como núcleo vocálico), haríamos la siguiente escansión:

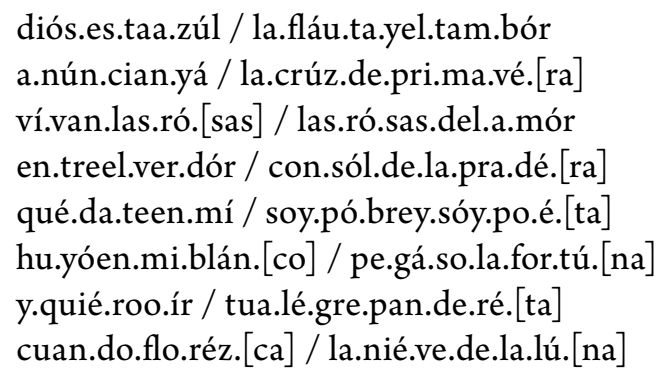

Es cierto que, contando las sílabas «a la francesa», serían versos de 4+6 sílabas, esto es, décasyllabes, que en español equivalen a los endecasílabos. Pero no tiene sentido aplicar unos criterios que, de ser generalizados, nos obligarían a llamar dodecasílabos a los versos alejandrinos, heptasílabos a los octosílabos del romance y decasílabos a los endecasílabos del soneto, sin hacer distinción alguna entre versos simples y compuestos en lo que concierne al cómputo silábico.

Los citados versos de Juan Ramón Jiménez son, sin lugar a dudas, versos compuestos, dodecasílabos del tipo $5+7$, que se adaptan muy bien al conjunto de los poemas del libro Baladas de primavera, en el que encontramos abundantes ejemplos de dodecasílabos del tipo 5+7, y del 6+6, así como decasílabos simples con acentos en las sílabas $3^{\text {a }}, 6^{\text {a }}$ y 9 a , y decasílabos compuestos $4+6$ y $5+5$, ritmos todos ellos propios del movimiento modernista en que se insertan. Nada de esto tiene que ver con el libro Ancia, ni con el conjunto de la obra juanramoniana, ni con la poesía clásica, ni con la poesía 
actual, donde el predominio del endecasílabo hace impensable una segmentación de este verso en dos hemistiquios.

En el ritmo del verso intervienen, así pues, muchos factores. En el caso concreto del verso endecasílabo, el armazón básico viene dado por la posición de los acentos principales que venimos llamando rítmicos. Otros acentos, secundarios, han recibido a veces el nombre de extrarrítmicos, término híbrido de una etimología latina (extra) y otra griega (rhythmós). Sería preferible decir metarrítmicos. Por otra parte, no existen acentos obstruccionistas o antirrítmicos, que vendrían a contradecir la eufonía del verso. No hay acentos contiguos en la línea del verso. Por definición, la sílaba acentuada lo es en un entorno. No es que las sílabas contiguas carezcan de acento, ya que todas las sílabas han de tener una determinada intensidad acústica para que sean perceptibles, sino que su acento es menor que el de la sílaba que ocupa la posición privilegiada. Veamos, finalmente, un ejemplo muy sencillo e ilustrativo en la famosa «Sonatina» de Rubén Darío:

La princesa está triste... ¿Qué tendrá la princesa?

Los suspiros se escapan de su boca de fresa, que ha perdido la risa, que ha perdido el color.

La princesa está pálida en su silla de oro, está mudo el teclado de su clave sonoro, y en un vaso, olvidada, se desmaya una flor.

En estos alejandrinos, versos compuestos $7+7$, cada hemistiquio tiene un ritmo marcadamente ternario, con acentos en las sílabas $3^{a}$ y $6^{a}$. Este ritmo es, por lo demás, simple y reiterativo, y nos induce a leer «está triste» como «estatriste», «está pálida» como «estapálida», y «está mudo» como «estamudo»:

la.prin.cé.saes.ta.trís.te / que.ten.drá.la.prin.cé.sa

la.prin.cé.saes.ta.pá.[li].da / en.su.sí.lla.de.ó.ro

es.ta.mú.doel.teclá.do / de.su.clá.ve.so.nó.ro 
Es evidente que el acento de la palabra está ha desaparecido en la línea sintagmática. No funciona en el verso. Si queremos referirnos, en la línea del verso, al acento de la sílaba -tá de la palabra aislada, podemos utilizar el término pararrítmico, que no es propiamente acento del verso, pero que está ahí, como matiz de la sílaba en la palabra aislada, y que contribuye a flexibilizar y enriquecer la eufonía rítmica.

Quizá pueda pensarse que ese acento pararrítmico no ha desaparecido totalmente, sino que está sólo atenuado, o que se ha producido un cambio tonal entre la sílaba que soporta el acento rítmico o metarrítmico y la sílaba contigua, o que se ha intercalado un breve silencio entre las dos sílabas. En cualquier caso, esto ocurrirá siempre que tenga lugar un choque acentual entre una sílaba tónica en la palabra aislada y una sílaba tónica marcada por el acento rítmico o metarrítmico, en todo tipo de versos y en todas las posiciones. La casuística de estos hipotéticos choques acentuales sería interminable, y su estudio a nada nos llevaría.

En definitiva, y hablando con propiedad, no existen, no pueden existir, acentos contiguos en el verso español. De las supuestas sílabas tónicas en contacto, una de ellas, la que ocupa la posición marcada por el acento rítmico o metarrítmico, es la que posee la más alta intensidad acústica, es decir, ese latido rítmico que llamamos acento. Los relieves acústicos de la sílaba o las sílabas adyacentes, acentos realmente existentes en las palabras aisladas, quedan neutralizados en la línea del verso. Nos hemos venido refiriendo a ellos con el nombre de pararritmicos. 


\section{VERSOS DE FINALAGUDO, GRAVE Y ESDRÚJULO}

$\mathrm{E}$

$S$ un hecho reconocido por todos los metristas que, en lo relativo al cómputo silábico, existe una equivalencia entre los versos de terminación llana con $x$ sílabas, los de terminación aguda con $x-1$ sílabas y los de terminación esdrújula con $x+1$ sílabas. Dicho de otra manera: en los versos de terminación aguda se cuenta una sílaba más, y en los de terminación esdrújula una sílaba menos. Las explicaciones que se han venido dando a este fenómeno son por lo demás diversas.

Ya los primeros preceptistas advirtieron esta circunstancia. Muy ilustrativo es el testimonio de Juan Díaz de Rengifo, autor español del siglo XVI, que compara en su Arte poética los siguientes versos ${ }^{42}$ :

las flores odoríferas

el árbol que se trasplantó

Ambos versos constan de ocho sílabas -escribe-, y no por eso son «de redondilla». La razón es que «faltó el accento en la penúltima, que auía de ser larga $\gg$. Y puntualiza que «no basta que el verso tenga las syllabas que le convienen, y que no tenga más, ni menos, sino es menester que lleue la quantidad que dentro de su especie pide».

42 DÍAZ RENGIFO, Juan: Arte poética española. Salamanca: Miguel Serrano de Vargas, 1892, p. 21. 
En efecto, los octosílabos castellanos -versos «de redondilla»más frecuentes son los de terminación llana. $\mathrm{El}$ «accento» recae en ellos en la penúltima sílaba, que, según Rengifo, «auía de ser larga», esto es, tónica. La «quantidad» es aquí un confuso recuerdo de la calidad de las sílabas, largas y breves, de las lenguas clásicas. El tratadista no hace más que seguir los modelos de la gramática clásica y la preceptiva tradicional al uso, según los cuales se identificaban las sílabas largas con las tónicas, y las breves con las átonas.

En los citados ejemplos, las flores odorificas es un verso que termina en palabra esdrújula, mientras que el árbol que se trasplantó lo hace en palabra aguda. Ambos constan realmente, o gramaticalmente, si se quiere, de ocho sílabas. Pero, rítmicamente, el primero sólo tiene siete, y el segundo alcanza la cifra de nueve. No son, por lo tanto, verdaderos octosílabos o versos de redondilla.

Ya a finales del siglo xv, Juan del Encina había identificado las sílabas breves con las átonas y las largas con las tónicas: «Y avemos de notar que sílabas breves en el romance llamamos todas las que tienen el acento baxo, y luengas o agudas se dizen las que tienen alto el acento ${ }^{43}$. Considera Juan del Encina como luenga la última sílaba de los versos con final agudo, y así cuenta una sílaba más «quando la última es luenga, que entonces vale por dos, y tanto tardamos en pronunciar aquella sílaba como dos» ${ }^{44}$.

Los prestigiosos tratados de poética del renacimiento italiano abundan en la misma visión de la cantidad silábica. Así, en las Prose della volgar lingua ${ }^{45}$ (1525) de Pietro Bembo, se afirma que en nuestro vulgar siempre es larga la sílaba portadora del acento, y breves las demás. En los versos agudos, la sílaba final pesa mucho y vale por dos; de ahí que haya de contarse una sílaba más. Por el contrario,

${ }^{43}$ ENCINA, Juan del: Arte de poesía castellana (1496), en LÓPEZ ESTRADA, Francisco (ed.): Las poéticas castellanas de la Edad Media. Madrid: Taurus, 1984, pp. 89-90.

${ }^{44}$ Ibíd., p. 87.

45 BEMBO, Pietro: Prosas de la lengua vulgar. Ed. bilingüe. Trad. esp. de Oriol Miró Martí. Madrid: Cátedra, 2011. 
en los esdrújulos, las sílabas finales son ligeras, y hay que contar una sílaba menos ${ }^{46}$.

En la Poetica ${ }^{47}$ (1529 y 1562), una de las principales obras en lengua toscana del humanista italiano Giovan Giorgio Trissino, se sostiene que es breve la sílaba que «se profiere en poco espacio de tiempo», y larga «la que en más», de tal manera que «se tarda tanto en proferir una sílaba larga como dos breves». Piensa el tratadista que en la lengua toscana sigue habiendo sílabas largas y breves, y que «todo aquel que quiera considerar la longitud y brevedad de algunas sílabas, tanto graves como agudas, extraerá mucha utilidad de tal cosa y dará mucho ornamento a sus poemas ${ }^{48}$.

Del mismo modo, Antonio Sebastiano Minturno, en su tratado L'arte poetica ${ }^{49}$, advierte que al final del verso «crece una sílaba el esdrújulo, y falta una sílaba en aquel que lleva el acento en la última». En consecuencia, en el esdrújulo «dos sílabas valen por una», y en el agudo la última sílaba «vale por dos».

El conflicto entre la métrica silábico-acentual de las lenguas vernáculas, de raíces medievales, y la métrica cuantitativa, de corte latinizante y helenizante, defendida por los humanistas, da origen a distintas querellas, que se formulan y entablan en el renacimiento europeo entre los antiguos y los modernos. Destaca entre ellas la que tuvo lugar en la Inglaterra isabelina en torno al uso del verso rimado. Se podría pensar, tal vez, que la modernidad habría de estar del lado del humanismo renacentista. Pero no es así. Lo nuevo, lo moderno, es lo gótico, lo medieval; mientras que las actitudes renacentistas suponen una vuelta al pasado, a lo antiguo.

46 Vid. PARAÍSO, Isabel: «Las teorías métricas de Pietro Bembo en las Prose della volgar lingua (Prose nelle quali si ragiona della volgar lingua». Rhythmica, Revista Española de Métrica Comparada, 2012, X, 12, pp. 133-155.

47 TRISSINO, Giovan Giorgio: La Poética. Ed. bilingüe. Trad. esp. y estudio de Isabel Paraíso. Madrid: Arco/Libros, 2014.

48 Vid. TORRE, Esteban: «Giovan Giorgio Trissino: La Poética». Rhythmica, Revista Española de Métrica Comparada, 2014, XII, 12, pp. 211-215.

${ }^{49}$ MINTURNO, Antonio Sebastiano: Arte poética. Ed. bilingüe. Trad. esp. y estudio de Ma. del Carmen Bobes Naves. Madrid: Arco/Libros, 1009. 
Paradigma de esta apasionada polémica entre antiguos y modernos es la entablada en Inglaterra, en los albores del reinado de Jacobo I Estuardo, entre Thomas Campion y Samuel Daniel. En 1603, publica Samuel Daniel una Defence of Ryme en abierta oposición a las Observations in the Art of English Poesie, de Thomas Campion, impresas un año antes ${ }^{50}$. Para Thomas Campion, en la poesía, es fundamental el número (number), entendido no sólo como mero cómputo silábico, sino como expresión de. la calidad (value) de los sonidos largos o breves (the length or shortness of their sound), esto es, la cantidad silábica. Si los versos griegos y latinos se basaban en el número y en la cantidad silábica (number and quantitie of syllables), los versos ingleses se sustentan en la medida y el acento (measure and accent). Las sílabas de acentuación aguda, tónicas, y las sílabas de acentuación grave, átonas, harían el papel de largas y breves respectivamente.

Avanzado el siglo XVIII, Ignacio de Luzán escribe en su Poética que «en las lenguas española e italiana el accento agudo suple en cierto modo la cantidad, y hace que la sílaba parezca larga». En la primera mitad del siglo XIX, las ideas imperantes sobre esta materia seguirán siendo las mantenidas en la Poética de Luzán, publicada por primera vez en Zaragoza en 1737, y nuevamente en Madrid en 1789, como edición póstuma, corregida y aumentada por su mismo autor. Admite Luzán que la pronunciación «no se conserva ya en las lenguas vulgares tal como fue en la Griega y Latina», y que se ha perdido «aquella tan cabal y delicada distinción con que las sílabas largas se pronunciaban en dos tiempos, y las breves en uno». Pero, con todo, no puede acabar de creer que «nuestra pronunciación (hablo de Españoles e Italianos) quanto a las largas y breves sea totalmente diversa de la antigua, de modo que no haya quedado alguna distinción bastante para la harmonía poética $\gg^{51}$.

\footnotetext{
${ }^{50}$ Vid. DANIEL, Samuel: Defensa de la rima. Ed. bilingüe. Trad. esp. y estudio de Juan Frau. Prólogo de Esteban Torre. Valladolid: Universidad, 2011.

51 LUZÁN, Ignacio de: La Poética, o reglas de la poesía en general, y de sus principales especies, Ed. corregida y aumentada, tomo I. Madrid: Sancha, 1789, pp. 328-336.
} 
La identificación de las sílabas tónicas con las largas, y las átonas con las breves, es un prejuicio que en cierto modo ha llegado hasta nuestros días, no sólo en la aclimatación de los pies métricos grecolatinos (yambos, troqueos, dáctilos, etc.) a los actuales pies o cláusulas rítmicas, sino también en el cómputo silábico de las terminaciones agudas y esdrújulas, otorgándosele a la tónica final de la terminación aguda el valor de dos tiempos silábicos, y, a las dos sílabas postónicas de la terminación esdrújula, el valor de un solo tiempo silábico.

Serán Andrés Bello y Eduardo Benot, autores de los que me ocupo con algún detenimiento en sendos capítulos del presente libro, quienes liberen a la ciencia del verso del espejismo de la duración silábica y de la consiguiente distinción entre sílabas largas y breves. Pero, con todo, en este espejismo se verán involucrados en el siglo $\mathrm{xIX}, \mathrm{y}$ aun en el $\mathrm{xx}$, no sólo los teóricos de la métrica, sino también algún poeta de la talla de Rubén Darío. Cuando el gran poeta nicaragüense intenta aclimatar a la métrica española el hexámetro clásico, piensa que con el juego saltarín de sus cláusulas rítmicas ternarias ( «Ínclitas razas ubérrimas, sangre de Hispania fecunda...») estaría insuflando una nueva vida al antiguo sistema combinatorio de las sílabas largas y breves. Y, así, afirma categóricamente, en 1909, que «malgré la opinión de tantos catedráticos, hay sílabas largas y breves, y que lo que ha faltado es un análisis más hondo y musical de nuestra prosodia $\gg^{52}$.

Con toda seguridad, está Rubén Darío aludiendo, y también contradiciendo, a tratadistas como Andrés Bello y Eduardo Benot, que había publicado en 1892 un extenso tratado de métrica ${ }^{53}$, en el que se rebaten una y otra vez los criterios cuantitativos. Tal vez la referencia a un análisis más «musical» de nuestra prosodia esté relacionada con las tesis defendidas por Sinibaldo de Mas, autor

52 DARÍO, Rubén: Historia de mis libros (1909), en Obras completas, t. I, Crítica y Ensayo, Madrid: Afrodisio Aguado, 1950, p. 216.

53 BENOT, Eduardo: Prosodia castellana i versificación. Madrid: Pedro Núñez, [1892]. Ed. facsimilar al cuidado de Esteban Torre: Prosodia castellana y versificación. Anejo I (2003) de Rhythmica, Revista Española de Métrica Comparada. 
de un curioso libro titulado Sistema musical de la lengua castellana, cuya primera edición data de $1832^{54}$. Para Eduardo Benot, Sinibaldo de Mas fue uno de los «últimos representantes de lo antiguo ${ }^{55}$, y censura repetidas veces sus «extravagantes reglas ${ }^{56}$.

Parte Sinibaldo de Mas del supuesto de que las sílabas castellanas, al igual que las griegas y las latinas, pueden ser largas y breves, $y$ formula a este respecto una serie de teoremas o reglas para medir la cantidad silábica, al tiempo que establece una lista de doscientas sílabas breves (tales con las de las palabras día, iría o ileso) y otras tantas sílabas largas (las de circunstancias, obstrucción o industrias). Escribe Benot que Sinibaldo de Mas «hacía leer ambas listas con el reloj en la mano a quien quiera que le negaba la existencia de breves y largas». En cualquier caso, «el experimento no evidenciaba que hubiese en castellano sílabas relacionadas entre sí $2: 1 \gg^{57}$.

Hay, sin embargo, una observación de Sinibaldo de Mas sobre la equivalencia de finales agudos, graves y esdrújulos, que se encuentra en franca oposición a los criterios cuantitativos y que merece ser destacada ${ }^{58}$. Para este autor, los versos Mil placeres nos vienen de Dios (de nueve sílabas), Mil placeres nos dieron los dioses (de diez sílabas) y Mil placeres nos dieron los números (de once sílabas) son equivalentes. «Generalmente se ha creído -advierte- que un verso en final agudo tenía una sílaba menos, porque dicho agudo es largo $y$ vale por dos; pero esto es un error muy grave». La explicación del fenómeno, en efecto, «nada tiene que ver con la cantidad». Lo que ocurre es, sencillamente, que «el oído mide el verso por el último acento, y no por la última sílaba» ${ }^{59}$.

\footnotetext{
54 Vid. MAS, Sinibaldo de: Sistema musical de la lengua castellana. Ed. y estudio de José Domínguez Caparrós. Madrid: CSIC, 2001.

55 BENOT, Eduardo: Ob. cit., t. I, p. 166.

56 Ibíd., t. I, pp.184 y 394; y t. III, pp. 12, 18, 22 y 29.

57 Ibíd., t. I, p. 183; y t. III, p. 15.

58 Vid. TORRE, Esteban: «Sinibaldo de Mas: Sistema musical de la lengua castellana $\gg$. Lexis, 2002, XXVI, 2, pp. 613-616.

59 MAS, Sinibaldo de: Op. cit., p. 49.
} 
De inspiración musical es también la métrica de Miguel Agustín Príncipe, coetáneo de Sinibaldo de Mas. En su Arte métrica elemental ${ }^{60}$, dispuesta en forma de diálogo entre un joven aficionado a las Bellas Artes y el autor, nos habla de corcheas, semicorcheas, el «compás» y la «frase música». Como «frase música» entiende el verso desde la sílaba inicial hasta la última acentuada, esto es, el «conjunto o sucesión de sonidos que todo verso encierra como tal, a contar desde su primera sílaba hasta su postrera acentuada $\gg^{61}$. Rítmicamente, el verso termina en la última sílaba acentuada, «y esa sílaba es precisamente en la que termina la frase música, es decir, esa serie de sonidos que hacen que el verso sea ya en ella tal verso, independientemente de otras $u$ otras sílabas que puedan añadirse al fin ${ }^{62}$. Y es que, en efecto, «lo que esencialmente constituye al verso es solamente su frase música, o sea, el conjunto o sucesión de sus sonidos o sílabas, a contar desde la primera hasta su postrera acentuada» ${ }^{63}$. Según esto, no debería ser el verso llano, sino el sono-final o agudo, el que se tomara como punto de referencia para la denominación de los versos castellanos. De este modo, el octosílabo debería propiamente llamarse heptasílabo, el eneasílabo octosílabo, y así todos los demás ${ }^{64}$.

60 PRÍNCIPE, Miguel Agustín: Arte métrica elemental, o sea, tratado analítico de versificación castellana, en Fábulas en verso castellano y en variedad de metros. $2^{\mathrm{a}}$. ed. económica sin láminas. Madrid: Ibo Alfaro,1862 [la 1ª ed. con láminas es de 1861], pp. 385-662.

61 Ibid., p. 461.

62 Ibíd., p. 462.

63 Ibíd., p. 465.

64 Análogos criterios habrían de ser mantenidos más tarde por GRAÑA ETCHEVERRY, Manuel: «La equivalencia de los oxítonos, paroxítonos y proparoxítonos a fin de verso», Revista do Livro, 1957, II, 8, pp. 9-56. Sin embargo, los postulados métricos que subyacen en todo el trabajo de este autor sostienen que el verso está constituido por pies, por lo que deberíamos medir pies y no sílabas. Con lo cual, el armazón teórico de la equivalencia de finales oxítonos, paroxítonos y proparoxítonos se viene abajo, y automáticamente se deshace la unidad del verso. 
Acertada es la observación. Los versos de diez sílabas con terminación aguda, los de once sílabas de terminación llana y los de doce con terminación esdrújula tienen la misma medida rítmica, diez sílabas, hasta la última acentuada, y es por es esto por lo que son métricamente equivalentes. Los llamamos endecasílabos, ya que los de once sílabas de terminación llana son los más frecuentes en español, o en italiano. Pero los podríamos llamar también decasílabos, que es la denominación que encontramos precisamente en la métrica de algunas lenguas, como la inglesa (decasyllable), la portuguesa (decassílabo) o la catalana (decasíl.lab).

Joaquín Moreno Pedrosa analiza la influencia de los conceptos musicales de Miguel Agustín Príncipe en la teoría métrica de Antonio Carvajal, quien recoge los conceptos de compás y frase música de Miguel Agustín Príncipe, si bien prefiere atribuir la equivalencia de los finales agudos, llanos y esdrújulos a la duración de las sílabas. Así, en los finales agudos, habla de una mayor «resonancia» o duración del silencio que sigue a la sílaba final tónica, que estaría dotada de un acento «circunflejo ligado»; y, en los esdrújulos, se produciría una «síncopa». La palabra vendría a ser una especie de materia moldeable, plástica, elástica, que se podría expandir si termina en sílaba tónica, y contraer si es tónica la penúltima. Moreno Pedrosa conceptúa justamente esta explicación como «de un marcado carácter impresionístico, y carente de verificación contrastable ${ }^{65}$.

José Domínguez Caparrós, en referencia a las distintas explicaciones que, en la teoría métrica tradicional, se han tratado de dar a la equivalencia de finales agudos, graves y esdrújulos ${ }^{66}$, hace mención de ciertas investigaciones modernas, «fundadas en mediciones experimentales», que hablan de un desdoblamiento de la vocal

${ }^{65}$ MORENO PEDROSA, Joaquín: «El ritmo del verso en las poéticas contemporáneas: un ejemplo en la Generación del 70», Rhythmica, Revista Española de Métrica Comparada, 2014, XII, 12, pp. 109-124. Vid. también MORENO PEDROSA, Joaquín: Poesía y poética de Antonio Carvajal. Sevilla: Padilla, 2007.

${ }^{66}$ DOMÍNGUEZ CAPARRÓS, José: Contribución a la historia de las teorías métricas en los siglos XVII, XVIII y XIX. Madrid: CSIC, 1975, pp. 177-187; Métrica española. Madrid: Síntesis, 1993, pp. 72-73, y Madrid: UNED, 2014, p. 62. 
tónica final o de una equivalencia de sensación temporal o de tiempo psicológico. Se trata, respectivamente, de sendos trabajos de María Josefa Canellada y Jens Koed Madsen, y de Antonio Quilis. Convendría analizar detenidamente estas investigaciones, ya que, como enseguida veremos, no son más que variantes del empeño tradicional en fundamentar la equivalencia en la duración.

El desdoblamiento de la vocal tónica final, que ya defendía Vicente Salvá en el primer tercio del siglo XIX, la sido nuevamente invocado por María Josefa Canellada y Jens Koed Madsen ${ }^{67}$. Vicente Salvá, en su Gramática de la lengua castellana (1830), nos dice que «en las palabras que acaban por una vocal aguda, hace la voz una especie de compensación duplicándola», y así «pronunciamos desdén, vendrá como si estuviera escrito desdéèn, vendráà»; en cambio, «en los esdrújulos pasamos tan de corrido por la sílaba media entre la acentuada y la última que no se percibe, de modo que pronunciamos línea, máximo casi como si estuviese escrito lina, maxmo ${ }^{68}$. Por otra parte, asegura que «los autores que han escrito de la prosodia española han observado, desde los más antiguos, que también tenemos nosotros sílabas largas y breves, acentuadas o agudas y graves, y que no es indiferente emplear éstas o las otras para que el verso conste ${ }^{69}$.

Para Canellada y Madsen, tras el estudio de numerosas grabaciones, existe un «alargamiento», que puede llegar a ser un auténtico «desdoblamiento» de la vocal final. Los principales informantes fueron un hablante catalán y una niña de dos años y tres meses. En el caso del hablante catalán, la vocal final, «con la correspondiente velarización» (al en social) permite que se pueda apreciar el desdoblamiento (sociáal). Por su parte, la niña, que está aprendiendo a leer distingue y silabea muy bien palabras como tío, tía. Pero, cuando ve por primera vez escritas palabras como papá, mamá, trata de leerlas,

\footnotetext{
67 CANELLADA, María Josefa, y MADSEN, Jens Koed: Pronunciación del español. Lengua hablada y literaria. Madrid: Castalia, 1987.

68 SALVÁ, Vicente: Gramática de la lengua castellana según ahora se habla. Ed. de Margarita Lliteras. Madrid: Arco/Libros, p. 789.

69 Ibíd., p. 787.
} 
y pronuncia pa-pá-a, ma-má-a. De ahí deducen, sin más, Canellada y Madsen que en el verso ocurre lo mismo que en el habla del niño: «la vocal tónica final se desdobla». No es preciso indicar que el valor probatorio de tales observaciones es nulo, y que, por supuesto, no es extrapolable al terreno de la métrica.

El intento de fundamentar en la duración el fenómeno de la equivalencia en la percepción de los versos oxítonos, paroxítonos y proparoxítonos aparece claramente en un trabajo de Antonio Quilis $^{70}$, quien llega a hablar de la cantidad silábica, y la mide en centésimas de segundo. Los resultados obtenidos tras la medición del tiempo en la lectura de una serie de versos conducen al reconocimiento de que «los valores no son absolutos $»^{71}$, si bien existiría «una clara tendencia» hacia: 1) una mayor duración de la sílaba oxítona, y 2) una menor duración de las dos últimas sílabas de las palabras proparoxítonas.

De esta manera, la mayor duración de la sílaba oxítona justificaría la adición de una sílaba más en los versos de terminación aguda, y la menor duración de las dos sílabas postónicas nos llevaría al cómputo de una sílaba menos en los versos de terminación esdrújula. Al final del trabajo, se afirma que la equivalencia «no es de tiempo real, sino de sensación temporal». Años después, se sigue manteniendo que «la compensación temporal no es, evidentemente, de tiempo real, sino de percepción temporal ${ }^{72}$. Después de haber realizado una minuciosa cuantificación del tiempo cronológico, se

${ }^{70}$ QUILIS, Antonio: «La percepción de los versos oxítonos, paroxítonos y proparoxítonos en español». Revista de Filología Española, 1970, L, 1-4, pp. 273-286.

${ }^{71}$ El empeño en encontrar valores absolutos, con datos experimentales, aparece también en GILI GAYA, Samuel: «Introducción a los estudios ortológicos y métricos de Bello», en Obras completas. Estudios filológicos I, cit., p. LXXXVI: «Carecemos de comprobaciones experimentales que aclaren definitivamente la causa de que el acento agudo final de verso añada a éste una sílaba para el cómputo, y de que los finales esdrújulos valgan una sílaba menos».

72 QUILIS, Antonio: «Vigencia de las teorías ortológicas y métricas de Bello», en Homenaje a Andrés Bello en el bicentenario de su nacimiento (1781-1981), Diálogos hispánicos de Amsterdam, no 3. Amsterdam: Rodopi, 1982, p. 151. 
recurre a la noción de tiempo psicológico o vivencial, concepto relativista que carece de toda aplicación práctica en lo que concierne al cómputo silábico.

Más que en los criterios de la cantidad silábica, que no tiene en español ni en otras lenguas modernas justificación alguna, la explicación de la equivalencia de finales agudos, graves y esdrújulos ha de ser buscada en la concepción del verso como unidad rítmica, la consideración de la pausa como límite de la unión y la separación de los versos, y el reconocimiento del carácter culminante de la última sílaba acentuada. En esta última sílaba termina realmente el verso. La pausa es el factor demarcativo esencial, distinguiendo y separando los versos en la serie poemática. En virtud de la pausa, la última sílaba acentuada del verso adquiere un carácter culminante, por lo que el verso termina realmente en esta sílaba. Incluir en el cómputo silábico una sílaba más, postónica, en el caso de las terminaciones llanas, es algo que pertenece al dominio de lo convencional y forma parte del acervo de una tradición literaria.

Si después de la última sílaba acentuada, y precediendo a la pausa, aparece una sílaba átona (en las palabras llanas), o aparecen dos sílabas átonas (en las palabras esdrújulas), es algo que carece de interés desde el punto de vista métrico. De ahí que los siguientes versos de León Felipe tengan equivalencia métrica ${ }^{73}$ :

este dolor de no tener ya lágrimas que ya no es más que arruga y sequedad mecanismo, sin lágrimas, del llanto

En el primer verso, de terminación esdrújula, contamos doce sílabas; en el segundo, de terminación aguda, con las pertinentes sinalefas, apreciamos diez sílabas; y en el tercero, de final grave, once sílabas. Pero los tres presentan equivalencia métrica. Y no tiene sentido el tratar de restar o sumar sílabas arbitrariamente. Lo que ocurre es que todos estos versos tienen la misma medida, diez sílabas, hasta la última acentuada, y por este motivo son métricamente equivalentes.

${ }^{73}$ Vid. TORRE, Esteban: Métrica española comparada. Sevilla: Universidad, 1999. 
Los podemos llamar «decasílabos», tal como se hace precisamente en los sistemas métricos de otras lenguas, como la inglesa, la portuguesa o la catalana. En español, o en italiano, donde los versos de final esdrújulo o agudo son excepcionales, se optó por tomar como punto de referencia el verso de terminación llana, de once sílabas, dándoles a todos ellos en consecuencia la denominación de «endecasílabos».

En un tratado de métrica catalana, Salvador Oliva advierte de una manera explícita que, al escandir, el verso, ha seguido siempre la convención catalana, segons la qual el nombre de síl.labes es compta des de la primera de tots a l'última tònica ${ }^{74}$. Y esto es también aplicable a los hemistiquios. Así, por ejemplo, el alejandrino, con dos hemistiquios separados por la cesura, constará de doce sílabas.

Idénticos criterios se siguen en los actuales tratados de versificación portuguesa, en los que sólo se cuenta hasta la última sílaba acentuada: Metricamente, a contagem das sílabas apenas se faz até ao último acento tónico ${ }^{75}$. Y se nos advierte que el proceso de cómputo silábico que suprime las átonas del verso não deve ser tomado por mera convenção, ya que se asienta en el hecho de que, en virtud de la pausa final del verso, las sílabas átonas no desempeñan un papel rítmico: equivalen a sílabas de transição, de caída suave de la voz en el silencio.

Las sílabas átonas finales fueron incluidas por Tomás Navarro Tomás en el llamado período de enlace, «en el que se suman la última sílaba acentuada, las inacentuadas finales, las sílabas de esta misma clase iniciales del verso inmediato y la pausa intermedia» ${ }^{76}$. Con el concepto de «período de enlace» se escamotea el problema de los finales llanos y esdrújulos, a la vez que se conculca el principio de la unidad del verso. La última sílaba acentuada, en la que culmina el

${ }^{74}$ OLIVA, Salvador: Mètrica catalana. Barcelona: Quaderns Crema, 1980, p. 5.

${ }^{75}$ CARVALHO, A. de: Tratado de versificação portuguesa. Coímbra: Almedina, 1991, pp. 16-22.

${ }^{76}$ NAVARRO TOMÁS, Tomás: Arte del verso, 4ª ed. México: Colección Málaga, 1968, pp. 21-22. 
ritmo del verso, y la pausa, que marca precisamente la frontera entre los versos, pasan a ser meros elementos integrantes del supuesto período de enlace. Como período rítmico interior se considera únicamente la parte del verso comprendida entre la primera sílaba acentuada y la que precede a la última tónica. Las sílabas átonas que preceden a la primera tónica vendrían a ser una especie de preludio o anacrusis, término que tiene un origen musical ${ }^{17}$.

El concepto de período rítmico, que constituye uno de los puntos fundamentales de la teoría del verso de Tomás Navarro Tomás, es para el autor checo Oldrich Belic uno de los más problemáticos. Aduce Belic que, según esa teoría, el verso quedaría reducido desde el punto de vista rítmico al período interior, es decir, «deja de existir como unidad rítmica», siendo así que, por el contrario, la versología moderna sostiene que «la unidad rítmica fundamental es el verso, todo el verso $\gg^{78}$.

Para Belic es muy significativo el hecho de que incluso un hispanista como el alemán Rudolf Baehr, que funda su concepción del ritmo versal español en la teoría de Navarro Tomás, no encuentre muy convincente que se sacrifique la unidad del verso al concepto de «período de enlace». De ahí que lo sustituya por el de «final de verso» (Versausgang), que comprendería la última sílaba acentuada, las postónicas y la pausa ${ }^{79}$. Por su parte, Francisco López Estrada, que traduce al español, junto con Klaus Wagner, la obra de Baehr ${ }^{80}$, considera como período de enlace sólo la «parte final» del verso, que va «desde la última sílaba tónica hasta el fin del verso ${ }^{81}$.

77 ORLANDO, Sandro: Manuale di métrica italiana. Bolonia: Bompiani, 1993, p. 15.

78 BELIC, O.drich: En busca del verso español. Praga: Univerzita Karlova, 1975, pp. 25-26.

79 BAEHR, Rudolf: Spanische Verslehre auf historischer Grundlage. Tübingen: Max Niemeyer, 1962, p. 8.

${ }^{80}$ BAEHR, Rudolf: Manual de versificación española, ed. y trad. esp. de F. López Estrada y K. Wagner. Madrid: Gredos, 1970

81 LÓPEZ ESTRADA, Francisco: Métrica española del siglo XX. Madrid: Gredos, 1969 , p. 57. 
Hace ver el profesor praguense que, si en algunos tipos de versos hay elementos rítmicos inferiores (pies métricos, por ejemplo), éstos carecen de entidad autónoma: «existen sólo dentro del verso, en función de él, y, sobre todo, respetando su unidad $\gg$. E insiste en el carácter culminante de la última sílaba acentuada del verso, en franca contradicción con el sistema de Navarro Tomás, donde esta sílaba no es sino el comienzo del período de enlace, por lo que «se halla ya como fuera del verso». En cuanto al concepto mismo de anacrusis, lo rechaza como algo «totalmente arbitrario» ${ }^{82}$.

Una firme defensa de las teorías de Tomás Navarro Tomás, frente a las objeciones de Oldrich Belic, fue realizada por María Josefa Canellada ${ }^{83}$. Pero ninguna de sus razones resultan convincentes. Llega a admitir la existencia de sílabas átonas «fuera de cuento» no sólo en el principio del verso, sino también en el interior del propio período rítmico. Y, así, nos habla de las admirables posibilidades rítmicas de la combinación de troqueos y dáctilos con pausas $\ll y$ alguna que otra sílaba suelta ${ }^{84}$. Es obvio que, con estos criterios, no se puede elaborar una teoría coherente del cómputo silábico, y mucho menos del ritmo.

Así pues, y en lo que concierne a la cuestión de la equivalencia de los versos con terminación aguda, llana o esdrújula, no parece que exista ninguna dificultad para la comprensión de un fenómeno que ha venido siendo admitido por la generalidad de los preceptistas, y que ha sido observado en la praxis común de la creación poética, siempre y cuando que se tengan en cuenta los siguientes principios teóricos: 1) la concepción del verso como unidad

${ }^{82}$ BELIC, Oldrich: Análisis estructural de textos hispanos. Madrid: Prensa Española, 1969, p. 181.

83 CANELLADA, María Josefa: «Sobre el ritmo de los versos españoles», Boletín de la Real Academia Española, LV, CCIV, 1975, pp. 421-427; «Más sobre el ritmo de los versos españoles (los pies)», Archivum, XXV, 1975, pp. 131-134; «Sobre el ritmo de versos españoles (algunas precisiones a Oldrich Belic) $\gg$, Revista de Dialectología y Tradiciones Populares, XXXIII, 1-4, 1976, pp. 83-86.

${ }^{84}$ CANELLADA, María José: «Sobre el ritmo de los versos españoles (algunas precisiones a Oldrich Belic)», cit., p. 85. 
rítmica, 2) la consideración de la pausa como límite de la unión y separación de los versos, y 3) el reconocimiento del carácter culminante de la última sílaba acentuada.

Problema distinto es el de la nomenclatura de los versos. ¿Habría que dar el nombre de decasílabos a aquellos versos cuya medida, hasta la última sílaba acentuada, ésta inclusive, es de diez sílabas? La cuestión es ahora meramente terminológica. Existen lenguas, como la española, en las que tales versos son considerados como endecasílabos, tomando como punto de referencia los versos de terminación llana, que constituyen la inmensa mayoría, y teniendo en cuenta todas sus sílabas, incluida la la final postónica. También en la métrica italiana se toma el verso de terminación llana como patrón para el cómputo silábico, ya que le parole piane sono quantitativamente prevalenti $i^{85}$.

En la lengua francesa, en la que desde luego no existen vocablos esdrújulos, se ha llegado a decir que sólo entran en juego los versos de final agudo. En realidad, esto no es cierto, ya que se da la oposición oxyton / paroxyton por ausencia o presencia de una sílaba final átona, cuyo núcleo vocálico está constituido por la llamada e muda o caduca, de pronunciación más virtual que real. Esta e muda cuenta, en todo caso, en el interior del verso, pero no en el final de verso o hemistiquio. De ahí que, en la práctica, todos los versos se consideren como de terminación aguda, y en consecuencia la denominación de los versos equivalentes a nuestros endecasílabos sea la de décasyllabe.

En las lenguas germánicas es donde existe una mayor tendencia a la consideración de los pies métricos, con el consiguiente olvido de la sílaba como elemento de la unidad versal. Así, en la métrica inglesa, se utiliza a veces el concepto de verso endecasílabo (decasyllable); pero es más frecuente la denominación de verso de cinco pies yámbico (five iambic feet) o pentámetro yámbico (iambic pentameter). El alemán, por su parte, es una lengua en la que el concepto mismo de sílaba resulta ciertamente conflictivo. Palabras como Vogel o Hemd aparecen unas veces como monosílabas y otras como bisílabas.

${ }^{85}$ BAUSI, F. y MARTELLI, M.: La métrica italiana. Florencia: Le Lettere, 1993, p. 22. 
Un tratadista ${ }^{86}$ ha podido justamente escribir que, en el verso alemán, sólo es fijo el número de las sílabas tónicas, mientras que el número de las átonas es fluctuante. A decir verdad, habría que matizar estas aseveraciones. Lo que ocurre es que existe un enorme contraste entre el lenguaje formal y el coloquial, con sus frecuentes formas contractas. Así, un mismo verso puede leerse como octosílabo o como endecasílabo ${ }^{87}$ :
Wieviel Sterne stehn am Himmel
Wieviele Sterne stehen an dem Himmel
(8 sílabas)
(11 sílabas)

Por lo que respecta a la denominación de los versos en relación con el número de sílabas, la métrica alemana es vacilante. Al verso equivalente al endecasílabo español o italiano se le llama, por ejemplo, endecasílabo italiano (italienischer Endecassilabo) o verso de once sílabas (Elfsilber), siempre que se trate de un verso de terminación llana. En otro caso, habría que hablar de versos de diez sílabas (Zehnsilber), si la terminación es aguda, o verso de doce sílabas (Zwölfsilber), si la terminación es esdrújula ${ }^{88}$. Y también se toma como modelo el verso francés (ein französischer 10/11-Silber) ${ }^{89}$, al que se considera como portador de diez u once sílabas.

Es importante tener en cuenta estos criterios, especialmente cuando se traducen al castellano tratados de métrica alemanes, como sucede en el caso del conocido manual de Rudolf Baehr ${ }^{90}$, donde, a pesar de la excelente traducción de Klaus Wagner, se encuentran alusiones a endecasílabos de doce sílabas, y a alejandrinos de trece, o quince, sílabas.

\footnotetext{
86 BREUER, D.: Deutsche Metrik und Versgeschichte. Munich: Wilhelm Fink, 1981, p. 44.

87 ALBERTSEN, L. L.: Neure deutsche Metrik. Berna: Peter Lang, 1984, p. 21.

88 Ibidem, pp. 75-76.

89 PAUL, O. y GLIER, I.: Deutsche Metrik, 9a ed. Munich: Max Hueber, 1989, p. 122. 90 Ob. cit.
} 


\section{PARTICULARIDADES DEL VERSO ALEJANDRINO}

$\mathrm{E}$

$\mathrm{N}$ todos los manuales de métrica española se da el nombre de alejandrino al tetradecasílabo, verso compuesto por dos hemistiquios heptasilábicos. Pero, frecuentemente, se hace mención de ciertas formas tridecasilábicas, tales como el alejandrino a la francesa y el alejandrino tripartito. En las páginas que siguen, se considerarán los fundamentos y la pertinencia de tales denominaciones. Se verá cómo realmente ha tenido un lugar en la métrica española el verso tridecasílabo, pero que en ningún caso se corresponde con el verso alejandrino.

La historia del alejandrino español está perfectamente esbozada en los estudios de Pedro Henríquez Ureña ${ }^{91}$. Tras nebulosas apariciones en el siglo XII, llega a ser la forma métrica característica del mester de clerecía en los siglos XIII y XIV. Sufre luego un olvido casi total, ya que, salvo esporádicas manifestaciones -por ejemplo, en la Diana enamorada de Gil Polo ${ }^{92}$ - no reaparece hasta el siglo XIX por obra de los románticos y modernistas.

En el período romántico, se adopta un riguroso modelo de acentuación trocaica, o de ritmo bipartito, para cada uno de los 91 HENRÍQUEZ UREÑA, Pedro: Obra Crítica. México: F.C.E., pp. 24-27 y 349-360. 92 Vid. MARASSO ROCA, A.: «Ensayo sobre el verso alejandrino», Boletín de la Academia Argentina de Letras, VII, 1939, pp. 63-127. 
dos hemistiquios, innovación que se atribuye a Zorrilla. Después de 1880, sobreviene la revolución de los modernistas, que, según apunta Henríquez Ureña, prefería formas de acentuación libre a las del verso rígidamente acentuado. Rubén Darío, por su parte, hace uso de un alejandrino de acentuación anapéstica, o de ritmo tripartito.

Posteriormente, Darío habría desarticulado por completo el alejandrino, haciendo alternar los versos tradicionales, en los que se mantiene la cesura entre los hemistiquios heptasilábicos, con otros versos carentes de cesura, llegando a escribir versos de trece sílabas, tales como los siguientes:

¿Ha nacido el apocalíptico Anticristo?

Coronada por el laurel del rey del día

Como expresión del llamado alejandrino tripartito, también de trece sílabas, con tres acentos que dividen el verso en tres grupos rítmicos, cita Henríquez Ureña los siguientes versos:

En los instantes del silencio misterioso

Del ruiseñor primaveral y matinal

El modelo de Darío para estos «descoyuntamientos» sería, principalmente, Paul Verlaine:

De la douceur, de la douceur, de la douceur

En composant des acrostiches indolents

Junto a los alejandrinos tripartitos, de trece sílabas, se cita también otro tipo de alejandrinos tridecasilábicos: el alejandrino a la francesa, sin cesura, cuyo primer hemistiquio había de terminar en palabra aguda, o bien en palabra llana cuya sílaba final pudiera unirse por sinalefa a la sílaba inicial del segundo hemistiquio. Esta denominación ya había sido empleada por Andrés Bello, quien introduce también el concepto de cláusula rítmica ${ }^{93}$.

93 BELLO, Andrés: Principios de la ortología y métrica de la lengua castellana. Madrid: Tello, 1890, p. 207. 
En realidad, estas formas métricas del alejandrino de trece sílabas, a la francesa, se habían ensayado ya en España desde el siglo XVIII, según se puede apreciar en los siguientes versos de Tomás de Iriarte:

En cierta catedral una campana había que sólo se tocaba algún solemne día...

Como hizo ver el profesor Maldonado de Guevara ${ }^{94}$, fue, en efecto, Tomás de Iriarte quien llevó a cabo la tarea de adaptar, en cierto modo, el alejandrino francés a la poesía española, deslindándolo expresamente del tetradecasílabo tradicional. Para ello, redactó dos fábulas con técnicas opuestas. En una de ellas, titulada La campana y el esquilón, a la que pertenecen los citados versos, hace un uso sistemático de la terminación aguda en el primer hemistiquio, de forma que una lectura apresurada del verso, que no tuviera en cuenta la cesura, habría de contar trece sílabas. O bien utiliza hemistiquios de terminación llana que hacen sinalefa con la palabra inicial del hemistiquio siguiente; con lo cual, si no se observa la cesura, resultarían asimismo trece sílabas.

En otra fábula, titulada La parietaria y el tomillo, realiza la operación contraria: evita totalmente la presencia del final agudo en el primer hemistiquio, o de la sinalefa entre el primero y el segundo, a fin de que todos los versos sean incuestionablemente de catorce sílabas.

Para Henríquez Ureña, estos alejandrinos a la francesa resultan ambiguos, ya que podrían también leerse como alejandrinos normales, esto es, de catorce sílabas, siempre que se respete la cesura, contándose una sílaba más en el caso del hemistiquio de terminación aguda, y no haciéndose la sinalefa cuando la terminación es llana. Sin embargo, para los otros supuestos alejandrinos de trece sílabas, como el alejandrino tripartito de Darío y de Verlaine, no da explicación alguna el ilustre hispanista, como no sea la de que, efectivamente, constan de trece sílabas.

${ }^{94}$ MALDONADO DE GUEVARA, F.: «La función del alejandrino francés en el alejandrino español de Rubén Darío», Revista de Literatura, IV, 1953, pp. 9-58. 
Sin embargo, todos los ejemplos citados podrían ser objeto de una oportuna escansión, mediante la cual los dos hemistiquios heptasilábicos del alejandrino tedradecasílabo quedarían perfectamente salvaguardados:

¿Ha nacido el apó[0]- / calíptico Anticristo?

Coronada por él[ $[0] /$ laurel del rey del día

En los instantes dél $[0] /$ silencio misterioso

Del ruiseñor primá $[0]$ / veral y matinal

Pero el profesor Maldonado de Guevara piensa que resultaría «violento y hasta brutal»95 introducir la cesura entre los dos hemistiquios del siguiente verso de Rubén Darío:

El chorro de agua de / Verlaine estaba mudo

Sin duda, para este autor, sería menos violento, más natural, efectuar una lectura tripartita del verso, con dos cesuras:

El chorro de agua / de Verlaine / estaba mudo

Y, en efecto, nos ofrece una serie de versos «trecenarios» e «indudablemente bicesurados», en los que para una mejor ilustración coloca «la violenta cesura que pretende ser central ${ }^{96}$ :

encarnación de la / divina primavera

y guárdame lo que / tú puedas del olvido

oh Sor María, oh Sor / María, oh Sor María

suene armoniosa a mi / piqueta de poeta

y el misterioso je- / roglífico adivina

El trabajo concluye con el recuerdo del famoso verso de Verlaine De la douceur, de la douceur, de la douceur, en el que se habría de inspirar Rubén Darío para la escansión de «Oh Sor María, oh Sor María, oh Sor María». Este verso, según el citado autor, habría de leerse «con dos cesuras, en esta forma: Oh Sor Marí- / a oh Sor Marí- /a ${ }^{95}$ Ob. cit., p. 38.

${ }^{96}$ Ibíd., p. 39. 
oh Sor María $\gg^{97}$. Con anterioridad, Julio Saavedra Molina había mantenido una postura análoga, interpretando los alejandrinos «de trece sílabas $\gg$ como versos organizados con tres compases ${ }^{98}$.

Es conocida la influencia de los simbolistas franceses, sobre todo Verlaine, en la métrica de Rubén Darío. Este hecho y la misma denominación de alejandrinos a la francesa hacen precisa una puntualización sobre los usos y convenciones del sistema métrico francés. Por lo pronto, conviene recordar, que, en la lengua francesa, el cómputo silábico llega sólo hasta la última sílaba acentuada, en el verso o en el hemistiquio. En consecuencia, el alejandrino tradicional francés, sería un dodecasílabo con dos hemistiquios hexasilábicos.

Maurice Grammont ${ }^{99}$ traza una tajante línea fronteriza entre el alejandrino clásico y el romántico. El alejandrino clásico (alexandrin classique) contendría cuatro elementos rítmicos, terminados cada uno por una sílaba acentuada. El acento segundo y el cuarto ocuparían un lugar estable en la sílaba sexta y en la duodécima respectivamente, mientras que los otros dos serían variables. Se trataría, por lo tanto, de un verdadero tetrámetro (tétramètre). Por el contrario, el verso romántico (vers romantique), empleado por Victor Hugo y por los poetas posteriores, carecería de acento en la sexta sílaba, y estaría dotado, por lo general, de tres elementos rítmicos. Se trataría, así, de un trímetro (trimètre).

Para Grammont, la cesura carece de importancia como elemento demarcador. Los cortes (coupes) que tienen lugar entre los grupos rítmicos, esto es, entre los pies métricos, se confunden con la pausa que marca la cesura (césure). La cesura no sería más que un simple corte (une simple coupe), pudiendo existir en el verso otros cortes tan nítidos como la cesura, $y$ otros acentos de intensidad tan fuertes, o incluso más fuertes que el de la sílaba sexta.

97 Ibíd., p. 58.

98 SAAVEDRA MOLINA, J.: «El verso que no cultivó Rubén Darío», Anales de la Universidad de Chile, 12, 1933, pp. 33-61.

99 GRAMMONT, M.: Petit traité de versification française. París: Armand Colin, 1974, pp. 49-60. 
De acuerdo con estos criterios, el alejandrino francés habría de dejar de ser considerado como un verso compuesto por dos hemistiquios (hexasilábicos, según el cómputo de la métrica francesa), y sería en realidad un verso simple, en el que sólo habría que distinguir acentos de intensidad y grupos rítmicos. La cesura no desempeñaría papel alguno a la hora de contar las sílabas.

Por otra parte, en la lengua francesa hay tener también en cuenta el problema de la $e$ muda. Y no sólo en el verso. En el mismo lenguaje ordinario, unas veces se pronuncia y otras no. Para Maurice Grammont, es desconcertante el hecho de tener que pronunciar las palabras en el verso ya de una manera, ya de otra. La cuestión se habría ido complicando de día en día hasta llegar a las más increíbles contradicciones. Dado el carácter «artificial» de la poesía francesa, que cada vez se aleja más de la «lengua real», habría una sola forma admisible de contar las sílabas: adaptarse lo más posible a la pronunciación del lenguaje ordinario ${ }^{100}$. De ahí a renunciar al cómputo silábico tradicional del alejandrino, especialmente tras las innovaciones de románticos y simbolistas, no hay más que una paso.

Éste es el paso que darán diversos tratadistas, entre ellos el investigador de origen húngaro Kibédi Varga, quien llega a afirmar que, después de Victor Hugo, la dislocación o incluso la destrucción del silabismo, sobre todo en lo que concierne al alejandrino, hace «inútil y absurda» cualquier clase de fidelidad a las reglas tradicionales ${ }^{101}$. El fragmento que sigue es especialmente ilustrativo, $y$ merece la pena su reproducción textual:

Le nombre varié- et variable, souvent, selon le lecteur-des accents à l'intérieur du vers et le problème de l'e muet font du syllabisme un système approximatif qui n'est perçu comme réel que grâce à des traditions et des illusions acceptées par le lecteur. D'un vers à l'autre, le nombre des syllabes n'est rigoureusement identique que dans la théorie ${ }^{102}$.

100 Ob. cit., p. 19.

101 KIBÉDI VARGA, A.: Les constantes du poème. Analyse du langage poétique. París: Picard, 1977, p. 83.

102 Ob. cit., p. 91. 
La falta de interés por el cómputo silábico queda, así, claramente confirmada: el silabismo se reduciría a un mero «sistema aproximativo», del que no tendríamos en absoluto un conocimiento intuitivo y directo (y, mucho menos, científico), sino que sólo podríamos acercarnos a él a través de «ilusiones»y «tradiciones» convencionales. Por otra parte, la constancia en el número de las sílabas de los versos no sería más que una pura abstracción «teórica», que se desvanecería ante la práctica confrontación con la realidad.

Cierto es que las aseveraciones de Kibédi Varga no constituyen un hecho aislado. Benoît de Cornulier ${ }^{103}$, por ejemplo, encuentra actitudes análogas en Souriau ${ }^{104}$, Gourmont ${ }^{105}$, Dufrenne ${ }^{106}$, Mazaleyrat ${ }^{107}$, Morier ${ }^{108}$; e indica que, para numerosos analistas del siglo $\mathrm{xx}$, el número exacto de sílabas, incluso en el alejandrino clásico, no es más que una superstición.

El siguiente alejandrino de Victor Hugo, según Kibédi Varga, habría de ser considerado como un simple metro ternario:

Au grand Paris / faisant sonner / sa grande armure

Admite, no obstante, que la lectura del alejandrino con un ritmo tripartito podría sugerir un cierto matiz de dulzura y armonía, que no corresponde realmente al patetismo marcial del verso de Victor Hugo. Habría, pues, que reintroducir los convenientes elementos acentuales que sirvan para separar las palabras faisant y sonner:

Au grand Paris / faisant // sonner / sa grande armure

103 CORNULIER, B. de: Théorie du vers. Rimbaud, Verlaine, Mallarmé. París: Seuil, 1982, pp.121-124.

104 SOURIAU, E.: La correspondance des arts. París: Flammarion, 1947.

105 GOURMONT, R. de: Esthétique de la langue française. París: Mercure de France, 1955.

106 DUFRENNE, M.: Le poétique. París: PUF, 1963.

107 MAZALEYRAT, J.: Pour une étude rythmique du vers français. Notes bibliographiques. París: Minard, 1963. Éléments de métrique française. París: Colin, 1974.

108 MORIER, H.: Dictionnaire de poétique et de rhétorique, 3ª ed. París: PUF, 1981. 
Podríamos pensar que el autor está defendiendo la posible existencia de un ritmo bipartito, y que considera como una auténtica pausa el corte que se produce entre faisant y sonner. Pero no es así. Expresamente nos advierte que no se trata, en modo alguno, de restituir el clásico alejandrino binario: sans restituer, bien entendu, l'alexandrin binaire ${ }^{109}$.

Tal es la actitud que la generalidad de los analistas franceses ante el alejandrino «romántico», así llamado por su mayor utilización en el siglo XIX, si bien ya había sido utilizado en los siglos precedentes, como lo atestigua el siguiente verso de Corneille: Toujours aimer, toujours souffrir, toujours mourir. En el clasicismo francés, sería impensable una lectura que no reconociera la existencia de dos hemistiquios, separados por la cesura:

Toujours aimer, toujours / souffrir, toujours mourir

Es cierto que la estructura sintáctica del verso, reforzada por la separación visual que suponen los signos diacríticos, podría inducir a una lectura ajustada a una segmentación tripartita:

Toujours aimer, / toujours souffrir, / toujours mourir

Esta última lectura es la preconizada, generalmente, por la moderna crítica francesa. No es de extrañar, por tanto, que en el estudio del correlato castellano del alejandrino francés, esto es, en el análisis de los llamados alejandrinos ternarios y a la francesa, se hayan venido empleando análogos criterios. El concepto de cesura, como elemento demarcador, se desvanece y queda sustituido por otras formas más difuminadas -cortes, cesuras móviles- que se introducen en el verso, acá y allá, de acuerdo con las estructuras semánticas y sintácticas, a las que el ritmo se adaptaría dócilmente.

Un importante avance en el estudio del verso alejandrino ha sido llevado a cabo por el poeta y ensayista Leopoldo de Luis, quien hace un detenido estudio de los alejandrinos de Juan Ramón Jiménez ${ }^{110}$,

109 KIBÉDI VARGA, A.: Ob. cit., p. 56.

110 LUIS, L. de: «Prólogo» a Juan Ramón Jiménez: La soledad sonora. Madrid: Taurus, 1981, pp. 9-47. 
sobre todo en lo que concierne al tratamiento de los hemistiquios, y deslinda cierta peculiaridades, que, con los oportunos retoques -he suprimido algunos ejemplos y apartados que no son pertinentes para el caso que nos ocupa-, son las siguientes:

1. Primer hemistiquio de seis sílabas, con la última acentuada (por su posición final, aun en el caso de ser una partícula gramaticalmente átona).

\subsection{Con preposición monosílaba:}

«En una barca de / blancura de azucena».

\subsection{Con artículo:}

«La música de las / tardes primaverales».

1.3. Con otra voz monosílaba:

«Teníamos los dos / desangradas las flores».

1.4. Con voz polisílaba aguda:

«Dichosos de envolver / en sombra los dolores».

1.5. Por corte tras una conjunción:

«Sublime de altas y / transfiguradas flores».

2. Primer hemistiquio heptasílabo, agudo o llano, con preposición:

«Despierta en el rosal a / los dulces ruiseñores».

«Te derramas llorando en / estrellas virginales».

3. Corte de una palabra para distribuir sus sílabas entre los dos hemistiquios (encabalgamiento léxico):

«Ah, quién pudiera pro- / longar eternamente».

Los apartados 1.1, 1.2 y 1.5pueden resumirse del siguiente modo: primer hemistiquio terminado en monosílabo átono. En una lectura apresurada, sin tener en cuenta la cesura, todos los ejemplos, y en especial el 1.1, corresponderían al llamado alejandrino ternario. Los apartados 1.3 y 1.4 se refieren a un primer hemistiquio terminado en palabra aguda. Sin la cesura, estos versos corresponden al denominado alejandrino a la francesa. 
En el apartado 3, encontramos un encabalgamiento léxico entre ambos hemistiquios. Si se lo ignora, estaríamos en presencia de un verso de división tripartita y, en consecuencia, se clasificaría como alejandrino ternario.

Con respecto al apartado 2 , en los ejemplos que se proponen entran en juego las circunstancias que se conocen con los nombres de sinafía y compensación:

Despierta en el rosal / a los dulces ruiseñores

Te derramas llorando / en estrellas virginales

En el verso primero, se da en efecto el fenómeno de la compensación, de aparición ciertamente rara en la poesía moderna y contemporánea, si bien cuenta con el ilustre precedente de su empleo en las famosas Coplas de Jorge Manrique. Mediante la compensación, no es preciso contar una sílaba más en el primer hemistiquio, a pesar de que termina en palabra aguda («rosal»), ya que se le añade la sílaba inicial del segundo hemistiquio («a»):

Despierta en el rosal a / los dulces ruiseñores

En el segundo verso, existe sinafía entre ambos hemistiquios, esto es, se da la unión silábica o zeuxis entre la sílaba «-do» (de «llorando») del primer hemistiquio y la sílaba «en» del segundo hemistiquio:

Te derramas llorando en / estrellas virginales

En relación con las distintas posibilidades de acoplamiento de los dos hemistiquios, podemos destacar, en definitiva, las siguientes particularidades métricas:

a) Primer hemistiquio terminado en palabra aguda, o en palabra llana cuya sílaba final pueda unirse por sinalefa (como si se tratara de un verso simple, sin cesura) a la sílaba inicial del segundo hemistiquio. Es lo que ocurre, por ejemplo, en estos versos de Juan Ramón Jiménez:

sobre cada jazmín una estrella se posa

y la luna moría en su cálido cielo 
Es evidente que, si no se prescinde de la cesura, se trata de versos compuestos, tetradecasílabos:

sobre cada jazmín / una estrella se posa y la luna moría / en su cálido cielo

Pero si se los considerara como versos simples, la medida sería entonces de trece sílabas, esto es, se trataría de los versos denominados alejandrinos a la francesa.

b) Primer hemistiquio terminado en monosílabo átono, o con encabalgamiento léxico entre ambos hemistiquios, como puede apreciarse en estos otros versos de Juan Ramón Jiménez:

En las paredes de mi alma enamorada

por la ventana -piedras dentro-, ¡luna blanca,

qué pobre juegas con la sombra de mi acacia!

Tanto en el verso primero como en el tercero, el primer hemistiquio termina en voz monosílaba átona, que, por obra de la cesura, se comporta como tónica. En el verso segundo, la primera sílaba («pie-») de la palabra encabalgada («piedras») se comporta también como sílaba tónica independiente. Se trata, por lo tanto, de unos primeros hemistiquios heptasilábicos, separados por la cesura de unos segundos hemistiquios también heptasilábicos:

En las paredes de / mi alma enamorada por la ventana -pie- / dras dentro-, ¡luna blanca, qué pobre juegas con / la sombra de mi acacia!

Pero, si se prescindiera de la cesura, podríamos hacer una división tripartita, estableciendo una segmentación rítmica de tres grupos de palabras. Habríamos de considerar estos versos, así pues, como alejandrinos ternarios:

En las paredes / de mi alma e-/ namorada, por la ventana / -piedras dentro-, / ¡luna blanca, que pobre juegas / con la sombra / de mi acacia! 
En favor de una interpretación tetradecasilábica de estos tipos de versos, con cesura media, abogan las opiniones y las lecturas de Arturo Marasso ${ }^{111}$, Roger D. Bassagoda ${ }^{112}$ y Dámaso Alonso ${ }^{113}$, entre otros autores. A decir verdad, tales peculiaridades en el verso alejandrino español no son más que variedades de un mismo y único patrón métrico: el verso tetradecasílabo, compuesto por dos hemistiquios heptasilábicos. Evidentemente, tanto el llamado alejandrino a la francesa como el ternario no son más que el resultado de una lectura inconsecuente con las convenciones de la métrica española.

Muchas otras circunstancias podrían concurrir en una lectura inadecuada del alejandrino. Consideremos los siguientes versos, también de Juan Ramón Jiménez:

Impenetrable es tu frente cual un muro.

Tan cerca de los ojos, ¿cómo retiene preso

tu pensamiento? ¿Cómo su recinto es oscuro,

bajo el cabello de oro, sobre el radiante beso?

Sólo el segundo y el cuarto ofrecen una fácil lectura como versos compuestos por dos hemistiquios heptasilábicos. En el verso tercero, podría resultar problemática la situación de la cesura media, que no se ajusta precisamente a la separación sintáctica y semántica de las cláusulas. Por lo que respecta al verso primero, el desconocimiento de las convenciones métricas podría conducir a una lectura errónea como verso simple de doce sílabas, ignorando la correcta segmentación rítmica:

Impenetrable es / tu frente cual un muro.

Tan cerca de los ojos, / ¿cómo retiene preso

tu pensamiento? ¿Cómo / su recinto es oscuro,

bajo el cabello de oro, / sobre el radiante beso?

111 MARASSO ROCA, A.: «El verso alejandrino (Apuntes para un estudio)», Humanidades. La Plata, 1923, pp. 123-170.

112 BASSAGODA, R. D.: «Del alejandrino al verso libre», Boletín de la Academia Argentina de Letras, XVI, 58, 1947, pp. 65-113.

113 ALONSO, D.: «Poetas españoles contemporáneos», en Obras Completas, IV. Madrid: Gredos, p. 559). 
También en la métrica francesa, y en las de otras lenguas donde se ha desarrollado el verso alejandrino, se podrían hacer análogas consideraciones, siempre que se tengan en cuenta las convenciones específicas de cada literatura. La métrica francesa difiere de la española en que no se cuenta la sílaba final postónica de los versos o de los hemistiquios paroxítonos, y no añade una más en los oxítonos. En consecuencia, l'alexandrin consta de doce sílabas, en lugar de las catorce que se asignan al alejandrino español. Veamos los mismos ejemplos que, según hemos tenido la ocasión de considerar más arriba, nos proponía Pedro Henríquez de Ureña:

De la douceur, de la douceur, de la douceur

En composant des acrostiches indolents

El primer verso pertenece al famoso soneto «Lassitude», de Paul Verlaine, y el segundo al no menos célebre $\ll$ Langueur $\gg$. Como indica, con un punto de ironía Benoît de Cornulier, es siempre Verlaine quien suele citarse cuando se quiere dar un ejemplo de alejandrino «anárquico», «desarticulado»y «libre» de toda regla: Quand il faut donner un exemple d'alexandrin «anarchique», «désarticulé», «affranchi» de toute règle, on cite Verlaine ${ }^{114}$. Pues bien, si no se ignora el fenómeno métrico de la cesura, la medida de estos versos se ajusta fácilmente al siguiente patrón:

De la douceur, de la / douceur, de la douceur

En composant des a- / crostiches indolents

En el primer verso, encontramos un primer hemistiquio que termina en monosílabo átono; y en el segundo, un encabalgamiento léxico entre ambos hemistiquios. Se trata, en definitiva, de dos claros ejemplos de alexendrins ternaires o trimètres, que admitirían por supuesto la siguiente lectura de ritmo tripartito:

De la douceur, / de la douceur, / de la douceur

En composant / des acrostiches / indolents

${ }^{114}$ CORNULIER, B. de: Ob. cit., p. 211. 
Desde el escueto punto de vista de la materialidad del cómputo silábico, es indiferente para la métrica francesa la división del verso en dos hemistiquios hexasilábicos $(6+6=12$ sílabas $)$ o en tres segmentos tetrasilábicos $(4+4+4=12$ sílabas). En todas las lecturas posibles, el alejandrino francés seguirá siempre siendo un verso dodecasílabo.

En español, sin embargo, difícilmente podrán computarse las catorce sílabas del alejandrino en el conocido verso de Rubén Darío, «Oh Sor María, oh Sor María, oh Sor María», si no se lleva a cabo una división en hemistiquios heptasilábicos: «Oh Sor María, oh Sor / María, oh Sor María». Y lo mismo sucedería en el alejandrino de otro gran modernista, Manuel Machado: «La Caridad, la Caridad, la Caridad». Únicamente el reconocimiento de la existencia de un encabalgamiento léxico, determinado por la cesura, podría justificar la regularidad silábica del tetradecasílabo, dividido en dos hemistiquios heptasilábicos: «La Caridad, la Ca- / ridad, la Caridad». A la hora de efectuar la escansión y la medida del alejandrino, habrá que tener siempre en cuenta las convenciones de las diversas métricas, separando y distinguiendo cuidadosamente sus criterios y sus peculiares terminologías. 


\section{TEÓRICOS}





\section{LAMÉTRICADE ANTONIO SEBASTIANO MINTURNO}

$\mathrm{E}$

ntre los tratadistas que configuran la poética o teoría literaria del Renacimiento italiano, destaca la figura de Antonio Sebastiano Minturno (1500-1574), autor de dos obras fundamentales: De poeta (1559), en lengua latina, y L'arte poetica (1564), en lengua italiana. No son ciertamente obras aisladas, sino insertas en un amplio conjunto de trabajos llevados a cabo por distintos autores coetáneos, tales como los comentarios a la Poética de Aristóteles de Francesco Robortello (1516-1567), en latín, o los de Lodovico Castelvetro (1505-1571), en italiano. En la actualidad, se trata desgraciadamente de obras más citadas que leídas, a pesar que algunas de ellas gozan de edición facsímil, como es el caso de L'arte poetica (Wilhelm Fink, Munich, 1971) de Minturno. Tanto ésta como el De poeta son, por otra parte, de fácil acceso a través de la oferta telemática de la casa Google.

La reciente aparición del Arte poética, con traducción española, en cuidada edición bilingüe ${ }^{115}$, hace ahora inexcusable la lectura de esta obra señera por parte de los estudiosos de la poética en general, y en particular de la métrica, a la que se dedican abundantes y

115 MINTURNO, Antonio Sebastiano: Arte poética, ed. y trad. esp. de Ma. del Carmen Bobes Naves. Madrid: Arco/Libros, 2009. 
enjundiosas páginas en los cuatro libros de que consta el tratado. La profesora María del Carmen Bobes Naves, autora de la encomiable traducción de la obra, nos hace ver en un esclarecedor estudio introductorio cómo nos hallamos ante la primera poética en lengua vulgar, que nos ofrece también por vez primera el esquema de los tres géneros de poesía: épica, escénica y mélica. Sin embargo, y como la misma profesora Bobes Naves se encarga de puntualizar, la obra carece de un esquema general, lo cual propicia las repeticiones y las divagaciones por temas colaterales. De ahí que se haga precisa una lectura sistematizadora, que, en lo que concierne a la métrica, será el objeto del presente trabajo.

El Arte poética consta de cuatro libros, organizados a modo de razonamientos o diálogos que mantiene Minturno con cuatro amigos, que son a la vez poetas y conocedores de la teoría literaria. Le solicitan éstos que explique en lengua vulgar lo que con anterioridad había escrito, en lengua latina, en su obra De poeta ${ }^{116}$. Se divide el De poeta en seis libros, de los que, en realidad, sólo se trata de la métrica escasamente en el libro tercero, a propósito de la versificación utilizada en las partes recitadas y en los coros de las tragedias, y con mayor extensión en el libro sexto, que dedica las páginas 489-509 a la composición (compositio), la armonía (concinnitas) y el ritmo (numerus).

En un trabajo sobre la teoría métrica del De poeta, considera el profesor Carlos de Miguel Mora, de la Universidad de Aveiro, que se le da un tratamiento escaso, somero e insuficiente ${ }^{117}$, ya que, de las 134 páginas de uno de sus seis libros -el sexto-, sólo diez están dedicadas a una pequeña exposición de la doctrina métrica. También hace referencia a la deuda contraída por Minturno con el

\footnotetext{
116 Antonii Minturni ad illustrissimum vibonensium ducem Hectorem Pignatellum, de poeta. Venecia: Franciscum Rampazetum, 1559. Sobre esta obra, vid. COLOMBO, Davide: «La struttura del De Poeta di Minturno». Acme: annali della Facoltà di lettere e filosofía dell'Università degli studi di Milano, 2002, Vol. 55, No. 2, pp. 187-200.

117 MIGUEL MORA, Carlos de: «La doctrina métrica en el De poeta de Minturno», en J. Luque Moreno y P. Díaz Díaz (eds.), Estudios de métrica latina. Granada: Universidad, 1999, pp. 617-632.
} 
Orator de Cicerón, del que reproduce varios párrafos palabra por palabra. Pero, a decir verdad, no son diez, sino veinte, las páginas que se dedican a la métrica, y además en formato de cuarto mayor. $\mathrm{Y}$, por otra parte, Minturno no oculta nunca la procedencia de sus citas: «lo que dice Cicerón» (quod ait Cicero), «como justamente dice Cicerón» (ut vere ait Cicero).

En cualquier caso, para la historia y la teoría de la métrica, revisten mayor interés las páginas del Arte poética que las de El poeta, que prácticamente se reduce a una minuciosa relación de los pies métricos -troqueos, espondeos, dáctilos, coriambos, molosos, peanes primeros, antibaquios, doriscos-, aunque también esboza algunas de las ideas que serán desarrolladas más tarde en el Arte poética, como por ejemplo la identificación de las sílabas «agudas» (tónicas) con las «largas», y las «graves» (átonas) con las «breves». Escribe Minturno que los gramáticos «dicen que la sílaba que suena de forma aguda es más larga que la que suena de forma grave» (Syllabam vero, quae acute sonat, longiorem esse aiuntque quam eam quae graviter), y que asimismo es más larga la sílaba «que se marca con una tilde circunfleja» (quae apice circunducto notatur). ${ }^{118}$

Por lo que respecta al Arte poética, su primer libro ${ }^{119}$ está dedicado a la poesía épica; pero, inicialmente, se hace un estudio general de la poesía, que se define como «imitación de varios tipos de personas, de modos diversos, con palabras, con armonía o con tiempos». El diálogo tiene lugar entre Vespasiano Gonzaga y Antonio Minturno, quien, en la mejor línea aristotélica, pasa revista a la materia, los instrumentos y los modos de la imitación.

Tras esta primera tríada, vienen otras. En la materia, esto es, en las cosas que se imitan, hay que considerar las costumbres, los sentimientos y los hechos de las personas. Éstas pueden ser mejores que los hombres de nuestra época, semejantes a ellos o peores que ellos. Por su parte, los instrumentos usados por el poeta, para hacer

\footnotetext{
118 De poeta, pág. 502.
}

119 Las citas están tomadas de las páginas 2-5 y 8 de la edición original (Venecia, 1564), y 157-163 y 169 de la traducción española (Madrid, 2009). 
imitaciones, son: las palabras, la armonía y los tiempos. Las palabras pueden ir «sueltas», esto es, «sin relaciones entre las sílabas, que con determinado y fijado número hacen los versos», o bien relacionadas «con medida establecida y ordenada con voces ligadas y fijadas, que llamamos versos».

Tres son también los modos o clases de poesía: épica, escénica y mélica o lírica. Tres son, asimismo, las especies de la épica: en prosa (diálogos y relatos), en verso (versos heroicos, versos bucólicos, elegías, epigramas, himnos, tercera rima, octavas) y mixta de verso y prosa (tal como en la Arcadia de Sannazaro, en el Ameto de Boccaccio o el Amore innamorato del propio Minturno). Y tres son, en fin, las clases de la poesía escénica: trágica, cómica y satírica. Sólo la mélica queda fuera de la tricotomía clasificatoria, al menos en este primer diálogo, ya que en el libro tercero se nos dirá también que tres son sus hacedores: líricos, ditirámbicos y gnómicos.

La imitación, y no el verso, es lo que verdaderamente hace poeta al escritor. En efecto, «la imitación hace poeta al escritor, no el escribir en pies medidos». Los que escribieron en verso de medicina, de música o de filosofía han de llamarse médicos, músicos o filósofos, y no poetas, «pues nada, a no ser el verso, tienen en común con Homero». En todo caso, el verso, vehículo de la poesía, es connatural al hombre, pues hemos nacido para hablar, para el canto, para la medida, para el tiempo. Y, como los versos no se hacen sin tiempo y sin medida, «hemos sido creados para hacer versos». El discurso suave que supone el hablar en verso es distinto del de la prosa. Y, «puesto que hablar en verso se hace con medida y con ritmo y con armonía», no hay nada que llegue a nuestros oídos con más dulzura y alegría. Es cierto que la prosa también está dotada de armonía y de ritmo, pero no «bajo normas», ni «con medida establecida».

Se entiende por armonía una «consonancia de voces diversas y acompasadas», y por ritmo «la medida del movimiento de las sílabas y de las palabras». El movimiento puede ser lento o rápido; y el espacio, largo o breve. Del movimiento veloz, viene el sonido agudo; y del movimiento lento, el grave. La armonía aparece en la 
consonancia de los versos, que se corresponden entre sí, más claramente que en los simples y desnudos, carentes de consonancia.

El libro segundo ${ }^{120}$ del Arte poética desarrolla, a través de un diálogo o ragionamento entre Angelo Costanzo y Minturno, la cuestión de la poesía escénica, que se define como imitación de cosas «de cierta grandeza», lo cual se realiza «no simplemente narrando, sino introduciendo personas en acción y diálogo, con discurso suave y deleitable; y con canto, y baile». De estos tres elementos -discurso, canto y baile- podrá estar presente sólo uno de ellos, o dos, o los tres conjuntamente. $Y$ es que «el placer y suavidad del habla no sólo procede del sonido, y de los tiempos de las palabras bajo las leyes de las sílabas, y de los pies, sino también del canto.»

La materia escénica puede ser de tres clases: grave (de personas elevadas e ilustres), común (de labradores, asalariados y comerciantes) y baja (de personas humildes y risibles). En correspondencia con estas tres clases de materia escénica, existirán tres formas de representación teatral: la tragedia, la comedia y la sátira. Por otra parte, según el modo de imitar, el poeta lírico (que «narra simplemente y sin ocultar su propia persona») se distingue del poeta épico (que «la oculta o la mantiene, en parte narrando o en parte introduciendo a otros que dialoguen»).

En el terreno de la comedia, defiende Angelo Costanzo el uso del «discurso libre y suelto que llamamos prosa», en el cual «se pueden poner los dichos y los hechos más cómodamente», porque no debe caber duda de que «hablar libremente y sin la atadura de las sílabas y de los pies no sea más cómodo y más adecuado para expresar nuestros pensamientos», teniendo además en cuenta que «la poesía no está en el verso más que en la prosa». Por otra parte, las cosas comunes y bajas que se tratan en la comedias exigen un lenguaje que esté «más cerca de la prosa que del verso». Aduce Minturno que los antiguos, cuyo juicio «es mejor y más digno», jamás llevaron la prosa al teatro, ni se representó nada que no hubiese sido

${ }^{120}$ Las citas están tomadas de las páginas 65-70, 107-109 y 160 del original (284-293, 367-371 y 473 de la traducción). 
escrito en verso. Ahora bien, es lícito utilizar versos sueltos, desnudos y carentes de rima (versi ignudi, e senza consonance: $i$ quali sciolti chiamarono), y también el ritmo dactílico que empleó Sannazaro en sus pastorales, fiel trasunto de los dáctilos latinos, que se llaman en lengua toscana sdruccioli (esdrújulos, "resbaladizos"), que corren y se deslizan como si resbalasen (come se sdrucciolassero).

En cuanto a la medida del verso toscano, dos son las formas fundamentales: los heptasílabos y los endecasílabos. Los primeros son considerados como quebrados o rotos (rotti), y los segundos como enteros y perfectos (interi e perfetti). Pero también puede haber versos quebrados de cinco sílabas, como en una canción de Dante:

Poscia ch' Amor del tutto m' hà lasciato,

Non per mio grato;

Che stato non havea tanto gioioso.

Un pentasílabo se inserta aquí entre dos endecasílabos. Pero existe rima interna del segundo endecasílabo con el pentasílabo:

Non per mio grato,

Che stato.

El segmento Che stato puede ser considerado como un quebrado de tres sílabas. En realidad, como apunta Minturno, «del verso de once sílabas podemos hacer versos de tres sílabas, de cinco y de siete». Y también de cuatro, de seis y de ocho. Se pone como ejemplo el verso $L^{\prime}$ aspetto Sacro de la terra vostra, de Petrarca, que se puede segmentar de varios modos:

L' aspetto

Sacro de la terra vostra

L'aspetto Sacro

De la terra vostra.

L'aspetto Sacro de la

Terra vostra. 
El endecasílabo ha dado origen, como vemos, a versos de tres, ocho, cinco, seis, siete y cuatro sílabas. No le pasó a Minturno desapercibido el hecho de que también habría que incluir en esta serie el verso de nueve sílabas:

\section{L'aspetto Sacro de la terra}

En cualquier caso, se considera que los versos cortos más usados son los de tres, cinco y siete sílabas, que, en verdad, son los que mejor se combinan con el endecasílabo, verso central de la poesía toscana. Estos versos son más blandos y más gráciles (piû molli e piû vaghi) que los de cuatro, seis, ocho y doce sílabas, que resultan más duros y ásperos (piû duri e aspri). Los primeros serían más aptos para la canción, y los segundos para los diálogos escénicos. El verso de doce sílabas, que «procedería de añadir una sílaba al verso entero y perfecto», es poco usado por los poetas toscanos; pero sí por el español Juan de Mena en la composición que se llama de arte mayor. Advierte Minturno que «crece una sílaba el esdrújulo, y falta una sílaba en aquel que lleva el acento en la última». En consecuencia, en el esdrújulo «dos sílabas valen por una», y en el agudo la última sílaba «vale por dos».

Se cuestiona en este diálogo en qué versos debe escribirse la poesía escénica. Si se tratara de la literatura griega o latina, la respuesta no tendría dificultad alguna, porque tanto en latín como en griego, y especialmente en griego, existen poetas excelentes, que nos podrían servir de guía. Pero, en la lengua toscana, «apenas hace cuarenta años que los nuestros han empezado a escribir poemas escénicos», y no todos siguen los mismos criterios. En todo caso, se proponen algunas reglas. Para los prólogos, que los griegos y latinos hicieron en versos yámbicos, se aconsejan los endecasílabos; para los episodios, los versos de siete u ocho sílabas, y a veces de tres o de cinco, «tejiéndolos según requiera la calidad del hábito o del acto representado», es decir, «en materia muy seria, o donde se narra, se hará uso de versos de once; en materia grave, podéis intercalar los de siete, y a veces el de ocho». Los versos más cortos, de tres o cinco sílabas, se reservan para «el habla presidida por el dolor o el llanto». 
Por lo demás, «en todos los episodios, en los que hubiere variedad de materia y de habla, usaréis variedad de versos, cambiando según juzguéis que lo requiera el caso».

Se advierte que todas las estancias han de ser como la primera, excepto la última, que recibe en toscano el nombre de commiato, esto es, "despedida", y equivale al epodo de los griegos. Tanto en el prólogo como en los episodios, se emplearán versos desnudos (versi ignudi), libres de las ataduras de las consonancias (liberi de' legami di consonanze). La razón es que éstas no son precisas en la narración y el diálogo. Por lo que respecta a los pies métricos, se considera que los toscanos pueden hacer versos del mismo modo que los hicieron los griegos y los latinos. Así, a los anapestos se asimilan los esdrújulos y, por extensión, todos los versos constituidos por palabras de muchas sílabas, donde los acentos son escasos y espaciados.

Más adelante, sin embargo, distingue entre dáctilos y anapestos. Los primeros son conjuntos de tres sílabas, de las cuales la primera es larga (tónica) y las otras dos breves (átonas), tales como scriuere, candido, pessimo, cuor mio. Los segundos constan de dos sílabas breves y una final larga, como validi. Si las tres sílabas son breves, el pie recibe el nombre de coreo, como ocurre, según Minturno, en la palabra varia. Por su parte, son yambos todas aquellas palabras de dos sílabas derivadas de voces griegas o latinas que no tienen larga la sílaba primera. Son asimismo yambos las palabras de dos sílabas que no lleven consonante entre ellas, como io, suo, lui, o no más de una consonante, siendo breve la primera sílaba, como amo, fede, rosa.

Cuando las dos sílabas son largas, el pie recibe el nombre de espondeo, bien entendido que las sílabas pueden ser largas porque en latín, de donde proceden, sean largas (por naturaleza), como dono, caro; o porque la vocal vaya seguida de dos consonantes (por posición), como ocurre en la primera sílaba de las palabras fronda y canto. Advierte Minturno, identificando una vez más las sílabas tónicas con las largas, que, en la lengua toscana, la penúltima sílaba de toda palabra llana ha de ser considerada siempre como larga: ardeva, signore, sedere. Si el pie bisilábico lleva larga la sílaba primera y breve la 
segunda, como legge, finge, vista, recibe el nombre de troqueo. Sería el pie más frecuente de la lengua toscana.

Hacia el final del diálogo, Angelo Costanzo le pide a Minturno que, ya que considera que la comedia no debe escribirse en prosa, sino en verso, especifique cuándo y cómo se debe emplear el metro. Responde Minturno que ya había hablado de ello con anterioridad, pero que, por hacer un breve recordatorio, ha de precisar que «todos los modos que siguieron los antiguos se reducen a tres, cuyos nombres son yambos, anapestos y troqueos». Constan de ocho o cuatro pies, y raras veces de dos. Para los prólogos, se utilizaban los senarios, que son yambos de seis pies; y para los diálogos de los actores, los versos cuadrados ${ }^{121}$, que son anapestos o troqueos de ocho pies. Entre los cuadrados, se ponían a veces los dímetros, que son de cuatro pies, y alguna vez los monometros, que son de dos. Pero, en la lengua toscana, en vez de senarios, se escriben versos de once sílabas; en vez de cuadrados, los versos de doce; en lugar de los dímetros, los versos de ocho o siete sílabas; y, en vez de monometros, los versos de tres o cuatro sílabas, o de cinco, «según pidiese la materia de que se hablase».

El libro tercero ${ }^{122}$, o tercer diálogo de la Poética toscana, es el que mayor extensión dedica al estudio del verso, la rima y las distintas estrofas y composiciones. El diálogo tiene esta vez lugar entre Bernardino Rota y Minturno, y se ocupa de la poesía mélica, cuyo origen no sería otro sino una acción de gracias al Dios todopoderoso. En efecto, las criaturas «a Dios, su padre y señor, le dieron las gracias, y lo celebraron haciéndole cantos con alabanzas y con concertada medida de los tiempos». Apolo, príncipe de la poesía, habría inventado la lira, para poner música al poema mélico; de ahí que podamos considerar a los líricos como a los primeros poetas

121 Sobre el verso cuadrado, vid. LUQUE MORENO, Jesús: Versus quadratus. Crónica de un verso milenario. Granada: Universidad, 2009. Y reseña de esta obra en TORRE, Esteban: «JESÚS LUQUE MORENO: Versus quadratus, cit». Rhythmica, Revista Española de Métrica Comparada, 2010, VIII, 8, pp. 239-242.

122 Las citas están tomadas de las páginas 167-169, 178 y 185-281 del original (496499, 517 y 531-723 de la traducción). 
de la historia. «Melos, voz de la que deriva el nombre de mélica, no significa otra cosa que canto, el cual, si se canta con la lira, se llama lírico». Los cantores de la poesía mélica se clasifican de acuerdo con la siguiente tríada: líricos, ditirámbicos y gnómicos.

También son tres las partes de la canción según el modelo seguido por Píndaro: vuelta, revuelta y estancia. Pero, en las canciones toscanas, «se llaman estancias las que en las pindáricas se llaman vueltas». La canción se define como «una composición hecha de palabras con armonía, bajo cierto número, y bajo cierta medida, tejidas y ordenadas para el canto». Es consciente Minturno -por boca de Bernardino Rota- de la insuficiencia de esta definición, que podría aplicarse a «todo lo que en verso se compone de forma ordenada», y especifica que se trata de «una composición magnífica y espléndida, y dividida en partes dirigidas a un sentimiento ${ }^{123}$. Por su parte, la instancia es una «composición de versos de sílabas limitadas bajo cierto canto y bajo cierto orden». A su vez, el canto es «armonía de los versos compuestos según cierto número».

Los versos que se utilizan en la canción son fundamentalmente el endecasílabo y el heptasílabo. Los versos de cinco sílabas aparecen con menor frecuencia, y menos aún los de tres. El verso de nueve sílabas se abandonó pronto, «porque era poco apreciado y producía aburrimiento, pues comprendía tres veces el trisílabo». En general, los versos de sílabas impares son los mejores, pues «los que tienen sílabas pares son muy duros y pocas veces se usan». Llega a decir Minturno que los versos de sílabas pares son duros, porque «retienen la naturaleza de los propios números», y, en relación con los de sílabas impares, «son como la materia respecto a la forma». Con esta invocación a la doctrina hilemórfica de Aristóteles, queda la cuestión plenamente justificada.

123 Estas palabras, «composición magnífica y espléndida», en verdad poco definitorias, llamaron sin embargo la atención de Francisco Cascales, que traduce literalmente en sus Tablas poéticas (1617) el texto original: «composición magnífica y espléndida, dividida en partes a sólo un pensamiento endereçadas» (composizione magnifica e splendida, e divisa in parti ad un sentimento indrizzate). Vid. CASCALES, Francisco: Tablas poéticas, ed. de Benito Brancaforte. Madrid: Espasa-Calpe, 1975, p. 237. 
Las estancias pueden ser continuadas o divididas. Estas últimas pueden ser, a su vez, simples y compuestas. Las simples constan de fronte y sirima; y las compuestas, de pies y versos. La cosa se complica aún más, puesto que tanto la fronte como la sirima pueden ser simples o compuestas. Además, «si la fronte es simple, conviene que la sirima sea compuesta». A partir de aquí, nos sumerge Minturno en un piélago interminable de frontes simples y compuestas, sirimas simples y dobles, partes, números, sílabas, versos, pareados, tercetos, cuartetos, estancias, vueltas y revueltas.

En los cuartetos, las rimas pueden ser cruzadas , «por derecho» (per diritto), abab, o abrazadas, «por oblicuo» (per obliquo), abba. Los tercetos pueden relacionarse, asimismo, por la rima de diversos modos. Pone Minturno varios ejemplos, que se atienen a los siguientes esquemas: $a b c a b c, a b c c b a, a b c b a c, a b c a c b, a b c b c a, a b c$ $c a b$. Se advierte que «hay otros modos de consonancia en los tercetos». En efecto, sólo se han consignado las seis permutaciones posibles con los elementos $a, b$ y $c$ del segundo terceto, ya que el primero permanece inalterable. En todos los casos, los versos que se usan en la canción constan de once sílabas «en el estilo heroico, es decir, cuando narramos», o cuando la materia es «grave e ilustre»; por el contrario, se utilizan los versos de siete sílabas «cuando el estilo es cómico, o la materia ligera y suave».

Atención especial se le presta a la sextina, que se compone de seis estancias o estrofas, de seis versos cada una de ellas. «La primera estancia es $a b c d e f$, la segunda $f a e b d c \gg$, y así sucesivamente, siempre con las mismas voces finales, de manera que el primer verso termina con la misma palabra que el último de la estrofa anterior, el segundo con la del primero, etc. Se añade al final la sezzaia, o contera, «de tres versos enteros», en los que se repiten las seis palabras finales, «a dos por verso». Estas seis palabras finales han de ser «bellas, vagas, elegantes, redondas, sonoras; más bien nombres que verbos; y sustantivos más que adjetivos, y de dos sílabas».

Se podría aumentar el número de las estrofas, «pero hasta ahora no se encuentra más de una vez repetido», y esto por dos motivos: 
«por lo fatigoso de la composición»y «por evitar el fastidio que el repetir demasiado las mismas voces supondría». Si Minturno hubiera tenido la mente matemática de un Juan Caramuel (16061682), las posibilidades combinatorias habrían aumentado de una manera considerable. En efecto, Caramuel, con los seis versos de la sextina, obtuvo en su Rhythmica (1665) nada menos que 720 permutaciones (6!, esto es, factorial de 6) frente a las seis estrofas de la sextina tradicional ${ }^{124}$.

El soneto es también objeto de particular estudio. «iQué es un soneto? Composición grave y elegante con palabras, con armonía de rimas y con medida de sílabas tejidas bajo cierto número de versos y limitada bajo cierto orden». Se diferencia del epigrama, que es una parte de la poesía épica, mientras que el soneto corresponde a la poesía mélica. Soneto es palabra que remite al sonido, como la canción al canto. «Y no porque la voz sea diminutiva denota bajeza alguna del estilo, sino más bien elegancia y belleza». En el soneto no cabe la imperfección o la mediocridad: sin elegancia y sin belleza «esta composición es especialmente nula o vale poco». En el soneto, «las palabras son elegidas y ordenadas de un modo bello y elegante», y son portadoras de «un dulce sentimiento», o bien están compuestas «de un modo grave y agudo». El soneto tiene un número determinado de versos y un final previsto, «que no se puede traspasar», frente al epigrama, que no requiere un número preciso de versos, pues a veces no son más de dos o cuatro.

Como quiera que la definición propuesta para el soneto es muy semejante a la de la canción, y la materia de ambas composiciones «es a veces grave e ilustre», conviene precisar que el soneto «no la dilata», como hace la canción, que «se puede enriquecer y engrandecer con prerrogativas de variadas digresiones», sino que viste esa materia «de todas aquellas riquezas que por sí misma en su pequeño cuerpo puede recibir $\gg \mathrm{y} \ll$ no añade cosas ajenas para

${ }^{124}$ Vid. CARAMUEL, Juan: Rítmica, ed. de I. Paraíso y trad. de A. Carrera. Valladolid: Universidad, 2007. Y PARAÍSO, Isabel: «La sextina y su teorización en Juan Caramuel», en A. Álvarez y otros (eds.), Lengua viva. Estudios ofrecidos a César Hernández Alonso. Valladolid: Universidad y Diputación, 2008, pp. 1163-1181. 
adornarla». Por otra parte, mientras que en la canción hay un número indeterminado de estancias, «en el soneto no puede haber ni más ni menos de catorce versos». Ésta es, al menos, «la forma de los sonetos que está en uso».

$\mathrm{Al}$ igual que la canción, el soneto consta de dos partes: fronte $\mathrm{y}$ sirima. La fronte está formada por dos cuartetos, y la sirima por dos tercetos. Como vemos, cada una de estas partes se divide, a su vez, en dos: vuelta y revuelta, «semejantes e iguales en el número y en la medida de los versos, con el concento de las rimas $\gg$. Las rimas de los cuartetos pueden ordenarse «o por oblicuo: $a b b a$, o por derecho: $a b a b \gg$. Si el primer cuarteto se ordena por derecho, el segundo se podrá ordenar de cuatro modos: $a b a b, b a b a, b a a b, a b b a$. Y si el primer cuarteto se ordena por oblicuo, el segundo «se puede variar de otro tantos modos; de ellos, el primero es $a b b a$, y es el más usado; el segundo, $b a a b$; el tercero, $b a b a$; el cuarto, $a b a b$. Queda, así pues, establecido que el esquema más frecuente de los cuartetos es abba $a b b a$. Pero pueden darse además otras muchas disposiciones, entre las que se consignan $a b b b$ baaa, aaaa $b b b b$, $a b a b b b a a, a b a b a a b b$.

En lo que concierne a los tercetos, las rimas pueden ser dos, o tres, ordenadas por derecho o por oblicuo. Con dos rimas, se proponen los siguientes esquemas: $a b a b a b, a b a a b a, a a b b b a, a b b a b b, a b a a b b$, $a b b a b a, a b b b a b$. Con tres rimas: $a b c a b c$ («el primero y el más general de los modos», que es el que aparece en los sonetos de Petrarca), $a b c b a c, a b c c b a, a b c b c a, a b b a c c, a b c c a b, a b c a c b, a b a c b c, a b a b c c, a a b$ $c b c$. Puesto que «elegir la variedad es propio de la mélica», y ya que no es posible alterar el número de los versos, es en las rimas donde reside «esta libertad de poder variarlas».

Las rimas de los tercetos han de ser diferentes de las de los cuartetos. En efecto, «esta diferencia es muy usada» y es la que se da en el Cancionero de Petrarca. En cuanto al número de sílabas del verso del que se hace el soneto, es «de once, y de ningún otro verso desde el tiempo de Petrarca». Existen otros muchos tipos de soneto, pero $\ll$ los que no tienen suficiente elegancia o vaguedad se han ido abandonando del todo». 
Enumera Minturno los sonetos simples, comunes y dobles, con cola, continuados, con vuelta, encadenados, repetidos, retrógrados, mudos, esdrújulos, mixtos y de varias lenguas. Son simples cuando todos sus versos son de once o de siete sílabas; comunes, cuando hacen uso de ambas formas de verso; y dobles, cuando intercalan dos heptasílabos en cada uno de los cuartetos endecasilábicos, y un heptasílabo en cada uno de los tercetos. Los cuartetos se convierten así en sextetos, y los tercetos en cuartetos. También se pueden intercalar dos heptasílabos en los tercetos, que se convierten en quintetos.

En los sonetos con cola o caudati, se ponen dos versitos de cuatro o cinco sílabas después de cada dos endecasílabos en ambos cuartetos, y uno más después de cada terceto. Estos pequeños versos riman entre sí, pero no con los endecasílabos. En los sonetos continuados, los tercetos tienen las mismas rimas que los cuartetos. En los sonetos con vuelta, se añade al final un verso que rima con el último; o dos, que riman entre sí; o tres, de los cuales el primero es de siete sílabas y rima con el último verso del soneto propiamente dicho, y los dos siguientes constan de once sílabas y riman entre sí. Como puede observarse, éste es el modelo, llamado con estrambote, que habría de seguir el famoso soneto de Cervantes dedicado al túmulo de Felipe II.

En los sonetos encadenados, el comienzo de cada verso rima con el final del verso precedente. En los repetidos, es la última palabra de cada verso la que se repite al comienzo del siguiente. En los retrógrados, se puede hacer una lectura coherente de derecha a izquierda, o de izquierda a derecha. Los llamados mudos (muti) terminan en palabra aguda, mientras que los esdrújulos (sdruccioli) terminan en palabra esdrújula. Otros son mixtos, misti, de ambas clases de versos. Finalmente, existen sonetos compuestos en dos o tres lenguas.

Varias páginas ocupa el estudio de la balada y su represa. Por balada se entiende «una composición vaga, agradable, con palabras tejidas y ordenadas, apta para el canto y el baile, y dividida en partes dirigidas a un sentimiento deleitoso, sujeta a cierto canto y bajo cierto orden». Tras esta definición profusa, difusa y redundante -palabras 
ordenadas con cierto orden, composición apta para el canto y sujeta a cierto canto- se especifica que la materia de la que trata es el amor. No conoce Minturno «ninguna que trate de otra cosa», y se canta «en el baile, el cual que no es de hombres graves, sino de jóvenes alegres y de graciosas y bellas damas ».

Consta la balada de tres partes: represa, mudanza y vuelta. La represa (ripresa) es, como su nombre toscano indica, continuación o repetición, «porque, al final de ella, los que cantan vuelven a cantar»; la mudanza (mutatione) se llama así «porque en ella cambia el canto»; y la vuelta (volta), «porque vuelve el canto de la represa, a la cual en el número de versos y en la medida de las sílabas es semejante e igual».

La represa puede estar formada por un pareado, por un terceto, por un cuarteto, por un quinteto o por un sexteto. Los versos pueden ser todos de once sílabas, o todos de siete, o de una y otra clase. Generalmente, el pareado es de versos «enteros», de once sílabas. La mudanza consta de dos partes, y raras veces de tres. Podrá ser de dos pareados, de dos tercetos o de dos cuartetos; pero también de dos quintetos, o de dos tercetos. En cualquier caso, «tantos y cuáles versos tiene la primera parte, otros tantos y tales conviene que tenga la segunda», guardándose siempre la correspondencia de las rimas. Por su parte, la vuelta «se compondrá de tales y cuantos versos esté compuesta la represa», y sus rimas se dispondrán de modo que el primer verso de la vuelta se corresponda o bien con el último de la mudanza, tal como ocurre en todas las baladas de Petrarca, o con algún otro elemento de la misma.

Se consideran baladas pequeñas las que tienen represa de dos versos, medianas las de tres, y grandes las de cuatro, cinco o seis. Por otra parte, pueden ser simples y desnudas (semplici e ignude), o vestidas (vestite), llamadas también replicadas (riplicate) y empujadas (spingate). Éstas no tienen más que una represa; pero, «si la materia lo requiere, tienen dos o más mudanzas y vueltas con el mismo orden, que después de la mudanza sigue la vuelta». 
Definición análoga a la de la balada recibe el madrigal, que se considera como «una vaga composición de palabras, con armonía de rimas y con medida de sílabas, organizadas bajo cierto canto y bajo cierto orden». Se desarrolla «en torno a temas rústicos, de donde toma el nombre», pues procede de mandre (rebaños), de donde viene mandriale (pastor), que más tarde derivó a madrigale (madrigal).

La medida de los versos del madrigal es siempre de once sílabas, ya que «mirando los Cancioneros de los antiguos, no encontraréis en el madrigal versos quebrados». El número de los versos oscila entre ocho y once. El madrigal de ocho versos está compuesto por dos tercetos y un pareado, de acuerdo con los siguientes esquemas: $a b c a b c d d, a b a b c b c c, a b b \quad b a a c c, a b b c d d e e, a b a b a b c c$. El de nueve versos consta de tres tercetos: $a b b a c c c d d, a b a b a b b c c, a b c, a b c, c d d$, $a b b b a c c d d$. El de diez versos se compone de dos tercetos y un cuarteto: $a b a c b c d e d e$; o de tres tercetos y un verso de vuelta: $a b a b b c d d c$ $c, a b a b c b c d e e$. por último, el madrigal de once versos consta de tres tercetos y un pareado: $a b b c d d$ eff $g g, a b b c d d d e c f f$.

Aunque el libro tercero del Arte poética trata de la poesía mélica, y de sus composiciones, se hace una breve incursión en el terreno de la poesía épica para hacer constar que en esta poesía existen tres clases de composición: los serventesios, los romances y las rimas sueltas.

El serventesio «es voz provenzal» y consiste en «un decir largo, como se requiere en el poema épico». Las partes de las que se componen reciben el nombre de cantos, según Dante, y capítulos, según Petrarca. Se hacen con cuartetos o tercetos, siendo estos últimos los más frecuentes, entrelazados de manera que «el siguiente terceto concierta con el anterior solamente en el segundo verso, de este modo: $a b a d b d>$. El último terceto de la serie se convierte en un cuarteto, «pues se añade un verso al final, a modo de vuelta, el cual concierta con el segundo del terceto de este modo: $a b a b$ ». Análogamente, si se trata de una serie de cuartetos, el cuarteto final se convierte en quinteto, pues se añade también un verso que concierta con «el último del cuarteto de esta manera: $a b b c c »$. 
Los romances (romanzi) se conciben en relación con el verbo romanzare, esto es, novelar, materia que corresponde al libro primero del Arte poética: «Pero de los romances se ha dicho bastante en el primer diálogo».

En cuanto a las rimas sueltas, «no sometidas a ninguna norma, a las cuales sometemos las canciones, los sonetos, las baladas, las frótolas, los madrigales, los serventesios y las estancias», se hace ver cómo «la poesía siempre se reservó y se reservará la libertad para componer». Mención expresa se hace de la octava real, u octava rima, «composición vaga y grave, a veces con imitación de actos dignos de la poesía épica», con versos dispuestos «de este modo: $a b a b$ $a b c c »$. Existen, así pues, tres rimas «de las cuales se responden por orden derecho el primero al primero, el segundo al segundo», y la última rima «queda integrada en un pareado concorde». De estas octavas rimas «se componen aquellas que por excelencia se llaman estancias», por su agradable armonía y por su adecuada extensión, que no es tan breve como el terceto o el cuarteto, ni larga con exceso.

Composición propiamente mélica es la frótola, usada por los modernos, que está hecha con versos de ocho sílabas. Su estilo es «bajo, pero agradable y agudo», y sirve muy bien para «bromear con proverbios y con dichos festivos». Es conocida también cono balada o barceleta. La frótola es, en verdad, semejante a la balada, «pues tiene represa, mudanza y vuelta». Existen varios modelos. Uno de ellos es el que marca la siguiente frótola de Lorenzo el Magnífico:

Donne belle io hô cercato

Lungo tempo del mio cuore:

Ringratiato sia tu Amore,

Ch'io l'ho pur al fin trovato.

Ell'è forse in questo Ballo,

Che'l mio cuor furato havia:

Hallo seco, e sempre havrallo,

Quanto sia la vita mia. 
Ell'è si benigna e pia,

Ch'ella havrâ sempre il mio cuore.

Ringratiato sia tu Amore;

Ch'io l'hô pur al fin trovato.

La primera estrofa constituye la represa, «de pareados concordes entre ellos oblicuamente»; la segunda estrofa es la mudanza, también de cuatro versos, o dos pareados, que ahora «conciertan por derecho». La tercera estrofa representa la vuelta. Remite ésta a la represa, pero de forma que su primer verso rima con el último de la mudanza, mientras que los tres siguientes tienen la misma rima que la represa. Los dos últimos versos de la vuelta son una exacta repetición de los dos últimos de la represa.

Otro modelo, con vuelta de sólo dos versos, pero con repetición de la represa, es la siguiente frótola de Serafino:
Ah, ah, ah, chi non ridesse
D'una si diforme vecchia;
Che per bella ogn'hor si specchia,
Pur com'altri le credesse.
O'tenace openione,
Quanti tu ne'nganni al mondo:
Contra te non val ragione:
Crudeltâ tu metti al fondo.
Solo à te pensier giocondo
Le menzogne son concesse.
Ah, ah, ah, chi non ridesse
D'una si diforme vecchia;
Che per bella ogn'hor si specchia, Pur com'altri le credesse.

La represa consta aquí de dos pareados con rimas por oblicuo, esto es, abrazadas. Se trata, en otras palabras, de una redondilla. La 
mudanza está formada también por cuatro versos con rimas por derecho, cruzadas. Consiste, por lo tanto, en una cuarteta. La vuelta es de dos versos, de los cuales el primero rima con el último de la mudanza, y el segundo con el primero de la represa. Ésta se repite, seguidamente, en su integridad.

Finalmente, en el libro tercero de la Poética toscana se hace referencia a la elegía, «común de los griegos y de los latinos», y a la sátira, «propia de los latinos», pues «es cosa digna que una y otra poesía no falte en nuestra lengua». También se dedican algunas páginas a la poesía yámbica y a los epigramas.

La elegía es «imitación de un suceso completo, lamentable, que se hace en tercetos». Aunque al principio «consistía en un lamento funeral y en alabar al muerto», más tarde se aplicó también a «cosas más ligeras», como los amores, ya que «los amantes, siendo por naturaleza aptos y dispuestos para lamentarse, parece que hicieron suya esta poesía».

La sátira es «imitación de un suceso vicioso y censurable, con versos desnudos y puros». El lenguaje ha de ser «sencillo y limpio», pero también «agudo», para reprender el vicio y tratar de enmendar la vida, con una visión «más bien universal que particular». En esto se diferencia de la poesía yámbica, «que reprende vicios de los particulares». Ariosto demostró que «se puede escribir la materia satírica perfectamente en tercetos», aunque, según Minturno, «le van bien las rimas sueltas y desnudas de consonancia». Por su parte, la poesía yámbica se puede escribir con versos de once o siete sílabas, en pareados, tercetos o cuartetos, y también en quintetos y sextetos. En cualquier caso, «las rimas sueltas de consonancia estarían muy bien en esta composición».

En cuanto al epigrama, se trata de una pequeña composición «con la cual se describe brevemente y agudamente todo lo que es digno de no ser olvidado». La brevedad es fundamental en el epigrama, que puede llegar a constar incluso de un solo verso, o de un pareado «con un verso de once sílabas y otro de siete», o con la misma medida, enlazados o no por la rima. 
En el libro cuarto ${ }^{125}$ se trata de las sentencias (sentenze) y las palabras (parole), a través del diálogo que tiene lugar entre Ferrante Carafa y Minturno. Se acude a la autoridad de Aristóteles que define la sentencia como «lo dicho, pero no todo, sino lo que se debe seguir como cosa excelente y buena, o evitar, como triste y mala».

Contiene este libro algunas observaciones de interés para la métrica, entre ellas las relativas a los diptongos. Unos «proceden de la lengua romana y de la griega $\gg$, otros son propios de la lengua toscana. En ocasiones, dos vocales contiguas se pronuncian separadamente. Así, la palabra oime consta de tres sílabas (o-i-me):

Oime terra è fatto il suo bel viso

( o-i-me-te-rraè-fat-toil-suo-bel-vi-so)

Pero también se puede dar una «reunión de vocales, que en griego se llama synaíresis». De esta manera, mediante la sinéresis, oime constaría sólo de dos sílabas:

Oime'l bel viso, oime'l soave sguardo

(oi-me'l-vi-so-oi-me'l-soa-ves-guar-do)

Algunas vocales contiguas, como ai, ei noi, forman diptongo al principio o en medio del verso; pero, al final, se pronuncian separadamente, como en fai (fa-i), lei (le-i), noi (no-i). Por otra parte, en la lengua toscana, también es posible «pronunciar tres vocales juntas, lo que podría llamarse triptongo», como iuo en lacciuolo.

El encuentro entre vocales puede tener lugar entre la última vocal de una palabra y la primera vocal de la palabra siguiente, ante lo cual cede una de estas dos vocales, es decir, se produce la elisión de una vocal, aunque Minturno no hace uso de este término. Así, encontramos ch'ascoltate, en lugar de che ascoltate, o la've en lugar de là ove. Puede también ocurrir que las vocales «se fundan totalmente», aunque «una y otra se oigan», produciéndose así la sinalefa, término que tampoco utiliza Minturno. Es lo que ocurre en la expresión siete offesi, donde se une la $e$ final de siete con la $o$ inicial de offesi.

125 Las citas están tomadas de las páginas 282, 290-291, 298-300, 321-345, 356-362 y 451 del original (726, 741-743, 757-761, 803-851, 873-885 y 1063 de la traducción). 
Por lo que respecta a la rima, «la consonancia se entiende no con la escritura, sino con el sonido». Por eso pecto rima con metto, y sancto con tanto. En ocasiones, se asimila la $i$ a la $e$, y la $u$ a la $o$. De ahí que los antiguos rimaran crede con vidi, y virtude con prode.

En cuanto a las palabras que se emplean en el verso, se hace constar que no son en realidad diferentes de las de la prosa, aunque los gramáticos mantienen lo contrario, diciendo que «tiene más licencia el poeta al versificar y al componer las voces», atendiendo más al sonido de las palabras que a las cosas «para dar placer a los oídos». Pero lo cierto es que las palabras que utiliza Boccaccio en la prosa son las mismas que emplea Petrarca en el verso. Carece de sentido el afirmar que en el verso abundan más las palabras del género masculino, como nuvolo o nuvileto, y en la prosa las del género femenino, como nuvola o nuvileta.

En cualquier caso, se debe hacer buen uso de las aliteraciones y de palabras sugerentes, «de modo que la misma voz diga lo que se quiere expresar». Entre los juegos aliterativos, se alude a la paronomasia, con voces que «tengan las mismas consonantes y no se cambie más que alguna vocal», como amore y amaro, o torre y terra. Las «concordancias de letras o de sílabas» son a veces casuales, «sin que nosotros las busquemos»; pero otras veces son «buscadas y encontradas» por el poeta «con mucho estudio». En los siguientes versos se imita, respectivamente, «el dulce temblor del aura»y «el gemido del ruiseñor $\gg:$

E fra le fronde fremer dolce l'aura.

Tutte le notti si lamenta e piagne.

Para que los versos estén bien compuestos, hay que tener también en cuenta el número de sílabas, porque si «las palabras de una sílaba son muchas juntas, el habla parece ir a saltos cortos y frecuentes». En efecto, «las partículas de una sílaba hacen el verso lentísimo», y «aumentan la velocidad las que tienen acento en la tercera silaba delante de la última», como bellíssimo, tímido, plácido, con las que los latinos hacían los versos anapésticos y dactílicos, y los toscanos los esdrújulos. La voz «más larga que puede caber en 
el verso en lengua toscana» es la de siete sílabas, como la palabra invisibilemente, utilizada por Petrarca:

Che'nvisibilemente i'mi disfaccio

En el verso, junto a las sílabas, hay que hacer consideración de los acentos, que son «un accidente de la voz, cuando se eleva o se baja, o se adapta al entorno». Pueden ser agudos, graves y oblicuos. Son agudos «cuando la voz se eleva», y graves «cuando se baja». El acento oblicuo, «que en latín se llama circunflejo», es aquel que «se adapta al entorno», de manera que, «según sea, se eleve o se baje». De las sílabas agudas y graves, pasa Minturno a hablar de las largas y breves. La sílaba es «larga por naturaleza» en suôno, cuôre, dolôre, y también lo es cuando «está seguida de dos consonantes», como ocurre en las palabras verso, corso, morto.

Cuando en verso termina en palabra aguda, la última sílaba «vale dos». Por el contrario, si termina en palabra esdrújula, las dos últimas sílabas no valen «más que una». Además del acento final del verso, existen otros en distintas posiciones. Así, en el heptasílabo, puede ir el acento en la segunda sílaba, en la tercera o en la cuarta.

Leggiádra ricoverse.

Con l'angélico seno.

L'alma dubbiósa e vaga.

En el endecasílabo, el acento puede incidir sobre la sílaba cuarta, o la sexta, o cuarta y octava, o sexta y octava; o cuarta, sexta y octava:

Se la mia vita da l'aspro tormento.

La notte che seguîl'horribil caso.

Rapido fiume, che d'alpéstra vena.

Di pensier in pensiér, di mónte in monte.

Spirto gentîl, che quélle mémbra reggi.

Cuando el acento recae sobre la sílaba cuarta, el endecasílabo es «más grave y más parecido al sáfico». También ha de caer en la 
octava, o en la sexta, ya que «el que es menos cohesionado es el que tiene el acento solamente en la cuarta». La variedad de ritmos será, en todo caso, la base de la buena versificación.

Los versos se relacionan entre sí mediante las consonancias, que algunos consideran como «el alma» de los versos, hasta el punto de que si fuesen privados de ella «perderían la vida». Pero no es así, porque «la consonancia es una cualidad del verso que entre los griegos y los latinos se consideró vicio». Hace constar Minturno que, gracias a «la excelencia de los buenos ingenios», era posible oír en su tiempo «las rimas (rime) que se llaman sueltas o desnudas».

Con el término rime se hace referencia a los versos y a las composiciones en general, de ahí que se pueda hablar de rimas sueltas o desnudas, es decir, carentes de la «consonancia» que hoy conocemos propiamente con el nombre de rima. Porque «el alma del verso, que es la medida de las sílabas bajo cierto número sometida, lo es sin la cohesión y los ornamentos de la consonancia». Puntualiza Minturno que se debe entender «por versos los latinos, y por rimas las composiciones vulgares». Ocurre que «el número de voces concordantes, que entre los griegos se llamaban ritmos (rhythmi), fueron llamados corruptamente, primero por los bárbaros y después por los nuestros, rimas (rime)». Y «rimas también se llamaron los versos que se adornaron de tales consonancias». Éstas pueden darse entre versos contiguos, o separados por «algún pequeño intervalo»; y «son menos deleitosas las que se responden de más lejos».

Al final de la obra, se pone de manifiesto -por boca de Vespasiano, interlocutor del primer diálogo- cuánto le debe a Minturno el estudio de la poesía. Del mismo modo que las Musas latinas han llegado hasta los tiempos modernos, las Musas toscanas «no tienen una obra más provechosa ni más digna de ser leída» que L'arte poetica. Minturno habría sido «el primero en dar perfectamente y poéticamente instrumentos tanto a los toscanos como a los latinos», siguiendo «el camino que Aristóteles y Horacio nos mostraron», por donde transitaron «Homero, Virgilio, Petrarca y Dante, y todos los antiguos que fueron apreciables». 
Como hemos tenido ocasión de ver, la Poética toscana de Antonio Sebastiano Minturno contiene un extenso repertorio de consideraciones sobre la versificación italiana, que constituye un no desdeñable tratado de métrica renacentista. Algunas de las composiciones estudiadas -el soneto, la octava real, la sextina- son formas canónicas que han perdurado hasta nuestros días. Otras, como la balada o el madrigal, tienen sólo un interés histórico. Habría también que destacar el papel que se le otorga al estudio del cómputo silábico y a la distribución acentual, si bien las sílabas tónicas, marcadas por el acento, se consideran como agudas o como largas; y las átonas, no marcadas, como graves o breves. Para el cómputo silábico, se tienen en cuenta, además de la unión vocálica de los llamados diptongos y triptongos, los fenómenos de la elisión, la sinalefa y la sinéresis.

Pero tal vez la aportación fundamental de la métrica de Minturno sea la consideración del verso italiano por excelencia, el endecasílabo, como «verso entero», esto es, como unidad rítmica fundamental del conjunto poemático y no como mero ensamblaje de unidades menores o pies métricos. Esta idea habría de ser fielmente recogida por los tratadistas españoles de la época. Así, Juan Díaz Rengifo nos habla en su Arte poética española (1592) del verso italiano entero y de su quebrado, que «se compone de siete syllabas ${ }^{126}$. Como es natural, Rengifo considera también como entero el verso tradicional castellano, el octosílabo, y cita como ejemplo las coplas de don Jorge Manrique, que «se componen de dos versos enteros, y luego un quebrado; luego otros dos enteros, y otro quebrado $\gg$. Del mismo modo, Francisco Cascales distingue los versos castellanos de los italianos: «Éstos, unos son enteros; otros, rotos $\gg^{128}$. Pero también el verso específicamente castellano, el octosílabo, puede tener su quebrado, «que es la mitad de un

\footnotetext{
126 DÍAZ RENGIFO, Juan: Arte poética española. Salamanca: Miguel Serrano de Vargas, 1592 , p. 15.

${ }^{127}$ Ibíd., p. 26.

128 CASCALES, Francisco: Tablas cit., p. 114.
} 
entero $\gg^{129}$, y aduce asimismo el ejemplo de las coplas de don Jorge Manrique.

La edición bilingüe de L'arte poetica (Arte poética), llevada a cabo por la profesora María del Carmen Bobes Naves, aparece con el texto italiano y el español enfrentados, en páginas pares e impares respectivamente, lo que facilita en todo momento la confrontación de la versión española con la obra original, que reproduce en facsímil la edición príncipe (G. Andrea Valvassori, Venecia, 1564).

Su título completo es L'arte poetica del Sig. Antonio Minturno, nella quale si contengono i precetti Heroici, Tragici, Comici, Satyrici, e d'ogni altra Poesia: con la dottrina de'sonetti, canzoni, et ogni sorte di Rime Thoscane, dove s'insegna il modo, che tenne il Petrarca nelle sue opere. Et si dichiara a'suoi luoghi tutto quel, che da Aristotele, Horatio, et altri auttori Greci, e Latini è stato scritto per ammaestramento di Poeti. Los ladillos o anotaciones marginales, que se deben a Valvassori, se traducen también y se colocan en el margen correspondiente del texto español.

129 Ibíd., p. 123. 



\section{LASANOTACIONESDE FERNANDO DE HERRERA}

$\mathrm{E}$

n el año 1580, se publicaron por primera vez en Sevilla las Obras de Garcilaso de la Vega con anotaciones de Fernando de Herrera, que edita y comenta treinta y cinco sonetos, cinco canciones, dos elegías, una epístola y tres églogas del poeta toledano. Con excepción de la epístola, cada una de las otras formas poemáticas va seguida de una extensa disertación de corte fundamentalmente histórico y erudito. Pero lo más interesante son los comentarios puntuales que hace a determinados versos, que nos revelan a un profundo conocedor de las teorías poéticas vigentes en la segunda mitad del siglo XVI y a un crítico literario extraordinariamente perspicaz y sensible.

Se ha venido repitiendo y poniendo énfasis en la importancia de Fernando de Herrera como «el primer crítico literario español», según ha escrito recientemente Rocío Badía ${ }^{130}$, quien aduce como citas de autoridad algunos trabajos de Oreste Macrì ${ }^{131}$, José Almeida ${ }^{132}$

130 BADÍA FUMAZ, Rocío: «Aspectos de la creación poética en las Anotaciones a la poesía de Garcilaso de Fernando de Herrera», Tonos digital. Revista electrónica de estudios filológicos, 2, 2013, $18 \mathrm{pp}$.

131 MACRÌ, Oreste: Fernando de Herrera. Madrid: Gredos, 1972.

132 ALMEIDA, José: La crítica literaria de Fernando de Herrera. Madrid: Gredos, 1976. 
y Manuel Ángel Vázquez ${ }^{133}$, además de hacerse eco de la opinión mayoritaria de Antonio Vilanova ${ }^{134}$, para quien las Obras de Garcilaso de la Vega con anotaciones de Fernando de Herrera ${ }^{135}$ constituirían «la más importante arte poética española del siglo XVI», junto a la Filosofía antigua poética de Alonso López Pinciano. En este mismo sentido, Pedro Piñero ${ }^{136}$ hace constar que el crítico y poeta sevillano habría conseguido formular con sus Anotaciones la primera gran poética de la historia de la literatura española.

A decir verdad, ya a finales del siglo XIX, Marcelino Menéndez Pelayo $^{137}$ había hecho ver la importancia de las Anotaciones de Fernando de Herrera, en competencia con las notas del Brocense, aparecidas seis años antes. Constituirían dichas Anotaciones «una cabal arte poética», elaborada a partir de los amplios conocimientos de los clásicos y de los italianos, así como de sus propias experiencias. Según Menéndez Pelayo, Herrera reunía todas las condiciones del auténtico humanista y hombre de letras: «era un gran crítico, un idólatra de la forma». En contraste con las notas eruditas, exegéticas, centradas en el estudio de las fuentes, de Francisco Sánchez de las Brozas ${ }^{138}$, las de Fernando de Herrera constituyen un verdadero curso de teoría literaria y su autor se nos revela como el primero de nuestros críticos del siglo $\mathrm{XVI}^{139}$. Con objeto de matizar y sopesar

133 VÁZQUEZ MEDEL, Manuel Ángel: Poesía y poética de Fernando de Herrera. Madrid: Narcea, 1983.

134 VILANOVA, Antonio: «Preceptistas españoles de los siglos XVI y XVII», en Guillermo Díaz Plaja, ed.: Historia general de las literaturas hispánicas, III. Barcelona: Barna, 1953, pp. 565-692.

135 HERRERA, Fernando de: Obras de Garci Lasso con anotaciones. Sevilla: Alonso de la Barrera, 1580.

136 PIÑERO RAMÍREZ, Pedro: «Fernando de Herrera, Anotaciones a la poesía de Garcilaso», Minerva Baetica, XXX, 2002, pp. 305-313.

137 MENÉNDEZ PELAYO, Marcelino: Historia de las ideas estéticas en España, 1883. $4^{\mathrm{a}}$ ed. Madrid: CSIC, 1974, pp. 733-735.

138 SÁNCHEZ [DE LAS BROZAS]. Francisco: Obras del excelente poeta Garci Lasso de la Vega. Con anotaciones y emiendas, 1574. (Ed. Madrid: Luis Sánchez, 1600).

139 Como advierte Juan Montero (1997: 92), «Herrera se olvida momentáneamente 
estas aseveraciones, el presente trabajo ofrece una atenta lectura de las Anotaciones, muy próxima al texto, en la que se ponen de relieve los conceptos y los términos utilizados por Herrera, referentes a la métrica y a la teoría del lenguaje figurado y tropológico.

De la edición de las Anotaciones de 1580, existen decenas de ejemplares, en España y fuera de España, y concretamente, en Sevilla -ciudad natal del teórico, crítico y poeta-, dos en la Biblioteca General de la Universidad de Sevilla (Signs. Res 11-5-11 y Res 213-19), y uno en la Biblioteca Capitular y Colombina (Sign. 88-510). Recuerdo la emoción que me produjo en su día tener entre mis manos un ejemplar de la edición princeps de las Anotaciones en la comúnmente conocida como Biblioteca del Rectorado, con motivo de una exhaustiva consulta de sus fondos antiguos para el estudio del pensamiento español en torno a la lengua y la literatura en la segunda mitad del siglo $\mathrm{XVI}^{140}$. En lo que concierne a la relación entre las palabras y las cosas, junto al parecer del licenciado Pedro de Guevara, para quien «de quanto se puede tratar, o son cosas, o conceptos, o vozes $>^{141}$, o del doctor Juan Sánchez Valdés de la Plata, que indica que la lengua es «intérprete y mensagera del entendimiento ${ }^{142}$, resplandecían las anotaciones de Fernando de Herrera

de su labor de editor para poner todo el énfasis en realizar la de comentarista y crítico de los versos garcilasianos», poniendo así de manifiesto que sus planteamientos «son bastante distintos de los que habían animado al Brocense». Vid. MONTERO, Juan: «Las Anotaciones, del texto al lector», en Begoña López Bueno, ed.: Las «Anotaciones» de Fernando de Herrera. Doce estudios. Sevilla: Universidad, 1997, p. 92. En esta misma línea, Valentín Núñez Rivera (1997: 116) hace ver cómo Fernando de Herrera, «a pesar de tener en cuenta en todo momento para su trabajo la edición de 1574, no nombra ni una sola vez al Brocense». Vid. NÚÑEZ RIVERA, J. Valentín: «Garcilaso según Herrera. Aspectos de crítica textual en las Anotaciones», en Begoña López Bueno, ed., cit., p. 116.

140 Vid. TORRE, Esteban: Sobre lengua y literatura en el pensamiento científico español de la segunda mitad del siglo XVI. Sevilla: Universidad, 1984.

141 GUEVARA, Pedro de: Breve y sumaria declaración de la Arte general. Madrid: Pedro Madrigal, 1580, p. 14.

142 SÁNCHEZ VALDÉS DE LA PLATA, Juan: Coronica y historia general del hombre. Madrid: Luis Sánchez, 1598, p. 140. 
al Soneto XI de Garcilaso, en las que se afirma que «las palabras son imágenes de los pensamientos»y, precisamente por eso, conviene que sean claras, llanas, enteras. Cierto es que, muchas veces, hay oscuridad en los pensamientos, pero «no deve oscurecerse más con las palabras, porque basta la dificultad de las cosas $\gg^{143}$.

Desde 1973, disponemos de una edición facsimilar, inicialmente preparada por Alfredo Carballo, y prologada finalmente por Antonio Gallego Morell ${ }^{144}$, quien con anterioridad había publicado un importante trabajo sobre Garcilaso de la Vega y sus comentaristas ${ }^{145}$. Una segunda edición facsímil, con estudio biobibliográfico, fue publicada en 1998 por Juan Montero ${ }^{146}$. En 2001, aparece la edición de Inoria Pepe Sarno y José María Reyes Cano ${ }^{147}$, con un aparato crítico insuperable, que incluye variantes, problemas textuales, fuentes, fundamentos teóricos y todo tipo de datos históricos y referencias mitológicas. La lectura está facilitada por la modernización de los moldes de imprenta, la puntuación y los signos diacríticos. Se harán todas las citas teniendo en cuenta el texto de esta edición, señalando el poema concernido y, en su caso, la línea del verso correspondiente al comentario herreriano.

Dedica Fernando de Herrera a cada uno de los géneros poéticos de Garcilaso, tras el Soneto I, la Canción I, la Elegía I y la Égloga I, una extensa parrafada o «discurso», en donde se definen y comentan las respectivas características de dichos géneros. Por lo

143 HERRERA, Fernando de: Ob. cit., p. 126.

144 GALLEGO MORELL, Antonio, ed.: Obras de Garcilaso con anotaciones de Fernando de Herrera. Madrid: CSIC, 1973.

145 GALlegO MORELL, Antonio, ed.: Garcilaso de la Vega y sus Comentaristas. Obras completas del poeta acompañadas de los textos íntegros de los comentarios de El Brocense, Fernando de Herrera, Tamayo de Vargas y Azara. $2^{\circ}$ ed. revisada y adicionada. Madrid: Gredos, 1972.

146 MONTERO, Juan, ed.: Obras de Garci Lasso de la Vega con anotaciones de Fernando de Herrera. E. facsímil con un «Estudio biobibliográfico. Sevilla: Universidades de Córdoba, Huelva y Sevilla / Grupo PASO, 1998.

147 PEPE, Inoria, y REYES, José María, eds.: Fernando de Herrera. Anotaciones a la poesía de Garcilaso. Madrid: Cátedra, 2001. 
que respecta a las formas estróficas, menciona el terceto, el terceto encadenado, el cuartel (cuarteto) y la octava real.

El soneto es «la más hermosa composición i de mayor artificio y gracia de cuantas tiene la poesía italiana i española». En ningún otro género se requiere más cuidado y pulcritud, ya que en él no se admite el menor error ni una sola palabra que sea «ociosa o vana». El tema ha de ser expuesto de una manera clara y sencilla, «huyendo la oscuridad i dureza »:

...y la brevedad suya no sufre, que sea ociosa, o vana una palabra sola. I por esta causa su verdadero sugeto i materia deve ser principalmente alguna sentencia ingeniosa i aguda, o grave, i que meresca bien ocupar aquel lugar todo; descrita de suerte que paresca propria $\mathrm{i}$ nacida en aquella parte, huyendo la oscuridad i dureza.

En realidad, estas palabras de Fernando de Herrera no son más que una mera traducción literal de un texto de Lorenzo de' Medici:

La brevità del sonetto non comporta, che una sola parola sia vana, ed il vero subietto e materia de' sonetti per questa ragione debbe essere qualche acuta, e gentile sentenza, narrata attamente, ed in pochi versi ristretta, fuggendo la oscurità e durezza ${ }^{148}$.

La correspondencia textual fue ya puesta de manifiesto por Gary Joseph Brown ${ }^{149}$, quien hizo ver que la fuente directa de Herrera, por lo que respecta a sus ideas sobre el soneto, reside en el Comento de Lorenzo de' Medici. Una reseña en las páginas 375-376 de la Revista de Filología Española (vol. LX, no 1/4, 1978-80) dio oportuna noticia de este importante hallazgo, indicando cómo, en cualquier

148 MEDICI, Lorenzo de': Comento de' miei sonetti, ed. de Tiziano Zanato. Florencia: Leo S. Olschki, 1991, p. 150. La primera edición del Comento de los sonetos de Lorenzo de' Medici data de 1554, realizada en Venecia por los hijos de Aldo Manucio, como añadido a una nueva edición de la Poesie volgari del «Magnífico». Existen manuscritos en distintas instituciones, entre ellas la Biblioteca Capitular y Colombina de Sevilla (Sign. 7-1-33).

149 BROWN, Gary Joseph: «Fernando de Herrera and Lorenzo de' Medici: The Sonnet as Epigram», Romanische Forschungen, LXXXVII, 1975, pp. 226-238. 
caso, «termina diciendo Brown, es Herrera el más lúcido y original de todos los preceptistas españoles del Siglo de Oro». En efecto, concluye Brown que, a pesar de que autores contemporáneos de Herrera, como el Prete Jacopín ${ }^{150}$, o investigadores recientes, como Adolphe Coster ${ }^{151}$, Robert Mills Beach ${ }^{152}$ o Robert Pring-Mill ${ }^{153}$, hayan podido criticar su plagiarism, las observaciones de Herrera sobre el soneto demuestran un profundo conocimiento que dimana inicialmente de su propia experiencia.

El favorable juicio de Brown no fue obstáculo para que algún tratadista ${ }^{154}$ presentara, cinco años después, los citados textos como algo novedoso, que vendría a revelarnos la «sumisión» de Fernando de Herrera al pasaje de Lorenzo de' Medici y su reprobable «proceder moral» ${ }^{155}$, poniéndose así en evidencia «el verdadero perfil deontológico de Herrera como artista» y su «dudoso valor ético ${ }^{156}$. Hasta su misma prosa es conceptuada mordazmente como «el castellano del andaluz». En consecuencia, la opinión de Menéndez Pelayo, según la cual las Anotaciones constituirían una lograda arte poética, asentada sobre su profundo conocimiento de

150 Para la polémica entablada entre Fernando de Herrera y el Prete Jacopín, vid. ASENCIO, José María: Fernando de Herrera. Controversia sobre sus «Anotaciones» a las obras de Garcilaso de la Vega. Sevilla: Sociedad de Bibliófilos Andaluces, 1870; MONTERO, Juan: La controversia sobre las «Anotaciones» herrerianas. Sevilla: Ayuntamiento-Alfar, 1987; MORROS, Bienvenido: Las polémicas literarias en la España del siglo XVI: A propósito de Fernando de Herrera y Garcilaso de la Vega. Barcelona: Quaderns Crema,1998.

151 COSTER, A.: Fernando de Herrera (El Divino), 1534-1597. París: Champion, 1908. 152 BEACH, Robert Mills: Was Fernando de Herrera a Greek Scholar? Filadelfia: Universidad de Pensilvania, 1908.

153 PRING-MILL, Robert: «Escalígero y Herrera: citas y plagios de los Poetices Libri Septem en las Anotaciones», Actas del Segundo Congreso Internacional de Hispanistas. Nimega, 1967, pp. 489-498.

154 LÁZARO CARRETER, Fernando: «Dos notas sobre la poética del soneto en los “Comentarios” de Herrera», Homenaje a F. Sánchez Castañer. Anales de Literatura Hispanoamericana, VIII, 1980, pp. 315-321.

155 Ibid., p. 319.

156 Ibíd., p. 321. 
los clásicos y de los italianos, y sobre sus propias experiencias, sería un juicio elaborado «con sensible rapidez ${ }^{157}$.

La cuestión de la copia o el plagio en las Anotaciones ha de ser considerada, en cualquier caso, desde una perspectiva histórica. Como señala Ángel Luis Luján ${ }^{158}$, la técnica de la copia era habitual y nada escandalosa en la época. Bienvenido Morros, que ha dedicado un extenso y bien documentado artículo a las fuentes de las Anotaciones ${ }^{159}$, hace ver cómo Herrera traduce unas veces al pie de la letra y otras se aparta del texto original: «en raras ocasiones menciona la fuente (o simplemente se refiere a un vago e indefinido "dicen algunos"), mientras que en las más la silencia ${ }^{160}$. Se trataría, en todo caso, «de una práctica generalizada entre los humanistas ${ }^{161}$.

Volviendo al «discurso» sobre el soneto, es preciso indicar cómo, para Herrera, la claridad y la sencillez que requiere este género no han de ser llevadas al extremo de que se pierdan «los números i la dinidad conveniente». La dificultad del soneto deriva de «estar encerrado en un pequeño y perpetuo espacio», y es mayor que en los versos latinos, «porque en nuestra lengua, assí como en la toscana, demás de los pies, que más por naturaleza que por alguna regla es necesario guardar en los versos, concurre también esta dificultad de las rimas», y ciertamente «nuestros versos no están faltos de pies, porque se pueden componer muchos que contengan onze sílabas sin que en ellos se perciba algún sonido de versos o cualquiera otra diferencia de la prosa».

\footnotetext{
157 Ibíd., p. 315.

158 LUJÁN, Ángel Luis: «Las Anotaciones de Herrera y las formas estilísticas de la tradición hermogeneana», Hispanic Review, 68, 2000, pp. 359-380.

159 MORROS, Bienvenido: «Las fuentes y su uso en las Anotaciones a Garcilaso», en Begoña López Bueno, ed.: Las «Anotaciones» de Fernando de Herrera. Doce estudios. Sevilla: Universidad, 1997, pp. 37-89.

160 Ibíd., p. 57.

161 Ibíd., p. 58. Sobre el concepto de la «imitación» en la poética renacentista, vid. PEGO PUIGBÓ, Armando: «Hipertextualidad e imitación (A propósito de los “espíritus de amor" de Garcilaso)», Revista de Literatura, 65, 2003, pp. 5-29.
} 
El verso endecasílabo, el metro central de la poética herreriana, ha de tener obviamente once sílabas. Pero no basta con esto. Hay que tener en cuenta también los «números» y los «pies», es decir, el ritmo y sus correspondientes pautas acentuales. En otro caso, las once sílabas no constituirían un auténtico verso, y no se diferenciarían en nada de la prosa. El soneto «consta de catorze versos endecasílabos i se divide en cuatro partes». Las dos primeras se llaman «en lengua italiana, del número de cuatro versos de que se compone, primero i segundo cuadernario, i cuartel en la nuestra». Las dos últimas partes, «de tres versos en que se cierra cada una, se apellidan primero i segundo ternario, o terceto».

En cuanto al «ritmo i consonancia», eso es, la rima, es la misma en los dos cuarteles o cuartetos, mientras que los tercetos llevan «cadencias» diferentes. En el soneto, los endecasílabos no han de estar siempre sometidos a la esticomitia. Por el contrario, se permite el encabalgamiento, «que cortar el verso en el soneto, como Quién me dixera, cuando en las pasadas / oras, no es vicio, sino virtud». En todo caso, «este rompimiento no á de ser contino, porque engendra fastidio la perpetua semejança».

Debemos a Francisco Petrarca el arte de los sonetos, porque él fue «el primero que los labró bien i levantó en la más alta cumbre de l' acabada hermosura i fuerça perfeta de la poesía», destacando también en este arte Iacobo Sannazaro y Pietro Bembo. En España, «aunque la poesía no es tan generalmente onrada i favorecida como en Italia», existen asimismo destacados sonetistas, sin que haya que remitirse «a la edad de Boscán, como piensan algunos», ya que el Marqués de Santillana es autor de algunos sonetos que son «dinos de veneración». Tras él vienen Juan Boscán ${ }^{162}$, Diego

162 Cita Herrera a Juan Boscán a continuación de Diego de Mendoza y Gutierre de Cetina. Lo deja en último lugar, precisamente porque le dedica una especial atención. No obstante, se ha querido ver en este hecho una prueba del «proceso de postergación cronológica al que es sometido el verso del barcelonés» (Javier Lorenzo, 2013: 167) en la recepción de Boscán en las Anotaciones de Herrera. Vid. LORENZO, Javier: «Sobre un silencio de Herrera: Jorge de Montemayor y el problema de la modernidad en las Anotaciones $\gg$, eHumanista, 17, 2011, pp. 478-495. 
de Mendoza, Gutierre de Cetina y, sobre todo, Garcilaso de la Vega, «príncipe de la poesía en nuestra lengua».

La canción es un poema lírico «nacido para alabanças i narraciones de cosas hechas, i deleites i alegrías i convites». Requiere este género «ingenio vivo i espiritoso, voluntad cuidadosa i trabajadora, juicio despierto y agudo, las vozes i oración polida, limpia, castigada, eficaz i numerosa». Acertadamente, relaciona Herrera los poemas líricos con las voces griegas $\grave{\delta} \delta \dot{~(c a n t o, ~ p o e s i ́ a ~ l i ́ r i c a), ~}$ $\mu \varepsilon \dot{\lambda}$ os (canto rítmico) y $\mu \circ \lambda \pi \dot{\eta}$ (canto unido al baile), «porque no se pronunciavan sin el canto i la lira». De ahí que Horacio llamara «Odas a sus libros, porque se cantavan».

Consta la canción de distintos «miembros, que se llaman estanças, cuyo número i modo de versos i rimas, junto con las vozes, que consuenan, puede colocar el poeta como le pareciere, i componer d' ellos la primera estança, siguiéndola sin variar en las siguientes». Reproduce Herrera las palabras de Pietro Bembo: en las canciones «se puede tomar cualquier número, tipo i rima de versos para componer la primera estrofa», pero «una vez escogidos, será necesario seguirlos en las otras con las mismas leyes que el poeta ha tomado libremente ${ }^{163}$.

Tiene «tres partes principales: principio, narración, salida o fin». El fin, la última estancia «se llama conviato en toscano». Hace Herrera una mención muy escueta de las estancias o partes de la canción, afirmando que la última estancia se llama conviato en la lengua toscana. En realidad, se refiere al commeatus (permiso, licencia para salir) latino, o commiato italiano.

Contrasta la brevedad en la descripción herreriana de las canciones con la gran extensión que le dedica algún tratadista en lengua

163 BEMBO, Pietro: Prosas de la lengua vulgar, ed. y trad. española de Oriol Miró. Madrid: Cátedra, 2011. Vid. PARAÍSO, Isabel: «Las teorías poéticas de Pietro Bembo en las Prose nelle quali si ragiona della volgar lingua $\gg$, Rhythmica. Revista española de métrica comparada, X, 10, 2012, pp. 133-155. Considera esta autora las Prose della volgar lengua de Pietro Bembo como la primera Gramática del volgare italiano. Su teoría métrica, en cambio, sería breve y generalista, no pasando de constituir un documento meramente curioso. 
toscana, como Antonio Sebastiano Minturno, a quien precisamente Herrera cita en varias ocasiones. Indica Minturno ${ }^{164}$ (2009) que las estancias pueden ser continuadas o divididas. Estas últimas pueden ser, a su vez, simples y compuestas. Las simples constan de fronte y sirima; y las compuestas, de pies y versos. La cosa se complica aún más, puesto que tanto la fronte como la sirima pueden ser simples o compuestas. Además, si la fronte es simple, conviene que la sirima sea compuesta. A partir de aquí, nos sumerge Minturno en un piélago interminable de frontes simples y compuestas, sirimas simples y dobles, partes, números, sílabas, versos, pareados, tercetos, cuartetos, estancias, vueltas y revueltas ${ }^{165}$. Es de agradecer la brevedad de Fernando de Herrera.

La elegía es una forma de poesía mélica, que, según Herrera, se llamó elegidia (plural de elegidion, pequeña elegía), porque se reunían las musas en Lesbos en las celebraciones funerales y solían prorrumpir allí en lamentaciones. Tras exponer diversas hipótesis sobre su origen, termina reconociendo, con Horacio, «que no se sabe su autor». En cuanto a la etimología del término, cita, entre otras, la acertada teoría de Pomponio Gáurico, quien sostenía que el término proviene de $\dot{\varepsilon} \lambda \varepsilon \gamma \varepsilon i ́ a$. Y se nos dice que ha de ser «cándida, blanda, tierna, suave, delicada, tersa, clara», y además «noble, congoxosa en los afetos i que los mueva en toda parte; ni mui hinchada ni mui umilde; no oscura con esquisitas sentencias i fábulas mui buscadas; que tenga frequente comiseración, quexas, exclamaciones, apóstrofos, prosopopeyas, escursos o parébases». Su ornato deberá ser «más limpio i reluciente que peinado i compuesto curiosamente».

Los españoles, cuya lengua «es sin alguna comparación más grave i de mayor espíritu i manificencia que todas las que más se estiman de las vulgares», lograron «hermosear sus escritos variamente con flores y figuras», y mostrar en ellos no sólo «carne i sangre»,

164 MINTURNO, Antonio Sebastiano: Arte poética, ed. y trad. española de María del Carmen Bobes Naves. Madrid: Arco/Libros, 2009.

165 Vid. TORRE, Esteban: «La métrica de Minturno», Rhythmica. Revista española de métrica comparada, VIII, 8, 2010, pp. 191-217. 
sino también «nervios». Y no ha de reputarse como falta «tener el estilo levantado, como no sea túmido, que es cuando uno emprende grandes cosas i no las acaba». Ciertamente es difícil «dezir nueva i ornadamente las cosas comunes», de ahí la importancia de «hazer nuevo lo que no lo es».

Por su parte, los italianos imitaron a los latinos en los tercetos, «que son dichosamente traídos de la elegía». Y «tomaron por nombre tercia rima i cadena», esto es, tercetos encadenados. En esta forma estrófica, fue Dante «el primero por ventura de todos, porque ante d' él no está en memoria quién lo supiese».

Las églogas, «llamadas propriamente églogas de $\dot{\kappa} \kappa \lambda \circ \gamma i \zeta \omega$, verbo griego que en el lenguaje romano sinifica seligo, en el nuestro escojo, como versos escogidos i bien compuestos, son el más antiguo género de poesía». Aunque su temática es variada, «parece que es más antigua la amatoria». Como quiera que los griegos escribieron las églogas en hexámetros, «en lengua dórica, es razón que fueron dóricos los inventores d' esta poesía». Se llamó bucólico «del nombre de los boyeros, que los latinos apellidan bvbulcos, i ßovkódovs los griegos, que es el más aventajado género de pastores; porque, como escrive Elio Donato, tres son los géneros de pastores que tienen dinidad en las bucólicas: los bubulcos, los opiliones (dichos casi como oviliones), que son ovegeros, i últimos de todos los épolos, que son los cabrerizos». Los temas de las bucólicas son «las cosas i obras de los pastores, mayormente sus amores, pero simples i sin daño, no funestos con rabia de celos, no manchados con adulterios; competencias de rivales, pero sin muerte i sangre $\gg$. Los pastores ofrecen a sus amadas dones que «tienen más estimación por la voluntad que por el precio, porque envían mançanas doradas o palomas cogidas del nido».

La dicción de las églogas es «simple, elegante»; los sentimientos, «afetuosos i suaves»; las palabras «saben al campo i a la rustiqueza de l' aldea, pero no sin gracia ni con profunda inorancia i vegez, porque se tiempla su rusticidad con la pureza de las vozes proprias al estilo». Los más destacados autores son Virgilio y Garcilaso «i 
al contrario Batista Mantuano i Iuan del Enzina, infacetíssimos escritores de églogas». Entre los griegos, destaca Teócrito, y entre los latinos, Virgilio. «Desde éstos hasta la edad de Petrarca i Bocacio no uvo poetas bucólicos». Últimamente, «florecieron Sanazaro i Gerónimo Vida». En España, «sin alguna comparación, es príncipe Garci Lasso».

Tras las octavas reales de la Égloga III, indica Herrera que «sin duda alguna fue autor de las estanças o rimas otavas Iuan Bocaccio». Estos versos «se llaman del número d' ellos otava rima, i se responden alternadamente desde el primero hasta el sesto verso en las vozes postreras, que se terminan semejantemente; i los dos que restan, que perfecionan i acaban el sentido, i por esso se llaman la llave en toscano, tienen unas mesmas cadencias, diferentes de las primeras».

Luego explica que rima proviene del griego pú $\vartheta \mu o ́ s$, que corresponde al numerus latino. De este comentario a la Égloga III se deduce, según Emiliano Díez Echarri, que Fernando de Herrera «identifica la rima con el ritmo», pues «confunde en un solo concepto rima y ritmo, dándoles idéntica etimología ${ }^{166}$. Es cierto: rima y ritmo tienen la misma etimología. No yerra en esto Fernando de Herrera. Pero es que, además, con el nombre de rima se designaba en el siglo XVI, en España, y no sólo en España, toda clase de composición poética. Por eso escribe Herrera que la rima es «una resonancia, dize el Trissino en su Poética, que resulta de cierta cantidad i calidad de sílabas puestas juntamente ${ }^{167}$. En definitiva, «rima es número y consonancia».

Por rima entiende Herrera la rima consonante. De ahí que tenga como «vicio» el «assonante». En los versos «estuvo halagando las culebras / de las hermanas negras malpeinadas» (Égloga II, 945-946) es asonante la rima al mezzo «culebras/negras». Y anota

\footnotetext{
166 DÍEZ ECHARRI, Emiliano: Teorías métricas del Siglo de Oro. Apuntes para la historia del verso español. Madrid: CSIC, 1949, pp. 105 y 120.

167 Vid. TRISSINO, Giovan Giorgio: La Poética, ed. y trad. española de Isabel Paraíso. Madrid: Arco/Libros, 2014, p. 97: «La rima es lo que los griegos llaman "rithmo" y los latinos "número"; por lo cual se puede decir que rima, ritmo y número son lo mismo. [...] Es una resonancia que resulta de cierta cantidad y cualidad de sílabas, puestas juntas según una norma».
} 
Herrera: «el assonante, que responde a esta voz, i los que ái en esta égloga, puedes i deves, acabo i hago, campo i blanco, sangre i estambre, quiere $\mathrm{F}$ [rancisco] de Medina que sea en nuestra lengua figura assonancia». Sucede esto «cuando la sílaba, que suena para la consonancia, es poco diferente del' antecedente como avía de ser». Esta figura «sirve para escusar el vicio, i no para imitallo». En cualquier caso, «à de ser con tan poca diferencia, que casi engañe al oído». Garcilaso hace uso en otros lugares de la rima al mezzo. Así, por ejemplo, en el primer parlamento de Camila, en la Égloga II, 721-725: «Si desta tierra no è perdido el tino, / por aquí el corço vino, qu' à traído / después que fue herido, atrás el viento. / ¿Qué rezio movimiento en la corrida / lleva, de tal herida lastimado?». No distingue Herrera entre la rima al mezzo y la rima interna de los versos leoninos, y anota en relación con los citados versos: «los versos, que los antiguos llamaron leoninos, i no sabemos por qué, son viciosos en la poesía latina».

Garcilaso utiliza ampliamente el endecasílabo blanco. No le pasó desapercibido a Herrera este extremo, y así apunta a continuación de la Epístola: «Estos versos, que por no ligarse con alguna lei de números de semejante cadencia en el último asiento, se llaman sueltos en el vulgar italiano». El «defeto de la consonancia» debe ser compensado con un cuidadoso «ornamento». Estos versos «son invención de los poetas modernos, porque no se halla memoria dellos en los antiguos italianos». Siguiendo a Cintio Giraldo, considera como «inventor destos versos al Trissino, que escribió en ellos la Italia libertada».

En conexión con el «número», esto es, el ritmo, la musicalidad del verso, está su medida, a la que Fernando de Herrera dedica una particular atención. Y cuestión capital para el cómputo silábico es el contacto entre vocales, ya sea en el interior de la palabra, ya sea entre palabras contiguas. Así, en el verso «iëndo m’ alexando cada día» (Soneto III, 3), Herrera pone la crema o signo de la diéresis sobre la $e$ (iëndo), y anota: «Diéresis o división, porque no se atan en este verbo estas dos vocales primeras, i con ellas se va apartando el verso». 
La diéresis o azeuxis «aparta», alarga, aleja el verso, haciendo de él un perfecto endecasílabo; pero es que, además, tiene un valor simbólico de alejamiento: «sinifica aquella disolución de letras el intento de Garci Lasso». En todo caso, apuntilla Herrera, «cuando no fuera natural división d'estos elementos, o no fuera hecho artificiosamente aquel desatamiento, lícito es distraer las vocales, pues vemos que Terencio hizo trisílabo uëro i cuadrisílabo ü̈rginem».

También utiliza Herrera el punto alto $\left(^{*}\right)$ como signo de la azeuxis. En relación con el verso «de áspera corteza se cubrían» (Soneto XIII, 5), escribe en nota dé áspera, señalando con el punto sobre la $e$ que Garcilaso «deshizo» la sinalefa. «El mesmo Lasso, en el Soneto 16: Mas infición dè àire en solo un día». Y pone otros ejemplos de versos propios, como «i la montañá ȧspera parece» $\mathrm{y}$ «Aquí no èntra quien no es desdichado». Para el verso «ipiensas qu' es otro el fuego qu' en Oèta ... ?» (Elegía I, 253), indica: «Aquí está desatado el diftongo de Oèta, que en nuestra lengua diremos Eta».

A propósito del verso «no quedarà ya tủ àlmà èntera» (Elegía I, 42), advierte: «Algunos, pareciéndoles que está falto este verso de Garci Lasso, no considerando la diéresis, lo an emendado, o dañado, d' esta suerte: no quedarà ya toda tu alma entera». $Y$ añade: «Pero Garci Lasso, que conocía mejor los números, se contentó con aquel modo; porque de más de sinificar assí la falta del' alma, que él pretendió mostrar, no es floxo número de verso, sino artificioso i no ageno de suavidad $\gg$. Como oportunamente señalan los atentos editores Inoria Pepe y José María Reyes ${ }^{168}$, se refiere Herrera a la enmienda propuesta por Francisco Sánchez el Brocense ${ }^{169}$. Pero, a decir verdad, en este caso resulta difícil mantener el ritmo o «número» del endecasílabo, que exigiría esta lectura: no.que.da.rá. ya.tu.al.ma.en.té.ra. Si la primera dialefa o azeuxis (tu / alma) es aceptable, no lo es tanto la segunda (alma / entera).

Distinto es el caso de la lectura herreriana del Soneto XXIII:

168 PEPE, Inoria, y REYES, José María: Ob. cit., p. 577.

169 SÁNCHEZ [DE LAS BROZAS], Francisco: Ob. cit., p. 17. 
En tanto que de rosa i açucena

se muestra la color en vuestro gesto,

i que vuestro mirar, ardiente, onesto,

enciende el coraçon i lo refrena...

El Brocense ${ }^{170}$ había escrito así el último endecasílabo de este primer cuarteto: «con clara luz la tempestad serena». Seguía el texto de la edición princeps de los poemas de Garcilaso de la Vega, editados como Libro IV en las obras de Juan Boscán ${ }^{171}$, si bien hace constar: «Otros leen Enciende el coraçón, y lo refrena» ${ }^{172}$. Pero Fernando de Herrera prefiere esta última lectura, y anota: «Assí se á de leer, i d' esta suerte dice don Antonio Puertocarrero que lo tiene de su suegro. Porque, como anda impresso, más sirve de sustentamiento del cuartel que de prosecución del intento». Piensa que la otra lectura nos ofrece un verso ripioso, de relleno, que sólo sirve «de sustentamiento del cuartel», es decir, para completar el cuarteto.

La elección de Fernando de Herrera no es caprichosa. La mirada de la doncella es ardiente, por lo que enciende el corazón; y, a la vez, es honesta, por lo que lo refrena. Así, escribe Herrera: «usa aquí Garci Lasso de hermosíssima figura, regressión o reversión, dicha

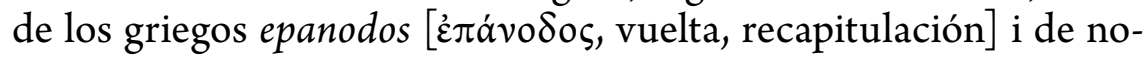
sotros rebuelta, cuando bolvemos a las palabras ya propuestas por causa de mostrar la diferencia». Es de lamentar que el hispanista Elias L. Rivers ${ }^{173}$, que no parece tener una especial simpatía por las Anotaciones en su edición crítica de las Obras de Garcilaso, desestime la feliz enmienda de Fernando de Herrera.

\section{${ }^{170}$ Ibíd., p. 8.}

171 BOSCÁN, Juan: Las obras de Boscán y algunas de Garcilasso de la Vega. Barcelona: Carles Amorós, 1543, p. 198.

172 SÁNCHEZ [DE LAS BROZAS], Francisco: Ob cit., pp. 81-81v., anotación 26. En la misma anotación, escribe el Brocense: «Este florido soneto es sacado del Tasso». Cita también a Ausias March, y añade: «Entrambos lo podrían sacar de aquel florido epigrama, que anda entre las obras de Virgilio, cuyo título es Rosa, y el postrer dicho dize assi: Collige, virgo, rosas».

173 RIVERS, Elias L., ed.: Garcilaso de la Vega. Obras completas con comentarios. Madrid: Castalia, 1981. 
Otras enmiendas de las Anotaciones son igualmente oportunas y estimables. Así, el verso «y más me duele el no osar deziros» (Soneto XXXVII, 3, de la edición de Rivers) aparece en la edición de Fernando de Herrera como «i más me duele nunca osar deziros» (Soneto XXXII, 3). Según Rivers, con esta enmienda o variante Herrera habría evitado «el hiato difícil» de $\left\langle\right.$ no osar» ${ }^{174}$. Aunque, a decir verdad, no era tan «difícil» este hiato, dialefa o azeuxis, ya que en la conciencia lingüística del hablante español del primer tercio del siglo XVI estaba aún presente el recuerdo del antiguo non, lo cual impedía la sinalefa o zeuxis entre «no»y «osar». Estimable es también la enmienda al verso «do quiera que sauces de oy más se hallen» (Égloga III, 359), que aparece en las Anotaciones como «do quiera que d'oi más sauzes se hallen».

La sinéresis o zeuxis aparece marcada por una tilde de acento circunflejo $(\wedge)$, o bien dos tildes (" " "'), que posiblemente sean un recurso alternativo del tipógrafo. Esto es lo que, por ejemplo, encontramos en el verso «Yo avîa jurado nunca más meterme» (Soneto VII, 9). Anota Herrera: «Este verbo es bisílabo por la sinéresis o contracción, que es juntamiento o encogimiento de dos sílabas en una, i d' esta suerte ai muchos versos en Garci Lasso».

En efecto, en los endecasílabos de Garcilaso es frecuentísima la sinéresis ${ }^{175}$, zeuxis o unión silábica de la vocal tónica $i$ con las vocales abiertas $a$ y $o$, como en «Hermosas ninfas qu' en el rîo metidas» (Soneto XI, 1). Se considera también sinéresis la unión silábica de las vocales cerradas $i$ y $u$, como en el verso «la claridad contempla, el ruîdo siente» (Canción IV, 98), al que anota Herrera: «Esta sinéresis o contración, que Diómedes llama episinalefa, es conjunción de dos sílabas en una, i es frequentíssima a Garci Lasso».

La zeuxis entre vocales de palabras contiguas, o sinalefa, también es tenida en cuenta por Herrera. Así, a propósito del Soneto XII, escribe: «En este soneto se hallan muchas sinalefas, que es el

\footnotetext{
${ }^{174}$ Ibid., p. 162.

175 TORRE, E.: «La perfección de algunos endecasílabos imperfectos de Garcilaso de la Vega, Rhythmica. Revista española de métrica comprada, X, 10, 2012, pp. 187-204.
} 
concurso de solas vocales, dicho propriamente en lengua latina elisión, o colisión, o concursión, i en la nuestra herimiento». Y, en relación con el verso «i si no lo fabrico i lo renuevo» (Elegía II, 163), indica que las vocales «suenan más dulcemente que las consonantes i assí hazen más blanda la oración i con más lenidad i no con tanto ruido i estruendo». Pero un exceso de vocales y el encuentro entre ellas harían que la oración fuera «llena demasiadamente i viciosa $\gg$ : «Llámase el concurso o herimiento i colisión de las vocales sinalefa

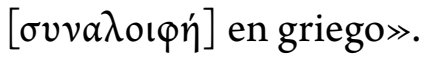

Hace uso Fernando de Herrera, como hemos tenido ocasión de ver, de los términos diéresis, sinéresis, sinalefa. Esta última se relaciona también con la elisión. Si tenemos en cuenta además los conceptos de hiato y diptongo, y en nuestros días la más reciente denominación de dialefa, como opuesta a la sinalefa, la terminología se complica y enmaraña, sobre todo cuando no existe una utilización unívoca de estos términos por parte de los distintos autores. De ahí la propues$\mathrm{ta}^{176}$, formulada en estos últimos años, de llamar sencillamente zeuxis a la unión silábica de dos o más vocales en contacto, y azeuxis a la separación de las mismas en sílabas diferentes, tanto en el interior de la palabra aislada como entre palabras contiguas. En cualquier caso, lo que persigue Herrera, con su peculiar notación de la diéresis o azeuxis (iëndo) y la sinéresis o zeuxis (avîa, rîo) en el interior de la palabra, así como de la dialefa, ausencia de sinalefa o azeuxis (montaña $\dot{a} s p e r a$, aquí nöèntra) entre palabras contiguas, es indicar claramente cuándo hay unión silábica o zeuxis $\left({ }^{\wedge}\right)$ y cuándo hay desunión o azeuxis ("en la palabra aislada, entre palabras contiguas).

La preocupación de Fernando de Herrera por la división silábica de las palabras y de las frases, con vistas a una adecuada escansión del verso, reaparecerá tres siglos más tarde en los escritos de

176 TORRE, Esteban: «Zeuxis y azeuxis en la configuración silábica», Rhythmica. Revista española de métrica comparada, IX, 9, 2011, pp. 183-199; y «Zeuxis y azeuxis: más sobre vocales en contacto», Rhythmica. Revista española de métrica comparada, XI, 11, 2013, pp. 187-205. 
Eduardo Benot. En un primer momento ${ }^{177}$, propone el polígrafo gaditano la colocación de dos puntos o crema para indicar la azeuxis: rïó, desafió; o bien una tilde como la del acento grave francés: riò, desafiò. Posteriormente, a partir de 1865, prefiere hacer uso del llamado subpunto ${ }^{178}$ : rịó, desafịó. En su monumental Prosodia castellana y versificación ${ }^{179}$ (Benot, 1892) utiliza ya sistemáticamente, tanto en el verso como en el texto doctrinal, el subpunto como índice tipográfico ${ }^{180}$, lo cual constituye un verdadero tesoro para los estudios de prosodia y para la ciencia del verso.

Tampoco se le pasan por alto a Fernando de Herrera los juegos aliterativos como elementos ornamentales y genuina expresión del simbolismo fónico. Así, en el verso «de mi bien a mí mismo voi tomando» (Soneto XIX, 5), anota: «Suave es i agradable el verso que tiene anominación en las sílabas, que es lo que dizen otros aliteración». Cita a Petrarca, en el Soneto I: «di me medesmo meco mi vergogno», que tradujo Garcilaso en la Égloga I: «i de mí mismo yo me corro agora». Y añade: «A esta concinidad de tres aliteraciones llama Marciano Capela, en el Libro 5, metacismo; cuando la conjunción de la voz se colide muchas veces con este elemento $m \gg$. En el verso «o a la que por el cielo congelado» (Canción I, 4), apunta: «Es landacismo, donde la $l$ suena muchas vezes». Y a propósito del verso «el humo sube al cielo, el son s' escucha» (Elegía II, 60), escribe: «Es sygmatismós, que ai tres $s$ en principio de 3 diciones» ${ }^{181}$.

177 BENOT, E.: Nuevo método del Dr. Ollendorf para aprender a leer, hablar y escribir un idioma cualquiera. Adaptado al italiano. Cádiz: Revista Médica, 1853, p. xxiv.

178 BENOT, Eduardo: Ollendorf reformado. Gramática inglesa, y método para aprenderla. Cuarta edición corregida nuevamente. Cádiz: Verdugo Morillas y Compañía, 1865 , p. 4: «Un punto colocado debajo de una vocal indica que esta vocal no forma diptongo con la siguiente».

179 BENOT, Eduardo: Prosodia castellana y versificación. Madrid: Juan Muñoz Sánchez, 1892. Ed. facsímil al cuidado de Esteban Torre: Anejo de Rhythmica. Revista española de métrica comparada, 2003

180 BENOT, Eduardo: Prosodia castellana..., cit., p. 5: «Un punto bajo una vocal indica que esta vocal no se junta a la sílaba siguiente ni el diptongo ni en la sinalefa».

${ }^{181}$ Y explica Herrera: «el lugar es de aquel maravilloso verso i lleno de celeridad, nec se 
Especialmente sensible es Fernando de Herrera al ritmo acentual. A propósito del verso «Cortaste 'l árbol con manos dañosas» (Soneto XXV, 3), advierte que «à de leerse haziendo assiento en el árbol». Es tan fuerte, en efecto, el acento de la sílaba 4a (ár-, de árbol) que todas las demás quedan debilitadas hasta llegar a la $10^{a}$ final. Así pues, podemos hacer la siguiente lectura: cor.tas.te'l.ár.bol. con.ma.nos.da.ñósas.

Aparecen otros endecasílabos en la obra poética de Garcilaso de la Vega con fuerte acentuación en las sílabas $4^{\text {a }}$ y $10^{\mathrm{a}}$, y con intensidades y tonos más atenuados en las sílabas intermedias. Este tipo de endecasílabo ha sido tildado a veces de verso «desmayado», aunque también puede considerarse como una variedad del endecasílabo sáfico:

$$
\begin{aligned}
& \text { pienso remedios en mi fantasía (Soneto III, 6) } \\
& \text { libre 'llugar a la desconfiança (Soneto IV, 4) } \\
& \text { en salvo d 'estos acontecimientos (Soneto XX, 6) } \\
& \text { Después acá de lo que consentí (Soneto XXVII, 5) } \\
& \text { a romper esto en que yo me metí (Soneto XXVII, 8) } \\
& \text { mas es a tiempo que de mi baxeza (Soneto XXVIII, 7) } \\
& \text { un dulce amor, y de mi sentimiento (Soneto XXXI, 2) } \\
& \text { me quexo a vos como si en la verdad (Canción II, 24) } \\
& \text { un campo lleno de desconfiança (Canción IV, 89) } \\
& \text { Algunos premios o agradecimientos (Elegía I, 92) } \\
& \text { se contradizen en lo que profieren (Elegía II, 15) } \\
& \text { Quál es el cuello que como en cadena (Égloga I, 131) } \\
& \text { hinchen el aire de dulce armonía (Égloga II, 69) } \\
& \text { al sueño ayudan con su movimiento (Égloga II, 76) } \\
& \text { Tras esto luego se me presentava (Égloga II, 1122) } \\
& \text { salir el humo de las caserías (Égloga II, 1871) }
\end{aligned}
$$

Todos estos versos han de leerse poniendo énfasis -haziendo assiento, según el sentir de Herrera- en la palabra portadora del acento

iam capit unda, uolat vapor ater ad auras, donde Virgilio puso tres $U$ en principio de 3 diciones». Este verso virgiliano (Aen., VII, 466) aparece citado en PONTANO, Giovanni: I dialoghi. Ed. de Carmelo Previtere. Florencia: Sansoni, 1943, p. 185. Vid. ALCINA ROVIRA, Juan Francisco: «Herrera y Pontano: la métrica en las Anotaciones», Nueva Revista de Filología Hispánica, XXXII, 2, 1983, pp. 340-354. 
correspondiente a la sílaba $4^{\text {a }}$. No se trata en absoluto de versos defectuosos, flojos o desmayados, sino que, por el contrario, las dos cúspides acentuales de las sílabas $4^{\mathrm{a}}$ y $10^{\mathrm{a}}$, en contraste con la suave atenuación rítmica de las restantes sílabas, cumplen un oportuno papel de moderación y contrapunto en la serie versal. Más que de descuido o defecto, habría que hablar de exquisita labor de cincelado poético.

Preocupado por la perfección del verso endecasílabo, no es extraño que Fernando de Herrera encontrara dificultades para justificar la existencia de «endecasílabos» de diez o de doce sílabas. Así, en relación con el verso «adonde para siempre avrán d'estar» (Canción II, 12), escribe: «Los versos troncados, o mancos, que llama el toscano, i nosotros agudos, no se deven usar en soneto ni en canción». Y explica que «cuando los versos mudan la propria cantidad, que o son menores una sílaba o mayores otra, si no muestran con la novedad i alteración del número i composición algún espíritu i sinificación de lo que tratan, son dinos de reprehensión». Es decir: deben evitarse, en principio, los versos de una sílaba menos (agudos) o una sílaba más (esdrújulos).

Por lo que respecta a los esdrújulos, y a propósito del verso «verde texida, aquel valle atajávamos» (Égloga II, 210), escribe: «Quieren algunos que estos versos de 12 sílabas nascan de los endecasílabos, quitando de la última región el troqueo, como haga, i repuesto en su lugar el dátilo, hágase». Dicho de otro modo, tales versos de doce sílabas tienen alguna relación con los auténticos endecasílabos, y trata Herrera de explicarlo acudiendo a los principios de la métrica clásica. Y añade: «Otros entienden que sea invención sacada de los líricos asclepiadeos, como Maecenas atavis edite regibus, que es de 12 sílabas i esdrúxulas en el fin con dos sílabas graves, después de la 10, aguda o larga como nuestros esdrúxulos». Explica así su etimología: «Tomaron nombre de aquella ligera pronunciación que tienen con celeridad en el fin, llamándose versos esdrúxulos, porque sdrucciolare es en italiano aquel deslizar i huir de pies que haze el que passa por cima del ielo». 
Considera, de acuerdo con el criterio general de la época, como sílabas «graves», o breves, las dos sílabas átonas (undécima y duodécima) que siguen a la tónica final (décima) del endecasílabo, «aguda o larga». Asimilar las sílabas tónicas a las largas de la métrica clásica, y las átonas a las breves, es un prejuicio que estuvo vigente hasta los años finales del siglo XIX, y que, en ocasiones, ha llegado hasta nuestros días, no sólo en la aclimatación de los pies métricos grecolatinos a las actuales cláusulas rítmicas, sino también en el cómputo de las terminaciones agudas y esdrújulas, otorgándosele a la tónica final de la terminación aguda el valor de dos tiempos silábicos, y a las dos postónicas de la terminación esdrújula el valor de un solo tiempo silábico. En cualquier caso, es digna de admiración la prudencia de la que hace gala Fernando de Herrera al abordar este tema. Admite la existencia de versos agudos de diez sílabas y esdrújulos de doce junto a los canónicos versos llanos de once sílabas, que serían propiamente los versos endecasílabos. Para los agudos y esdrújulos, que implican «novedad i alteración del número», exige un especial «espíritu» y cuidado.

En lo que concierne al lenguaje tropológico y figurado, la «metáfora», o «traslación», juega un papel central en la poética de Fernando de Herrera. Aparece ya mencionada en las primeras anotaciones. En el verso «i a ver los passos por do m' á traído» (Soneto I, 2), advierte que «los passos» son «metáfora o traslación del caminante». Y, en relación con el verso «mas cuando del camino estó olvidado» (Soneto I, 5), indica que «prosigue en la metáfora, i es apódosis o redición, que aplica lo dicho».

En «mis lágrimas an sido derramadas / donde la sequedad i l' aspereza / dieron mal fruto d' ellas i mi suerte» (Soneto II, 9-11), considera la sequedad como «traslación de la agricultura», y añade que «de todos los ornamentos poéticos, el que más frecuentemente se usurpa i más parece por exemplo en la poesía es la traslación». A renglón seguido, da comienzo a una extensa disertación sobre la metáfora, distinguiendo inicialmente entre el significado recto, o propio, y el figurado, o tropológico: $\ll$ Cada una de las cosas tiene su 
nombre, porque de otra suerte no podríamos hablar propriamente, aunque son más las cosas que se an de sinificar que las palabras i los proprios que las sinifican».

Las palabras, como dice Aristóteles, son «proprias o agenas». Las proprias «se hallaron por necesidad, i son las que sinifican aquello en que primero tuvieron nombre». Las agenas nacieron «por ornato, i son las que se mudan de la propria sinificación en otra, a quien los griegos llamaron tropos de la mudança del enten-

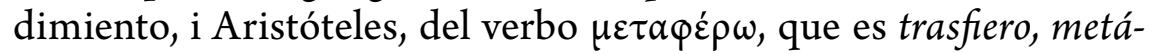
foras, i los latinos traslaciones». A este respecto, conviene recordar que tropo ( $\tau \rho \dot{\pi} \pi \varsigma$, vuelta, giro, manera, cambio) significa efectivamente «mudança», y metáfora ( $\mu \varepsilon \tau \alpha \varphi o \rho \alpha ́$, traslado) «traslación».

El pasaje aristotélico, tantas veces citado, dice exactamente:

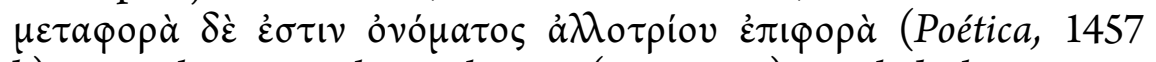
b). Literalmente: «la traslación ( $\mu \varepsilon \tau \alpha \varphi \circ \rho \alpha \dot{)}$ es el deslizamiento

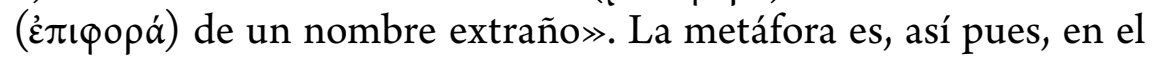
sentir aristotélico, un deslizamiento, un resbalón, un lapsus: hay una transposición de un nombre a una cosa distinta. Esta transposición puede ser, según Aristóteles, del género a la especie, de la especie al género, de la especie a la especie, o por una relación analógica.

Es la relación de analogía, o proporcionalidad, la que actualmente se considera como metáfora, mientras que las otras transposiciones suelen hoy recibir el nombre de sinécdoque (de $\sigma v v \varepsilon \kappa \delta o \chi \dot{\eta}, y$ éste de $\sigma \dot{v} v$, con, y $\dot{\varepsilon} \kappa \delta o \chi \eta \dot{\eta}$, recogida, sucesión, interpretación) o metonimia (de $\mu \varepsilon \tau \omega v v \mu \mu^{\alpha} \alpha$, empleo de un nombre por otro). Pero también hoy se habla, sencilla y genéricamente, de tropos o imágenes. Las excesivas distinciones forman parte más bien del ámbito erudito y académico que del crítico y teórico. En cualquier caso, Herrera no desconoce los términos sinécdoque y metonimia, como tendremos la ocasión de ver más adelante.

Sigue diciendo Herrera que «el primer uso d' estas vozes estrañas fue por necesidad, i después, viendo que hazía hermosa la oración, se valieron d' ella por gracia de ornato i deleite», y también «por metonimia, o antonomasia, o perífrasis, o ipérbole; 
i por las demás figuras con que se haze la oración más grave o más elegante ${ }^{182}$. Y añade: «assí como no se deve hablar siempre proprio, no se á de hablar siempre figurado, porque á de aver modo en el uso, que es en estas cosas singular virtud». Por otra parte, $\ll$ no todas las traslaciones que admiten los poetas tienen lugar en la prosa; i muchas de las que entran en la oración suelta no caben en el verso».

Y no debe confundirse la metáfora con la comparación: «es de notar que la traslación donde interviene esta parte, casi, o como, se llama semejança i no traslación». Tampoco debe confundirse con

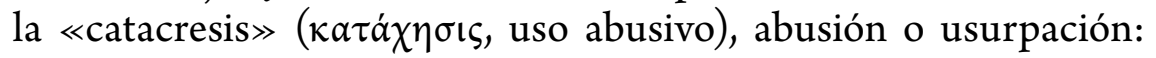
«la abusión es donde falta de todo punto el nombre, i la metáfora donde uvo otro», y hay catacresis «cuando usurpamos i nos servimos con abuso de las vozes agenas por la semejança, como si fuessen proprias», de ahí que digamos «parricida al que mató al ermano, porque no se dize fratricida».

Se relaciona con la metáfora la alegoría, «que es en latín diversiloquio o, como traduze Quintiliano, inversión, porque sinifica decir o predicar otra cosa; en nuestra lengua se podrá llamar permutación i trocamiento de las vozes al sentido», lo cual ocurre «cuando se dize una cosa i se entiende otra». En cambio, la metáfora es «traslación de una palabra, como decir el río de la elocuencia por la copia».

En los versos «mi alma os á cortado a su medida; / por ábito de l' alma misma os quiero» (Soneto V, 10-11), anota Herrera: «Es ábito disposición de lo perfeto a lo mejor. Esta disposición, si es conviniente a la naturaleza de la cosa, se dize buena, i si no, mala. En este lugar sinifica vestido, i es metáfora». Está aquí presente el juego metafórico del término hábito (latín habitus, francés habit, catalán hàbit) como costumbre y como vestido. El poeta desea revestirse de la amada: ha cortado, con el paño de ella, con la entretela de su ser, un traje a la medida de su propia alma. La imagen

\footnotetext{
182 Vid. CUEVAS, Cristóbal: «Teoría del lenguaje poético en las Anotaciones de Fernando de Herrera», en Begoña López Bueno, ed.: Las «Anotaciones» de Fernando de Herrera. Doce estudios. Sevilla: Universidad, 1997, pp. 157-172.
} 
está tomada de Ausiàs March: Amor, Amor: un hàbit m' he tallat / de vostre drap, vestint-me l'espirit ${ }^{183}$.

La misma imagen aparece también en el Soneto XXVII de Garcilaso: «Amor, amor, un ábito vestí, / el cual de vuestro paño fue cortado». A propósito de estos versos, advierte el Brocense: «Este soneto es traduzido de Ausias March, poeta lemosino $\gg^{184}$. Los mismos versos fueron también vertidos al castellano por Jorge de Montemayor: «Amor, Amor: un hábito he cortado / de vuestro paño, el alma lo ha vestido ${ }^{185}$. El mismo Herrera hace constar su fuente: «Este pensamiento es de Ausiàs, i pareció tan bien a don Diego de Mendoça que lo traduzió». No cita, sin embargo, la versión de Jorge de Montemayor ${ }^{186}$.

Como más arriba se indicó, Fernando de Herrera hace uso también de los términos metonimia y sinécdoque. A propósito del verso «la imagen amarilla del ermano» (Elegía I, 29), nos dice que «la metonimia» es «figura que los latinos llaman denominación o trasnominación, deduzida de $\mu \varepsilon \tau o v o \mu a ́ \zeta \omega$, que es trasnombro». En realidad, toda transposición de nombres puede ser tenida por metáfora o metonimia. Así, en el verso «no recostado en urna 'l dulce frío» (Elegía I, 145), la mezcla cenestésica de los sentidos del gusto y del tacto en el sintagma «dulce frío», es considerada por Herrera como «metáfora del gusto al tocamiento», y especifica que «frío es sustantivo». La relación metonímica de causa a efecto aparece

183 MARCH, Ausiàs: Obra poética completa, I, ed. bilingüe de Rafael Ferreres. Madrid: Castalia, 1979, p. 394.

184 SÁNCHEZ [DE LAS BROZAS], Francisco: Ob. cit., p. 83, anotación 31.

185 MARCH, Ausiàs: Poesías, traducidas por Jorge de Montemayor, ed. e introducción de Martín de Riquer. Barcelona: Planeta, 1990, p. 116. Vid. NOGUERAS VALDIVIESO, Enrique, y SÁNCHEZ RODRIGO, Lourdes: «Ausiàs March y Jorge de Montemayor: traducción e interpretación», Annexes des Cahiers de linguistique hispanique médiévale, 14, 14, 2000, p. 373: «la versión de Jorge de Montemayor moderniza e italianiza el texto».

186 Vid. LORENZO, Javier: «Sobre un silencio de Herrera: Jorge de Montemayor y el problema de la modernidad en las Anotaciones $\gg$, eHumanista, 17, 2011, p. 481): Fernando de Herrera «no menciona ni una sola vez a Montemayor en sus Anotaciones». 
también con el nombre de metalepsis ( $\mu \varepsilon \tau \dot{\alpha} \lambda \eta \psi \iota \varsigma$, cambio, permuta). Así, a propósito del verso «la sombra se veía / venir corriendo apriessa» (Égloga I, 414-415), apostilla: «Es metalesis, que del efeto se viene a la causa. Porque ya era noche se vía la sombra. I es epéntesis en el verbo veía, en lugar de vía».

Sobre el verso «Luego los aparejos ya de Marte» (Égloga II, 1354), se dice: «Metonimia figura, cuando el nombre de la causa se trasfiere al efeto». Y, en la anotación al verso «Italia tuvo tantas vezes puesto» (Égloga II, 1557), puede leerse: «Es metonimia cuando el nombre de la cosa sugeta se trasfiere a la que se le ayunta, como decir Italia por italianos. O cuando se entiende lo que contiene por lo contenido». Y se especifica: «es sinédoque, llamada latinamente conceción o inteleción, cuando se concibe en el ánimo más o menos, o otra cosa diferente de lo dicho; o cuando se pone la unidad en vez de la multitud o al contrario. Aquí es sinédoque de número por número, Italia por italianos».

Herrera hace uso también del término metagoge ( $\mu \varepsilon \tau \alpha \gamma \omega \gamma \eta \dot{\eta}$, transporte, traslación). A propósito del verso «la fuente clara $i$ pura, murmurando» (Égloga II, 1152), escribe: «Es metagoge, figura que los latinos apellidan tradución, cuando se refieren las cosa que pertenecen al sentido a las que carecen d'él, como reír el campo, alegrarse la tierra, etc.» Según el Diccionario de la Lengua Española, de la Real Academia, metagoge es «una especie de metáfora, que consiste en aplicar voces significativas de cualidades o propiedades del sentido a cosas inanimadas». Y se pone como ejemplo, precisamente, reírse el campo.

Entre las llamadas figuras de construcción, recoge Herrera la zeugma ( $\zeta \varepsilon v \gamma \mu \alpha$, ligadura, junta). En los versos «Cuando me paro a contemplar mi estado / i a ver los passos por do m'á traído» (Soneto I, 1-2), señala a propósito de la forma verbal paro: «Es figura zeuma, que sinificará en español ligadura o ayuntamiento, cuando un verbo se llega comúnmente a muchas sentencias i conviene a todas con igual sinificado, como éste, que se refiere a contemplar i ver». Hace también mención del quiasmo ( $\chi\llcorner\alpha \sigma \mu o ́ s$, incisión en 
forma de aspa), figura que consiste en cruzar las cuatro partes de una doble antítesis. En los versos «Tu templo i sus paredes é vestido / de mis mojadas ropas i adornado» (Soneto VII, 5-6), anota Herrera: «Puede ser esta figura xiasmós». Se corresponden el término «tercero [vestido] al primero [templo] i el cuarto [adornado] al segundo [paredes] $\gg^{187}$.

De las figuras retóricas, la poliptoton ( $\pi 0 \lambda \dot{v} \pi \tau \omega \tau$ ov, de varios casos) se trae a colación a propósito de los versos «sé que m’ acabo, i más é yo sentido / ver acabar conmigo mi cuidado. / Yo acabaré, que m' entregué sin arte / a quien sabrá perderme i acabarme» (Soneto I, 7-10). Hay poliptoton en el verbo acabar: «Este verbo, repetido cuatro vezes con variación de tiempo, sirve en lugar de la figura polítoton o tradución en nuestra lengua». Y especifica Herrera que esta figura «no como piensan algunos es aquí vicio, sino hermosísima virtud de la oración» En cambio «no lo es por do, traído tres vezes» al comienzo del mismo soneto: «Cuando me paro a contemplar mi estado / i a ver los passos por do m’á traído / hallo, según por do anduve perdido... / a tanto mal no sé por dó é venido» (Soneto I, 1-3 y 5). En realidad, la repetición del sintagma por do no constituye una poliptoton, sino una simple iteración. No existen aquí distintos morfemas flexivos, como en el caso de acabo, acabar, acabaré. De ahí que Fernando de Herrera haga constar que esta repetición, «por do, traído tres vezes», no tiene la hermosura de la auténtica poliptoton.

Considera también Herrera como poliptoton o traducción la serie ofensa, ofensor, ofendido que aparece en los siguientes versos «Mas yo haré qu' aquesta ofensa cara / le cueste al ofensor, que ya estói sano, / libre, desesperado i ofendido» (Soneto XXXIII, 1214). Escribe el crítico sevillano: «Estas tres voces variadas hacen una hermosa tradución de quien se á ya tratado en el Soneto I».

${ }^{187}$ Herrera toma la definición y adapta su ejemplo al propuesto por ESCALÍGERO, Julio César: Poetices libri septem. Lyon: Antoine Vincent, 1561, p. 204). Parte Escalígero de los versos virgilianos Munera portantes, eborisque, aurique talenta, / Et sellam... (Aen., 11, 333-334). Se corresponde aquí el término primero (eboris) al cuarto (sellam), y el segundo (auri) al tercero (talenta). 
Pero, a decir verdad, la figura retórica que entra aquí en juego no es la traducción o politototon, sino la derivación, esto es, la repetición de términos con igual lexema y distintos morfemas derivativos.

Hay asíndeton (å $\sigma u ́ v \delta \varepsilon \tau \tau$, no unido, desligado) en «gentes, costumbres, lenguas é passado» (Soneto III, 4). En este verso, anota Herrera, «usa Garci Lasso de la figura asíndeton o diáliton $\left[\delta \dot{ }^{\prime} \lambda v \tau o v\right.$, disuelto, separado]». Tambien advierte el «asíndeton» en el verso «Corrientes aguas puras, cristalinas» (Égloga I, 239). En el Soneto XII, 2, «loco, imposible, vano, temeroso», se da asimismo «la dissolución, o assíndeton», además de «esta congerie

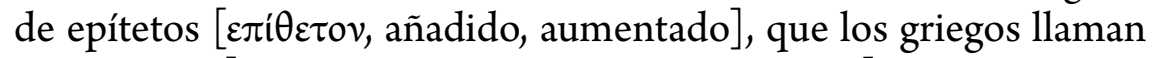

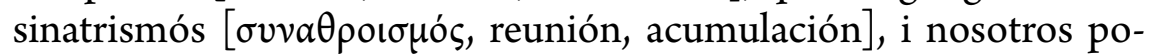
demos nombrar amontonamiento de vozes». Existe aquí, así pues, abundancia de «epítetos, llamados por otro nombre apósitos, i en vulgar ayuntados». Y, en relación con los versos «donde no hallaréis sino mentiras, / vinos azedos, camareras feas, / varletes codiciosos, malas postas, / gran paga, poco argén, largo camino» (Epístola, 7376), escribe Herrera: «Sinatrismós, acervo, congerie i asíndeton».

Otras figuras retóricas de amplificación y repetición son la expolición (expolitio, pulimento, amplificación) y la hendíadis ( $\varepsilon v \delta i \alpha$ $\delta$ vorv, uno mediante dos). En los versos «Yo, que desde la noche a la mañana, / i del un sol al otro» (Égloga II, 176-177), existe «espolición, i espergesia, que es declaración de la sentencia, cuando se esplica una mesma cosa trocando las sentencias $\gg$. En el verso «la caça a cuestas, i la red cargando» (Égloga II, 232), «la red de la caça» es «figura endíadis, cuando el sustantivo por causa del verso se desata en el ayuntado o agetivo, o se contraen dos sustantivos en uno». Y

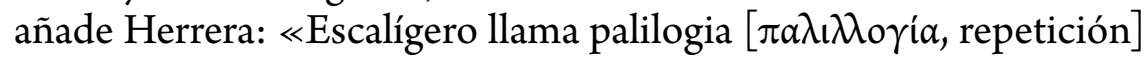
a esta figura». El ejemplo propuesto por Escalígero, indica Herrera, es molemque et montes, tomado de Virgilio (Aen., 1, 65): Hoc metuens: molemque et montes insuper altos.

Aparecen también en las Anotaciones las figuras llamadas anadiplosis (å $v \alpha \delta i \pi \lambda \omega \sigma \iota \varsigma$, reduplicación) y complexión (complexio, abrazo, reunión). A propósito de los versos «tan sólo, que aun de 
vos me guardo en esto. / En esto estói i estar é siempre puesto» (Soneto V, 4-5), en los que se repite en esto, anota Herrera: «La repetición al fin i al principio d' estos dos versos se llama anadiplosis poética o redoblamiento $\gg$. Y, con respecto al verbo estaba en $\ll$ Estava yo a mirar i, peleando / en mi defensa, mi razón estava $\gg$ (Canción IV, 41), escribe: «Este uerbo al principio i al fin d' estos dos versos, que haze círculo en ellos, es figura simploce o complexión en latín, i en nuestra lengua repetición del verbo en principio i fin».

Figuras retóricas mencionadas también por Herrera son la enála-

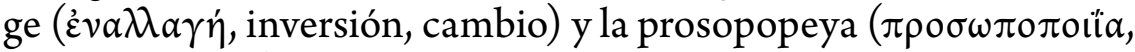
personificación). En el Soneto XV, 1, «Si quexas i lamentos pueden tanto», la sustitución de pudieron por pueden «es enálage del tiempo». En la Elegía II, 27, «siempre à llevado i lleva Garci Lasso», habla Garcilaso, pero aparece en tercera persona: es «enálage de la tercera persona por la primera». Y, a propósito del Soneto X, 1-2, $\ll \mathrm{O}$ dulces prendas por mi mal halladas, / dulces y alegres cuando Dios quería», indica el comentarista: «sírvese aquí de la figura prosopopeya, que los Latinos llaman conformación, i en nuestra lengua podrá tener por nombre fingimiento o hechura de persona».

Entre las figuras de dicción, se hace referencia a las siguien-

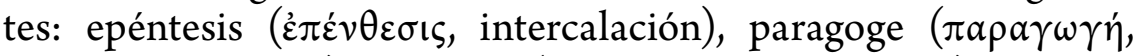

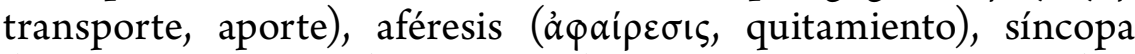

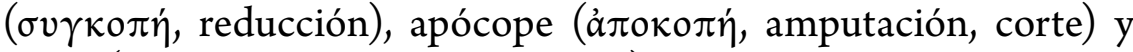

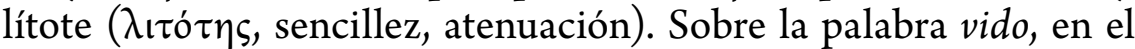
verso «Mas desque vido bien que, corrompiendo» (Elegía I, 226), se anota: «Epéntesis, que es interposición de una letra o sílaba en medio de la dición», ya que aparece vido por vio, que es la forma considerada por el comentarista como de uso normal ${ }^{188}$. En la palabra veloce de «qu' el veloce correr del agua enfrena» (Elegía II, 189), hay «paragoge o adición al fin, por veloz». En «secutando el

188 En el devenir diacrónico, vido precede a vio, por lo que más bien habría que considerar la pérdida de la $d$ en esta última forma verbal como un caso de síncopa. Cfr. MENÉNDEZ PIDAL, Ramón: Manual de gramática hitórica española (1904). Madrid: Espasa Calpe, 1994, p. 318+: «vīdit vido (hoy vulgar), vío (en los textos antiguos consonante de río), moderno vió». 
efeto de su assunto» (Égloga II, 253), hay «aféresis o detración de una letra o sílaba en el principio de la dición, porque devía decir essecutando. En nuestra lengua se dirá (si se sufre) quitamiento». En el verso «abraçád de mi parte, si pudierdes» (Epístola, 82), aparece pudierdes por pudiéredes, y se anota: «en este verbo ai figura síncopa, que es cortamiento i detración de una letra i sílaba en medio de la voz». También en el verso «él solo con despierta vigilança» (Égloga II, 1234) anota Herrera: «Síncopa», ya que aparece vigilança por vigilancia. En el verso «antes d' aqueste al val de la hortiga» (Égloga II, 854), anota: «Apócope o cortamiento», ya que aparece val por valle. En relación con los versos «No soi, pues, bien mirado, / tan disforme ni feo» (Égloga I, 175-176), escribe: «Es figura litote, cuando se dize menos i se entiende más; porque quiere parecer mui hermoso, pero huyó de la jatancia».

Es sabido que Fernando de Herrera se había propuesto la redacción de una completa Poética, que no sabemos si se llegó a escribir, pero que, en todo caso, no ha llegado hasta nosotros. En efecto, en el comentario a la Canción I, cuando se refiere a los poetas «vulgares» en relación con los griegos y latinos, declara que no se extiende demasiado en este tema «por aver de escrevir dellos, si diere espacio la vida, i no fueren contrarias las ocasiones, en los libros de la poética». Ningún otro dato tenemos sobre estos «libros de la poética». No obstante, las numerosísimas referencias que en sus Anotaciones hace a las cuestiones métricas y al lenguaje tropológico y figurado, y que he tratado de reunir, resumir y sistematizar aquí en sus rasgos fundamentales, nos revelan sin duda alguna a un profundo conocedor de las teorías poéticas clásicas y renacentistas, y también a un excelente poeta, que proyecta sobre una obra ajena sus propias ideas, con la generosidad, la dedicación y la perspicacia de un consumado crítico literario.

No comparto el adverso juicio de Emiliano Díez Echarri ${ }^{189}$, para quien Herrera no sería precisamente un Góngora o un Lope en lo que concierne a la sonoridad y a la cadencia métrica: $\ll$ Hora es ya de

189 DÍEZ ECHARRI, Emiliano: Ob. cit., p. 105. 
situar a este poeta -todo rimbombancias i oquedades- en el lugar que le corresponde». Según Díez Echarri, sólo en el soneto de la página 52 de las Anotaciones, ofrecido a la honra de Garcilaso, podríamos encontrar hasta cinco versos «que a duras penas tolera el oído medianamente formado»:

$$
\begin{aligned}
& \text { Mvsa, esparze purpúreas, frescas flores (v. 1) } \\
& \text { Arda la rota aljava i passadores (v. 5) } \\
& \text { la mirra i casia, i cuanto el encubierto (v. 6) } \\
& \text { yaze entre verdes hojas d'amaranto (v. 11) } \\
& \text { venere 'l alto i noble i tierno canto (v 14) }
\end{aligned}
$$

Pero la verdad es que ningún oído, no ya medianamente, sino exquisitamente formado, encontraría dureza alguna en estos versos, en especial el undécimo, «yaze entre verdes hojas d'amaranto», en el que a la melodía de una delicada secuencia de vocales se añade una perfecta orquestación consonántica. Cierto es que, en el esplendor de los Siglos de Oro -Lope de Vega, Luis de Góngora, Francisco de Quevedo-, pueden tal vez quedar ensombrecidos los brillantes versos de Fernando de Herrera. En todo caso, el objeto de estas páginas no era el estudio del Herrera poeta, sino del Herrera teórico y crítico literario ${ }^{190}$. Y, a este respecto, sigue teniendo plena vigencia y queda corroborada la penetrante visión de Marcelino Menéndez Pelayo, para quien las Anotaciones constituyen un verdadero curso de teoría literaria. Su autor se nos revela, efectivamente, como un consumado idólatra de las formas y como un extraordinario crítico literario: el primero de nuestros críticos del siglo XVI.

190 En la trayectoria poética de Fernando de Herrera, podría también rastrearse la estructura de sus bases teóricas. Vid. MONTORI DE GUTIÉRREZ, Violeta: Ideas estéticas y poesía de Fernando de Herrera. Miami: Ediciones Universal, 1977, p. 44: «sus versos ilustran lo que expone teóricamente en sus Comentarios». 


\section{ORTOLOGÍA Y MÉTRICA DE ANDRÉS BELLO}

$\mathrm{E}$

115 de octubre de 2015 se cumplieron 150 años de la muerte de Andrés Bello (1781-1865) en Santiago de Chile. Había nacido el ilustre filólogo, metrista, poeta, traductor, filósofo, ensayista, político, diplomático y jurista venezolano en la ciudad de Caracas el 29 de noviembre de 1781. Desde 1810 hasta 1829, reside en Londres, donde fue redactor del periódico El Español, relacionándose con personajes del mundo de las letras, como José María Blanco-White, Vicente Salvá o Bartolomé José Gallardo, y de la política, como Antonio José de Irisarri, encargado de negocios de Chile, o Francisco Antonio Pinto, futuro presidente de esta nación hispanoamericana. Abandona Inglaterra el 14 de febrero de 1829, trasladándose a Chile, donde permanece hasta su muerte, y donde llegó a obtener la nacionalidad chilena, el puesto de senador por la ciudad de Santiago y el cargo de primer rector de la Universidad de Chile.

En 1981, bicentenario de su nacimiento, fue objeto de diversos homenajes en las dos orillas del Atlántico. Los días 3 y 4 de ese año, tuvo lugar una mesa redonda en torno a la obra del gran humanista en los departamentos de español de Amsterdam y de Utrecht, y las comunicaciones presentadas se publicaron oportunamente en 
un volumen del Spaans Seminarium de Amsterdam ${ }^{191}$. Del mismo modo, el Centro de Lingüística Hispánica, del Instituto de Investigaciones Filológicas de la Universidad Nacional Autónoma de México, le rindió homenaje durante los días 7 y 8 de diciembre de $1981^{192}$. También el Instituto de Chile se sumó a esta serie de merecidos homenajes ${ }^{193}$.

Las páginas que se dedican aquí y ahora a su recuerdo están centradas en la doctrina métrica sostenida por Andrés Bello en su obra Principios de la ortología y métrica de la lengua castellana, editada por vez primera en $1835^{194}$. La métrica de Bello supone, como tendremos ocasión de ver, un poderoso avance hacia la modernidad, en especial en lo que se refiere a las ideas vigentes en su tiempo sobre la cantidad silábica, el verso como unidad rítmica y la cuestión de los finales agudos graves y esdrújulos. En el prólogo de la edición

191

Homenaje a Andrés Bello en el bicentenario de su nacimiento (1781-1981), Diálogos hispánicos de Amsterdam, no 3. Amsterdam: Rodopi, 1982. Se tratan diversos aspectos de los estudios gramaticales, filosóficos, jurídicos y de crítica literaria. Un artículo de Antonio Quilis se ocupa de la «Vigencia de las teorías ortológicas y métricas de Bello».

192 LOPE BLANCH, Juan Miguel (ed.): Homenaje a Andrés Bello. México: UNAM, 1983. En varios artículos, se estudian distintos aspectos gramaticales, tales como la teoría de los tiempos, los nexos, los pronombres y adverbios relativos, o la reforma ortográfica. No hay ninguna referencia a las cuestiones de ortología y métrica.

193 Homenaje a don Andrés Bello. Santiago: Instituto de Chile, 1982. Sólo un artículo de Ambrosio Rabanales, «Vigencia de las ideas lingüísticas y gramaticales de don Andrés Bello», se ocupa de las cuestiones filológicas. No se menciona la métrica.

194 BELLO, Andrés: Principios de la ortolojía i métrica de la lengua castellana. Santiago de Chile: Imprenta de la Opinión, 1835. Nuevas ediciones en Santiago de Chile: Imprenta del Progreso, 1850; Imprenta de la opinión, 1859. Reediciones en Caracas y Bogotá. Obras completas en Santiago de Chile, Madrid y Caracas: Obras completas de don Andrés Bello. Santiago de Chile: Imprenta de Pedro G. Ramírez (tomos I-XIII), 1881-1890; Imprenta Cervantes (tomos XIV-XV), 1891-1893. Obras completas. Opúsculos gramaticales I. Principios de la ortología y métrica de la lengua castellana. Madrid: Tello, 1890 (todas las citas de la Ortología y métrica se harán por esta edición). Obras completas. Estudios filológicos I. Principios de la ortolojía i métrica de la lengua castellana (con una «Introducción a los estudios ortológicos y métricos de Bello» de Samuel Gili Gaya). Caracas: Biblioteca Nacional, 1954. Obras completas. Caracas: Fundación La Casa de Bello, 1981-1986. 
de 1835, nos advierte el autor que creyó conveniente añadir a la Ortología, «que comprende, como parte integrante, la doctrina de los acentos y las cantidades, llamada comúnmente Prosodia», un tratado de Métrica, ya que «la Prosodia y la Métrica son dos ramos que ordinariamente van juntos, porque se dan la mano y se ilustran recíprocamente». Y explica:

En la Métrica doy un análisis completo, aunque breve, del artificio de nuestra versificación, y de los verdaderos principios o elementos constitutivos del metro en la poesía castellana, que bajo este respecto tiene grande afinidad con la de casi todas las naciones cultas modernas. Pero me era imposible emprender este análisis sin que me saliesen al paso las reñidas controversias que han dividido siglos hace a los humanistas, acerca de las cantidades silábicas, el oficio de los acentos y la medida de los versos. Después de haber leído con atención no poco de lo que se ha escrito sobre esta materia, me decidí por la opinión que me pareció tener más claramente a su favor el testimonio del oído. [...] No disimularé que mi modo de pensar está en oposición absoluta con el de dos eminentes literatos, autor el uno [José Gómez Hermosilla] de un excelente tratado de literatura y traductor de Homero, y recomendable el otro [Mariano José Sicilia] por la publicación de los primeros elementos de Ortología que se han dado a luz sobre la lengua castellana.

Desde el comienzo de su obra, se muestra Andrés Bello preocupado por la cuestión central de la Métrica, que no es otra que «la medida de los versos», así como por «el oficio de los acentos» en las secuencias rítmicas y «las reñidas controversias» sobre una hipotética pervivencia de «las cantidades silábicas», esto es, la existencia o no en la lengua española de sílabas largas y breves. También desde el principio, acude al «testimonio del oído» como a la más fiable fuente de opinión.

La actitud de Andrés Bello ante la medida del verso es bien clara y sencilla. El oído ha de ser siempre nuestro guía para la percepción de las sílabas y los acentos. En el capítulo IV de la parte I, «De las 
sílabas», una nota inicial nos indica que «para la debida inteligencia de éste y los siguientes capítulos, conviene que el alumno aprenda a percibir por el oído la medida de los versos octosílabo y endecasílabo». Este primordial adiestramiento resultará ser fácil y sólo requerirá un corto ejercicio. Pero «el que no lo consiga, perderá el tiempo en el estudio de la prosodia y métrica».

Para Bello, no existen en castellano sílabas largas y breves, en el sentido de que una sílaba larga valga por dos breves. Las combinaciones de sonidos que llamamos sílabas «aunque no se pronuncian en tiempos exactamente iguales, se acercan con todo a la razón de igualdad en sus cantidades o duraciones». Es por eso por lo que «constando $a$ de un solo elemento, y siendo cons una de las sílabas más complejas que tiene el habla castellana, sin embargo a y cons distan menos de la razón de igualdad que de la razón de 1 a $2 \gg^{195}$.

No distingue Bello entre sílabas tónicas y átonas, sino entre sílabas agudas y graves: «Las vocales acentuadas se llaman agudas, y las inacentuadas graves ${ }^{196}$. El acento interviene en la duración de la sílaba; pero, en cualquier caso, no han de identificarse las agudas con las largas, y las graves con las breves:

La duración de las sílabas depende del número de elementos que entran en su composición y del acento. Así, en las cuatro sílabas de que consta la dicción transcribiese, es indudable que la primera, trans, requiere más tiempo que la segunda, cri, por componerse aquélla de cinco elementos y ésta de tres; y no es menos cierto que la sílaba bié, compuesta de tres elementos, uno de los cuales es la vocal acentuada $e ́$, se pronuncia en más tiempo que la cuarta, se, que se compone de una sola consonante y una sola vocal que carece de acento. A pesar de estas diferencias, las duraciones o cantidades en todas las sílabas castellanas se acercan más a la razón de igualdad que a la de 1 a $2^{197}$.

\footnotetext{
195 BELLO, Andrés: Principios de la ortología y métrica de la lengua castellana. Madrid: Tello, 1890, p. 134-136.

196 Ibíd., p. 153.

197 Ibíd., pp. 199-200.
} 
En el Apéndice IX de la Ortología y métrica, «Sobre la teoría del metro», insiste una vez más sobre el problema de la duración de las sílabas en castellano: «Las tiene largas y breves, porque es innegable que no todas consumen exactamente igual tiempo». Pero, se pregunta, ¿cuánto mayor es la duración de las largas? Y responde que no alcanza a determinarlo. En todo caso, «lo seguro es que las largas están a las breves en una relación mucho más cercana a la igualdad que a la de 2 a $1 \gg^{198}$.

Los «dos eminentes literatos» aludidos en el prólogo de la primera edición de la Ortología y métrica, José Gómez Hermosilla y Mariano José Sicilia, son directamente señalados en el Apéndice VI, «Sobre la cantidad prosódica»:

En el Arte de hablar de D. José Gómez Hermosilla, y en las Lecciones de ortología y prosodia de D. Mariano José Sicilia, se inculcan ideas muy opuestas a las mías acerca de las cantidades o duraciones relativas de las sílabas castellanas. [...] Pero en lo que más me parece flaquear la teoría prosódica de este erudito escritor es en la evaluación relativa de las breves y largas. La larga, según el Sr. Hermosilla, dura dos tiempos; la breve, uno. Yo no veo que esto se nos haga sensible en el mecanismo de los versos castellanos, o se pruebe de cualquier otro modo. De que una sílaba se pronuncie más rápidamente que otra no se deduce que haya entre ellas la razón particular de 1 a 2 . [...] Comparemos estos dos vocablos: remedó y remendó. Men es sin duda más largo que me; pero ciertamente las dos duraciones no están en relación de 2 a $1^{199}$.

D. Mariano José Sicilia divide las sílabas en breves, más breves, largas y más largas. [...] La clasificación toda adolece del defecto gravísimo de no poderse comprobar por la práctica de los poetas, que debe ser la piedra de toque de toda teoría prosódica ${ }^{200}$.

\footnotetext{
198 Ibíd., pp. 435.

199 Ibíd., pp. 395-398.

200 Ibíd., pp. 401-405.
} 
En efecto, José Gómez Hermosilla sostenía en 1826, en su Arte de hablar en prosa y verso, que, «aunque nosotros no medimos los tiempos tan compasadamente como los antiguos, no prescindimos de ellos ni podemos prescindir ${ }^{201}$. Y no le cabe la menor duda de que la $o$ de orar es breve, mientras que la $o$ de obstar es larga, «prueba irrefragable de que, además del acento, hay otra cosa que puede hacer largas las sílabas ${ }^{202}$. Hermosilla da por supuesto que las sílabas acentuadas son largas.

Mariano José Sicilia, por su parte, sostenía en 1832, en sus Lecciones elementales de ortología y prosodia, que han sido muy diversos los pareceres de los autores sobre la cantidad silábica en la lengua castellana, «hasta el extremo de haber habido quien diga que nosotros no tenemos breves ni largas, [...] o que sólo eran largas las que llevaban el acento ${ }^{203}$. Las sílabas pueden ser breves, más breves, largas y más largas, según que ocupen un solo tiempo, menos de un solo tiempo, un tiempo y parte de otro, y dos tiempos ${ }^{204}$. En la lengua castellana, «la cantidad de las sílabas proviene de dos solas causas, a saber: $1^{\circ}$. Del material ortológico de cada sílaba. $2^{\circ}$. De la ley del acento predominante de la dicción ${ }^{205}$. En cada sílaba, «la sencillez o la pesadez» depende del número de sonidos que la compongan. Cuanto mayor sea éste, «mayor habrá de ser necesariamente la porción de tiempo que se invierta en pronunciarlas $\gg^{206}$. Es larga «toda silaba afectada por el acento predominante», y son breves «todas las sílabas que se siguen a la que lleva el acento predominante, aunque por su naturaleza sean largas $\gg^{207}$.

201 GÓMEZ HERMOSILLA, Josef: Arte de hablar en prosa y verso. Tomo II. Madrid: Imprenta Real, 1826, p. 109.

202 Ibíd., p. 120.

203 SICILIA, Mariano José: Lecciones elementales de ortología y prosodia. Madrid: Imprenta Real, 1832, p. VII.

204 Ibíd., p. 14.

205 Ibíd., p. 17.

206 Ibíd., pp. 17-18.

207 Ibíd., pp. 41-43. 
En relación con el problema de la equivalencia de los finales agudos, graves y esdrújulos en el verso, rebate Andrés Bello, en el Apéndice VII de sus Principios de ortología y métrica, las teorías de Francisco Martínez de la Rosa y de Vicente Salvá:

D. Francisco Martínez de la Rosa, que en una de las notas a su Poética ha comparado la versificación antigua con la moderna (y a mi parecer más acertadamente que Hermosilla y Sicilia), encuentra un vestigio de aquella compensación de largas y breves, que era de necesidad absoluta para el ritmo antiguo, en la sílaba de menos que tienen constantemente nuestros verso agudos, y la sílaba de más que ponemos siempre a los esdrújulos. «La palabra trémula consume a fin de verso los mismos tiempos que la palabra fuerte». Pero ¿por qué sólo a fin de verso? [... ¿ ¿No indica esto con toda claridad la influencia de la pausa, que hace de poca importancia las desigualdades de duración entre los finales graves, agudos y esdrújulos? Cuando en el final de un verso pongo el esdrújulo tenérsela en lugar de los graves tenerla o tenerse, ¿se podrá buenamente decir que se sustituyen dos breves a una larga? Es claro que no. [...] Y cuando sustituyo el final agudo tener al grave tenerle, ¿sustituyo acaso una larga a dos breves? Sin duda que no, porque lo mismo absolutamente es el ner en tener que en tenerle. [...] El tiempo que de este modo sobra, o falta, se embebe o suple en el reposo final del verso. [...] Son, pues, desiguales las duraciones de tenérsela, tenerse y tener, gastándose en la primera un tiempo más que en la segunda, y en la segunda un tiempo más que en la tercera. Si no se paliase esta desigualdad en el reposo con que termina el verso, no se toleraría ${ }^{208}$.

D. Vicente Salvá explica de otro modo la aparente equivalencia de los finales agudo, grave y esdrújulo; pero no con mejor suceso. Según este docto filólogo, no hay verdaderamente dicciones agudas ni esdrújulas en castellano: todas son graves. Pronúncianse (dice) desdén, vendrá como si estuviesen escritos desdéen, vendráa. Por el contrario (añade), en los esdrújulos pasamos tan de corrida sobre la vocal de la sílaba media, que no se la percibe (son palabras textuales); de manera

BELLO, Andrés: Ob. cit., pp. 406-407. 
que pronunciamos línea, máxima casi como si estuviesen escritos lina, maxma >.

Francisco Martínez de la Rosa, que representa tal vez el más firme baluarte en la defensa de la tesis cuantitativa, llega a afirmar en 1831, en distintos lugares de las notas a su Poética, que «los acentos son los que mejor nos indican la cantidad de las sílabas, es decir, las que son largas o breves ${ }^{209}$, que $\ll$ la cantidad de las sílabas, y no su simple número, influye en la versificación moderna más de lo que comúnmente se imagina $\gg^{210}$, y que, en definitiva, son los acentos los que «distinguen las sílabas largas de las breves ${ }^{211}$. En cuanto a la terminaciones agudas, graves y esdrújulas, «todo verso que acaba con acento agudo debe tener una sílaba menos que si acabase con grave; y todo el que acaba en palabra esdrújula (es decir, con acento agudo en la antepenúltima sílaba, siendo las dos últimas breves) debe tener una sílaba más ${ }^{212}$. Así, la palabra trémula «aunque conste de tres sílabas, consume al fin del verso los mismos tiempos musicales que la palabra fuerte, que tiene sólo dos sílabas $\gg^{213}$

Vicente Salvá, en su Gramática de la lengua castellana (1830), nos dice que «en las palabras que acaban por una vocal aguda, hace la voz una especie de compensación duplicándola», y así «pronunciamos desdén, vendrá como si estuviera escrito desdéen, vendráà»; en cambio, «en los esdrújulos pasamos tan de corrido por la sílaba media entre la acentuada y la última que no se percibe, de modo que pronunciamos línea, máximo casi como si estuviese escrito lina, maxmo ${ }^{214}$. Por otra parte, asegura que «los autores que han escrito de la prosodia española han observado, desde los más antiguos,

209 MARTÍNEZ DE LA ROSA, Francisco: Poética. Palma: Villalonga,1831, p. 162.

210 Ibíd., p. 164.

211 Ibíd., p. 177.

212 Ibíd., pp. 164-165.

213 Ibíd., p. 165.

214 SALVÁ, Vicente: Gramática de la lengua castellana según ahora se habla. Ed. de Margarita Lliteras. Madrid: Arco/Libros, p. 789. 
que también tenemos nosotros sílabas largas y breves, acentuadas o agudas y graves, y que no es indiferente emplear éstas o las otras para que el verso conste $\mathrm{e}^{215}$.

Frente a las opiniones de José Gómez Hermosilla, Mariano José Sicilia, Francisco Martínez de la Rosa y Vicente Salvá, autores coetáneos de Andrés Bello, expresa una y otra vez el maestro venezolano su oposición absoluta a la pertinencia métrica de los criterios cuantitativos, ya que es del todo irrelevante la mayor o menor duración de las sílabas, que en cualquier caso distan más de la razón de 1 a 2 que de la razón de igualdad. Por lo que respecta a la equivalencia de los finales agudos, graves y esdrújulos, rechaza que la última sílaba del final agudo valga por dos, porque esto no sería más que un pretendido «vestigio» de la versificación antigua. Si la sílaba ner de tener hubiera de valer por dos, también habría de valer por dos la sílaba ner de tenerle, o la sílaba ner de tenérsela. Tan aguda, larga o acentuada sería esta sílaba en la palabra aguda como en la llana o en la esdrújula. Para Andrés Bello, la explicación del fenómeno de la equivalencia residiría en «la influencia de pausa», que hace «de poca importancia» las desigualdades de duración entre los finales agudos, graves o esdrújulos. En virtud de la pausa, la sílaba que sobra en el esdrújulo, o falta en el agudo, «se embebe o suple en el reposo final del verso». Tampoco se sostiene la teoría de Salvá, según la cual todas las palabras serían llanas en castellano.

En esta misma línea, Luis de Mata y Araujo afirma en 1839, en sus Lecciones elementales de literatura, que «las naciones modernas, y entre ellas la nuestra, no haciendo percibir en la pronunciación tan distintamente la cantidad de las sílabas, fundaron su versificación en el número determinado de éstas, en la disposición de los acentos y de las cesuras o pausas ${ }^{216}$. Pero, más adelante, se adhiere plenamente a la tesis cuantitativa, y escribe que «las sílabas en castellano, lo mismo que en las demás lenguas, son largas o breves: es

215 Ibíd., p. 787.

${ }^{216}$ MATA I ARAUJO, Luis: Lecciones elementales de literatura, aplicadas especialmente a la castellana. Madrid: Norberto Llorencio, 1839, p. 236. 
breve la sílaba en cuya pronunciación se emplea un tiempo, y larga en la que se emplean dos tiempos»; y, a renglón seguido, explica que «la $o$ de amo (yo) es breve, y en amó (aquél) es larga; y cualquiera advertirá que se emplea doble tiempo en la pronunciación de la segunda que en la de la primera $\gg^{217}$.

Más que en los criterios de la cantidad silábica, que no tiene en español ni en otras lenguas modernas justificación alguna, la explicación de la equivalencia de finales agudos, graves y esdrújulos ha de ser buscada en la concepción del verso como unidad rítmica, la consideración de la pausa como límite de la unión y la separación de los versos, y el reconocimiento del carácter culminante de la última sílaba acentuada. Andrés Bello, que tan certeramente supo apreciar la falta de pertinencia de la duración o cantidad en la medida del verso, no podía admitir el absurdo de que en los finales agudos la sílaba tónica valiera por dos, y en los finales esdrújulos las dos sílabas postónicas valieran por una. Justamente encontró en la pausa la explicación de la equivalencia versal. En la pausa se diluirían, se embeberían, la sílaba postónica de los finales graves y las dos sílabas postónicas de los finales esdrújulos. De ahí a reconocer que el verso, como unidad rítmica, termina en la última sílaba acentuada no hay más que un paso.

Para el filólogo venezolano, el lenguaje poético no es algo artificioso, alejado del lenguaje ordinario. Así, a propósito de la sinalefa, escribe que «esto se verifica no sólo en poesía, sino en el lenguaje ordinario, de cuya pronunciación no es lícito al poeta alejarse $\gg^{218}$. $Y$ es tal «la propensión de nuestra lengua a la sinalefa $»^{219}$, que ni los signos de puntuación, ni las pausas sintácticas que éstos señalan, se oponen a su realización. Es más, «entre dos dicciones, pronunciadas por diversos interlocutores en el drama, es tan necesaria la sinalefa como en boca de una sola persona $\gg^{220}$.

\footnotetext{
217 Ibíd., pp. 353-354.

218 BELLO, Andrés: Ob. cit., p. 229.

219 Ibíd., p. 235.

${ }^{220}$ Ibíd., p. 236.
} 
En relación con el contacto entre vocales que pertenecen a distintas palabras, explica que, si no se produce la sinalefa, tiene lugar el hiato. $Y$, entre vocales que pertenecen a una misma palabra, pueden existir diptongos, o su disolución mediante la diéresis, así como hiatos, o su contracción mediante la sinéresis. No le pasa desapercibido al filólogo el hecho de que los diptongos $i e, u o$, procedentes de las tónicas breves latinas $\check{e}, \check{o}$, son indisolubles:

Cuando los sonidos simples $e, o$, han pasado bajo la influencia del acento a los sonidos compuestos ié, ué, estas combinaciones forman diptongos absolutamente indisolubles, como sucede en diente, fuente, huerto, muerte, viento, nacidos de los vocablos latinos dente, fonte, horto, morte, vento, y en pienso, quiero, ruego, inflexiones de los verbos pensar, querer, rogar 221 .

Introduce Bello el concepto de cláusula rítmica: «Todas las cláusulas rítmicas que se usan en la versificación castellana son disílabas o trisílabas $\gg^{222}$. Las primeras pueden ser trocaicas y yámbicas; las segundas, dactílicas, anfibráquicas y anapésticas. Y hace una distinción entre versos de rítmico trocaico y versos de ritmo yámbico. Entre los primeros se encontrarían el octosílabo, el hexasílabo y el tetrasílabo. Entre los segundos, el alejandrino a la francesa, el endecasílabo, el eneasílabo y el heptasílabo. En el verso endecasílabo «es de necesidad acentuar la 6. ${ }^{\mathrm{a}}$ y $100^{\mathrm{a}}$ sílaba, o la 4.a $8 .^{\mathrm{a}}$ y $10 .^{\mathrm{a}} \gg^{223}$.

Particular atención se le dedica al endecasílabo sáfico. Curiosamente, habrá que tener ahora en cuenta la cantidad silábica, aunque se advierte que no se trata aquí de hacer valer una sílaba larga por dos breves, sino que «la ligereza de las sílabas en determinados parajes da al verso un aire característico»:

\footnotetext{
221 Ibíd., p. 207.

222 Ibíd., p. 273.

223 Ibíd., p. 318.
} 
Tenemos especies de versos en que es importante la cantidad silábica, por requerirse en ellas, además de ciertos acentos, que algunas de las sílabas inacentuadas sean breves; no porque sustituidas a éstas las largas variasen la medida o el ritmo, como en la versificación latina y griega, sino porque la ligereza de las sílabas en determinados parajes da al verso un aire característico. Los versos de esta especie que se usan más frecuentemente en castellano son el sáfico y el adónico. El sáfico es un endecasílabo que [...] debe acentuarse en la 4. ${ }^{\mathrm{a}}, 8 .^{\mathrm{a}}$ y $10{ }^{\text {a }}$; pero en que se apetece además:

1. ${ }^{\circ}$ Un acento sobre la $1 .^{a}$ sílaba.

20. Que las sílabas 2. ${ }^{\mathrm{a}}$ y $3 .^{\mathrm{a}}$ sean breves.

3. ${ }^{\circ}$ Que sean también breves la 6. ${ }^{\mathrm{a}}$ 7. ${ }^{\mathrm{a}}$ y $9 .^{\mathrm{a}}$ sílabas.

4. ${ }^{\circ}$ Que el primer hemistiquio termine en dicción grave.

5. ${ }^{\circ}$ Que no haya sinalefa en la cesura.

[...] He aquí un verso sáfico perfectamente regular:

Dulce vecino de la verde selva.

(Villegas)

Además de los acentos indispensables de las sílabas ci, ver, sel, tenemos otro en $d u l$; la pronunciación se desliza con la mayor suavidad y ligereza sobre las sílabas $c e, v e, d e, l a, d e$; el primer hemistiquio termina en la dicción grave vecino, y no hay sinalefa entre los dos hemistiquios $\gg^{224}$.

Es de advertir que Andrés Bello denomina «cesura» al corte que se produce tras la sílaba $5 .^{\mathrm{a}}$, habiendo de recaer el acento de la 4. ${ }^{\text {a }}$ sobre palabra llana (Dulce vecino / de la verde selva). Se trata propiamente de un verso simple bimembre, en el que Bello considera los dos miembros como «hemistiquios».

Sirva este breve recuerdo como homenaje al gran filólogo, poeta y metrista venezolano, que supo librar a la métrica castellana

${ }^{224}$ Ibíd., pp. 326-328. Andrés Bello, poeta, latinista y traductor de Horacio, pone en práctica estos preceptos con mayor o menor fortuna. Vid. HERRERA MONTERO, Rafael: «Andrés Bello, traductor de una oda de Horacio». Cuadernos de Filología Clásica. Estudios latinos, 1995, 8, pp. 299-314. 
de algunos prejuicios y lastres que desgraciadamente han venido arrastrándose, en una buena parte, hasta nuestros días. Para Andrés Bello, la prosodia del verso no es algo distinto de la del lenguaje ordinario, el oído debe primar siempre en su medida, y su enseñanza ha de basarse en la intuición y el ejercicio, más que en las lucubraciones y el mero afán especulativo y clasificatorio. Porque lo que verdaderamente importa en el verso es su lectura directa, su comprensión, su «audición», y el disfrute que esta lectura proporciona. 



\section{PROSODIA YVERSIFICACIÓN DE EDUARDO BENOT}

D iscípulo del sevillano Alberto Lista fue el gaditano Eduardo Benot (1822-1907). Desde muy joven, desempeñó el cargo de director del colegio que fundara en Cádiz su erudito maestro. Tuvo una notable incidencia en la vida pública, en calidad de diputado a Cortes, senador y ministro de Fomento, y fue autor de una ingente y enjundiosa producción, que va desde los tratados de matemáticas hasta los de astronomía, y desde los estudios gramaticales hasta la ciencia del verso.

Sus trabajos mayores son Arte de hablar, gramática filosófica de la lengua castellana, que es obra póstuma, publicada en 1910, y Prosodia castellana i versificación, aparecida en 1892 (Madrid: Juan Muñoz Sánchez), en vida de su autor. Esta última fecha es conjetural, ya que no aparece en ningún lugar del libro. No obstante, es la comúnmente aceptada ${ }^{225}$. Si el Arte de hablar contiene «ideas utilísimas para el estudio de nuestra lengua», en palabras de su prologuista ${ }^{226}$, la Prosodia constituye un instrumento ciertamente imprescindible

225 Es la que da en 1893 LA VIÑAZA, C. de: Biblioteca histórica de la filología castellana. Madrid: Tello, 1893, p. 538. Esta obra sería la «más completa y extensa de cuantas hasta el día se han escrito».

226 TORRES REINA, J.: «Prólogo» a BENOT, E.: Arte de hablar, gramática filosófica de la lengua castellana. Madrid: Sucesores de Hernando, 1910, p. XIX. 
para el mejor conocimiento de la historia y la estructura del verso español. De la primera de las citadas obras existen otras varias ediciones $^{227}$, y su doctrina gramatical ha sido objeto de diversos trabajos académicos ${ }^{228}$, artículos ${ }^{229} \mathrm{y}$ estudios monográficos ${ }^{230}$. Pero, en lo que concierne a la ciencia del verso, para la consulta de la primera y única edición de la Prosodia castellana y versificación, que es en términos actuales un auténtico y valiosísimo Tratado de métrica española, el estudioso no disponía, hasta la edición facsimilar de $2003^{231}$, más que de la obligada visita a las bibliotecas públicas, o del difícil y azaroso recurso a las librerías de ocasión.

227 Madrid: Sucesores de Hernando, 1921; Buenos Aires: Anaconda, 1945; Barcelona: Anthropos, 1991 (ed. facsímil de Ramón Sarmiento).

228 RAMOS CAMPOS, J. A.: Las ideas gramaticales de Eduardo Benot, tesis de licenciatura. Granada: Universidad, 1974; MARTÍNEZ LINARES, M. A.: Las ideas gramaticales de Eduardo Benot, tesis doctoral. Alicante: Universidad, 1989; JIMÉNEZ GÁMEZ, R.: La cuestión educativa en Eduardo Benot, tesis de licenciatura. Cádiz: Diputación, 1984.

LOPE BLANCH, J. M.: «La cláusula y el análisis del discurso», Nueva Revista de Filología Hispánica. XXVIII, 1979, pp. 1-29. HERNÁNDEZ GUERRERO, J. A.: «Análisis crítico del verbo en Eduardo Benot», Revista de la Sociedad Española de Lingüística. XIII, 1983, pp. 149-160. MARTÍNEZ LINARES, M. A.: «La “oración compuesta por subordinación” en la gramática de Eduardo Benot», Estudios de Lingüística de la Universidad de Alicante. 5, 1988-1989, pp. 191-199. LOPE BLANCH, J. M.: «El concepto de cláusula en E. Benot», Revista de Filología Española. LXXIV, 1994, pp. 271-28; «Eduardo Benot y la clasificación de las oraciones», Romanistik in Geschichte und Gegenwart. 1, 1995, pp. 7-15; «Eduardo Benot y los fundamentos de la clasificación oracional», en La clasificación de las oraciones. Historia de un proceso. México: UNAM, 1995, pp. 47-65; MESA, J.: «Arte de hablar y pragmática: Notas sobre el pensamiento lingüístico de Eduardo Benot (1822-1907)», Historiographia Linguistica. XXII, 1995, pp. 91-121.

230 SARMIENTO, R.: «Introducción» a BENOT, E.: Arte de hablar..., cit., ed. facsímil. Barcelona: Anthropos, 1991, pp. VII-XLIX; MARTÍNEZ LINARES, M.A.: Sobre las "partes de la oración" y la teoría gramatical de Eduardo Benot (1822-1907). Alicante: Universidad, 2001; HURTADO VALERO, P. M.: Eduardo Benot: Una aventura gramatical. Madrid: Verbum, 2002.

231 BENOT, E.: Prosodia castellana y versificación, ed. facsímil al cuidado de Esteban Torre. Anexo 1 de Rhythmica. Revista española de métrica comparada. Sevilla: Padilla Libros, 2003. 
Eduardo Benot, hijo de Julián Bernardo Benot, de origen italiano, y de Rafaela Rodríguez, nació en Cádiz el 26 de noviembre de 1822. De familia culta, aunque de no muy elevada posición social, habría de llegar a ser «uno de los más ilustres hijos de Cádiz, y sin duda el más querido y respetado de sus hombres públicos $\gg^{232}$. La precaria salud de su primera infancia no impidió que recibiera una educación esmerada, primero en su propia casa y después en la escuela de Antonio Hurtado y Medialdea, en el colegio de San Pedro y en el de San Felipe Neri. En este último, estudió literatura con Alberto Lista, filosofía con Juan José Arbolí y física y química con el médico José Gardoquí.

Tras unos años de dedicación a tareas burocráticas en la Beneficencia Municipal de Cádiz, comenzó a dar clases de filosofía en el colegio de San Felipe Neri, como sustituto de Juan José Arbolí, en el año 1848. Cuatro años después, al ser preconizado Arbolí obispo de Guadix y Baza, asume Eduardo Benot las tareas de dirección del colegio. Y allí permaneció hasta el año 1867, en que marchó a París para estudiar la Exposición. De su dedicación total y abnegada a la enseñanza, durante diecinueve años, dan fiel testimonio los métodos docentes ensayados y la multitud de obras publicadas. En los últimos años de su polifacética vida, aún seguirá soñando con el ideal inalcanzable de poseer un colegio propio en donde llevar a cabo su programa pedagógico. Y, así, escribe en una carta dirigida al canónigo José María León y Domínguez:

Muchas veces $[. .$.$] me veo al frente de un colegio, organizado a mi$ modo, de quinientos o seiscientos alumnos listos y despabilados (no quiero nada con tontos), sostenidos exclusivamente a mis expensas, sin necesidad de retribución ninguna recibida de los padres o encargados. Pero, como usted ve, estos sueños son las últimas llamaradas de una luz próxima a apagarse para siempre ${ }^{233}$.

\footnotetext{
232 LEÓN Y DOMÍNGUEZ, J. M.: Recuerdos gaditanos. Cádiz: Cabello, 1897. Reproducido en «Notas biográficas», Arte de hablar..., cit. p. V.

233 LEÓN Y DOMÍNGUEZ, J. M.: «Notas biográficas», cit., p. X.
} 
A partir de 1850 comienza a publicar su Nuevo método del Doctor Ollendorf, para aprender a leer, hablar y escribir un idioma cualquiera, con volúmenes especiales dedicados al inglés, al francés, al italiano y al alemán. En los prólogos de la primera edición (1851) y de la segunda (1853) de la Gramática francesa, reproducidos en la primera edición (1853) de la Gramática italiana ${ }^{234}$, establece ya las bases de su programa pedagógico y esboza las líneas maestras de sus ideas gramaticales. Nos recuerda que las lenguas se estudian para hablar, y que no se aprende a hablar sino hablando. No se trata, pues, de memorizar palabras aisladas y enumerar una serie infinita de reglas gramaticales, sino de aprender a combinar frases y oraciones y a pensar directamente en la lengua que se estudia. De nada sirve conocer las reglas de formación de los plurales ni de la conjugación, si no se sabe hacer aplicación de ellas. En las gramáticas hechas hasta el día, se había abandonado al cuidado del discípulo la práctica del idioma. Por el nuevo método, todo depende del maestro, sin exigir del discípulo más que paciencia. El mérito principal del sistema radica en que, insensiblemente y sin esfuerzo, enseña y habitúa a pensar en el idioma que se aprende.

Ahora bien: si los idiomas se estudian para hablar; y si el hablar sólo consiste en formar continuamente oraciones, mediante la trabazón de las palabras, y las combinaciones de otras, con las cuales quiere el uso en cada lengua que se signifiquen determinadas ideas, ¿qué concepto debe formarse de las gramáticas en que se trata aisladamente de lo que en ellas se denomina partes de la oración, y aisladamente también, en lo que llaman sintaxis, de la combinación parcial de las palabras, y todo lo más, de la oración, sin cuidarse jamás de la combinación de las oraciones ${ }^{235} \ldots$ ?

\footnotetext{
234 BENOT, E.: Nuevo método del Dr. Ollendorf para aprender a leer, hablar y escribir un idioma cualquiera. Adaptado al italiano. Cádiz: Imprenta de la Revista Médica, 1853.

235 Ibid., p. VIII.
} 
Se trata, por tanto, de aprender a combinar palabras, ya que lo que hacemos cuando hablamos es simplemente afirmar que una idea, enunciada por una palabra, conviene o no con la idea que enuncia otra palabra. Pero el número de las voces del idioma más rico es muy corto en comparación con las ideas que podemos expresar:

Y es que las palabras tienen una significación tan general, que, para hablar de un objeto cualquiera de los que nos rodean, necesitamos a cada instante restringirles la significación. Sin recurrir a principios filosóficos ajenos de este lugar, podrá notarse que un vocablo cualquiera, por ejemplo, mesa, no indica objeto ninguno: ninguno absolutamente; porque esa voz no designa ni esta mesa ni aquella, ni ninguna en particular, por lo mismo que las designa todas; de tal suerte que, si quiero señalar una mesa determinada, necesito agregar otras palabras que restrinjan y limiten su generalidad, diciendo por ejemplo la mesa en que acostumbro a trabajar u otra cláusula semejante ${ }^{236}$.

Desde el principio, el discípulo aprenderá a componer frases, a expresarse con frases, primero muy sencillas, y después, gradualmente, más complejas; desarrolladas siempre bajo las tres formas, positiva, interrogativa y negativa. He ahí la esencia del método de Ollendorf: sistematizar el proceso natural y espontáneo del aprendizaje de las lenguas. El discípulo se ve obligado a expresarse en el idioma que aprende, $y$ a usar frases que van siempre a la vanguardia de las reglas:

Oigamos al mismo autor. Mi sistema -dice- está fundado sobre este principio: cada pregunta contiene casi completa la respuesta que debe darse, quedando sólo a cargo del discípulo el construir la ligera diferencia entre la pregunta y la respuesta; pero, como en la lección que a cada tema precede se hallan explicadas las reglas y los principios necesarios para ello, no puede experimentar la menor dificultad, ya en responder, ya en dirigirse a sí propio preguntas análogas o semejantes. Esta paridad entre la pregunta y la respuesta tiene otra ventaja.

236 Ibíd., p. X. 
Cuando el maestro enuncia la primera, enseña la pronunciación y facilita al discípulo el reproducirla por sus propios órganos. [...] Por otra parte, como la frase no puede desarrollarse sino en alguna de las tres formas, interrogativa, negativa o positiva, resulta que, estando toda la obra calculada teniendo en consideración estos principios generales, llega el discípulo al fin sin darse cuenta de haber recorrido todos los elementos filosóficos del lenguaje, y de que por consiguiente nada le queda por aprender, puesto que desde el instante de empezar no ha hecho más que repetir los mismos principios, adaptándoles nuevas palabras, nuevos giros, de manera que es imposible no grabar en la memoria de un modo indeleble los modismos y las expresiones más difíciles ${ }^{237}$.

En las ediciones de 1853 de la gramática francesa y de la italiana, según el método Ollendorf, se ocupa también Eduardo Benot de una cuestión que será el eje vertebrador de sus preocupaciones métricas: la división silábica de las palabras y de las frases, con vistas a la escansión del verso:

Como algunas veces forman diptongos las vocales, v.g. sirvió, dio, y otras veces no los forman, como rió, desafió, se necesita expresar esta circunstancia, y al efecto se usará de un signo que indique la ausencia del diptongo ${ }^{238}$.

En un primer momento, propone colocar dos puntos, o crema, para indicar el hiato: rió, desafió; o bien un acento como el grave francés: riò, desafiò. Tal es el sistema que adopta en las citadas ediciones. Posteriormente, a partir de 1865, prefiere hacer uso del llamado subpunto ${ }^{239}$ : rịó, desafịó. Pero, en algunas palabras, y sin

\footnotetext{
237 Ibíd., p. XIII.

238 Ibíd., p. XXIV.

239 BENOT, E.: Ollendorf reformado. Gramática inglesa, y método para aprenderla, Cuarta edición corregida nuevamente. Cádiz: Verdugo Morillas y Compañía, 1865 , p. 4: «Un punto colocado debajo de una vocal indica que esta vocal no forma diptongo con la siguiente».
} 
que el sentido se altere, puede producirse o no el diptongo: ruina o rụina, diario o dịario, ampliando o amplịando, león o lẹón. He ahí el problema que plantean las vocales en contacto:

La gran dificultad para los extranjeros, y que lo es también notabilísima para los españoles, es, en el caso de estar contiguas dos o más vocales, conocer cuándo cada vocal se pronuncia en el tiempo de una sílaba, o bien, saber cuándo las dos o más vocales contiguas se pronuncian en la variable duración de una sílaba.

Por ejemplo, en el verso:

Oíais, mujeres desdichadas,

cada una de las cuatro vocales de oíais exige el tiempo de una sílaba, como si se dijese:

mirábanlos, mujeres desdichadas,

mientras que en el verso

Estos Fabio ¡ay dolor! que ves ahora

las cuatro vocales io ay se pronuncian juntas en el tiempo de una sílaba, como si se dijese:

Estos Fabi dolor que ves ahora ${ }^{240}$.

Junto con el número de sílabas, los acentos son la base sobre la que se sustentará la métrica para Eduardo Benot. Ya desde las primeras páginas de sus gramáticas según el método Ollendorf, muestra un especial cuidado en establecer una clara distinción entre acento y tono ${ }^{241}$, y entre acento y cantidad silábica ${ }^{242}$. De todas estas cuestiones volverá a ocuparse en sus trabajos posteriores, aclarando

240 Ibíd., p. 3.

${ }^{241}$ Ibíd., p. 1, nota 2: «Todavía se lee en gramáticos modernos que acento es el tono con que se pronuncia una palabra, ya subiendo, ya bajando la voz, sin embargo de que el número de vibraciones por segundo no tiene nada que ver con el empuje del aliento al pronunciar las palabras, que es lo que constituye el acento en el idioma castellano».

242 Ibíd., p. 3: «En cantará la sílaba de más acento es ra, y la de más cantidad es can; en constó, tó tiene el acento y cons la cantidad. Esto no quiere decir que el acento y la cantidad no puedan reunirse a veces en la misma sílaba, como sucede en consta y cántara, donde cons y can son las sílabas que a la vez tienen el acento y la cantidad». 
y ampliando sin cesar las ideas que, al principio, no estaban más que esbozadas.

A estos años de intensa dedicación a la enseñanza en el colegio San Felipe Neri (1848-1867) corresponde también un curioso estudio monográfico sobre la acentuación ${ }^{243}$, que, en un primer momento, no fue más que un opúsculo escrito por Benot para presentarlo a la Real Academia Española, que le había nombrado en 1863 correspondiente español. Se imprimieron sólo cien ejemplares, de 56 páginas; pero la segunda edición ${ }^{244}$ habría de ser notablemente ampliada, hasta alcanzar las 248 páginas. Se propone Benot demostrar que nuestra prosodia no tiene nada en común con la griega ni con la latina, porque la nuestra es acentual y no cuantitativa. Por otra parte, la duración o cantidad de nuestras sílabas nunca se da en la razón de 2 a 1 , como ocurre en la relación de largas y breves grecolatinas. Nuestro sistema prosódico depende fundamentalmente de las sílabas y del acento, bien entendido que han de estudiarse en la frase y no en la palabra aislada. Como medio de notación para la separación de sílabas, cuando existen vocales en contacto, recurre nuevamente al subpunto, como signo diacrítico que permite saber que la vocal que lo lleva no se une a la siguiente, ni en diptongo dentro de la misma palabra, ni en sinalefa en palabras contiguas.

Por esos mismos años, publica también ensayos de carácter específicamente pedagógico ${ }^{245}$, donde vuelve a plantearse la cuestión de la enseñanza de las lenguas. A diferencia del latín, que se enseña declinando y conjugando, mediante el estudio de las palabras aisladas, considera Benot que las lenguas modernas se aprenden para hablarlas. Y el hablar consiste en enunciar juicios, que se expresan no con palabras, sino con oraciones, proposiciones o periodos, los

243 BENOT, E.: Examen crítico de la acentuación castellana. Cádiz: Imprenta de la Revista Médica, 1866.

244 Madrid: Viuda de Hernando y Compañía, 1888.

245 BENOT, E.: Observaciones sobre la educación. Cádiz: Imprenta de la Revista Médica, 1857; y Errores en materia de educación y de instrucción pública. Cádiz: Imprenta de la Revista Médica, 1859. 
cuales tienen en cada lengua sus reglas especiales y su manera peculiar de coordinación. Por consiguiente, las lenguas deben enseñarse no por clasificaciones gramaticales, sino «por medio de oraciones en que se observe la construcción propia del idioma que se aprende $\gg^{246}$.

En cualquier caso, la regla de oro del buen maestro es no presumir de haber enseñado una verdad por el solo hecho de decirla y demostrarla. Es preciso, además, que el discípulo tenga ojos abiertos para ver esa verdad y una decidida voluntad de recibirla:

Si por enseñar se entiende, como general y erróneamente se cree, cierta acción del maestro, causa exterior del comprender del alumno, entonces diremos que esto de enseñar es una quimera, porque en este sentido bien se puede afirmar que nadie enseña; mas si por enseñar se entiende cierta acción del maestro, ocasión exterior y estímulo de los actos internos en cuya virtud el alumno se apodera de las cosas que le ponen por delante, las coge, las aprehende, las aprende, se las hace suyas, se las asimila, entonces se ha formado del significado de esa palabra el debido concepto ${ }^{247}$.

La actividad docente de Eduardo Benot, durante su etapa gaditana, no se limitaría al dominio de la filosofía y la filología, sino que también organizó en el Colegio de San Felipe Neri un completísimo gabinete de Física. A partir del año 1857, explica Geodesia y Astronomía en San Fernando, donde había sido nombrado jefe del Observatorio de la Marina. Escribe, además, algunas obras dramáticas, y revisa una y otra vez las múltiples reediciones de sus gramáticas. En 1863, la Real Academia Española le distingue con el título de académico correspondiente.

En 1867 marcha a París para estudiar la Exposición Internacional, y después su vida transcurrirá fundamentalmente en Madrid, donde la dedicación docente cederá el paso a la actividad política.

\footnotetext{
246 BENOT, E.: Errores en materia de educación..., cit. p. 193. Cito por la 2a. ed., s. a. [1862].

247 Ibíd., p. 129.
} 
En enero de 1869 se celebran elecciones a Cortes Constituyentes ${ }^{248}$, y los republicanos consiguen 85 escaños, frente a los 156 de los progresistas y a los 20 de los absolutistas. Eduardo Benot, que militaba en el partido republicano, consigue un acta de diputado a Cortes por Jerez de la Frontera. En la sesión parlamentaria del 20 de mayo de 1869 , fue uno de los setenta y tres diputados que votaron en contra de la continuación de la Monarquía. No obstante, las Cortes elaboraron una Constitución monárquica, que fue promulgada el 6 de junio de 1869, nombrándose regente al general Serrano y presidente del gobierno al general Prim. La candidatura de Amadeo de Saboya fue aprobada por las Cortes el 16 de noviembre de 1870, con cien votos en contra, entre los que se contaba el de Eduardo Benot.

Disueltas las Cortes Constituyentes, fue elegido senador en las elecciones de septiembre de 1872 . Se distinguió por su oposición a la Corona, defendiendo abiertamente los intereses republicanos y apoyando la emancipación de las colonias. El 11 de febrero de 1873, el Congreso y el Senado se reúnen en Asamblea Nacional y proclaman la República. Eduardo Benot actuaba entonces como secretario. En las elecciones a las nuevas Cortes Constituyentes, del 10 al 13 de mayo, fue elegido una vez más diputado. Los republicanos consiguieron en esta ocasión una mayoría abrumadora.

Los acontecimientos políticos se suceden, a partir de ahora, con una rapidez vertiginosa. El 8 de junio se proclama la República federal, el 11 de junio Estanislao Figueras abandona el poder, y ese mismo día Francisco Pi y Margall es designado segundo presidente de la República. Se forma nuevo gobierno, en el que Eduardo Benot ocupa la cartera de Fomento. Fue un gobierno efímero, que duró sólo desde el 11 hasta el 28 de junio de 1873. Poco después, el 18 de julio de ese mismo año, Pi y Margall presenta la dimisión. Se trata de un periodo ciertamente turbulento de la vida política, ya que desde el 11 de febrero, fecha de la proclamación de la República, hasta el 18 de julio hubo cinco cambios de gobierno y dos de presidente.

248 Vid. TUÑÓN DE LARA, M.: Historia de España, VII. Barcelona: Labor, 1981, pp. 255 y ss. 
En las tres semanas escasas en las que estuvo Eduardo Benot al frente del Ministerio de Fomento, puso en práctica algunas medidas de excepcional importancia para el país, entre las que destacan la creación del Instituto Geográfico y Estadístico y la elaboración del proyecto de la que puede considerarse como primera ley obrera promulgada en España. La ley, que fue aprobada el 11 de julio de 1873 (Gaceta de Madrid del 28 de julio), cuando ya había cesado como ministro, aunque no como diputado, regula el horario y las condiciones higiénicas del trabajo de los menores de edad y establece las bases de los jurados mixtos.

El sucesor de Pi y Margall en la presidencia de la República, Nicolás Salmerón, desempeñó el cargo durante dos meses escasos, ya que dimitió el 7 de septiembre de 1873 por motivos de conciencia, al negarse a firmar la pena de muerte impuesta por los tribunales a algunos sediciosos. Le sucedió Emilio Castelar, que asimismo dimitió de su cargo, al haber perdido un voto de confianza, a primeras horas del día 3 de enero de 1874. Poco después, el general Pavía ocupó violentamente el Parlamento. Eduardo Benot fue uno de los diputados que se opusieron más vivamente a aquel atropello, increpando a la tropa y pidiendo a voces armas.

La caída definitiva de la República, tras el pronunciamiento en Sagunto del general Martínez Campos el 29 de diciembre de 1874, y la restauración de la Monarquía supusieron un duro golpe para la actividad política de Eduardo Benot. Tras un breve exilio en Portugal, se afinca en Madrid y, hasta su muerte, siguió militando en el Partido Republicano Federal. En las elecciones de marzo de 1893, fue elegido por última vez diputado, obteniendo una de las exiguas 33 actas que habían conseguido los republicanos, frente a las 61 de los conservadores y las 295 de los liberales. Su presencia en la Cámara sería en esta ocasión meramente testimonial, limitándose a acudir a algunas sesiones para emitir su voto.

Pasado el fervor militante del quinquenio 1869-1873, vuelve Benot a su intensa actividad científica y literaria. En 1881, su ensayo Movilización de las fuerzas del mar o aprovechamiento de los motores 
irregulares contra las mareas y las olas le vale el premio de la Academia de Ciencias y su ingreso en la misma. En 1889 pronuncia, con el título ¿Qué es hablar?, su discurso de ingreso en la Real Academia Española. Recopila, ordena y amplía sus escritos anteriores, perfilando sus ideas gramaticales en los Breves apuntes sobre los casos y las oraciones (1888), la Arquitectura de las lenguas (ca. 1889) y el Arte de hablar, obra póstuma publicada en 1910.

Su doctrina sobre la versificación aparece ampliamente desarrollada en Versificación por pies métricos (1890), Diccionario de asonantes y consonantes (1893) y, sobre todo, en Prosodia castellana y versificación (s. a. pero 1892). Del primero de los libros citados, se hizo una pequeña tirada de cincuenta ejemplares, que el autor regaló «a sus doctos amigos» ${ }^{249}$. Una vez más, nos hace ver la infundada pretensión de acudir en la métrica española a la distinción entre largas y breves, que no existen en modo alguno en castellano con el carácter temporal de la razón 2:1, tal como se da en la lengua griega o en la latina. En esta obra se hace también uso del subpunto como índice tipográfico, el cual, como tuvimos ocasión de ver, ya había sido empleado en la cuarta edición de la Gramática inglesa (1865) y en el Examen crítico de la acentuación castellana (1866).

Los días de Eduardo Benot terminan el 27 de julio de 1907. Ochenta y cinco años de una fructífera vida, intensamente dedicada a la participación ciudadana, a las letras y a la ciencia, merecieron el reconocimiento de la prensa diaria de la época ${ }^{250}$, que le describe como un hombre comprometido, sabio, sencillo y austero. Él mismo había hecho alusión, ya en sus primeros años de docencia gaditana, a su talante revolucionario y progresista:

249 LA VIÑAZA, C. de: Ob. cit., p. 536.

250 El País, diario republicano, 28 de julio de 1907: «España perdió ayer a una de sus más puras glorias, a uno de los contados hijos que le dan honra y renombre, y a un ferviente patriota». El Nuevo régimen, semanario federal, 5 de agosto de 1907: «Prosista irreprochable, poeta inspirado, filósofo eminente, político, matemático, físico, astrónomo». 
Me han dicho que soy revolucionario. ¿No he de serlo? Quiero el progreso, como lo quieren cuantos corazones generosos ven los males y vislumbran el remedio. Tengo entera conciencia de mis opiniones, y las expongo. Ataco con energía las viejas rutinas y rancias preocupaciones, fenómenos del mundo moral, que, mientras más viejas son, más fuerzas tienen ${ }^{251}$.

Considerado como uno de los miembros de la llamada generación del 68, junto a figuras tan significativas como Giner de los Ríos y Pi y Margall, Eduardo Benot influyó sin duda alguna en los hombres del 98. A las conocidas tertulias de su casa madrileña acudieron, entre otras personalidades ilustres, los hermanos Machado. Don Antonio dedicó al «venerable maestro D. Eduardo Benot» el poema LII, «Fantasía de una noche de abril», de las Soledades ${ }^{252}$.

En lo que concierne específicamente a la métrica española, la obra Prosodia castellana y versificación de 1892 constituye el tratado más extenso y completo de cuantos hasta el momento se habían escrito. Consta de siete libros, distribuidos en tres tomos en $4 .^{\circ}$ mayor: tomo I, 423 pp.; tomo II, 584 pp.; tomo III, 447 pp.+ XCI pp. de sumario e índice.

En el prólogo de la obra, que está escrita en forma epistolar y en un estilo claramente discursivo y polémico, aunque no exento de una noble y fina ironía, se lamenta Eduardo Benot de las inexactitudes, errores y deficiencias de los estudios españoles sobre prosodia y versificación. Cita, con todo, como autoridades a los preceptistas americanos Andrés Bello y Eduardo de la Barra, aunque hace constar la disparidad de sus puntos de vista y la parcialidad de los estudios de estos autores.

En consecuencia, se propone llevar a cabo un análisis exhaustivo de la prosodia y la versificación, o en otros términos, de la acentuación y el ritmo, completando así lo ya expuesto en anteriores

\footnotetext{
251 BENOT, E.: Errores en materia de educación ..., cit., p. IV.

252 MACHADO, A.: Poesías completas, ed. crítica de O. Macrì. Madrid: Espasa-Calpe, 1989, p. 863.
} 
trabajos, tales como el Examen crítico de la acentuación castellana o la Versificación por pies métricos. Y, desde el primer momento, pone de manifiesto su obsesiva preocupación por el problema que, para la medida y la separación de las sílabas, supone la situación contigua de dos o más vocales. Una y otra vez, hace ver la conveniencia de utilizar el subpunto:

Un punto bajo una vocal indica que esta vocal no se junta a la sílaba siguiente ni en diptongo ni en sinalefa ${ }^{253}$.

Sólo habré de decir en este prólogo algunas palabras sobre el subpunto, índice tipográfico empleado en esta edición, y de que ya había yo hecho uso en otros libros míos, especialmente en la parte española de mi Gramática para aprender inglés, cuarta edición, de 28000 ejemplares, impresa en Cádiz el año de $1865^{254}$.

En lo que no he introducido variación ninguna ha sido en el sistema de distinguir con un punto por debajo toda vocal que no se une a la siguiente para constituir diptongo o sílaba métrica con ella ${ }^{255}$.

Sólo me cumple aquí anticipar que, en toda esta obra, un punto impreso bajo una vocal indica que esta vocal no forma diptongo o sinalefa con la siguiente; o bien que, en versificación, no constituiría sílaba métrica con ella ${ }^{256}$.

$Y$ es necesario el subpunto, porque falta en español un índice ortográfico, no de fuerza sino de duración, que dé el valor de una sílaba métrica a toda vocal que no se una, ya en diptongo a la vocal inmediata de su mismo vocablo, ya en sinalefa a la vocal inicial o a las vocales iniciales del vocablo siguiente ${ }^{257}$.

El primer tomo contiene, además del prólogo, los libros primero y segundo, que tratan respectivamente de los sonidos y los acentos.

253 BENOT, E.: Prosodia castellana..., cit., tomo I, p. 5, nota 1.

${ }^{254}$ Ibid., p. 6.

255 Ibid., p. 11.

256 Ibíd., p. 12.

257 Ibid., p. 13. 
Parte Benot de las cualidades físicas del sonido, en cuanto movimiento vibratorio periódico, y de su percepción por el oído. Relaciona, justamente, la intensidad del sonido con la amplitud de las vibraciones, y su altura o tono con la frecuencia o número de vibraciones por segundo. Considera que el timbre está en dependencia de los llamados armónicos (harmoniques, de los franceses) que acompañan al tono fundamental, aunque él prefiere denominarlos hipertonos (Obertöne, de los alemanes), ya que no siempre suponen un elemento de armonía. Los sonidos pueden ser vocales o consonantes. De las relaciones de unos sonidos vocales con otros surgen el acento, la cantidad y la entonación.

$\mathrm{Al}$ estudio pormenorizado del acento, al que se le concede una importancia excepcional, por estar realmente fundadas en él la prosodia y la versificación castellanas, está dedicado el libro segundo. Hay que evitar, ante todo, el error de confundir el acento con la cantidad. En griego y en latín había vocales largas y breves, siendo larga la que exigía para su pronunciación un tiempo doble al de la breve. La duración de las vocales era, así pues, 2:1. Esta relación se llamaba cantidad, y en ella se basaba la versificación antigua. Pero en español, aunque hay sílabas más largas que otras (por ejemplo, transporte: en decir trans se invierte más tiempo que en decir por, y mucho más que en decir te), no se dividen en dos clases, según la razón 2:1.

El segundo tomo comprende los libros tercero y cuarto, dedicados respectivamente al estudio de los diptongos y las sinalefas. Nuestra lengua se caracteriza por ser diptongal y sinaléfica. Cuando dos vocales se pronuncian en un solo tiempo silábico, decimos que constituyen un diptongo. Pero las dificultades de nuestra prosodia comienzan precisamente cuando dos o más vocales se encuentran contiguas, ya que pueden pronunciarse en el solo tiempo de una sílaba, lo cual es lo más frecuente, pero también en dos tiempos, esto es, en dos sílabas. Por otra parte, en el estudio de los diptongos, es de absoluta necesidad distinguir si las vocales están acentuadas o no, ya que las reglas referentes a los diptongos inacentuados no son 
las mismas que las reglas relativas a las parejas de vocales situadas en sílaba tónica.

En el libro cuarto se estudian las sinalefas, que pueden ser binarias, ternarias, cuaternarias, quinarias o senarias, según que en el contacto entre vocales pertenecientes a palabras inmediatamente sucesivas se produzcan diptongos, triptongos, tetraptongos, pentaptongos o hexaptongos. También aquí, del contacto entre vocales contiguas, puede surgir la unión silábica o, por el contrario, el hiato. El acento juega, asimismo, un papel esencial en la versificación y en la prosodia. Es, en palabras de Eduardo Benot, el sol central de la diptongación y de la sinalefación. El acento natural de cada palabra no puede variar de lugar, pero sí es susceptible de ser vigorizado en la frase y en la línea del verso, especialmente en virtud de las pausas y la entonación expresiva. Las sinalefas aumentan la riqueza silábica del español, siempre que se respeten las leyes fisiológicas y acentuales de los sonidos, sílabas, palabras y frases, y no se oscurezcan o violenten las pausas y los acentos rítmicos de los versos.

El tomo tercero y último comprende los libros quinto, sexto y séptimo, además de un extenso sumario de las cuestiones tratadas en los siete libros y un índice alfabético de términos métricos y de palabras cuya prosodia haya sido en ellos objeto de estudio.

El libro quinto, que lleva específicamente el título de Métrica espanola, es un amplio tratado de la versificación en general, así como de la «nueva métrica» por pies acentuales y las distintas combinaciones métricas. Insiste Benot en el hecho de que el acento que, naturalmente, posee cada palabra no cambia nunca de vocal ni de sitio, pero se vigoriza por su situación en la frase, por la influencia de las pausas y por el énfasis que se ponga en la pronunciación de la frase y el verso. Las bases de la actual métrica española son, en fin de cuentas, los acentos y el número de sílabas. La distribución de los acentos ha de seguir las pautas del ritmo, que supone periodicidad y repetición. Si nuestras enunciaciones no guardan el debido ritmo, es decir, si no se aprecian periódicamente pausas y grupos acentuales, entonces nuestros pensamientos aparecerán expresados simplemente en prosa. En 
la «métrica nueva», el ritmo se efectúa por medio de pies acentuales, disílabos y trisílabos, bien entendido que los pies de la nueva versificación española no son pies cuantitativos como los griegos y latinos, sino pies acentuales. De esta métrica existían ya precedentes, como el decasílabo anapéstico, el endecasílabo dactílico o el dodecasílabo anfibráquico.

La importancia de una buena versificación es capital. Cierto es -apunta Benot- que, en las obras poéticas, lo primero es la poesía; pero, en las obras en verso, lo primero es el verso. No servirán, por tanto, como disculpas para una mala versificación las posibles dificultades técnicas o los desaciertos en que los mismos clásicos hayan podido a veces incurrir. Del estudio de las anormalidades observadas en la versificación podemos sacar también provecho, tanto o más que del estudio de las formas regulares. Al análisis de los versos defectuosos está dedicado precisamente el libro sexto, que tiene por título El hospital de los incurables. Habría que habilitar, en efecto, un hospital en donde alojar convenientemente, en distintas salas, a un buen número de versos incurables. Los versos pueden ser malos por falta o sobra de sílabas, por no tener los acentos en su sitio, por acentos obstruccionistas, por sinalefas obstruccionistas, por asonancias internas, por asonancias con versos cercanos, etc. También puede haber versos enfermos por demencia o falta de sentido común, aunque éstos, más que a un hospital, deberían ir a una casa de locos. Y, según Eduardo Benot, asusta pensar lo inmenso que tendría que ser el manicomio capaz de recibir a todos los dementes de la literatura española.

Por último, el libro séptimo se ocupa de las estrofas. Advierte Benot que la rítmica se basa en la pluralidad de los versos, de todos los versos de la serie poemática, y nunca en uno solo. De ahí la importancia del estudio de las estrofas. Como regla común, se establece que los consonantes no han de ser asonantes entre sí dentro de la misma estrofa, ni de los versos cercanos de las estrofas contiguas.

En el conjunto de la obra, resalta como objetivo principal de estos siete libros de prosodia castellana y versificación la firme voluntad 
de llevar a cabo un minucioso análisis de la medida del verso, esto es, de su escansión, de la separación de las sílabas, del cómputo silábico, de la distribución acentual. Toda la teoría métrica de Eduardo Benot podría, en definitiva, sintetizarse en la siguiente cita textual:

Las bases de la actual métrica son:

Número fijo de sílabas.

Acentos obligados.

Acentos supernumerarios, nunca obstruccionistas ${ }^{258}$.

Para Eduardo Benot, fue Ignacio de Luzán quien, con la doctrina contenida en su Poética, habría venido a introducir un elemento de desorden y confusión en la métrica castellana:

... aquel hombre enmarañó el estudio de la acentuación castellana con las teorías de largas y de breves, de graves y de agudas, de dáctilos y espondeos, de hexámetros y pentámetros... propias de las prosodias antiguas, y que no existen de modo alguno en español como en los tiempos de las antiguas Grecia y Roma ${ }^{259}$.

Y es que, en efecto, Luzán había escrito en su Poética que «en las lenguas española e italiana, el acento agudo suple en cierto modo la cantidad, y hace que la sílaba parezca larga $\gg^{260}$. Admite Luzán que la pronunciación «no se conserva ya en las lenguas vulgares tal como fue en la griega y latina», y que se ha perdido «aquella tan cabal y delicada distinción con que las sílabas largas se pronunciaban en dos tiempos, y las breves en uno»; pero con todo, no puede acabar de creer que «nuestra pronunciación (hablo de españoles e italianos) cuanto a las largas y breves sea totalmente diversa de la antigua, de modo que no haya quedado alguna distinción bastante para la harmonía poética» ${ }^{261}$.

\footnotetext{
258 Ibíd., p. 30.

259 Ibid., p. 166.

${ }^{260}$ LUZÁN, I. de: La Poética, o reglas de la poesía en general, y de sus principales especies, I, ed. corregida y aumentada. Madrid: Antonio Sancha, 1789, p. 336.

261 Ibíd., p. 328.
} 
La actitud de Luzán es compartida por la mayoría de los tratadistas españoles de la primera mitad del siglo Xıx. Así, por ejemplo, en 1826, a José Gómez Hermosilla no le cabe la menor duda de que la $o$ de orar es breve, mientras que la de obstar es larga, «prueba irrefragable de que, además del acento, hay otra cosa que puede hacer largas las sílabas ${ }^{262}$. Hermosilla da por supuesto que las sílabas acentuadas son largas. Por su parte, Francisco Martínez de la Rosa, que representa tal vez el más firme baluarte en la defensa de la tesis cuantitativa, llega a afirmar que «los acentos son los que mejor nos indican la cantidad de las sílabas, es decir, las que son largas o breves $\gg^{263}$, que $\ll$ la cantidad de las sílabas, y no su simple número, influye en la versificación moderna más de lo que comúnmente se imagina $»^{264}$, y que, en definitiva, son los acentos los que «distinguen las sílabas largas de las breves ${ }^{265}$.

Bien es verdad que, pocos años después, estos criterios no habían sido compartidos por el eminente filólogo Andrés Bello cuando, en el prólogo de la edición de 1835 de sus Principios de ortología y métrica, hace mención de las «reñidas controversias que han dividido siglos hace a los humanistas, acerca de las cantidades silábicas, el oficio de los acentos y la medida de los versos ${ }^{266}$. Una y otra vez, expresa el maestro venezolano su oposición absoluta a la pertinencia métrica de los criterios cuantitativos, ya que «todas las sílabas son sensiblemente iguales en la duración, o por lo menos distan más de la razón de 1 a 2 que de la razón de igualdad $\gg^{267}$.

262 GÓMEZ HERMOSILLA, J.: Arte de hablar en prosa y verso, II. Madrid: Imprenta Real, 1826, p. 120.

263 MARTínEZ DE LA ROSA, F.: Poética. Palma: Villalonga, 1831, p. 162.

264 Ibid., p. 164.

265 Ibíd., p. 177.

266 BELLO, A.: Principios de la ortología i métrica de la lengua castellana. Santiago de Chile: Imprenta de la Opinión, 1835. Cito por Obras completas, I. Madrid: Tello, 1890, p. 105.

267 Ibíd., p. 258. 
En el espejismo de la duración silábica, y en la consiguiente distinción entre sílabas largas y breves, se vieron involucrados no sólo los teóricos de la métrica, sino también algún eximio versificador de la talla de Rubén Darío. Cuando, en 1905, el gran poeta nicaragüense intenta aclimatar a la métrica española el hexámetro clásico con sus Cantos de vida y esperanza (recuérdese el ritmo dactílico de «Ínclitas razas ubérrimas, sangre de Hispania fecunda»), piensa que con el juego saltarín de sus cláusulas rítmicas ternarias está insuflándole una nueva vida al antiguo sistema combinatorio de las sílabas largas y breves. Y, así, unos años después, escribe:

Elegí el hexámetro por ser de tradición grecolatina y porque yo creo, después de haber estudiado el asunto, que en nuestro idioma, malgré la opinión de tantos catedráticos, hay sílabas largas y breves, y que lo que ha faltado es un análisis más hondo y musical de nuestra prosodia $^{268}$.

Es evidente que Rubén Darío está aquí aludiendo, y también contradiciendo, a tratadistas como Bello o Benot. La postura de este último es tajante a este respecto:

Pero ¿ese sistema prosódico de la antigüedad ha llegado hasta nosotros? ¿Existen en español sílabas que necesiten invariablemente un tiempo para pronunciarse, mientras que otras requieren medio tiempo? ¿Tenemos, pues, sílabas largas y breves iguales a las latinas en la razón invariable 2:1? No, sin duda alguna. Dudarlo sería no tener oídos $^{269}$.

Una y otra vez, insiste Eduardo Benot en el hecho de que «en español hay sílabas más largas y más breves que otras; pero no vocales largas y breves como las latinas en razón $2: 1 \gg^{270}$. Así, por ejemplo, la 268 DARÍO, R.: Historia de mis libros [1909], en Obras completas, I, Crítica y ensayo.
Madrid: Afrodisio Aguado, 1950, p. 216.
269 BENOT, E.: Prosodia castellana..., cit., p. 181.
270 Ibíd., p. 182. 
palabra trance consta de dos sílabas, y con toda seguridad invertimos más tiempo en pronunciar la primera sílaba, tran, que la segunda, ce; pero esto no implica que la duración de tran sea el doble que la de ce. Y arremete, con especial denuedo, contra las tesis defendidas por Sinibaldo de Mas, autor de un curioso libro titulado Sistema musical de la lengua castellana, cuya primera edición data de $1832^{271}$. Para Eduardo Benot, Sinibaldo de Mas fue uno de los «últimos representantes de lo antiguo ${ }^{272}$, y censura repetidas veces sus «extravagantes reglas ${ }^{273}$.

Parte Sinibaldo de Mas del supuesto de que las sílabas castellanas, al igual que las griegas y latinas, pueden ser largas y breves, y formula a este respecto una serie de teoremas o reglas para medir la cantidad silábica, al tiempo que establece una lista de doscientas sílabas breves (tales como las de las palabras día, iría o ileso) y otras tantas sílabas largas (como las de circunstancias, obstrucción o industrias). En relación con estos criterios, que en realidad no distan mucho de los ya fijados por Luzán o Gómez de Hermosilla, escribe Benot:

Hacía leer ambas listas con el reloj en la mano a quien quiera que le negaba la existencia de breves y de largas en castellano; y, como todos se veían obligados al cabo a confesar que la lectura de la primera lista exigía menor duración que la de la segunda, concluía que en español era posible hacer versos a la latina. ¡Patente error! ¡Conclusión no contenida en las premisas! Porque en leer la segunda lista se echase más tiempo que en leer la primera, no era lícito deducir que se invertía el doble; y, por tanto, el experimento no evidenciaba que hubiese en castellano sílabas relacionadas entre sí 2:1, según era preciso probar para inferir que en nuestra lengua es posible hacer hexámetros iguales a los griegos y latinos ${ }^{274}$.

${ }^{271}$ MAS, S. de: Sistema musical de la lengua castellana, ed. de José Domínguez Caparós. Madrid: CSIC, 2001.

272 BENOT, E.: Prosodia castellana..., cit., p. 166.

273 Ibíd., t. I, pp. 184 y 394; y t. III, pp. 12, 18, 22 y 29.

274 Ibid., t. III, p. 15. 
Y, pasando de las consideraciones teóricas a la práctica de la versificación según los moldes grecolatinos, nos dice:

La aplicación de los arbitrarios principios de las largas y las breves fue una verdadera desdicha. De la bondad del árbol se juzga por la bondad de los frutos. [...] Se lanzaron a predicar con el ejemplo, y dieron a luz, como acabados modelos, muchos renglones desiguales; de los que se mostraban tan satisfechos como de obras maestras. Y en verdad que al leerlos (en cuanto es posible, pues a terminarlos no creo que haya llegado paciencia humana), al leerlos no sabe uno qué sea más de admirar, si la buena fe de sus autores, o la absoluta carencia de ritmo con que se dedicaban a destrozar los oídos castellanos ${ }^{275}$.

Al final del tomo I de su extensa obra sobre la prosodia castellana y el arte de hacer versos, en una brevísima conclusión, resume así su doctrina el filólogo gaditano: «A mi entender es estéril todo intento de introducir condiciones cuantitativas en nuestra versificación acentual ${ }^{276}$. No obstante, deja abierto un resquicio a la posibilidad de introducir en la métrica española algún nuevo elemento rítmico, más allá de la constancia o regularidad métrica preconizada por las preceptivas castellanas de un Rengifo o un Cascales. Y, así, a renglón seguido, añade: «Sólo donde exista marcadísima diferencia entre lo largo y lo breve, podrá la cuantidad ser elemento de versificación». Es muy posible que, más que la cantidad silábica, esté teniendo en cuenta aquí Eduardo Benot los marcados y reiterativos ritmos de las cláusulas binarias y ternarias de los poetas modernistas.

En cualquier caso, podemos ver cómo los estudios sobre el verso y su estructura, que en los últimos años han venido experimentando un feliz y creciente desarrollo, serían difícilmente explicables si legáramos al olvido las investigaciones precedentes, no sólo en lo que concierne a los estudios más cercanos del pasado siglo $\mathrm{xx}$, sino en todo lo que se refiere a ese amplio periodo de pensamiento

\footnotetext{
275 Ibíd., t. III, pp. 16-17.

276 Ibíd., t. I, p. 420.
} 
neoclásico, romántico y positivista que va desde la Poética de Ignacio de Luzán hasta la Prosodia castellana y versificación de Eduardo Benot, pasando por el Arte de hablar en prosa y verso de José Gómez Hermosilla, el Sistema musical de la lengua castellana de Sinibaldo de Mas o los Principios de ortología y métrica de Andrés Bello, por citar sólo algunos de los tratados más significativos. Entre todos ellos, el de Eduardo Benot constituye un hito insoslayable en el estudio evolutivo de la métrica española y su teoría. Su peculiar sistema de notación, que nos permite una sencilla y pronta distinción entre hiatos y diptongos, diéresis y sinéresis, dialefas y sinalefas, mediante el uso del subpunto, representa un tesoro de valor incalculable para la ciencia del verso. El análisis detenido de esta obra contribuirá, sin duda, al esclarecimiento de muchas cuestiones, aún oscuras en la actualidad, en el dominio del versolibrismo, la métrica tradicional y las pautas que subyacen en las formas a veces irregulares, al menos aparentemente, de una parte de la poesía contemporánea. 



\section{CRÍTICA Y ANÁLISIS}





\section{LA PERFECCIÓNDE ALGUNOS ENDECASÍLABOS «IMPERFECTOS» DE GARCILASO DE LA VEGA}

L

a perfección del verso endecasílabo de Garcilaso de la Vega introductor, junto con Juan Boscán, de esta forma métrica en Jla poesía castellana, y punto de arranque de la moderna literatura española- no impide que algunos críticos y teóricos hayan querido señalar en su obra la existencia de versos irregulares o defectuosos, que no se atienen a las pautas generalmente admitidas como canónicas para el endecasílabo español. Se aducen, así, casos de endecasílabos dactílicos ${ }^{277} \mathrm{y}$ de acentuación anómala o deficiente. A continuación, se tendrán en cuenta las distintas circunstancias

${ }^{277}$ El endecasílabo dactílico, cuyo ritmo ternario podría asimilarse al del dodecasílabo castellano medieval, no tuvo buena acogida en la nueva métrica italianizante del Renacimiento, a pesar de haber sido empleado profusamente en la lengua toscana por el maestro Petrarca. Caso distinto habría de ser el de las cláusulas trisilábicas de la poesía romántica y, sobre todo, de la poesía modernista, en donde se inserta muy bien el ritmo ternario del endecasílabo dactílico. Aparece, así, en composiciones de Rubén Darío, Salvador Rueda, Francisco Villaespesa y algunos poetas menores. Su eco llega hasta Gerardo Diego, Rafael Alberti o Miguel Hernández. No se encuentra en Juan Ramón Jiménez, ni en Manuel Machado, ni en Antonio Machado. Vid. un amplio y documentado estudio sobre esta forma métrica en DOMÍNGUEZ CAPARRÓS, José: El moderno endecasílabo dactílico, anapéstico o de gaita gallega. Anejo III de Rhythmica. Revista Española de Métrica Comparada. Sevilla: 2009. 
en las que el verso garcilasiano haya podido dar motivo, de alguna forma, a tales calificaciones.

Los versos que más frecuentemente se presentan como ejemplos de endecasílabos dactílicos son los siguientes ${ }^{278}$ :

Tus claros ojos ¿a quién los volviste? (Égloga I, 128)

En esto 'stoy y estaré siempre puesto (Soneto $\mathrm{V}, 5$ )

En relación con el primero de estos dos supuestos endecasílabos dactílicos, Elias L. Rivers advierte en su edición de las Obras completas de Garcilaso que ya Tomás Navarro Tomás había llamado la atención sobre «el carácter dactílico de este verso, que lleva acento en la 7a sílaba (cfr. Henríquez Ureña, RFE, VI, [1919], 132-157) $\gg^{279}$. A este respecto, Miguel Ángel Márquez ${ }^{280}$ precisa que «de hecho, en toda la obra de Garcilaso, sólo se aducen unos pocos casos que dudosamente pueden ser considerados endecasílabos dactíli$\cos \gg^{281}$, y añade en nota:

E. Torre postula que esos escasos ejemplos de dactílicos en Garcilaso de la Vega podrían resolverse si tenemos en cuenta las diferencias que separan el castellano de Garcilaso de la Vega de nuestro español culto. En el caso de Égloga I, 128, podría considerarse la posibilidad de que el pronombre «los» fuera tónico; así el verso cumpliría función rítmica. En el caso de Soneto V, 5, la solución habría que buscarla en la forma verbal «estaré», cuyo origen perifrástico es «estar he». La acentuación aguda del infinitivo de la perífrasis («estár») daría como resultado un verso con acentos en $2^{\mathrm{a}}, 4^{\mathrm{a}}, 6^{\mathrm{a}}, 8^{\circ}$ y $10^{\mathrm{a}}$ sílabas $^{282}$.

${ }^{278}$ Si no se advierte otra cosa, todas las citas se harán por GARCILASO DE LA VEGA: Obras completas con comentario, edición crítica de Elias L. Rivers. Madrid: Castalia, 1981.

279 RIVERS, Elias L.: Obras cit., p. 277, nota a v. 128.

${ }^{280}$ El profesor Márquez es autor de un enjundioso artículo sobre la tipología del endecasílabo, basada en su ritmo acentual, que se define en términos de cláusulas cuaternarias y binarias. Vid. MÁRQUEZ, Miguel Ángel: «Ritmo y tipología del endecasílabo garcilasiano». RLit, 2009, LXXI, 141, pp. 11-38. Este artículo ha servido de estímulo y punto de partida para la elaboración del presente trabajo.

${ }^{281}$ Ibid., p. 20.

${ }^{282}$ Ibid., nota 22. 
En efecto, los dos versos citados se adaptan perfectamente a las formas canónicas del endecasílabo; el primero como endecasílabo sáfico, y el segundo como pentámetro yámbico:

tus.clá.ros.ó.jos.a.quien.lós.vol.vís.te

en.és.to’s.tóy.yes.tá.re.siém.pre.pués.to

En el primero de estos dos versos (égloga i, 128), el pronombre «los» refuerza con el acento de intensidad el movimiento de los ojos de la mujer amada, que rehúyen la mirada del poeta. Por lo demás, la acentuación de las formas pronominales, generalmente átonas, no es excepcional en poemas del siglo XVI, y tampoco lo es en composiciones contemporáneas, incluso en posición enclítica, según puede apreciarse en los siguientes endecasílabos de Blas de Otero:

de encima. Déjame, con mi vacío ${ }^{283}$

deen.cí.ma.dé.ja.mé.con.mi.va.cí.o

O si no, déjanos precipitarnos ${ }^{284}$

o.si.nó.de.ja.nós.pre.ci.pi.tár.nos

En el segundo verso (Soneto V, 5), hemos de tener presentes la formación y la historia del futuro en lengua romance. Como es sabido, se realiza mediante el compuesto de infinitivo + presente: estar he > estaré. Como ya hizo ver don Ramón Menéndez Pidal, «la lengua no perdió el sentido de la composición de estos tiempos sino muy entrada la Edad Moderna ${ }^{285}$. Por esta razón, se admitía la interposición de uno o más pronombres entre el infinitivo y el auxiliar: dar le has, por le darás; traer nos lo has, por nos lo traerás.

Es obvio que, como palabras aisladas, tanto «quién» como «estaré» son portadoras de acento, en contigüidad a «los» en el primer verso, y a «siempre» en el segundo. Ahora bien, como ya el metrista

283 OTERO, Blas de: «Lastima», en Ancia. Madrid: Visor, 1971, p. 49, v. 2.

284 OTERO, Blas de: «Basta», en Ob. cit., p. 40, v. 13.

285 MENÉNDEZ PIDAL, Ramón: Manual de gramática histórica española, 14a. ed. Madrid: Espasa-Calpe, 1973, p. 324. 
gaditano Eduardo Benot había hecho notar a finales del siglo XIX, en el verso endecasílabo «no deben concurrir inmediatas i tocándose dos sílabas intensas i vigorosas», ya que el acento natural constitu$y e n t e$ hace que el acento contiguo «se ofusque i desvanezca ${ }^{286}$.

Ocurre que el acento, por sí mismo, no es en el verso español una entidad absoluta, sino relativa: la sílaba acentuada lo es siempre en relación a un entorno, esto es, a la sílaba que la precede y a la sílaba que la sigue. En realidad, todas las sílabas, en sí mismas, son tónicas: todas llevan acento, todas gozan de una intensidad acústica o energía suficiente para que puedan ser perceptibles; todas tienen un determinado tono o frecuencia de ciclos sonoros. Pero llamamos tónica a la sílaba más acentuada en relación a un entorno de sílabas menos acentuadas, que tienen la consideración de átonas.

Las sílabas átonas, contiguas a la tónica en la secuencia versal, pueden ser portadoras de acento en las palabras aisladas a las que pertenecen. En estas circunstancias, reciben a veces la denominación de sílabas con acento antirrítmico. Señala Miguel Ángel Márquez que estos acentos antirrítmicos, «situados en posición inmediata a un acento rítmico, implican una elevación del tono» ${ }^{287}$, y anota:

Según Torre, en los casos en los que concurren dos acentos contiguos, teniendo en cuenta que el tono de cada sílaba depende del entorno, una de las dos sílabas sería más relevante por el tono y asumiría la función rítmica del verso ${ }^{288}$.

Convendría precisar que el acento rítmico está en función no sólo del tono o frecuencia de cada una de las sílabas, sino también y fundamentalmente de la energía o intensidad acústica de ellas. En ocasiones, el tono viene a matizar el ritmo y a resolver el posible conflicto entre el papel del acento de intensidad en la palabra

\footnotetext{
286 BENOT, Eduardo: Prosodia castellana i versificación [1892], edición facsímil al cuidado de Esteban Torre. Sevilla: Padilla Libros, 2003, I, p. 198.

287 MÁRQUEZ, Miguel Ángel: «Ritmo» cit., p. 14.

${ }^{288}$ Ibíd., p. 15, nota 10.
} 
aislada y su posición en el conjunto de la secuencia versal. Es lo que ocurre, por ejemplo, en el verso «cierra la puerta, hijo mío» de Federico García Lorca ${ }^{289}$. Como palabra aislada, «hijo» es portadora de acento en su primera sílaba. Sin embargo, en la línea del verso (cié.rra.la.puér.tahi.jo.mí.o), la mayor energía del acento de intensidad que incide sobre la primera sílaba de la palabra «puerta» hace que la sílaba hi- (de hijo) quede absorbida por zeuxis o sinalefa en la sílaba átona -ta (de puerta), de manera que la sílaba resultante -tahi- es átona en la secuencia versal. Pero ocurre, no obstante, que la palabra «hijo» conserva una cierta independencia acentual con respecto a la palabra «puerta», en virtud del tono o frecuencia acústica. Existe, en efecto, entre puér-y -tahi- un sensible cambio de tono, lo cual no tiene que implicar necesariamente una elevación del mismo. En el caso que nos ocupa, se aprecia entre puér-y -tahiun semitono descendente. En otros términos: puér- es el sostenido de -tahi-, o-tahi- es el bemol de puér-.

Aduce Márquez otros dos posibles ejemplos de endecasílabo dactílico en Garcilaso de la Vega:

Está y estará tanto en mí clavada (Égloga III, 7)

hinchen el aire de dulce armonía (Égloga II, 69)

En el primero de estos dos endecasílabos, análogamente a lo que ocurre en Soneto V, 5, habría que leer el verbo estará como estar ha, con lo que estaríamos en presencia de un pentámetro yámbico:

\section{es.tár.yes.tár.ha.tán.toen.mí.cla.vá.da}

Pero, al parecer, no podríamos hacer con la misma facilidad una lectura regular del segundo verso, «cuyo ritmo dactílico -se afirmaes incuestionable $\gg^{290}$. Habría que precisar, sin embargo, que entre el verbo «hinchen» y la partícula «de» existe una fuerte rección o relación gramatical. La partícula «de» no es aquí meramente una 289 Vid. TORRE, Esteban: El ritmo del verso (Estudios sobre el cómputo silábico y la distribución acentual, a la luz de la Métrica Comparada, en el verso español moderno). Murcia: Universidad, 1999, pp. 42-50.

290 MÁRQUEZ, Miguel Ángel: «Ritmo» cit., p. 20, nota 22. 
preposición (pre-posición) átona, antepuesta (ante-puesta) al sintagma nominal «dulce armonía», sino que está estrechamente ligada al verbo «hinchen», cuyo significado completa y especifica, adquiriendo así un marcado relieve semántico y fonético en la línea del verso.

Por otra parte, las similitudes y los contrastes de timbre que se dan entre las sílabas de/dul-, ambas con dental inicial, resalta aún más la privilegiada posición $6^{a}$ de la sílaba de, que se equilibra en suave balanceo con la sílaba $7^{a}$ dul- (de dulce). Tras el fuerte impulso de la sílaba $4^{a}$ (áy-, de ayre), se suceden «con dulce armonía» los tonos y las intensidades de las restantes sílabas, hasta llegar a la $10^{\mathrm{a}}$ sílaba final. Es algo análogo en lo que ocurre en el siguiente endecasílabo:

Cortaste'l árbol con manos dañosas (Soneto XXV, 3)

A propósito de este verso, Fernando de Herrera nos advierte que «à de leerse haziendo assiento en el árbol ${ }^{291}$. Es tan fuerte, en efecto, el acento de la sílaba $4^{\text {a }}$ (ár-, de árbol) que todas las demás quedan debilitadas hasta llegar a la $10^{a}$ final. Así pues, tanto en Égloga II, 69, como en Soneto XXV, 3, podemos hacer la siguiente lectura:

hin.chen.el.áy.re.de.dul.cear.mo.ní.a

cor.tas.te'lár.bol.con.ma.nos.da.ñó.sas

Otros endecasílabos podemos encontrar, en la obra poética de Garcilaso de la Vega, con fuerte acentuación en las sílabas $4^{a}$ y $10^{a}$, y con intensidades y tonos más atenuados en las sílabas intermedias. Este tipo de endecasílabo ha sido tildado a veces de verso «desmayado», aunque también puede considerarse como una variedad del endecasílabo sáfico:

$$
\begin{aligned}
& \text { pienso remedios en mi fantasía (Soneto III, 6) } \\
& \text { libre el lugar a la desconfianza (Soneto IV, 4) }
\end{aligned}
$$

291 HERRERA, Fernando de: Obras de Garcilaso de la Vega con anotaciones [1580], edición facsimilar de Antonio Gallego Morell. Madrid: CSIC, 1973, p. 191, nota a cortaste. 
en salvo destos acontecimientos (Soneto XX, 6)

Después acá de lo que consentí (Soneto XXVII, 5)

A romper esto en que yo me metí (Soneto XXVII, 8)

mas es a tiempo que de mi bajeza Soneto XXVIII, 7)

un dulze amor, y de mi sentimiento (Soneto XXXI, 2)

me quexo a vos como si en la verdad (Canción II, 24)

un campo lleno de desconfianza (Canción IV, 89)

Algunos premios o agradecimientos (Elegía I, 92)

se contradicen en lo que profieren (Elegía II, 15)

Quál es el cuello que como en cadena (Égloga I, 131)

Al sueño ayudan con su movimiento (Égloga II, 76)

Tras esto luego se me presentaba (Égloga II, 1122)

Salir el humo de las caserías (Égloga II, 1871)

Todos estos versos han de leerse poniendo énfasis - haziendo assiento, según el sentir de Herrera- en la palabra portadora del acento correspondiente a la sílaba $4^{\mathrm{a}}$. No se trata en absoluto de versos defectuosos, flojos o desmayados, sino que, por el contrario, las dos cúspides acentuales de las sílabas $4^{\mathrm{a}}$ y $10^{\mathrm{a}}$, en contraste con la suave atenuación rítmica de las restantes sílabas, cumplen un oportuno papel de moderación y contrapunto en la serie versal. Más que de descuido o defecto, habría que hablar de exquisita labor de cincelado poético.

En algunos otros endecasílabos de Garcilaso de la Vega, podría llevarse a cabo una doble lectura: como endecasílabos dactílicos con acento en la sílaba 7a, o como endecasílabos canónicos. En todos estos casos, es fácil llevar a cabo una adecuada lectura, desplazando el hipotético acento de la sílaba $7^{\text {a }}$ a la sílaba inmediatamente anterior $\left(6^{\mathrm{a}}\right)$ o posterior $\left(8^{\mathrm{a}}\right)$ :

y a ver los passos por do m'han traído (Soneto I, 2)

ya.vér.los.pá.sos.por.do.m’hán.tra.í.do

hallo, según por do anduve perdido (Soneto I, 3)

há.llo.se.gún.por.dóan.du.ve.per.dí.do 
sé que me acabo, y más é yo sentido (Soneto I, 7)

sé.que.mea.cá.boy.más.e.yó.sen.tí.do

como remedio más ya deffendido (Soneto II, 4)

co.mo.re.mé.dio.más.ya.def.fen.dí.do

mi inclinación por quien ya no porfío (Soneto VI, 12)

miin.cli.na.ción.por.quién.ya.no.por.fí.o

No pierda más quien ha tanto perdido (Soneto VII, 2)

no.piér.da.más.quie.há.tan.to.per.dí.do

como acontece a quien ha ya escapado (Soneto VII, 7)

co.moa.con.té.cea.quién.ha.yaes.ca.pá.do

me quitó al mundo y m'ha en ti sepultado (Soneto XVI, 13)

me.qui.toal.mún.doy.m’háen.ti.se.pul.tá.do

del grave mal que en mí está de contino (Soneto XX, 11)

del.grá.ve.mál.queen.míes[miés].ta.de.con.tí.no

Albanio es éste que 'stá 'quí dormido (Égloga II, 98)

al.bá.nioes.és.te.que’s.ta.quí.dor.mí.do

Cómo pudiste tan presto olvidarte (Égloga II, 578)

có.mo.pu.dís.te.tán.pres.tool.vi.dár.te

¡Oh santos dioses!, ¿qué’s esto que veo? (Égloga II, 775)

óh.san.tos.dió.ses.qué's.es.to.que.vé.o

Camila es ésta que está aquí dormida (Égloga II, 778)

ca.mí.laes.és.ta.quees.taa.quí.dor.mí.da

También han sido tildados de duros o forzados algunos endecasílabos de Garcilaso de la Vega en los que una vocal acentuada de la serie cerrada $/ i, u /$ se encuentra en contigüidad con vocal no 
acentuada de la serie /a,e,o/. El verso más frecuentemente citado es el siguiente:

Hermosas nymphas que en el río metidas (Soneto XI, 1) her.mó.sas.ným.phas.queen.el.río[rió].me.tí.das

La palabra río, considerada gramaticalmente como bisílaba, constituye aquí en realidad una sola sílaba métrica. Habría tenido lugar una «licencia» poética, llamada sinéresis, en virtud de la cual las vocales $i$ y $o$ no formarían ya hiato, sino diptongo. Ahora bien, difícilmente podría admitir la gramática tradicional un diptongo en el que la vocal nuclear fuera la más cerrada -la $i-$, mientras que la vocal más abierta -la $o$ - cumpliera meramente el papel de elemento marginal. Para que exista una sola sílaba, tendría que entrar en juego un mecanismo de dislocación acentual: el acento habría de desplazarse de la vocal más cerrada a la más abierta. En definitiva, en lugar de pronunciarse río, tendría que decirse rió.

Veamos lo que nos dice la Real Academia, en el Esbozo de una nueva gramática de la lengua española (1973), a propósito de un caso similar, esto es, de contacto de una vocal abierta y átona con una vocal cerrada y tónica. En esta ocasión, la unión silábica se da entre palabras contiguas:

Otra curiosa "licencia" poética, que en este caso afecta también a la rima, aparece en el endecasílabo de Garcilaso (Égloga I, v. 122): Y por nuevo camino el agua se iba, donde se computa como una sílaba el grupo vocálico final /éi/, con dislocación del acento, lo que no impide que iba sea consonante de estiva. Lo mismo ocurre en Góngora (Sonetos completos, ed. 1969, pág. 27): Que a Júpiter ministra el garzón de Ida, verso aconsonantado en -ida a pesar de la sinalefa /éi/, o en Ponga, pues, a las querellas que usa (ibíd., 127), con sinalefa /éu/, pero con rima $-u s a^{292}$.

292 Párrafo 1.6.8.c. 
Como es habitual en ciertos estudios gramaticales y académicos, se considera la sinalefa -al igual que la sinéresis- como una licencia, que en este caso es aún más «curiosa». Es de advertir que los grupos vocálicos que se aducen -/éi/, /éu/- se computan «como una sílaba». No es que realmente se piense que constituyen una auténtica sílaba, sino que se les concede ese valor sólo en virtud de la referida licencia poética. Por supuesto que se asume que el acento no puede recaer sobre la $i$ o la $u$-/eí/, /eú/-, vocales cerradas, sino sobre la $e$, vocal más abierta, dándose así una «dislocación del acento». Pero, a pesar de todo, se reconoce que existe rima en -iba, $-i d a$ y-usa.

Ahora bien, por definición, la rima no es otra cosa sino la completa igualdad de sonidos con que terminan dos o más palabras a partir de la última vocal acentuada. Por lo tanto, y en pura lógica, si existe rima (que sí que existe), el acento ha de recaer, necesariamente, en la $i$ de $i b a$, en la $i$ de Ida y en la $u$ de usa:

y.por.nué.vo.ca.mí.noel.á.gua.seí.ba

quea.jú.pi.ter.mi.nís.trael.gar.zon.deí.da

pón.ga.pues.fín.a.las.que.ré.llas.qeú.sa

Para que exista rima, no puede darse la dislocación del acento. Así pues, habría que revisar algunos criterios tradicionales, y afirmar que, en casos como éstos, no tiene sentido desplazar el acento a la vocal más abierta. Es precisamente la vocal más abierta la que se oscurece y se hace menos perceptible, hasta el punto de asumir el papel de mero elemento marginal. Si no queremos incurrir en la contradicción de admitir simultáneamente la existencia de rima y de dislocación acentual, hemos de rechazar decididamente esta última. Asílo percibían Góngora y Garcilaso. Y asílo percibe el atento lector actual de poesía. De forma análoga, el río donde juguetean las hermosas ninfas de Garcilaso (Soneto XI, 1) puede seguir siendo río, y no rió, como palabra monosilábica:

her.mó.sas.ným.phas.queen.el.río.me.tí.das 
Fernando de Herrera escribía rîo, y en otros lugares mîos, perdîa, $v \hat{\imath} a$, queriendo indicar con el acento circunflejo la presencia de un especial fenómeno fonético, que afectaba directamente al grupo vocálico. La vocal resaltada por la tilde era precisamente la $i$, la más cerrada, que pasaba a ser así el centro del grupo silábico. Podríamos hablar simplemente de diptongo, o unión de vocales en contacto, frente a hiato, o desunión de las vocales. Pero, como en otro lugar se ha señalado ${ }^{293}$, sería preferible hablar de zeuxis frente a azeuxis.

En efecto, zeuxis es término más exacto que diptongo, ya que su significado no se limita a sólo dos elementos fónicos. Pueden ser tres (elllamado triptongo) o más las vocales que se agrupen en una unidad

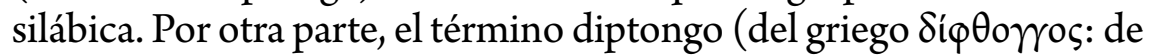
doble sonido) es algo impreciso: no señala si los dos sonidos o vocales están unidos en una sola sílaba o separados en sílabas diferentes. Del mismo modo, azeuxis carece de las connotaciones peyorativas del hiato (del latín hiatus: hendidura, grieta, abertura, bostezo), que implican una carga afectiva de cacofonía no deseada.

En todos los casos de vocales en contacto, sería más oportuno hablar simplemente de unión o desunión silábica. Y, para ello, la lengua griega nos proporciona dos términos claramente delimita-

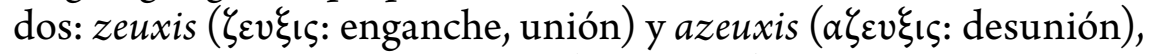

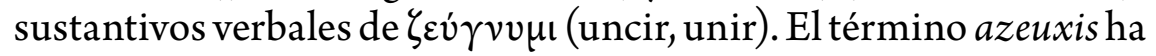
venido ya siendo utilizado en la lengua española, justamente como sinónimo de hiato o encuentro de dos vocales que se pronuncian en sílabas diferentes. No ocurre lo mismo con el término zeuxis, como alternativa a la palabra diptongo, pues hasta ahora no ha formado parte de la nomenclatura métrica.

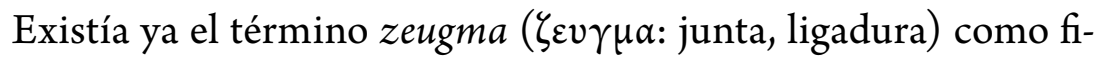
gura retórica de construcción, que también es sustantivo verbal de

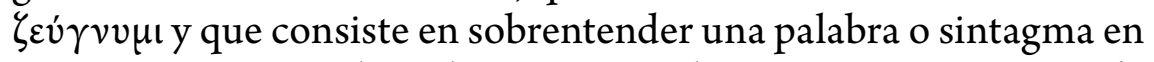
varias oraciones o cláusulas, aunque sólo esté presente en una de ellas. Tanto zeuxis como zeugma son, así pues, sustantivos verbales,

293 TORRE, Esteban: «Zeuxis y azeuxis en la configuración silábica». Rhythmica, Revista española de métrica comparada, 2011, IX, 9, pp. 183-199. 
si bien el primero expresa la acción del verbo, y el segundo, el resultado. Es lo mismo que ocurre con los términos sintaxis ( $\sigma \dot{v} v \tau \alpha \xi ı$ : orden, disposición, orden de combate) y sintagma ( $\sigma \dot{v} v \tau \alpha \gamma \mu \alpha$ : ordenamiento, constitución, fila de combate), sustantivos verbales que expresan respectivamente la acción y el resultado de $\sigma v v \tau \alpha ́ \sigma \sigma \omega$ (ordenar, organizar).

En los endecasílabos de Garcilaso, es frecuentísima la zeuxis o unión silábica de la vocal cerrada tónica $i$ con las vocales abiertas átonas $a$ y $o$. Se indica con acento circunflejo, de acuerdo con la pauta marcada por Herrera, la situación de la $i$ afectada por la zeuxis:

Yo avîa jurado nunca más meterme (Soneto VII, 9)

a poder mîo y a mi consentimiento (Soneto VII, 10)

por do los mîos, de tal calor movidos (Soneto VIII, 6)

Señora mîa, si yo de vos ausente (Soneto IX, 1)

Con más piedad devrîa ser escuchado (Soneto XV, 12)

y más del bien que allí perdîa muriendo (Soneto XXIX, 7)

ya yo con mi dolor sin guîa camino (Soneto XXXII, 2)

allá os yrîa a buscar como perdido (Canción I, 12)

que nunca dîa ni noche cessan della (Canción III, 13)

que de la vîa espantosa atrás me torne (Canción IV, 131)

serîa de mí, hermosa flor de Gnido (Canción V, 12)

fuerça de tu beldad serîa cantada (Canción V, 22)

d'aquesto un frîo temor assí a desora (Elegía II, 43)

el fuego que'l amor tenîa encendido (Elegía II, 66)

ternîa presente por mejor partido (Elegía II, 117)

y agradecerîa siempre a la ventura (Elegía II, 118)

que avîa de ver, con largo apartamiento (Égloga I, 285)

podrîan tornar d'enfermo y descontento (Égloga II, 16)

que della un punto no sabîa apartarme (Égloga II, 181)

que vîa bolar aquella vanda amiga (Égloga II, 250)

todos venîan al suelo mal su grado (Égloga II, 255)

seguîase lo que apenas tú barruntas (Égloga II, 271)

Parecîa que mirando las estrellas (Égloga II, 272)

rompîa con gritos ella y convocava (Égloga II, 276)

venîa por nuestra mano, y la cuitada (Égloga II, 294) 
verîa d'aquella que yo tanto amava (Égloga II, 471)

antes, con mi llorar, hazîa espantados (Égloga II, 516)

me preguntaban quáles avîan sido (Égloga II, 522)

de quantas digo quien devrîa escucharme (Égloga II, 597)

y temerario error que avîa seguido (Égloga II, 660)

que avîa de ser quien diese la doctrina (Égloga II, 1324)

el qual venîa con Phebo mano a mano (Égloga II, 1329)

vio que'ra el que avîa dado a don Fernando (Égloga II, 1339)

Luego venîa corriendo Marte airado (Égloga II, 1379)

que'l sol embîa delante, resplandece (Égloga II, 1393)

y claro rîo, gozoso de tal gloria (Égloga II, 1470)

en Flandes avîa sido, y el osado (Égloga II, 1539)

y parecîa que'l ocio sin provecho (Égloga II, 1596)

que avîa de ser guïada por su mano (Égloga II, 1606)

el rîo le daba dello gran noticia (Égloga II, 1754)

a las que avîa de Tormes aprendido (Égloga II, 1822)

mas con la lengua muerta y frîa en la boca (Égloga III, 11)

que'n delgadeza competîan con ellos (Égloga III, 102)

de las colores que antes le avîan dado (Égloga III, 114)

mostrava en la labor que avîa texido (Égloga III, 146)

pintado el caudaloso rîo se vía (Égloga III, 201)

contento con lo mucho que avîa hecho (Égloga III, 208)

cuya vida mostrava que avîa sido (Égloga III, 227)

de dos pastores que venîan cantando (Égloga III, 291)

deste dîa, para mí mayor que un año (Égloga III, 320)

La unión silábica de la zeuxis (tanto en el caso del comúnmente llamado diptongo, como en la sinéresis, la sinalefa o la sinafía) y la separación silábica de la azeuxis (llámesela hiato, diéresis o dialefa) son fenómenos por lo demás habituales, que tienen lugar tanto en la línea sintagmática del verso como en la del lenguaje ordinario, y se realizan no sólo en el interior de la palabra aislada, sino también entre palabras contiguas. En el dominio de la métrica, la poética y la estética, carece de sentido la antigua distinción entre sílabas métricas y gramaticales, o la más reciente entre sílabas fonéticas y fonológicas, tal como se hace en la Nueva gramática de la lengua española (2010): 
Las sílabas fonológicas no se corresponden necesariamente con las sílabas fonéticas. En el verso entre el vivir y el soñar (Machado, Nuevas canciones), se observa la diferencia entre estos dos aspectos. Las sílabas fonológicas en.tre.el.vi.vir.y.el.so.ñar se convierten desde el punto de vista fonético en en.trel.vi.vir.yel.so.ñar ${ }^{294}$.

Se nos dice que las sílabas fonológicas «se convierten» en fonéticas, cuando lo que sucede es justamente lo contrario: es la realidad fonética la que se abstrae y se convierte en sistema fonológico. La sílaba presupone el sonido, que es lo que el oído directamente capta. Y conviene poner énfasis en la cualidad acústica, auditiva, del sonido, no en el aspecto meramente oral y articulatorio o en la consideración física de la onda sonora. La sílaba no tiene en sí misma valor fonológico alguno, a no ser como unidad mínima portadora de un acento. Aunque, a decir verdad, el acento viene a su vez definido, tautológicamente, por un mayor relieve de la sílaba acentuada. La sílaba remite al acento, y el acento a la sílaba.

El análisis de las sílabas y los acentos, que configuran el armazón rítmico del verso, pertenece al dominio de la métrica, la poética y la estética, y no a los estudios gramaticales o lingüísticos. Con buen criterio, la Real Academia Española, que todavía en el Esbozo de 1973 prestaba alguna atención a las sílabas, el acento y la fonología sintáctica, pasa ya por estas cuestiones como sobre ascuas en la Nueva gramática de 2010; y, en el Manual de la Nueva gramática, dedica significativamente a las unidades fónicas sólo dos brevísimos párrafos ${ }^{295}$, que vienen a ocupar no más de media página de un total de novecientas noventa y tres. Por su parte, el tercer volumen de la Nueva gramática de 2011, dedicado específicamente a la fonética y la fonología, considera como «una cuestión controvertida» la agrupación silábica de las vocales en español ${ }^{296}$.

Con criterios métricos, estéticos y poéticos, y atendiendo también a la historia de la lengua, pueden resolverse algunos otros

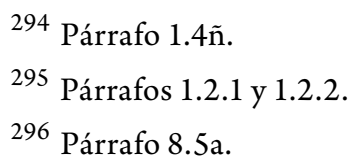


problemas que pueden tal vez surgir en la lectura de los endecasílabos de Garcilaso de la Vega. Veamos algunos ejemplos:

y más me duele el no osar deciros (Soneto XXXVIII, 3)
y.más.me.dué.leel.nó.o.sár.de.zí.ros

Este verso reza así en la edición de Fernando de Herrera:

I mas me duele nunca osar deciros (Soneto XXXII, 3)

i.más.me.dué.le.nún.cao.sár.de.zí.ros

Según Rivers, con esta enmienda o variante Herrera habría evitado «el hiato difícil ${ }^{297}$ de $\ll$ no osar». Pero, a decir verdad, no es $\tan$ «difícil» este hiato, dialefa o azeuxis. En la conciencia lingüística del hablante español del primer tercio del siglo xvi estaba aún presente el recuerdo del antiguo non, lo cual impedía la sinalefa o zeuxis entre «no»y $\ll$ osar $\gg$.

En el siguiente verso, la forma «sino» (de si y no) que aparece escrita como una sola palabra, no pierde su valor original (si no, si no es, a no ser):

$$
\begin{aligned}
& \text { yo no nascí sino para quereros (Soneto V, 9) } \\
& \text { yo.no.nas.cí.si.nó.pa.ra.que.ré.ros }
\end{aligned}
$$

En otros versos, los pronombres «me»y «los» aparecen como formas tónicas, tal como se dijo a propósito de Égloga I, 128:

dándome a entender que mi flaqueza (Canción I, 49)

dan.do.mé.aen.ten.dér.que.mi.fla.qué.za

que ya no me refrenará el temor (Canción II, 24)

que.ya.no.mé.re.fre.na.ráel.te.mór

juntándolos, con un cordón los ato (Égloga I, 363)

cor.tán.do.lós.con.ún.cor.dón.los.á.to

297 RIVERS, Elias L.: Obras cit., p. 162, nota 3. 
Como es sabido, la acentuación de la sílaba final de las palabras esdrújulas es habitual en el endecasílabo inglés shakespeareano. Y no es infrecuente en la métrica castellana. Así, en el siguiente verso, ha de leerse lagrimás por lágrimas:

en lágrimas, como el lluvioso viento (Elegía I, 23)

en.la.gri.más.co.moel.llu.vió.so.vién.to

Los versos que a continuación se relacionan, claramente acentuados en las sílabas $2^{\circ}, 8^{a}$ y $10^{a}$, llevan en posición $4^{\mathrm{a}}$ las partículas «que»y «de» respectivamente. Esta posición, lugar privilegiado de expectativa para la realización del endecasílabo sáfico, confiere a dichas partículas un especial relieve, que enfatiza las expresiones «el fruto que»y «lo menos de»:

el fruto que con el dolor sembramos (Égloga II, 9)

el.frú.to.qué.con.el.do.lór.sem.brá.mos

lo menos de lo que’n tu ser cupiere (Égloga III, 31)

lo.mé.nos.dé.lo.que’n.tu.sér.cu.pié.re

En situación análoga se encuentra la expresión «do quiera que» en este otro verso:

do quiera que sauzes de oy más se hallen (Égloga III, 359)

do.quié.ra.qué.sau.zes.deoy.más.se.hállen

Resulta ciertamente difícil prescindir en este caso del acento de la palabra sauzes. Es preferible, sin duda alguna, la variante que nos ofrece Herrera:

do quiera que d'oi mas sauzes se hallen do.quié.ra.que.d'oi.más.sau.zes.se.hállen

Finalmente, hay que advertir que algunos textos de la edición de Rivers exhiben innegables imperfecciones; pero éstas en modo alguno son responsabilidad de Garcilaso de la Vega. Así, por ejemplo, los sonetos XXXIX y XL acumulan tantos defectos que obligan a 
descartar categóricamente la autoría garcilasiana. Ya el mismo Rivers hizo notar, a propósito de estos sonetos, cómo «Keniston (pp. 216-217), por sus endecasílabos y rimas defectuosas, cree que no pueden ser auténticos y los edita en apéndice ${ }^{298}$. A todo amante de la buena poesía, que leyera inadvertidamente tales sonetos, se le recomienda contrarrestar su comprensible enojo con el recuerdo de algunos de los mejores versos del verdadero Garcilaso:

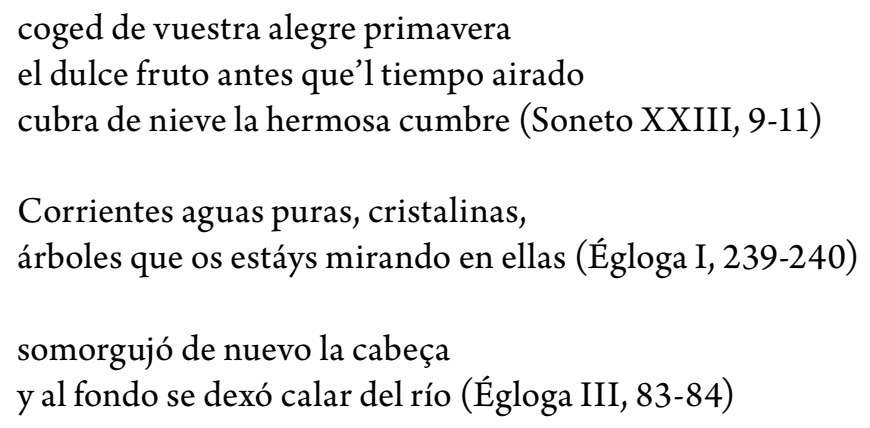

No, no existen endecasílabos defectuosos, ni anómalos, ni dactílicos, en la poesía de Garcilaso de la Vega. Un exhaustivo análisis de toda su obra así lo pone de manifiesto. Estamos en presencia de un auténtico poeta, un poeta nato, uno de los más altos exponentes -junto a San Juan de la Cruz, Gustavo Adolfo Bécquer o Rosalía de Castro- de la mejor poesía lírica española de todos los tiempos. El eco de los perfectos endecasílabos de Garcilaso llega hasta nuestros días a través de las voces de Juan Ramón Jiménez, Manuel Machado, Antonio Machado, Jorge Luis Borges, Federico García Lorca, Blas de Otero...

298 Ibíd., p. 164. 



\section{LOS SONETOS DE JUANRAMÓNJIMÉNEZ}

$\mathrm{E}$

NTRE los poemas publicados por Juan Ramón Jiménez durante los últimos meses de su estancia en Sevilla, concretamente desde marzo de 1899 a marzo de 1900, figura -junto a algunas rimas, canciones y endechas- un pequeño ramillete de sonetos ${ }^{299}$. El primero de ellos, cuando Juan Ramón no había cumplido aún los dieciocho años, apareció con el título «A varios amigos» en el diario El programa, de Sevilla, el 2 de marzo de 1899. Poco después, el 2 de julio del mismo año, se volvió a publicar en Vida nueva, de Madrid, con ligeras variantes, entre ellas el título, que ahora se expresa irónicamente como «A varios ¿amigos?».

El poeta, muy joven, pero maduro ya en la reflexión y en la agridulce vivencia del desengaño, y con fuertes resonancias de las meditaciones poéticas de un Espronceda, un Campoamor o un Núñez de Arce, escribe:

Vosotros que tenéis los corazones

podridos del placer y de la orgía,

y que pasáis un día y otro día

entregados al ocio y las pasiones,

${ }^{299}$ Vid. URRUTIA, Jorge (ed.): Primeros poemas. Juan Ramón Jiménez. Sevilla: Point de Lunettes, 2003. 
sin conciencia, sin dignas ambiciones, y $\sin$ fe, que es la luz que el alma guía, ¿impíos os burlasteis de la mía porque alentaba ensueños e ilusiones?

Semejáis charca inmóvil, cenagosa; yo, soy torrente de agua impetuosa, y vuestro vil escarnio no me inquieta.

¡Infelices! os miro con desprecio... ¡En superior a ustedes yo me precio tan sólo con soñar que soy poeta ${ }^{300}$ !

En el periódico sevillano El programa, aparecerán semanas después otros dos sonetos: «La fiesta de mayo» (30 de abril) y «Triste ley» (30 de julio). Si en este último ${ }^{301}$ podemos vislumbrar apacibles imágenes renacentistas («el verde valle, mágica espesura / por do corre el riachuelo sosegado») y percibir filosóficas trazas gongorinas $(\ll i$ Que al fin vuelva a parar todo en la nada! $\gg)$, en $\ll$ La fiesta de mayo» escuchamos los insistentes ecos de una rotunda voz declamatoria. Véanse los tercetos:

Con esplendor y lujo engalanadas vienen las santas cruces, rodeadas por la plebe que grita delirante.

Y dominando a todo el sol radiante, cual la antorcha de luz resplandeciente de la cristiana $\mathrm{Fe}$, viva y triunfante $\mathrm{e}^{302}$.

${ }^{300}$ Ibíd., p. 124. El profesor Urrutia, en el estudio previo de su cuidada edición (pág. 62, nota 55), hace ver el garboso andalucismo de la versión de El programa: «En superior a ustedes yo me precio», cuando inmediatamente antes había escrito «os miro con desprecio». Se corrige en el texto de Vida nueva: «superior a vosotros yo me aprecio».

${ }^{301}$ Ibíd., p. 154.

${ }^{302}$ Ibíd., p. 141. 
De análogo tenor son los sonetos publicados, también en el año 1899, en El correo de Andalucía, de Sevilla, el 13 de marzo ( $\ll$ Consuelo»), y en Vida nueva, de Madrid, el 30 de abril «Sarcasmo»), el 17 de septiembre («Plegaria») y el 29 de octubre («Paisaje»).

Cierra esta serie de sonetos el que lleva por título «Marchita», publicado en Vida nueva el 18 de marzo de 1900. En franca sintonía con el movimiento modernista, el poeta ensaya ahora nuevas combinaciones métricas, describe escenas lúgubres y melancólicas, y se deja llevar por el ritmo y el color:

A la oliente sombra del rosal de sangre, del rosal florido,
muerta su inocencia, muerta la fragancia de su frente pura,
llora sin consuelo la pálida niña por su amor perdido,
llora abandonada, con ardiente llanto de inmensa amargura.

El gemido horrible, el gemido fúnebre de su pecho herido halla frío sepulcro en la helada calma de la noche oscura, sin que allá a lo lejos tenga un eco mágico en otro gemido, sin besar el alma que su alma loca busca con ternura...

¡Pobre niña pálida, pobre niña amante, pobre confiada, que en las negras garras de un amor ingrato quedó desflorada! ...Ya el pesar la duerme... y dormida ríe con blancos delirios...

Y llorando, el viento, le da un dulce beso, un beso doliente, y compadecido de la niña pálida, corona su frente con guirnalda triste, triste y melancólica, de nevados $\operatorname{lirios}^{303} \ldots$

Sombra, sangre, fragancia, palidez, amor, llantos, amargura, fríos sepulcros, ecos mágicos, rosas y lirios. Y, en el último terceto, «un dulce beso, un beso doliente» nos introduce ya en el léxico habitual del futuro Juan Ramón Jiménez. El poeta se adiestra en la escritura, juega con las formas. El soneto clásico, de versos endecasílabos, se ensancha en una estructura más compleja. Los ${ }^{303}$ Ibíd., p. 179. 
versos constan ahora de dieciocho sílabas, dispuestas en periodos rítmicos hexasilábicos: «El gemido horrible, / el gemido fúnebre / de su pecho herido». Se trata, en realidad, de versos compuestos de $6+6+6$ sílabas. Cada uno de estos elementos hexasilábicos goza de una entidad versal propia: son pequeños versos, oligostiquios ${ }^{304}$, que no admiten entre sí la sinalefa y que siguen las pautas versales en lo que concierne a los finales esdrújulos, como se puede apreciar en el citado verso, o en los siguientes:

... y compadecido / de la niña pálida, / corona su frente con guirnalda triste, / triste y melancólica, / de nevados lirios...

La influencia de Francisco Villaespesa y de Rubén Darío es aquí evidente. En abril de 1900, llamado precisamente por estos admirados e influyentes maestros, se traslada Juan Ramón a Madrid, si bien volverá a Moguer, su ciudad natal, a finales de mayo. Fruto de su breve estancia en la capital de España es la publicación en ese mismo año de los libros Ninfeas -impreso en tinta verde, con título ideado por Valle-Inclán-y Almas de violeta -impreso en tinta morada, con título inventado por Rubén Darío- ${ }^{305}$. Sus excesos modernistas fueron prontamente detectados por cierto sector de la crítica y por el propio Juan Ramón Jiménez. En 1901, durante su estancia en un nosocomio francés, y más tarde en el Sanatorio del Rosario, de Madrid, redacta la mayor parte de los poemas que formarán el libro Rimas, cuya primera edición habría de aparecer en Madrid en 1902. Esta vez la crítica le fue francamente favorable, como lo demuestra la lista de personalidades que «con tanto cariño escribieron» sobre el libro -Manuel Bueno, Pedro González Blanco, Manuel Machado, Ramón Pérez de Ayala, etc.-, según consta en la nota de agradecimiento del propio Juan Ramón Jiménez en su libro Arias tristes, publicado en Madrid, 1903.

${ }^{304}$ Rehúyo el nombre de hemistiquio, que etimológicamente implica «medio verso». Se pueden propiamente considerar dos hemistiquios en un verso, pero no tres hemistiquios. Prefiero, así pues, hablar en este caso de oligostiquios.

${ }^{305}$ Vid. ALBORNOZ, Aurora de: «Prólogo» a Juan Ramón Jiménez: Arias tristes. Madrid: Taurus, 1981, p. 15. 
El prestigio alcanzado con Rimas -y consolidado con Arias tristes- no fue obstáculo para que Juan Ramón lo persiguiera con saña para destruirlo. No en balde, como señala Ángel González, en Rimas hay una veintena de poemas procedentes de sus libros de 1900, cuatro de Ninfeas y dieciséis de Almas de violeta ${ }^{306}$. En cualquier caso, tanto en Rimas como en Arias tristes se afianza el poeta en el empleo de las sencillas formas de los cantares y el romance, especialmente este último, que es el cauce métrico de casi la totalidad de Arias tristes. Más adelante, asistiremos al predominio de las estancias de versos alejandrinos y de las silvas de ritmo endecasilábico. El soneto, forma poética de estructura más cerrada y compleja, queda durante largos años en el olvido.

Hay que esperar hasta dieciocho años después de la publicación de los primeros sonetos, cuando ya el poeta ha duplicado sus años adolescentes, para que aparezca en la Casa Editorial Calleja, en Madrid, 1917, una colección de cincuenta y cinco sonetos con el título de Sonetos espirituales. En el mismo año y en las mismas prensas se publica también el Diario de un poeta recién casado. Ambos libros representan la plenitud de la actividad creadora de Juan Ramón, si bien los Sonetos, «un libro más bien marginado por la crítica» ${ }^{307}$, en palabras de Allen W. Phillips, se considerará mayoritariamente, y por el mismo Juan Ramón, como el final de una época, mientras que el Diario vendría a ser el punto de arranque de su posterior evolución. Algunos de los sonetos habían sido previamente publicados, entre 1914 y 1915, en Los Lunes del Imparcial, de Madrid. A estos años corresponde la redacción de la totalidad de la obra, según figura en la portada de la edición de 1917 y en las sucesivas reimpresiones y reediciones. En conversación con Juan Guerrero Ruiz, el 13 de junio de 1915, el poeta confiesa encontrarse en un periodo muy crítico de su vida, a la vez que se manifiesta claramente satisfecho de la excelencia de los Sonetos:

${ }^{306}$ Vid. GONZÁLEZ, Ángel: «Prólogo» a Juan Ramón Jiménez: Rimas. Madrid, Taurus, pp. 16-17.

307 PHILLIPS, Allen W.: «Prólogo» a Juan Ramón Jiménez: Sonetos espirituales. Madrid: Taurus, 1981, p. 11. 
[...] estoy muy contento con ellos. Creo que llegan a la perfección, pero no entienda usted esto en el sentido vano de la palabra -no es eso lo que le digo-, creo que son, me parecen, perfectos, porque están hechos naturalmente, de una vez, sin corregir nada [...]. Sólo se debe escribir lo justo, lo honrado [...]. Debemos escribir como se habla, de una manera clara, elevada, natural... Estos Sonetos espirituales son clásicos, con elementos modernos. El libro, que consta de 102 o 103, va dividido en tres partes: «Amor», «La Amistad»y «Sonetos íntimos» ${ }^{308}$.

Años después, el 21 de marzo de 1931, el poeta dice sentirse avergonzado por algunos de sus libros, a saber, por «todos los anteriores a los Sonetos, Estío, Platero (hasta cierto punto), el Diario, etc. ${ }^{309}$. Y, el 11 de abril de 1934, en uno de los múltiples proyectos para la edición completa de su «Obra», reserva un libro para los Sonetos espirituales, junto con los Idilios plásticos y Estío ${ }^{310}$. Del alto concepto en que tenía Juan Ramón a los Sonetos da fe la inclusión de alguno de ellos en obras tan emblemáticas como la Segunda antolojía poética (Madrid: Calpe, 1922), la Antolojía poética (Buenos Aires: Losada, 1944) o la Tercera antolojía poética (Madrid: Biblioteca Nueva, 1957).

En la redacción de los Sonetos espirituales fue decisivo el contacto con Zenobia Camprubí, en todos los aspectos, incluido su extraordinario conocimiento de la lengua inglesa, que sin du0da hubo de influir poderosamente en las lecturas de Juan Ramón. Entre los autores ingleses, desempeña un papel excepcional el poeta británico, de origen italiano, Dante Gabriel Rossetti. El paralelismo entre los sonetos de Juan Ramón y los de Rossetti ha sido puesto de manifiesto por

308 GUERRERO RUIZ, Juan: Juan Ramón de viva voz. Madrid: Ínsula, 1961, p. 35. El texto original completo de Juan Guerrero Ruiz - «cónsul general de la poesía española», en el sentir de Federico García Lorca- ha sido recuperado por Editorial Pre-Textos (Valencia, 1999), con prólogo y notas de Manuel Ruiz-Funes Fernández.

${ }^{309}$ Ibid., p. 91.

${ }^{310}$ Ibid., p. 329. 
Allen W. Phillips ${ }^{311}$ y más recientemente por Juan Cano Ballesta, ${ }^{312}$ quien sugiere que a Juan Ramón «le debió impresionar la idea de escribir, cual Rossetti sobre Elisabeth Siddal, un libro de sonetos amorosos sobre su propia historia de amor con Zenobia Camprubí» ${ }^{313}$.

Resulta, sin embargo, difícil establecer un parangón entre las circunstancias vitales de la deslumbrante, lánguida y sensual Elisabeth, que se suicidó con láudano a los dos años de su matrimonio, y la fina, culta y hacendada Zenobia, que sería el soporte de Juan Ramón durante toda su vida. Ahora bien, existen llamativos nexos estructurales entre The House of Life: A Sonnet-Sequence, de Dante Gabriel Rossetti (1828-1882), y Sonetos espirituales, de Juan Ramón Jiménez (1881-1958), que conviene dilucidar.

Por lo pronto, veamos el número de poemas que constituyen cada una de las dos colecciones de sonetos. A primera vista, la cifra es dispar: 102 (o 103) en el poemario de Rossetti y 55 en el de Juan Ramón. Pero hay que hacer algunas consideraciones. Sucede que, en la edición de The House of Life, de 1881, y en las siguientes tiradas ${ }^{314}$, encontramos 101 sonetos, sin contar el inicial, titulado precisamente «Sonnet». Serían, por lo tanto, 102 los poemas. No obstante, hay que señalar que el soneto VI, «The kiss», lleva el duplicado VI a: «Nuptial Sleep», titulado originalmente «Placata Venere», que había sido publicado en 1870, pero que fue suprimido en la edición de 1881 por el propio Rossetti, debido a los furibundos ataques de algunos sectores de la crítica. Se lo consideraba como un verdadero atentado a la moral pública, ya que se describía en él a una pareja que se quedaba dormida tras el éxtasis del amor. En cualquier caso,

311 PHILLIPS, Allen W.: Ob. cit., pp. 11-14.

312 CANO BALLESTA, Juan: «Los Sonetos espirituales de Juan Ramón Jiménez y el prerrafaelismo de Dante G. Rossetti», en Actas del XIII Congreso de la Asociación Internacional de Hispanistas, Madrid, 6-11 de julio de 1998, ed. de Florencio Sevilla y Carlos Alvar. Madrid: Castalia, 2000, pp. 504-513.

${ }^{313}$ Ibíd., p. 505.

314 Utilizo la edición bilingüe de Pre-Textos: Dante Gabriel Rossetti: La casa de la vida, ed. y trad. de Francisco M. López Serrano. Madrid, 1998. 
volvió a ser incluido en las ediciones posteriores, siendo así 103 el número de los sonetos. Pues bien, Juan Ramón Jiménez, en la ya citada conversación con Juan Guerrero Ruiz, menciona los Sonetos espirituales como «un libro que consta de 102 o 103». La coincidencia de cifras no es, obviamente, casual.

El prologuista de los Sonetos espirituales en la Edición del Centenario de las obras de Juan Ramón Jiménez, Allen W. Phillips, atribuye la reducción del número de sonetos (de 102 o 103 a sólo 55) a la autoexigencia del poeta, «quien desecha casi la mitad de los sonetos al ordenar la edición definitiva $\gg^{315}$. Pero, a decir verdad, esa sorprendente coincidencia de cifras -102 o 103- debe atribuirse más bien al fuerte impacto que la obra de Dante Gabriel Rossetti produjo en el espíritu de Juan Ramón Jiménez y a su consiguiente deseo de noble emulación. Los sonetos ingleses tuvieron que ser un reto irresistible para el poeta, máxime cuando también en España se habían publicado ya, pocos años antes, dos importantes libros de sonetos: Rosario de sonetos líricos (Madrid: Imprenta Española, 1911), de Miguel de Unamuno, y Apolo: Teatro pictórico (Madrid: Prudencio Pérez de Velasco, 1911), de Manuel Machado.

El soneto inaugural de The House of Life lleva por título «Sonnet» $y$ es un encendido elogio de esta forma poética, que plasma -como en una instantánea o imagen congelada- un momento de la vida, del amor o de la muerte. El soneto viene a ser, así, un monumento del momento: A Sonnet is a moment $>$ s monument. Paralelamente, Juan Ramón Jiménez inicia sus Sonetos espirituales con el que titula «Al soneto con mi alma», donde se considera al soneto como trasunto de inmortales maravillas y síntesis de lo finito y lo ilimitado. El libro de Juan Ramón lleva además, como cita previa, las primeras frases del poema de Rossetti:

\section{A Sonnet is a moment's monument, Memorial from the Soul's eternity \\ To one dead deadless hour.}

315 PHILLIPS, Allen W.: Ob. cit., p. 15. 
Un instante, una hora, muere; y es, a la vez, inmortal. La eternidad del alma se erige como monumento recordatorio de ese breve instante. Son innegables las resonancias clásicas, grecolatinas. El soneto se nos presenta como una moneda, con su cara y su cruz, que sirve para pagar el debido tributo al barquero Caronte a la hora de atravesar la laguna Estigia. Grabadas en marfil o en ébano, sus palabras se erigen como grandioso monumento perdurable, para toda la eternidad. Es inevitable el recuerdo horaciano:

Exegi monumentum aere perennius

regalique situ pyramidum altius ${ }^{316}$...

(Acabé un monumento más durable que el bronce, más alto que la cámara real de las pirámides...)

Juan Ramón Jiménez, superada ya la barrera de los treinta años, ${ }^{317}$ y asumidos los postulados poéticos del modernismo hispánico y del simbolismo francés, se remonta ahora a las fuentes del modern style y encuentra en el prerrafaelismo inglés un perfecto modelo de belleza desnuda, naturaleza ideal, depurada expresión de la temporalidad como reflejo del mundo interior. El pintor y poeta Dante Gabriel Rossetti había fundado, en 1848, junto con John Everett Millais y William Holman Hunt, la Hermandad Prerrafaelista, cuyo objetivo era recuperar la primitiva pureza de los inicios del Renacimiento, antes de Rafael. El poeta -y también pintor- Juan Ramón Jiménez, de la mano de Rossetti, vuelca en el soneto su afán de conseguir una poesía auténticamente pura, y escribe «Al soneto con mi alma»:

Como en el ala el infinito vuelo, cual en la flor está la esencia errante,

${ }^{316}$ HORACIO: Carmina, 3, 30. Vid. TORRE, Esteban: La poesía de Grecia y Roma. Ejemplos y modelos de la cultura literaria modern. Huelva: CSIC-Universidad de Huelva, 1998, pp. 168-169.

${ }^{317}$ Vicente Aleixandre solía referirse a la «edad difícil» de los treinta años como frontera que el poeta habría de franquear, para no diluirse en otras preocupaciones y seguir siendo auténticamente poeta. 
lo mismo que en la llama el caminante

fulgor, y en el azul el solo cielo;

como en la melodía está el consuelo, $y$ el frescor en el chorro, penetrante, y la riqueza noble en el diamante, así en mi carne está el total anhelo.

En ti, soneto, forma, esta ansia pura copia, como en un agua remansada, todas sus inmortales maravillas.

La claridad sin fin de su hermosura es, cual cielo de fuente, ilimitada en la limitación de tus orillas ${ }^{318}$.

En el sentir de Juan Ramón Jiménez, el soneto viene a ser la forma con la que el ansia pura del poeta plasma las inmortales maravillas de su anhelo total. Los estrictos límites de esta forma poética son los que, precisamente, posibilitan la ilimitada expresión de una claridad sin fin, el arranque ilusionado de un vuelo infinito.

El libro de Rossetti, The House of Life, consta de dos partes: Youth and Change, juventud y cambio, juventud y vida, que se materializan en el amor; y Change and Fate, cambio y destino, esto es, vida y muerte. Los Sonetos espirituales de Juan Ramón nos hablan asimismo del amor, de la vida y de la muerte, con un léxico que es, por sí solo, suficientemente explícito: amor, llama, ascua, fuego, lumbre; fulgor, esplendor, claridad, aurora, luz; aroma, fragancia, flores, lirio, rosa, azucena; alegría, dulzura, paz, belleza; alma, corazón, inmortal, infinito, ilimitado, perfección, eternidad. Y, por otra parte, las nieblas, las tinieblas: sombra, negrura, oscuridad; ansiedad, amargura, tristeza, melancolía; otoño, octubre, ocaso, crepúsculo, poniente, noche, nada. El poeta había pensado también en el título Sonetos interiores, en perfecta sintonía con los mundos interiores

318 JIMÉNEZ, Juan Ramón: Sonetos espirituales, cit., p. 61. 
del prerrafaelismo y con su propia sensibilidad. De hecho, encontramos varias referencias a los «caminos interiores», la «sombra interior $\gg$, la «morada interior $\gg$ :

Eres la primavera verdadera;

rosa de los caminos interiores...

(Soneto II)

...Inmensa aurora

es tu sombra interior, fresca y sonora...

(Soneto XXI)

Por ti en la tarde, el alba le encristala

la morada interior...

(Soneto XXXIII)

Esta capacidad de interiorización, de saber escuchar voces ocultas en lo más profundo de sí mismo y del mundo exterior, no es algo realmente privativo de Juan Ramón Jiménez o del prerrafaelismo, sino que es patrimonio común de todos los poetas. Así lo supo ver Rubén Darío cuando dedicaba al joven de dieciocho años Juan Ramón, para el libro Ninfeas, el poema «Atrio» (París, 1900), soneto en versos alejandrinos, cuyos tercetos son los siguientes:

¿Te enternece el azul de una noche tranquila?

¿Escuchas pensativo el sonar de la esquila

cuando el Ángelus dice el alma de la tarde?...

¿Tu corazón las voces ocultas interpreta?

Sigue, entonces, tu rumbo de amor. Eres poeta.

La belleza te cubra de luz, y Dios te guarde. ${ }^{319}$

319 DARÍO, Rubén: Obras completas, Tomo V, Poesía. Madrid: Afrodisio Aguado, 1953, p. 1310. 
La belleza cubrió de luz cumplidamente al poeta de Moguer, iluminando su extensísima obra, su elaborada poesía, pura, perfecta, en la que los Sonetos espirituales marcan un punto de máxima plenitud. Atrás quedaron los primeros escarceos de sus sonetos juveniles, y poco interesan ya las etapas y vericuetos del camino recorrido: prerrafaelismo, simbolismo, modernismo. Lo verdaderamente importante es ahora la sublime hermosura de sus versos:

En la suntuosidad gris del poniente,
que enarbola la pena de la tarde,
el día corto muere, en un alarde
de color y de luz, hondo y vehemente.[...]

(Soneto XXXVI)

Esparce octubre, al blando movimiento

del sur, las hojas áureas y las rojas,

y en la caída clara de sus hojas

se lleva al infinito el pensamiento.[...]

(Soneto LV)

En toda la obra poética de Juan Ramón Jiménez, y muy en especial en los Sonetos espirituales, alienta siempre el sentimiento nostálgico de un amor y una felicidad inalcanzables, que conduce finalmente a un ensimismamiento sobrecogedor. Entre la vida y la muerte, el amor y el abandono, el poeta se encierra en su propio pensamiento. Llega a creer que su corazón es el centro del universo, que sin él todo se desvanecería. En el Soneto VIII, titulado «Nada», nos dice abiertamente que, si su corazón cayera al agua, el mundo se congelaría en un desolado vacío. En el Soneto XX, que lleva por título «Octubre», piensa que, si su corazón se sembrara, surgiría un árbol puro de amor eterno. Y todo esto en el marco de una belleza vibrante y enfermiza.

El léxico de los Sonetos espirituales es, por sí solo, suficientemente explícito: amor, alma, corazón, llama, ascua, fuego, lumbre; fulgor, esplendor, claridad, aurora, luz; aroma, fragancia, flores, lirio, rosa, 
azucena; primavera, abril, alegría, dulzura, paz, belleza; inmortal, infinito, ilimitado, eternidad. Y, por otro lado, nieblas, tinieblas, sombra, negrura, oscuridad; ansiedad, amargura, tristeza, melancolía; otoño, octubre, ocaso, crepúsculo, poniente, noche, nada. En especial, destacan la primavera y el otoño, el amor y el corazón, el todo y la nada, que constituyen precisamente el núcleo de los sonetos «Nada»y «Octubre», tal vez los más hermosos y los que mejor expresan el solipsismo del poeta.

En el Soneto VIII, «Nada», se opone al abandono y a la lejanía del mundo exterior, simbolizado por la mujer amada, el ensimismamiento absorto del corazón del poeta:

A tu abandono opongo la elevada torre de mi divino pensamiento; subido a ella, el corazón sangriento verá la mar, por él empurpurada.

Fabricaré en la sombra la alborada, mi lira guardaré del vano viento, buscaré en mis entrañas mi sustento... Mas ¡ay! ¿y si esta paz no fuera nada?

¡Nada, sí, nada, nada!... - O que cayera mi corazón al agua, y de este modo fuese el mundo un castillo hueco y frío...

Que tú eres tú, la humana primavera, la tierra, el aire, el agua, el fuego, ¡todo!, ... iy soy yo sólo el pensamiento mío!

Ella, distante, hermosa y humana como la primavera, lo es todo. Es ella, está ahí. Es pura naturaleza: tierra, aire, agua, fuego. Es el mundo exterior. La fuerza cósmica de los elementos naturales se contrapone abiertamente al delicado pensamiento, al «divino pensamiento», del poeta. Frente al desvaído y tibio abandono de la 
mujer, surge el ardiente colorido de su sangriento corazón. Se encerrará el poeta en su torre de marfil, en su castillo de naipes, intentando fabricar luces con las sombras, dulces sonidos con la amarga vacuidad del viento. Buscará en sí mismo, en sus propias entrañas, su razón de ser. Al fin y al cabo, su pensamiento, su corazón, su «yo» constituyen la única realidad cognoscible. Sólo en este mundo interior podrá encontrar la paz.

Pero iy si esta paz no fuera nada? Nada, sí, sombras, vacío, desolación. El sangriento, el inflamado corazón del poeta, subido a la torre vigía de su ensimismado pensamiento, podrá tal vez teñir con su púrpura las aguas circundantes. Pero iy si este corazón naufragara, cayera al agua, se desvaneciera? En tal caso, el universo entero desaparecería. El mundo, ese castillo de naipes fabricado a la medida del poeta, se quedaría hueco y frío, y finalmente se derrumbaría.

Veamos ahora lo que se nos dice en el Soneto XX, «Octubre»:

Estaba echado yo en la tierra, enfrente del infinito campo de Castilla, que el otoño envolvía en la amarilla dulzura de su claro sol poniente.

Lento, el arado, paralelamente abría el haza oscura, y la sencilla mano abierta dejaba la semilla en su entraña partida honradamente.

Pensé arrancarme el corazón, y echarlo, pleno de su sentir alto y profundo, al ancho surco del terruño tierno,

a ver si con partirlo y con sembrarlo, la primavera le mostraba al mundo el árbol puro del amor eterno. 
Es sabido que Juan Ramón Jiménez manifestó alguna vez su escasa simpatía por este soneto ${ }^{320}$, lo cual no implica en absoluto una merma de su indudable belleza. Tanto en «Nada», donde aparece «la elevada / torre», como en «Octubre», donde se nos habla de «la amarilla / dulzura»y «la sencilla / mano», los encabalgamientos ${ }^{321}$ proporcionan elasticidad y armonía a la solemnidad del verso endecasílabo. En el primer cuarteto, el claro sol poniente del otoño envuelve con amarilla dulzura los extensos campos castellanos. Es obvio que, propiamente hablando, lo que es amarillo es el claro sol del ocaso, y su visión produce en el observador una agradable sensación de dulzura. Pero, en virtud de una lograda hipálage, el adjetivo «amarillo» califica a la «dulzura», originándose así una hermosa sinestesia o fusión de imágenes visuales y gustativas.

En el segundo cuarteto, se describe la acción fertilizadora del arado y la semilla en la entraña de la tierra, «partida honradamente». La madre tierra ha sido fecundada, con honra, en un amoroso maridaje. Sería inútil tratar de encontrar aquí algún atisbo de preocupación social por el honrado quehacer del labrador. Nada más lejano a la intención del poeta. La escena de la siembra es contemplada además a una cierta distancia, desde la atalaya de una peculiar posición: «echado yo en la tierra».

En los tercetos, se da a conocer la verdadera actitud del poeta. Piensa que, si sembrara también su propio corazón, semilla de los más altos y profundos sentimientos, al llegar la primavera surgiría un árbol puro de amor eterno, que asombraría al mundo entero. Como en el soneto «Nada», al mundo exterior se opone su corazón ensimismado.

320 Vid. JIMÉNEZ, Juan Ramón: Antología general en prosa, ed. y prólogo de Ángel Crespo y Pilar Gómez Bedate. Madrid: Biblioteca Nueva, 1981, p. 843: «Hay un soneto mío, que yo detesto, el que empieza: Estaba echado yo en la tierra, enfrente del infinito campo de Castilla».

321 Sobre el encabalgamiento en Sonetos espirituales, vid. MARTÍNEZ FERNÁNDEZ, José Enrique: «Efectos expresivos del encabalgamiento en Sonetos espirituales y Estío, de Juan Ramón Jiménez», Rhythmica. Revista española de métrica comparada. VII, 2009, pp. 177-199. 
El «corazón» aparece, por cierto, en numerosas ocasiones a todo lo largo del poemario. En el Soneto II, es claramente símbolo del amor. Este soneto, que lleva por título «Primavera», está dirigido a la mujer inspiradora, que representa el esplendor del mes de abril:
Abril, sin tu asistencia clara, fuera
invierno de caídos esplendores...
Eres la primavera verdadera;
rosa de los caminos interiores...

El corazón y el pensamiento del poeta vienen a ser los depositarios de una luminosa ofrenda de paz y de misterio:

Mi corazón recogerá tu rosa...
tu luz se dormirá sobre mi frente...

La mujer es primavera, rosa, luz. El poeta es pensamiento ensimismado, corazón expectante. También en el Soneto III el corazón implica amor y claridad:
¡Ay, qué vivir de bienaventuranza
la de un amor guardado, este divino fuego...!
Mas si me quitas tú esa luz, oscuro quedará mi existir, y astrosas nieblas decorarán mi corazón...

En el Soneto XV, el veraz corazón y el pensamiento firme zozobran ante la eventualidad de un no deseado olvido:

¿Cómo era, Dios mío, cómo era?

${ }_{-¡}$ Oh, corazón falaz, mente indecisa...-

El olvido es asimismo la fuente de un amargo desasosiego. El corazón en el Soneto XVIII viene a ser, sin el amor, como las hojas secas de las polvorientas ramas otoñales: 
Corazón, seco, vano y pobre nido en que los sempiternos resplandores hallan, un punto, refulgente calma. Cuando el amor te deja en el olvido, se truecan en ceniza tus fulgores...

En el Soneto XIX, titulado precisamente «El corazón roto», el término aparece en dos ocasiones:

Creí que el pobre corazón ya estaba compuesto para siempre. Me lo había atado con las cuerdas de poesía de mi lira alta y pura...

Entre las rosas, tú te apareciste, como siempre reidora e inconstante, salvando redes y tendiendo lazos... El mirar noble se me puso triste, y el mal atado corazón amante se me quedó, otra vez, hecho pedazos.

El poeta se refugia en sí mismo, atando su corazón con las cuerdas de su pura y excelsa poesía. Ella se le aparece de repente entre rosas, como una alegre, difusa, inconstante y fugitiva revelación, que le incita a salir fuera de sí, a entregarse. Pero, una vez más, el poeta se repliega sobre sí mismo, quedando su corazón hecho pedazos.

En el Soneto XXV, nos habla de odios y de traiciones, de palomas con corvo pico de ave carnicera, y de su propio corazón, convertido en una insana gruta:

¿Por qué la estrella altiva y pura era el seco nido de la noche umbría? ¿La paloma inmortal cómo encendía corvo pico de ave carnicera?

...Hablaba el niño con palabra impura, el corazón era una gruta insana... 
En el Soneto XXVIII, se contrapone el auténtico amor, puro y verdadero, al rojo impulso de un corazón meramente carnal:
Soñaba yo, cantando, en la alegría
del amor solo, puro y verdadero...
El otro amor, el rojo, repetía
por el ocaso sordo y dominguero
su corazón de carne...

El Soneto XXIX, nos muestra cómo la tristeza y el duelo del roto corazón del poeta se pueden ver recompensados por la paz y la belleza de la mujer amada:

¡Cómo mi corazón, hecho pedazos, agradece el dolor, el beso ardiente con que tú, sonriendo, lo compones!

En el Soneto XXX, se compara el corazón del poeta al pajarillo ciego con el que jugaba un niño:
Tenía el niño al pajarillo ciego
en una noria de juguete atado...
...Me dormí luego
partido el corazón...
...entre lo trastornado
del soñar, era él pájaro de fuego.
Llama sólo, ojos toda, y noria, a una,
en la que mi dolor loco giraba...

El Soneto XXXI se titula, como el II, «Primavera», y está dedicado «A una mujer». Tras invocar el olor de la rosa, el brillo de las estrellas y el trino del ruiseñor, el poeta confiesa:

Y el tierno olor me es malo, y el divino

fulgor azul deja mi frente oscura

y me hace sollozar de desventura

del ruiseñor el brote cristalino. 
Incapaz de asumir tanta belleza, echa de menos aquella dulce amargura, aquella maravillosa pena, que solía albergar en su corazón:

Y no es aquella pena prodigiosa

que el corazón antiguo me lamía

con su lengua de miel insuperable.

Sin embargo, el poeta desearía romper el habitual cerco de tristeza que oprime su corazón, y exclama desesperadamente:

¡Haz que me huela plácida la rosa,

que la estrella me inflame de poesía,

que el ruiseñor me suene deleitable!

En el Soneto XXXII, se dirige al extenso mar, donde, al atardecer, se difuminan los diversos colores que suscita la luz del sol. Querría el poeta que también se diluyera y muriera en él toda la belleza de la mujer amada:

¡Si su belleza en mí morir pudiera como en ti, mar, se borran los colores que el sol divino te dejó...!

De este modo, el sufrimiento de su corazón se igualaría al sereno anochecer del mar, ya sin colores, o con el apagado y uniforme color del olvido:
¡Mar, toma tú, esta tarde sola y larga, mi corazón, y da a su sufrimiento tu anochecer sereno y extendido!
¡Que una vez sienta él cual tú, en la amarga
infinitud de su latir sangriento,
el color uniforme del olvido!

Siempre que se nombra el corazón, se trata desde luego del corazón del poeta. Excepcionalmente, en el Soneto XXXIV, se hace referencia al corazón y a la frente de la mujer amiga, eso sí, junto a su propia frente y junto a su propio corazón: 
Pronto vendrá esta luna sobre el frío del jardín, cuando yo, serenamente, torne de estar, mi frente con tu frente, tu corazón, amiga, con el mío.

El Soneto XXXVII lleva una dedicatoria: «A Amós Salvador y Carreras, que, estando yo enfermo, me regaló con su estereoscopio». El estereoscopio es un antiguo y curioso aparato óptico de visión binocular, en el que cada ojo ve una imagen tomada con un ángulo diferente, de tal modo que se produce una fusión de imágenes, dando lugar a la percepción de los objetos en relieve. El corazón del poeta se siente embelesado $-\ll i$ oh montones de luz, oh pedrerías / de color...!»- al contemplar en relieve, a través del estereoscopio, unas fotografías:

Una andariega primavera hirviente bajó, hormiguero de oro, de la frente al corazón gentil y embelesado...

El Soneto XXXVIII es un canto a la amistad, que llega al corazón del poeta como la miel al panal. No es el poeta quien la ofrece, sino quien la recibe:

Otra vez, amistad, a mí has venido, dulce, con todo el corazón abierto como un panal. ... No sé si estaba muerto. ¡Sé que a su claridad he revivido!

En el Soneto XXXIX, el poeta, extasiado ante la contemplación de las verdes ramas de los árboles, que arden con el oro de una puesta de sol que se derrama sobre ellas, iguala su corazón a estas últimas ramas del atardecer:

¡Cómo mi corazón os tiene, ramas últimas, que sois ecos, y sois gritos de una hastío inmortal de incertidumbres! ¡Él, cual vosotras, se deshace en llamas, 
y abre a los horizontes infinitos

un florecer espiritual de lumbres!

Cuando llega el otoño, el corazón del poeta sigue pensando en la primavera, por más que ésta se encuentre impregnada de dolor y de tristeza, tal como se expresa en el Soneto XLI:

El recio corazón ¡con qué contento piensa en mayo, brotado de dolores!

Es ya el otoño, y en el yermo y puro sendero de mi vida sin fragancia, la hoja seca me dora la cabeza...

Si en el Soneto XXX el poeta comparaba su corazón al pajarillo atado en una noria de juguete, en el Soneto XLIII su corazón es también como un pajarillo, que entra volando en un recinto del que no puede escapar:

Se entró mi corazón en esta nada, como aquel pajarillo, que, volando, de los niños, se entró, ciego y temblando, en la sombría sala abandonada.

Como en el Spleen de Charles Baudelaire, donde la esperanza es como un murciélago encerrado en la lóbrega cueva del mundo, que lastima sus alas contra las paredes y se rompe la cabeza contra el techo ${ }^{322}$, el pobre pajarillo de Juan Ramón Jiménez -su tierno corazón- intentará también romper su encierro; pero caerá, al fin, sin vida, en el rincón de una desierta sala:

322 Quand la terre est changée en un cachot humide / Où l'espérance, comme une chauve-souris, / S'en va battant les murs de son aile timide / Et se cognant la tête à des plafonds pourris... (cuando la tierra es sólo una lóbrega cueva, / en donde la esperanza, pobre pájaro ciego, / que lastima sus alas contra el muro, se eleva, / choca con lo más alto y se deshace luego...). Vid. TORRE, Esteban: 33 poemas simbolistas. Madrid: Visor, 1995, pp. 38-39. 
De cuando en cuando, intenta una escapada

a lo infinito...

Pero tropieza contra el bajo cielo

una y otra vez, y por la sala

deja, pegada y rota, la cabeza...

En el Soneto XLVII, se emplea por dos veces la palabra «corazón», que el poeta compara con el roble o la encina. Al igual que la encina rebrota con vigor tras ser podada y herida por el hacha, el corazón del poeta se renueva al ser herido por el desconsuelo:

Vi el roble castigado, que, al constante

tornar de la sencilla primavera,

doraba la oquedad de su madera

con su tranquilo corazón fragante.

...Recordé el hacha que con tajo frío

abrió mi corazón, roble robusto,

primavera de oro y de consuelo...

La imagen procede de unos versos de Horacio, que Juan Ramón Jiménez cita al comienzo de este soneto XLVII, titulado «Hierro»: Duris ut ilex tonsa bipennibus / nigrae feraci frondis in Algido, / per damna, per caedes, ab ipso / ducit opes animumque ferro (Como la encina de negra fronda, podada por las duras hachas, en el fértil Álgido ${ }^{323}$, a pesar de los daños y los cortes, toma fuerzas y ánimo del mismo hierro) $)^{324}$.

También en el Soneto XLVIII aparece en dos ocasiones, en forma críptica, la palabra «corazón »:

323 El Álgido es un monte a cuatro leguas de Roma. Vid. DESPREZ, Ludovicus: Quinti Horatii Flacci opera. París: Fridericus Leonard, 1691, p. 381; y CAMPOS, Urbano: Horacio español, o poesías lyricas de Q. Horacio Flaco, texto bilingüe y notas. Madrid: Sancha, 1783, p. 291.

324 HORACIO (Carm., 4, 4, 57-60). Ab ipso ferro (del mismo hierro) es el emblema con que ilustra Fray Luis de León las portadas de sus obras y que aparece por primera vez en la edición de 1580 de la versión latina del Cantar de los Cantares. Vid. San José Lera, Javier: «Creación y recreación: los versos 31 a 35 de la Oda XII, "qué vale quanto vee”, de Fray Luis de León, en dos versiones», Analecta malacitana. 14, 1, 1991, pp. 173-181. 
Niño puro otra vez, el pensamiento

se me iba en lo más íntimo ocultando,

del ignorado corazón...

...el universo fui, resucitado

del corazón de la varona muerta.

Por último, en el Soneto LIV, el poeta cree haber oído una voz de niño, celestial hijo de una estrella, lucero matinal del primer corazón amante:
¿Lo oí? ¡Sí!... De una voz que no habló aquí, brote celestial, hijo de cristal, mecido por la cuna virginal de la estrella que, en sueños, escogí. ¿Del primer corazón que amó -¿lo vi?- lucero matinal...?

Si tenemos en cuenta que en Soneto VIII, «Nada», se utiliza la palabra «corazón» dos veces, y una en el Soneto XX, «Octubre», encontramos el término veintiséis veces en los cincuenta y cinco sonetos. La probabilidad de su aparición en alguna de estas composiciones supera, por tanto, el $45 \%$ y se aproxima al 50\%. Quiere esto decir que casi cada dos sonetos, encontraremos el «corazón» en uno de ellos.

El poeta no vuelve a utilizar ya más este molde poético, y se entrega a la búsqueda de otras formas de expresión, más abiertas. Lo cual no impide que su elogio al soneto, «Al soneto con mi alma», poema inaugural de los Sonetos espirituales, vuelva a repetirse, en 1918, en un poema del libro Eternidades dedicado a Dante Gabriel Rossetti $^{325}$ :

\footnotetext{
325 El poema, dedicado «A Dante [Rossetti]», lleva como cita un verso de Dante Alighieri, Allegro si, che appena il conoscia, perteneciente a un soneto de la Vita Nuova, 15, 4. Vid. ALIGHIERI, Dante: Opere, ed. de Marco Santagata. Milán: Arnoldo Mondadori, 2011, p. 960.
} 
Tu soneto, lo mismo

que una mujer desnuda y casta,

sentándome en sus piernas puras,

me abrazó con sus brazos celestiales.

Soñé, después, con ella.

Era una fuente

que dos chorros arqueaba en una taza

primera, la cual, luego, los vertía,

finos en otros $\operatorname{dos}^{326} \ldots$

Belleza limpia, sencillez escueta. He ahí las líneas esenciales del soneto, que para Juan Ramón Jiménez es como una mujer casta y desnuda. Cuartetos y tercetos vienen a ser, en el símil, brazos celestiales y piernas puras. El soneto es también como una fuente de agua clara, con dos chorros que surgen de cada una de las dos tazas: los dos cuartetos y los dos tercetos.

Juan Ramón consigue plenamente, con sus Sonetos espirituales, el ideal de la más exacta perfección, y merece figurar en la nómina de los mejores sonetistas, en lengua española, de todos los tiempos: Garcilaso de la Vega, Luis de Góngora, Francisco de Quevedo, o Jorge Luis Borges, Blas de Otero. Ahora bien, ¿supera la línea trazada por este excelso grupo? Sinceramente, creo que no. Demasiado corazón, demasiada nostalgia, demasiado ensimismamiento para los estrictos límites de estas peculiares formas poemáticas. La enfermiza belleza de la poesía juanramoniana encuentra, sin duda, mejores cauces en las andaduras anteriores y posteriores a los Sonetos espirituales.

326 JIMÉNEZ, Juan Ramón: Eternidades. Verso (1916-1917). Madrid: Taurus, 1982, p. 97. 


\section{RITMO Y GRAMÁTICA EN EL SONET0 «BASTA» DE BLAS DE OTERO}

$\mathrm{E}$

$\mathrm{N}$ las últimas décadas del pasado siglo $\mathrm{xx}$, las corrientes en boga de la teoría y de la crítica, en el terreno de los estudios literarios, arrastraban siempre las aguas de la ambigüedad, el plurisignificado de los textos, las múltiples lecturas, la polifonía, la indeterminación. Todo texto era sospechoso de una sutil manipulación y una interpretación sesgada. Algún autor se atrevía a sugerir tal vez que no todas las lecturas eran igualmente válidas: unas serían mejores que otras. Pero nadie osaba afirmar taxativamente que algunas de esas lecturas podrían ser erróneas, inaceptables o absurdas.

En el terreno de la poesía, los planteamientos fueron especialmente dramáticos. El lenguaje disgregado, en algunas formas del llamado verso libre, venía a potenciar las tesis del caos interpretativo, en el que todo vale y en el que nada realmente vale. Las aulas universitarias fueron particularmente sensibles a estos extremos. La poesía, en fin de cuentas, sería algo que per se no se entiende, ni tiene por qué entenderse. Cada cual podría dar así rienda suelta a su delirio imaginativo en la lectura de un poema. Pero, como quiera que la naturaleza del entendimiento humano rechaza lo ininteligible, el proceso de las múltiples lecturas abocaría necesariamente a 
la negación de la lectura misma y, en consecuencia, al desconocimiento y al rechazo de la obra poética.

Afortunadamente el quehacer universitario, en España y fuera de España, ha sabido superar esos bandazos de larvado relativismo o franco nihilismo. Cada vez con mayor frecuencia se publican trabajos esclarecedores en el ámbito de la ecdótica, la historia, la teoría y la crítica de distintas obras literarias. Quisiera contribuir a este renacer de los estudios literarios, que tratan de ofrecer una lectura coherente y adecuada, con unas breves reflexiones sobre la interrelación del ritmo y la gramática en el siguiente soneto de Blas de Otero:

Imagine mi horror por un momento que Dios, el solo vivo, no existiera, o que, existiendo, sólo consistiera en tierra, en agua, en fuego, en sombra, en viento.

Y que la muerte, oh estremecimiento, fuese el hueco sin luz de una escalera, un colosal vacío que se hundiera en un silencio desolado, liento.

Entonces ¿para qué vivir, oh hijos de madre, a qué vidrieras, crucifijos y todo lo demás? Basta la muerte.

Basta. Termina, oh Dios, de malmatarnos.

O si no, déjanos precipitarnos sobre $\mathrm{Ti}$-ronco río que revierte.

El poema, que lleva por título «Basta», se publicó por primera vez en 1951 en el libro Redoble de conciencia, y posteriormente en las distintas ediciones de Ancia y en Todos mis sonetos. La palabra inaugural es el verbo imagine, en tiempo presente y modo imperativo. Conviene hacer constar que se trata de la tercera persona del verbo, cuyo sujeto gramatical es mi horror. Todo lo que viene a continuación, tanto en el 
primer cuarteto como en el segundo, cumple el oficio de implemento o complemento directo. Otras formas imperativas aparecen en el segundo terceto: termina y déja(nos), segunda persona del verbo, cuyo sujeto es ahora Dios. Obviamente, la primera persona, la que instaura el discurso, es el yo del poeta, que invoca al estremecimiento -oh estremecimiento- en el segundo cuarteto, a la humanidad entera -oh hijos de madre- en el primer terceto, y al mismo Dios -oh Dios- en el segundo terceto.

El yo del poeta está presente, en singular, en la deixis personal del posesivo «mi» de mi horror, y con un sentido colectivo, en plural, en el pronombre «nos» de malmatarnos, déjanos y precipitarnos. En la cláusula imagine mi horror, el sujeto sintáctico es mi horror; pero es evidente que el sujeto psicológico del acto de imaginar es el yo del poeta, que imagina por un momento que Dios no existe, y ello le produce un sentimiento vertiginoso de horror. $Y$ sucede que el horror asciende al primer plano en la construcción gramatical, y pasa a ser el sujeto sintáctico del discurso.

Dios, el Dios vivo, aparece aquí como el solo vivo. Es de advertir que este solo es el núcleo sustantivo del sintagma. Con función adjetival, como adverbio, se encuentra marcado por la tilde en sólo consistiera. El poeta se considera hermanado con Dios en la soledad:
Mira, Señor, qué solos. Qué mortales.
Mira que, dentro, desde ahora, luego, somos, no somos -soledad-iguales.

Son las palabras finales del soneto «Soledad», perteneciente al libro Ancia, del que se toman ésta y las restantes citas de Blas de Otero. También se nombra la soledad de Dios en el segundo terceto del soneto $\ll$ Cuerpo de la mujer...»:

Suena la soledad de Dios. Sentimos

la soledad de dos. Y una cadena, que no suena, ancla en Dios almas y limos. 
En el primer cuarteto de «Basta», existe un marcado paralelismo sintáctico y rítmico entre el primer verso y el tercero, y entre el segundo y el cuarto. Entre los versos impares y los pares se da, en efecto, un suave encabalgamiento, que se extiende a todo lo largo del verso par. Por otra parte, existe una sombría y temblorosa aliteración de nasales y vibrantes en el primer verso, que se corresponde paralelísticamente con la protesta sibilante que anima el verso tercero. En cambio, las rimas se entrecruzan quiasmáticamente, relacionando el verso primero con el cuarto y el segundo con el tercero.

Toda esta armoniosa estructura sintáctica y rítmica se vendría abajo ante una lectura -evidentemente errónea- que considerara mi horror como complemento directo de imagine: *imagine usted mi horror. Invito a los profesores de Literatura de las enseñanzas medias y universitarias a proponer a sus alumnos este soneto como comentario. Es muy posible que la lectura errónea superara la cifra del cincuenta por ciento, con lo cual el poema quedaría radicalmente destrozado. Tendríamos que introducir un cambio en los signos de puntuación: dos puntos al final del primer verso. Habría que leer entonces ${ }^{*}$ Imagine mi horror por un momento: que Dios, el solo vivo, no existiera. De esta forma, desaparecería el encabalgamiento del primer verso sobre el segundo y, en consecuencia, se derrumbaría la estructura paralelística. El ágil entrecruzamiento de las rimas se vería, asimismo, trabado por la torpe esticomitia de los dos primeros versos. Y, por si fuera esto poco, el poeta se vería obligado a dirigirse al lector con un tratamiento de «usted», más marchoso que de cortesía.

El horror ante la inexistencia del Dios vivo se proyecta también sobre la existencia de un Dios cósmico, que «sólo consistiera en tierra, en agua, en fuego, en sombra, en viento». No puede por menos de recordarse el gongorino «en tierra, en humo, en polvo, en sombra, en nada». Pero, en especial, la mención de los elementos naturales enlaza con el soneto «Nada», del libro Sonetos espirituales de Juan Ramón Jiménez, que termina con los siguientes tercetos: 
¡Nada, sí, nada, nada!... - O que cayera

mi corazón al agua, y de este modo

fuese el mundo un castillo hueco y frío...-

Que tú eres tú, la humana primavera, la tierra, el aire, el agua, el fuego, ¡todo!,

... ¡y soy yo sólo el pensamiento mío!

La visión de Juan Ramón Jiménez se encuentra, en todo caso, a una enorme distancia del sentir de Blas de Otero. Para Juan Ramón, los elementos naturales encarnan la plenitud de la vida, la humana primavera, frente al ensimismamiento del poeta, que llega a pensar que el ahogamiento de su corazón traería consigo el fin del mundo.

Blas de Otero, en cambio, se aterra ante la idea de la mera existencia de un Dios cósmico, pura fuerza de la naturaleza, incapaz de garantizarle su propia eternidad. De ahí que la segunda cosa que imagina su horror es que la muerte nos abra sus puertas hacia la nada, hacia el vacío, hacia el silencio, hacia la oscuridad absoluta: Oh estremecimiento, imagine mi horror por un instante que la muerte fuese el hueco sin luz de una escalera. No existe una imagen mejor del vértigo, de la náusea, que la espiral de una escalera, de una escalera de caracol. Asistimos a un vacío colosal: el suelo se quiebra y se hunde, hasta caer en una sima húmeda, lienta, de silencio y desolación.

El poeta no se resigna a la destrucción, a la nada, a la muerte. Véase el primer cuarteto del soneto titulado «Hombre»:

Luchando, cuerpo a cuerpo, con la muerte,

al borde del abismo, estoy clamando

a Dios. Y su silencio, retumbando,

ahoga mi voz en el vacío inerte.

Otra vez el abismo, el hueco sin luz, y otra vez el silencio y el vacío. Y, una vez más, el silencio, el silencio de Dios, en los tercetos del soneto titulado precisamente «Poderoso silencio»: 
¡Poderoso silencio, poderoso

silencio! Sube el mar hasta ya ahogarnos

en su terrible estruendo silencioso.

¡Poderoso silencio con quien lucho

a voz en grito: grita hasta arrancarnos

la lengua, mudo Dios al que yo escucho!

Sobre el mar zozobroso en el que trágicamente naufraga la esperanza del poeta, Dios sería la única tabla de salvación posible, como se exclama en el primer terceto de «Muerte en el mar»:

Salva, ¡oh Yavé!, mi muerte de la muerte.

Ancléame en tu mar, no me desames.

Amor más que inmortal. Que pueda verte.

Pero el poeta ha vislumbrado la imagen de un Dios inexistente o cósmico, y ha sentido la náusea de la nada, el vértigo del vacío, la negrura de la muerte, de la que nadie le podrá salvar. En esta situación, ¿qué sentido tiene la vida, para qué seguir viviendo unos días, unas horas, unos instantes más? La humanidad entera ¿no es consciente de esto? Enfurecido y aturdido, Blas de Otero increpa a todos los seres humanos, que caminan ufanos por la vida como si nunca hubieran de morir: ¿para qué vivir, oh hijos / de madre? El encabalgamiento del sintagma hijos de madre es altamente expresivo: hijos... de madre.

Si no existe Dios, o si sólo consiste en el arrollador devenir del cosmos, ¿a qué viene rendirle culto, para qué las vidrieras, los crucifjos y todo lo demás? Se podría ver aquí una relación metonímica -de la parte al todo, o de lo particular a lo general-con la religión, con la iglesia. Pero en los crucifijos y en las vidrieras hay algo más que una mera imagen metonímica. Se trata de símbolos, de símbolos esenciales de la fe cristiana, en los que se da una estrecha conexión entre el plano sensorial y el abstracto. Las vidrieras representan la iglesia, pero son iglesia y siguen siendo vidrieras en esa fusión, en esa 
identidad, que recibe propiamente el nombre de símbolo. El lector intuye incluso el colorido de los cristales. Es más, lo percibe como perteneciente a las vidrieras de una catedral gótica.

«Basta» es también la palabra inicial del segundo terceto, pero esta vez tiene el valor exclamativo de una interjección. Todo el horror y el estremecimiento que trae consigo la visión de la inexistencia de Dios, toda la angustia y toda la ira del poeta, dejan paso ahora a una vehemente súplica: Termina, oh Dios, de malmatarnos. El Dios inexistente es ahora un Dios silencioso, mudo, distante, al que se le pide que ponga fin con la muerte a una vida larvada por la angustia de ser no otra cosa que un vivir para la muerte. Quien suplica no es ya un yo, sino un nosotros: acaba, oh Dios, de malmatarnos. El término «malmatar» venía siendo considerado como un neologismo, formado por analogía con la serie «malparir», «mal-

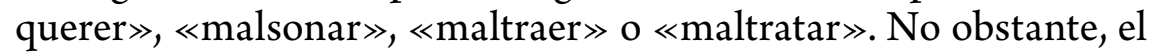
Diccionario de la lengua española de la Real Academia, en su edición vigesimotercera, documenta el verbo «malmatar» en algunos países centroamericanos como Nicaragua, El Salvador y Costa Rica.

Al final del poema, se hace patente la entrega sin reservas a la voluntad de Dios, en el que paradójicamente no se cree, pero que sin embargo se necesita desesperadamente: $O$ si no, déjanos precipitarnos / sobre $\mathrm{Ti}$-ronco río que revierte. El primero de estos dos versos es melódico, con acentos en las sílabas 3a, 6a y 10a o.si.nó... de.ja.nós...pre.ci.pi.tár.nos. Las dos cláusulas ternarias, acentuadas reiterativamente en la sílaba final (nó, nós), son el preludio del pentasílabo pre.ci.pi.tár.nos, con tres sílabas átonas en cascada delante de la final tónica, lo que confiere al verso un marcado matiz onomatopéyico. También es melódico el siguiente verso, donde el ronco río que revierte muestra además una evidente aliteración de sonidos vibrantes.

Dios es un río tumultuoso, un ronco, un bronco río, que revierte, que rebosa y lo llena todo. La palabra «revierte» puede considerarse como procedente del verbo «reverter» (rebosar) o del verbo «revertir» (volver). Parece aquí más oportuna la primera opción. 
No se puede descartar, en todo caso, la segunda. De hecho, el poeta utiliza el término «revertir» en el poema «Tierra»:

Detrás del hombre viene dando gritos

el abismo, delante abre sus hélices

el vértigo, y ahogándose en sí mismo,

en medio de los dos, el miedo crece.

Caerme, revertir, no haber nacido

humanamente nunca en ningún vientre.

Revertir, volver al estado anterior, en el que aún no había sido engendrado. No haber nacido, caer en el hueco de la nada. Y, una vez más, el abismo, el vértigo, el terror, el naufragio. Blas de Otero alza su frente al Dios. Le pregunta, le increpa, le desafía. Y va desgranando así uno a uno sus poemas, que en especial son sonetos:

Lenguas de Dios, preguntas son de fuego

que nadie supo responder. Vacío

silencio. Yerto mar. Soneto mío,

que así acompañas mi palpar de ciego.

Llambria y cantil de soledad. Quebranto

del ansia, ciega luz. Quiero tenerte, y no sé dónde estás. Por eso canto.

(«Estos sonetos»)

Oh Dios. Si he de morir, quero tenerte despierto. Y, noche a noche, no sé cuándo oirás mi voz. Oh Dios. Estoy hablando solo. Arañando sombras para verte.

(«Hombre»)

Arrebatadamente te persigo.

Arrebatadamente, desgarrando

mi soledad mortal, te estoy llamando

a golpes de silencio...

(«Tú, que hieres») 
No se sabe qué voz o qué latido, qué corazón sembrado de amargura, rompe en el centro de la sombra pura mi deseo de Dios eternecido.

$$
(\ll \mathrm{No} \gg)
$$

Enormemente herido, desangrándome, pisando los talones de la muerte, vengo, Dios, a decirte -si no a vertemi inmensa sed, mi sed de ti...

$$
(\ll \text { Cara a cara } »)
$$

De tanto hablarle a Dios, se ha vuelto mudo mi corazón...

$$
(\ll \text { Mudos } \gg)
$$

Ábreme. Ábreme, que vengo herido y moriría, oh Dios, si por la herida no saliese, hecha voz, mi ansia de verte.

(«No cuando muera he de callar»)

Me haces daño, Señor. Quita tu mano de encima. Déjame con mi vacío, déjame. Para abismo con el mío tengo bastante...

$$
\text { («Lástima } »)
$$

Escucha cómo estoy, Dios de las ruinas. Hecho un cristo, gritando en el vacío...

$$
\text { («Ecce homo») }
$$

Estoy temblando, tengo frío. Oh Dios, si supieses qué frío y cuánto miedo tiene el hijo del hombre...

$$
\text { («Hoja nueva } »)
$$


En lo que concierne a la medida y el ritmo del verso, he aquí el esquema de la separación silábica y la distribución acentual:

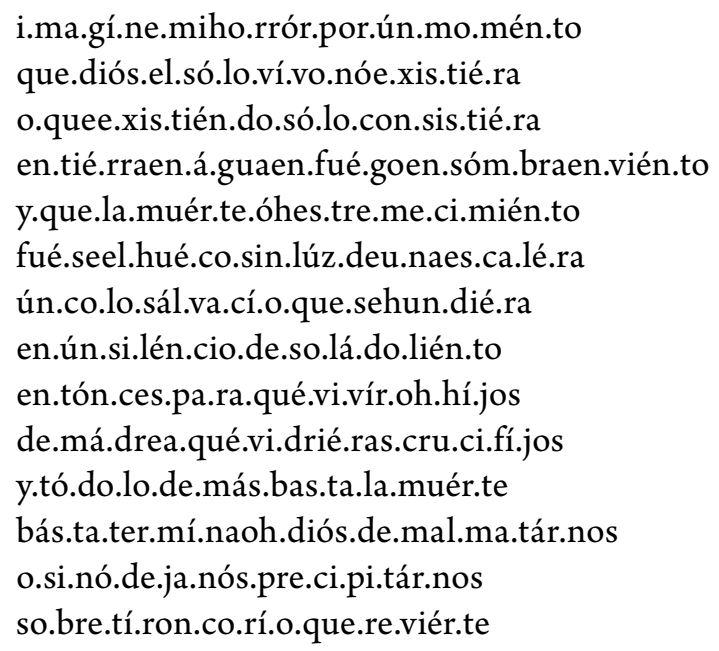

El verso 8 es un endecasílabo sáfico, con acentos rítmicos en las sílabas $4^{\mathrm{a}}, 8^{\mathrm{a}}$ y $10^{\mathrm{a}}$, y acento metarrítmico en la sílaba $2^{\mathrm{a}}$. Los restantes versos son endecasílabos comunes, con acentos rítmicos en las sílabas $6^{\mathrm{a}}$ y $10^{\mathrm{a}}$, y otros acentos, metarrítmicos, en diversas sílabas, que aparecen marcadas por la tilde. En el caso especial de los versos 2 y 4, están acentuadas todas las sílabas pares: estos endecasílabos reciben también el nombre de pentámetros yámbicos.

No se han señalado los acentos pararrítmicos de los versos 6, 9, $11,12,13$ y 14 . Son realmente acentos de la palabra aislada, pero no de la línea del verso. La contigüidad de estos acentos con los propiamente rítmicos o metarrítmicos determina su neutralización en la secuencia fónica. Cuando entran en contacto dos sílabas tónicas pertenecientes a dos palabras consecutivas, una de ellas ha de tener necesariamente un mayor relieve acentual. Por definición, la sílaba tónica, la más acentuada, lo es siempre en relación a un entorno de sílabas átonas o menos acentuadas. De ahí que, de las dos sílabas en contacto, la más acentuada asuma el papel de sílaba tónica. 
Las circunstancias en las que esto se produce son muy diversas. En el verso 6, la secuencia luz de una escalera es una cláusula hexasilábica, con sinalefa o zeuxis entre de y una (deu), y entre una y escalera (naes). La ú de la palabra una (ú.na) es tónica en el vocablo aislado; pero, al unirse con la $e$ de la palabra de en una sola sílaba, contigua a la tónica luz (lúz.deu), pierde su relieve acentual y pasa a ser una sílaba átona. En el verso 9, vivir, oh hijos consta de cinco sílabas, con dialefa o azeuxis entre oh e hijos. La palabra oh (óh) consta de una sílaba tónica como vocablo aislado, pero su contacto con vivir (vi.vír) e hijos (hí.jos) la convierte en átona (vír.oh.hí). Lo mismo ocurre en el verso 12, Termina, oh Dios: la zeuxis entre Termina y oh (naoh) hace que esta sílaba entre en contacto con mi (mí) de Termina y Dios (diós), por lo que pasa a ser átona (mí.naoh.diós).

Distinto es el caso de los versos 11, 13 y 14 . En el verso 11, se produce un choque entre las sílabas tónicas de las palabras demás y Basta. La sílaba más de demás es, sin duda alguna, la portadora del acento rítmico. En la sílaba Bas de Basta existe sólo un acento pararrítmico de la palabra aislada, que en la línea del verso se manifiesta por un cambio de tono y por la existencia de un breve silencio entre las dos sílabas contiguas. No es un acento del verso, y desde luego no es un acento «antirrítmico» como ha sido llamado en ocasiones. Los acentos rítmicos y metarrítmicos están claramente marcados por un mayor relieve de la intensidad acústica. Los pararrítmicos actúan en un nivel diferente, resaltando mediante el cambio de tono y el silencio intersilábico la sílaba de la palabra aislada que está en contacto con el acento rítmico o metarrítmico.

En los versos 13 y 14, los acentos pararrítmicos de las palabras déjanos y ronco entran en contacto con los acentos metarrítmicos de las palabras no y Ti. Se trata de endecasílabos melódicos, con acentos rítmicos en las sílabas $6^{a}$ y $10^{a}$, y metarrítmico en la sílaba $3^{a}$. Como en caso anterior, se da un breve silencio entre las sílabas $3^{\mathrm{a}} \mathrm{y}$ $4^{\text {a }}$, y un evidente cambio de tono, que es perceptible como un semitono descendente. En términos musicales, podríamos decir que la sílaba $4^{\mathrm{a}}$. vendría a funcionar como bemol de la $3^{\mathrm{a}}$. 
Es llamativa la perfección formal de la poesía de Blas de Otero. Como sonetista es insuperable y se inserta plenamente en la misma nómina que Garcilaso de la Vega, Luis de Góngora, Lope de Vega, Francisco de Quevedo, Juan Ramón Jiménez o Jorge Luis Borges. Quizá se le pueda acusar de un excesivo juego de aliteraciones y argucias fónicas en lo formal, y un desgarrado dramatismo en el contenido. Pero lo uno compensa lo otro. Y, desde luego, pocas voces hay como la suya que expresen mejor la sed de Dios y de eternidad. Podríamos encontrar un precedente en Miguel de Unamuno, a quien tenía precisamente en gran estima Blas de Otero. ¿Y por qué no remontarnos a San Juan de la Cruz? Sed de un Dios huidizo aflora, desde luego, en el Cántico espiritual:

\author{
¿Adónde te escondiste, \\ Amado, y me dejaste con gemido? \\ Como el ciervo huiste, \\ habiéndome herido; \\ salí tras Ti clamando, y eras ido.
}

También Blas de Otero es autor de un Cántico espiritual, publicado en 1942. Se trata de un pequeño libro de poemas, en homenaje a de San Juan de la Cruz, que incluye una decena de liras escritas al estilo del gran poeta y santo castellano:
Conmigo está mi dueño, leyendo su lectura silenciosa.
Mi dueño es muy pequeño,
mas tiene voz de rosa
cuando del alma el canto le rebosa.

Decididamente, Blas de Otero habla la misma lengua que San Juan de la Cruz. Quizás en un dialecto salvaje. Como advierte Dámaso Alonso, en el prólogo del libro Ancia, «hay cierta bronquedad, cierta hirsutez en su poesía». Pero don Dámaso se muestra abiertamente partidario de esta forma de expresión, y confiesa estar «harto 
de versos barbilampiñados, y a veces, una chispita bardajillos». Blas de Otero siente con ansias de muerte la lejanía y el silencio de Dios. Y canta arrebatadamente su ausencia. $\ll i A$ quién, sino a Dios, canta toda su poesía?», se pregunta el maestro Dámaso Alonso, y cree encontrar en el soneto «Basta», objeto de este pequeño comentario, «imágenes casi con posibilidad de traducción cinematográfica»: Dios, el amor y la muerte, y -en el centro de este triángulo esencial del hombre- un espantoso vacío.

Es obvio que los sonetos de Ancia no suponen el fin de la poesía de Blas de Otero, pero sí representan su punto culminante. En modo alguno pueden ser considerados como una breve fase, meramente transitoria. En ocasiones, se ha querido ver tres etapas en la poesía de Blas de Otero: religiosa, existencial y social. Los exégetas a ultranza de esta última etapa, los que le ofrecieron a su muerte un estruendoso homenaje en la plaza de toros de Las Ventas, en Madrid, sin haber leído nunca su obra ni ser capaces de calar en la hondura de sus versos, le relegaron pronto al más completo de los olvidos. También le quisieron ignorar los que tildaron en su día de heterodoxo el libro Ángel fieramente humano, y le negaron el premio Adonáis. No obstante, sobre tirios y troyanos, prevalece $-\ll$ oh Capitán, oh Capitán, ¡Dios mío!»- la poesía, fieramente humana, de Blas de Otero, de la que el soneto «Basta» es una muestra excelente. 

ÍNDICE 

Prólogo

Estudios precedentes

\section{TeOría}

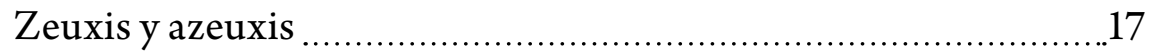

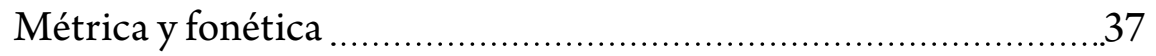

Acentos rítmicos, metarrítmicos y pararrítmicos ........................53

Versos de final agudo, grave y esdrújulo ....................................... 73

Particularidades del verso alejandrino .......................................... 89

\section{Teóricos}

La métrica de Antonio Sebastiano Minturno ...........................105

Las Anotaciones de Fernando de Herrera ....................................131

Ortología y métrica de Andrés Bello ..............................................161

Prosodia y versificación de Eduardo Benot .................................175

\section{Crítica y ANÁlisis}

La perfección de algunos endecasílabos «imperfectos» de Garcilaso de la Vega ................................................................201

Los sonetos de Juan Ramón Jiménez ..........................................219

Ritmo y gramática en el soneto «Basta» de Blas de Otero 

Se acabó de imprimir el 28 de enero de MMXVII, jornada en la que se conmemora la festividad de Santo Tomás de Aquino. 


